Hiking the valleys of quantum chemistry

by

\title{
Christine Marie Aikens
}

A dissertation submitted to the graduate faculty

in partial fulfillment of the requirements for the degree of

DOCTOR OF PHILOSOPHY

Major: Physical Chemistry

Program of Study Committee:

Mark Gordon, Major Professor

Jim Evans

David Hoffman

William Jenks

Ricky Kendall

Iowa State University

Ames, lowa 
Graduate College

Iowa State University

This is to certify that the doctoral dissertation of

Christine Marie Aikens

has met the dissertation requirements of lowa State University

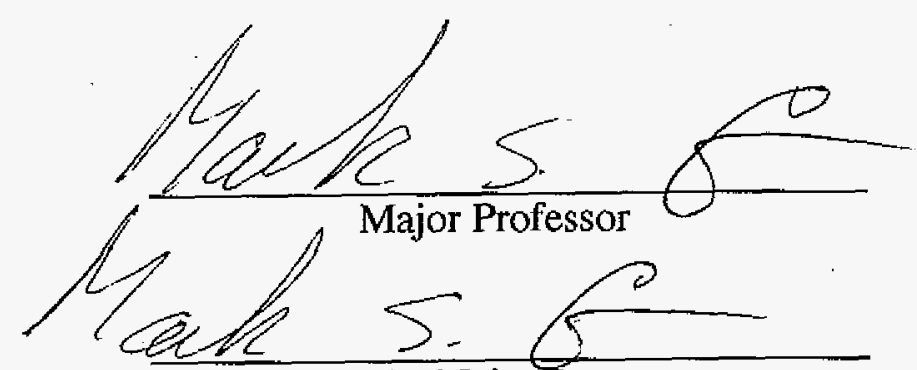

For the Major Program 
TABLE OF CONTENTS

ACKNOWLEDGMENTS $\quad \mathrm{v}$

CHAPTER 1. GENERAL INTRODUCTION

General Overview 1

Dissertation Organization 1

Theoretical Background 2

References 10

CHAPTER 2. ELECTRONIC AND MAGNETIC PROPERTIES OF $\mathrm{Y}_{2} \mathrm{Ti}(\mu-\mathrm{X})_{2} \mathrm{TIY}_{2}(\mathrm{X}, \mathrm{Y}=$ $\mathrm{H}, \mathrm{F}, \mathrm{Cl}, \mathrm{Br}$ ) ISOMERS
Abstract
Introduction
Computational Details
Results and Discussion
Conclusions
Acknowledgment
References and Notes

CHAPTER 3. INFLUENCE OF MULTI-ATOM BRIDGING LIGANDS ON THE ELECTRONIC STRUCTURE AND MAGNETIC PROPERTIES OF HOMODINUCLEAR TITANIUM MOLECULES
Abstract
Introduction
Computational Details
Results and Discussion
Conclusions
Acknowledgment
72
References

CHAPTER 4. SYSTEMATIC INVESTIGATION OF THE SOLVATION OF

NONIONIZED AND ZWITTERIONIC GLYCINE

Abstract

Introduction

Computational Methods $\quad 117$

Results and Discussion 120

Conclusions 132

Acknowledgment 133

References 133

CHAPTER 5. PARALLEL UNRESTRICTED MP2 ANALYTIC GRADIENTS USING THE DISTRIBUTED DATA INTERFACE

Abstract

Introduction

Parallel UMP2 Gradient AIgorithm $\quad 170$

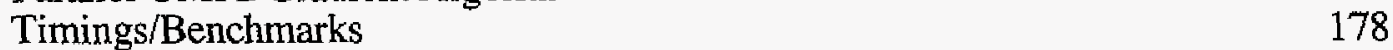

$\begin{array}{ll}\text { Conclusions } & 181\end{array}$

Acknowledgment 181

Appendix. Density Matrix Expressions 182

References 
CHAPTER 6. SCALABLE IMPLEMENTATION OF ANALYTIC GRADIENTS FOR SECOND-ORDER Z-AVERAGED PERTURBATION THEORY USING THE DISTRIBUTED DATA INTERFACE

Abstract

Introduction 198

Theory

202

Parallel ZAPT2 Gradient Algorithm

Timings

Conclusion

Acknowledgment

Appendix. Density Matrix Term Creation 


\section{ACKNOWLEDGEMENTS}

I would like to thank my adviser, Mark Gordon, for his support and encouragement during my graduate career. His emphasis on systematic development and getting the right answer for the right reasons has profoundly affected my approach to quantum chemistry. I would also like to thank the other members of the Gordon group for many enjoyable conversations and experiences. In particular, I am grateful to Mike Schmidt for the many hours we spent discussing the GAMESS program.

I would especially like to thank my husband Chris for his love and support during the last five years. I also want to express my appreciation to all of my friends and family members who have made the last few years more enjoyable. In addition, I am grateful to my parents for always encouraging me to reach my full potential.

This work was performed at Ames Laboratory under Contract No. W-7405-Eng-82 with the U.S. Department of Energy. The United States government has assigned the DOE Report number IS-T 2158 to this thesis. 


\section{CHAPTER 1. GENERAL INTRODUCTION}

"The underlying physical laws necessary for the mathematical theory of a large part of physics and the whole of chemistry are thus completely known, and the difficulty is only that the exact application of these laws leads to equations much too complex to be soluble. It therefore becomes desirable that approximate practical methods of applying quantum mechanics should be developed, which can lead to an explanation of the main features of complex atomic systems without too much computation."

P. A. M. Dirac, $1929^{1}$

\section{General Overview}

Since the early twentieth century, when scientists realized that classical mechanics could not properly describe physical phenomena at the atomic level, quantum chemistry has flourished. The development of quantum chemical methods and the application of these methods to interesting chemical problems have resulted in many valuable tools and insights that affect the world around us. As an example, the medical imaging field has profoundly benefited by new spectroscopic techniques.

Much of quantum chemistry deals with valleys of potential energy surfaces and with methods of determining the "slope" and "elevation" of the hills. So, sit back, relax, and let me be your guide as we hike the landscape of quantum chemistry.

\section{Dissertation Organization}

This thesis is concerned with both the application and the extension of quantum chemical methods. Each chapter of the thesis represents a paper that has been published in or will be submitted to a scientific journal. The first three chapters of this thesis describe contributions made to chemistry through the use of quantum chemical methods, while the final two chapters illustrate the development of new methods.

Chapter 2 and Chapter 3 characterize a study of the electronic structure and magnetic properties of homodinuclear titanium(III) complexes, in order to determine trends related to 
their potential use as molecular magnets. Chapter 2 focuses on hydride and halide bridging and terminal ligands, while Chapter 3 explores bridging ligands from other groups in the periodic table.

Chapter 4 portrays a study of the solvation of glycine. Microsolvation and continuum solvation approaches are investigated in order to study the structures of small glycine-water clusters and determine the energy difference between the zwitterionic and nonionized forms of glycine, the simplest amino acid.

Chapters 5 and 6 describe the implementation of analytic gradients, which are required for efficient molecular geometry optimizations, for two open-shell second-order perturbation theory methods. Chapter 5 discusses gradients for unrestricted Møller-Plesset perturbation theory, and Chapter 6 describes gradients for Z-averaged perturbation theory.

\section{Theoretical Background}

The non-relativistic time-dependent Schrödinger equation ${ }^{2-8}$ provides the basis for most quantum chemical methods. This equation is a complex partial differential equation involving both position $\ddot{r}$ and time $t$ :

$$
\frac{\partial \Psi(\vec{r}, t)}{\partial t}=-\frac{i}{\hbar} \hat{H} \Psi(\vec{r}, t)
$$

where $i=\sqrt{-1}, \hbar$ is Planck's constant divided by $2 \pi$, and $\hat{H}$ is the Hamiltonian operator. The solution of equation (1) yields $\Psi(\bar{r}, t)$, which contains all obtainable information about the system. If the Hamiltonian is independent of time, the full time-dependent Schrödinger equation is not required and the simpler time-independent Schrödinger equation,

$$
\hat{H} \Psi=E \Psi,
$$


may be used. In equation (2), the wave function $\Psi$ is an eigenfunction of the Hamiltonian with eigenvalue $E$. For a molecular system with $n$ electrons and $m$ nuclei, the Hamiltonian in atomic units may be expressed as

$$
\hat{H}=-\sum_{i=1}^{n} \frac{1}{2} \nabla_{i}^{2}-\sum_{A=1}^{m} \frac{1}{2 M_{A}} \nabla_{A}^{2}-\sum_{i=1}^{n} \sum_{A=1}^{m} \frac{Z_{A}}{r_{i A}}+\sum_{i=1}^{n} \sum_{j>1}^{n} \frac{1}{r_{i j}}+\sum_{A=1}^{m} \sum_{B>A}^{m} \frac{Z_{A} Z_{B}}{R_{A B}}
$$

where $\nabla^{2}$ is the Laplacian operator, $M_{A}$ is the ratio of the mass of nucleus $A$ to the mass of an electron, $Z_{A}$ is the atomic number of nucleus $A, r_{i A}$ is the distance between electron $i$ and nucleus $A, r_{i j}$ is the distance between electrons $i$ and $j$, and $R_{A B}$ is the distance between nuclei $A$ and $B$. The first and second terms in equation (3) represent the kinetic energy of the electrons and the nuclei, respectively. The third term is the Coulomb attraction between electrons and nuclei. The fourth and fifth terms correspond to the repulsion between electrons and between nuclei, respectively.

The Born-Oppenheimer approximation ${ }^{9}$ is used to reduce the complexity of the system. Since nuclei are much heavier than electrons, they move much slower, and therefore the electrons in a molecule may be viewed as moving in a field of fixed nuclei. Because of this approximation, the second term in equation (3) may be neglected and the fifth term may be considered to be a constant. The remaining three terms constitute the electronic Hamiltonian:

$$
\hat{H}_{\text {elec }}=-\sum_{i=1}^{n} \frac{1}{2} \nabla_{i}^{2}-\sum_{i=1}^{n} \sum_{A=1}^{m} \frac{Z_{A}}{r_{i A}}+\sum_{i=1}^{n} \sum_{j>i}^{n} \frac{1}{r_{i j}} .
$$

The electronic wave function in the field of fixed nuclei may then be determined by

$$
\hat{H}_{\text {elec }} \Psi_{\text {elec }}=E_{\text {elec }} \Psi_{\text {elec }} .
$$

The total energy is a sum of the electronic energy and the nuclear-nuclear repulsion energy: 


$$
E_{\text {tot }}=E_{\text {elec }}+\sum_{A=1}^{m} \sum_{B>A}^{m} \frac{Z_{A} Z_{B}}{R_{A B}}
$$

Once the electronic problem has been solved for a particular configuration of nuclei, it is subsequently possible to solve for the motion of the nuclei. In essence, in the BornOppenheimer approximation the nuclei move on a potential energy surface that is obtained by solving the electronic problem. This potential energy surface is of fundamental importance to the study of equilibrium structures and chemical reactions.

For systems with three or more interacting particles, an exact solution to the Schrödinger equation cannot be obtained because the interparticle distances are not separable. Thus, approximate methods must be developed, and this is a major thrust of modern quantum chemistry. As a first approximation, the repulsions that depend on the interparticle distances are ignored; this yields the independent particle model. A product of one-electron wave functions called orbitals is used to approximate the full wave function. This product, called a Hartree product, ${ }^{10 \cdot 12}$ is the origin of the tight-binding approximation, the extended Huickel approximation, and semi-empirical methods. An antisymmetric linear combination of Hartree products is used to form a Slater determinant ${ }^{13,14}$ in order to satisfy the antisymmetry principle. In a Slater determinant, the motion of elections with parallel spin is correlated, but the motion of electrons with opposite spin remains uncorrelated.

According to the variational principle, the best single determinant ground state wave function $\left|\Psi_{0}\right\rangle$ is the one that gives the lowest possible energy $E_{0}$, where

$$
E_{0}=\left\langle\Psi_{0}|\hat{H}| \Psi_{0}\right\rangle \text {. }
$$

In the Hartree-Fock approximation, ${ }^{10-12,15,16}$ the complicated many-electron repulsion problem is replaced by multiple one-electron problems in which electron repulsions are treated in an 
average way. Each electron is treated as though it moves in a potential field created by the nuclei and the average charge distribution of the other electrons. This averages out the instantaneous interactions between the electrons. Since the field seen by each electron depends on the orbitals of the other electrons, the Hartree-Fock equation is nonlinear and must be solved iteratively according to the self-consistent field (SCF) method. Trial orbitals for each electron are determined, and the electron density corresponding to these orbitals is calculated. New trial orbitals can then be determined. This procedure is repeated until the energy and trial functions do not change significantly.

In practice, each molecular orbital in the Hartree product may be expanded as a linear combination of basis functions. A molecular orbital $\psi_{i}$ can be written as

$$
\psi_{i}=\sum_{\mu=1}^{N} C_{\mu i} \phi_{\mu}
$$

where $C_{\mu i}$ are the molecular orbital expansion coefficients, $\mathrm{N}$ is the number of basis functions in the expansion, and $\phi_{\mu}$ are the basis functions. As the set of basis functions becomes larger and more complete, the molecular orbitals become more flexible and the Hartree-Fock energy $E_{0}$ approaches the complete basis set limit. In restricted Hartree-Fock (RHF) theory, $\alpha$ and $\beta$ electrons that are paired with each other are given the same spatial orbital. In unrestricted Hartree-Fock (UHF) theory, $\alpha$ and $\beta$ electrons have different spatial orbitals:

$$
\psi_{i}^{\alpha}=\sum_{\mu=1}^{N} C_{\mu i}^{\alpha} \phi_{\mu} ; \quad \psi_{i}^{\beta}=\sum_{\mu=1}^{N} C_{\mu i}^{\beta} \phi_{\mu} .
$$

Since this enhances the flexibility of the wave function, the UHF energy will in principle be lower than the RHF energy. However, the UHF functions are not eigenfunctions of the total 
spin operator, so they are contaminated by functions corresponding to states of higher spin multiplicity. The amount of spin contamination can provide a measure of the reliability of the UHF results.

The Hartree-Fock orbitals give the best possible single determinant description of the wave function. However, since the exact wave function is not truly a product of one-electron wave functions, there is a need for further improvement. The main drawback to the HartreeFock approximation is the neglect of electron correlation between electrons with opposite spins. This type of correlation is often termed dynamic electron correlation since it is related to the instantaneous correlations of electrons. The difference between the exact nonrelativistic Born-Oppenheimer energy and the Hartree-Fock energy is called the correlation energy, and much of the effort in the field of electronic structure theory is aimed at approximating this value. In theory, a variational full configuration interaction (CI) calculation in which the exact wave function is represented as a linear combination of Slater determinants with a complete basis set will yield the exact energy. However, this is computationally intractable. Truncated $\mathrm{Cl}$ methods can recover most of the correlation energy but they are not size-consistent, which means that the energy of a supermolecular system of two noninteracting molecules will not be the same as the sum of the energies of each molecule. Two size-consistent methods that recover much of the correlation energy include perturbation theory and coupled cluster methods. Coupled cluster (CC) methods provide good accuracy with a high computational cost, so they are currently useful primarily in single-point energy calculations, once geometries have been determined at a lower level of theory. 
In the perturbation theory approach, the total Hamilitonian of the system is divided into two pieces:

$$
\hat{H}=\hat{H}_{0}+\hat{V} .
$$

$\hat{H}_{0}$ is the zeroth-order part of the Hamiltonian, which has known eigenfunctions and eigenvalues. The remainder of the Hamiltonian is identified as the perturbation $\hat{V}$. The exact energy may be formulated as an infinite sum of contributions involving eigenvalues of $\hat{H}_{0}$ and matrix elements of the perturbation with eigenfunctions of $\hat{H}_{0}$. Ideally, the perturbation $\hat{V}$ will be small and the perturbation expansion will converge quickly so that low orders of perturbation theory will yield energies that closely approximate the total energy. Commonly, the perturbation theory of Rayleigh and Schrödinger is chosen with the Hartree-Fock Hamiltonian as $\hat{H}_{0}$. This is also known as Møller-Plesset perturbation theory. ${ }^{17}$ Second-order Møller-Plesset (MP2) perturbation theory often provides a substantial portion of the correlation energy at a relatively low computational cost, so it has become widely used, particularly for geometry optimizations.

In addition to dynamic electron correlation, there exists a second type of correlation energy, often called nondynamic electron correlation, which is due to near degeneracies. Systems with transition metals often have degenerate or nearly degenerate molecular orbitals, so a method that accounts for this must be employed. A single Slater determinant does not adequately describe the system, so a multi-determinantal wave function is required. In the multiconfiguration self-consistent field (MCSCF) method, the variation principle is used to optimize the $\mathrm{Cl}$ expansion coefficients and the orbitals for a wave function consisting of a relatively small number of determinants. Perturbation theory can be built on top of an 
MCSCF wave function in order to further account for dynamic electron correlation. These methods include second-order multireference Møller-Plesset (MRMP2) perturbation theory, ${ }^{18-20}$ multiconfigurational quasidegenerate perturbation theory (MCQDPT), ${ }^{21,22}$ and CASPT2. ${ }^{23}$

As mentioned above, equation (1) represents the best non-relativistic description of a molecular system. Relativistic effects are particularly important for heavier atoms, since they contain relatively fast-moving electrons. In order to account for relativistic effects, the full relativistic Dirac equation may be used in place of the non-relativistic Schrödinger equation. However in practice, a spin-orbit interaction term is commonly added to the Hamiltonian from equation (3):

$$
\hat{H}_{\text {toal }}=\hat{H}+\hat{H}_{s o}
$$

The Pauli-Breit spin-orbit coupling operator ${ }^{24}$ may be expressed as

$$
\hat{H}_{S O}=\frac{\Omega^{2}}{2}\left\{\sum_{i=1}^{n} \sum_{A=1}^{m} \frac{Z_{A}}{r_{i A}^{3}}\left[\left(\vec{r}_{i}-\vec{r}_{A}\right) \times \vec{p}_{i}\right] \cdot \vec{S}_{i}-\sum_{i=1}^{n} \sum_{j \neq i}^{n} \frac{1}{r_{i j}^{3}}\left[\left(\vec{r}_{i}-\vec{r}_{j}\right) \times \vec{p}_{i}\right] \cdot\left[\vec{S}_{i}+2 \vec{S}_{j}\right]\right\}
$$

where $\Omega$ is the fine structure constant, $\vec{p}_{i}$ is the electron momentum operator, and $\vec{S}_{i}$ is the electron spin operator. The first term in equation (12) is known as the one-electron spin-orbit coupling (SOC) operator, while the second term is known as the two-electron SOC operator. Matrix elements may be formed over the Breit-Pauli operator with the unperturbed eigenstates as the basis, and then the matrix is diagonalized to yield spin-orbit coupled wave functions.

The electronic structure methods described so far in this section provide a systematically improvable way of approximating the Schrödinger equation. The one-electron 
basis set in equation (8) may be progressively expanded. Higher orders of perturbation theory or a higher level of $\mathrm{CI}$ or $\mathrm{CC}$ theory may be used in order to recover a greater portion of the correlation energy and approach the full $\mathrm{CI}$ limit. However, the increased complexity of the basis set and the more accurate level of theory come with a greater computational cost. Hartree-Fock theory scales as order $N^{4}$, where $N$ is the size of the basis set. So, if the basis set size is doubled, the time required for the calculation will increase by a factor of 16 . Second-order perturbation theory scales as order $N^{5}$, so a similar growth in the basis set will increase the time requirements by a factor of 32 . Higher levels of theory have larger scaling, so they quickly become impractical for systems with many atoms. Although computer power is rapidly rising, it does not keep pace with the desire to investigate bigger molecular systems. The implementation of distributed memory parallel codes will help to alleviate this and will enable the exploration of larger systems.

Another method for reducing the time requirements of a calculation involves replacing a portion of the system by a classical potential. This potential may be systematically improved if it is based on quantum mechanics and incorporates the important physical effects inherent in the system. The Effective Fragment Potential (EFP) method is a generalized potential derived from $a b$ initio principles. The one-electron potentials are added to the ab initio electronic Hamilitonian. The original method (EFP1/HF) is specific to water and incorporates Coulombic interactions, induction/polarization interactions, and chargetransfer/exchange-repulsion terms. ${ }^{25,26}$. A density functional theory-based method (EFP1/DFT) includes some short-range correlation effects, ${ }^{27}$ and a second-order perturbation theory-based method (EFP1/MP2) includes dispersion effects and a second-order correction to polarization. ${ }^{28}$ In addition, a general effective fragment potential (EFP2) has also been 
developed. ${ }^{29.34}$ These potentials are especially useful during the exploration of potential energy surfaces of solvated systems.

\section{References}

(1) Dirac, P. A. M. Proc. R. Soc. London, Ser. A 1929, 123, 714.

(2) Schrödinger, E. Ann. Phys. 1926, 79, 361.

(3) Schrödinger, E. Ann. Phys. 1926, 79, 489.

(4) Schrödinger, E. Ann. Phys. 1926, 79, 734.

(5) Schrödinger, E. Ann. Phys. 1926, 80, 437.

(6) Schrödinger, E. Ann. Phys. 1926, 81, 109.

(7) Schrödinger, E. Die Naturwissenschaften 1926, 14, 664.

(8) Schrödinger, E. Phys. Rev. 1926, 28, 1049.

(9) Born, M.; Oppenheimer, J. R. Ann. Phys. 1927, 84, 457.

(10) Hartree, D. R. Proc. Cambridge Philos. Soc. 1928, 24, 89.

(11) Hartree, D. R. Proc. Cambridge Philos. Soc. 1928, 24, 111.

(12) Hartree, D. R. Proc. Cambridge Philos. Soc. 1928, 24, 426.

(13) Slater, J. C. Phys. Rev. 1929, 34, 1293.

(14) Slater, J. C. Phys. Rev. 1930, 35, 509.

(15) Fock, V. Z. Phys. 1930, 61, 126.

(16) Fock, V. Z. Phys. 1930, 62, 795.

(17) Møller, C.; Plesset, M. S. Phys. Rev. 1934, 46, 618.

(18) Hirao, K. Int. J. Quantum Chem. Symp. 1992, S26, 517.

(19) Hirao, K. Chem. Phys. Lett. 1992, 190, 374.

(20) Hirao, K. Chem. Phys. Lett. 1992, 196, 397. 
(21) Nakano, H. Chem. Phys. Lett. 1993, 207, 372.

(22) Nakano, H. J. Chem. Phys. 1993, 99, 7983.

(23) Anderson, K.; Malmquist, P.-Å.; Roos, B. O. J. Chem. Phys. 1992, 96, 1218.

(24) Bethe, H. A.; Salpeter, E. E. Quantum Mechanics of the One and Two

Electron Atoms; Plenum: New York, 1977.

(25) Jensen, J. H.; Day, P. N.; Gordon, M. S.; Basch, H.; Cohen, D.; Garmer, D.

R.; Krauss, M.; Stevens, W. J. Effective Fragment Method for Modeling Intermolecular Hydrogen-Bonding Effects on Quantum Mechanical Calculations. In Modeling the Hydrogen Bond; Smith, D. A., Ed.; ACS Symposium Series: Washington DC, 1994; Vol. 569; pp 139.

(26) Day, P. N.; Jensen, J. H.; Gordon, M. S.; Webb, S. P.; Stevens, W. J.; Krauss, M.; Garmer, D. R.; Basch, H.; Cohen, D. J. Chem. Phys. 1996, 105, 1968.

(27) Adamovic, I.; Freitag, M. A.; Gordon, M. S. J. Chem. Phys. 2003, 118, 6725.

(28) Song, J.; Gordon, M. S. manuscript in preparation.

(29) Jensen, J. H. J. Chem. Phys. 1996, I04, 7795.

(30) Jensen, J. H.; Gordon, M. S. Mol. Phys. 1996, 89, 1313.

(31) Jensen, J. H.; Gordon, M. S. J. Chem. Phys. 1998, 108, 4772.

(32) Gordon, M. S.; Freitag, M. A.; Bandyopadhyay, P.; Jensen, J. H.; Kairys, V.; Stevens, W. J. J. Phys. Chem. A 2001, 105, 293.

(33) Adamovic, I.; Gordon, M. S. Mol. Phys. 2005, 103, 379.

(34) Li, H.; Jensen, J. H.; Gordon, M. S. manuscript in preparation. 


\section{CHAPTER 2. ELECTRONIC STRUCTURE AND MAGNETIC PROPERTIES OF $\mathrm{Y}_{2} \mathrm{Ti}(\mu-\mathrm{X})_{2} \mathrm{TiY}_{2}(\mathrm{X}, \mathrm{Y}=\mathrm{H}, \mathrm{F}, \mathrm{Cl}, \mathrm{Br})$ ISOMERS \\ A paper published in The Journal of Physical Chemistry A \\ Christine M. Aikens and Mark S. Gordon}

The electronic structure and magnetic properties of homodinuclear titanium(III) molecules with halide and hydride ligands have been studied using single and multi-reference methods. Natural orbital occupation numbers suggest that the singlet states are essentially diradical in character. Dynamic electron correlation is required for calculating quantitatively accurate energy gaps between the singlet and triplet states. Isotropic interaction parameters are calculated and three of the compounds studied are predicted to be ferromagnetic at the MRMP2/TZV(p) level of theory. Zero-field splitting parameters are determined using CASSCF and MCQDPT spin-orbit coupling with three different electron operator methods. Timings for these methods are compared. Calculated dimerization energies suggest that all dimers studied are lower in energy than corresponding monomers. Monomer structures and vibrational frequencies are reported.

\section{Introduction}

It has been noted that "the most important developments in molecular magnetism in the last two decades have concerned compounds where several magnetic centers interact" (Ref. 1, p. 103). Two of the greatest challenges include the synthesis of molecular ferromagnets that retain their ferromagneticity at very high temperatures and the design of systems with strong interactions between distant metal centers. ${ }^{2}$ Since the bonding and magnetic properties of homodinuclear molecules arise from complex interactions between 
the two metal centers and between the metal centers and the bridging and terminal ligands, it is important to understand how changes in the ligands affect the magnetic properties of the system. To this end, homodinuclear copper(II) $\mathrm{d}^{9}$ molecules have been extensively studied, as they provide a molecular system with one unpaired electron on each metal atom. ${ }^{1-17}$ Homodinuclear titanium(III) molecules also have one unpaired electron on each metal center and provide an essential contrast to the copper(II) $d^{9}$ molecules due to differences in orbital occupation for the unpaired electrons and to the greater radial extension of the Ti $\mathrm{d}$ orbitals.

Compounds containing titanium have long been studied for their interesting magnetic properties. ${ }^{18-23}$ Recently, linear oxo-bridged heterodinuclear and homodinuclear compounds of titanium(III) have been examined using electron paramagnetic resonance (EPR), magnetic susceptibility studies, and $a b$ initio calculations, and some compounds have been found to be ferromagnetic. ${ }^{24-26}$ Two possible explanations have been advanced for the origin of the Ti-Ti exchange interaction that is apparently responsible for the observed magnetic properties: the direct overlap of the occupied $\mathrm{Ti} \mathrm{d}$ orbitals or an intramolecular superexchange pathway via the bridging ligands. ${ }^{27}$ For an exchange pathway involving direct overlap of d orbitals, a decrease in the metal-metal distance generally leads to an increase in the magnitude of the antiferromagnetic interaction. ${ }^{28}$ In a system with sizeable bridging ligands, the large Ti-Ti distance prevents the direct overlap of d orbitals and necessitates a superexchange pathway. Such pathways normally result in a smaller antiferromagnetic effect than does the direct overlap pathway. ${ }^{28}$ A few of the oxo-bridged dinuclear compounds do not interact via a superexchange pathway and consequently have a very small metal-metal interaction. ${ }^{24,29}$ Most of the dinuclear titanium(III) complexes studied to this point are 
antiferromagnetic,,$^{27,28,30-38}$ although two dinuclear complexes with extended ligand systems are also reported to be weakly ferromagnetic. ${ }^{34}$

Many of the experimentally known dititanium(III) bridged compounds have a planar ring structure, ${ }^{27.30 \cdot 32.35-37}$ so the $\mathrm{D}_{2 \mathrm{~h}}$ isomers of $\mathrm{Ti}_{2} \mathrm{X}_{2} \mathrm{Y}_{4}$ of interest in this work may be viewed as models for these compounds. Previous computational research has emphasized $\mathrm{Ti}_{2} \mathrm{H}_{6}$ as the simplest prototype for homodinuclear titanium(III) systems. ${ }^{39,40}$ In this work, we examine changes in magnetic properties and electronic structure due to variations in the bridging and terminal ligands in these systems, with $\mathrm{X}, \mathrm{Y}=\mathrm{H}, \mathrm{F}, \mathrm{Cl}, \mathrm{Br}$.

The dominant magnetic effect in most cases is the isotropic interaction. This is an electrostatic phenomenon that may be formally described as a coupling between local spin operators $\mathbf{S}_{\mathbf{A}}$ and $\mathbf{S}_{\mathbf{B}}$. The Hamiltonian for the coupling may be written

$$
\mathcal{H}=-2 \mathbf{J S}_{\mathrm{A}} \cdot \mathbf{S}_{\mathrm{B}^{*}}
$$

The isotropic exchange interaction parameter is defined by

$$
2 \mathrm{~J}=\mathrm{E}(\mathrm{S}=0)-\mathrm{E}(\mathrm{S}=1),
$$

where $S$ is the spin quantum number for the system and the magnetic susceptibility is given by

$$
\chi=\frac{2 N g^{2} \beta^{2}}{k T}\left[3+\exp \left(\frac{-2 J}{k T}\right)\right]^{-1}
$$

where $N$ is Avogadro's number, $g$ is the average electronic gyromagnetic ratio, $\beta$ is the Bohr magneton, $\mathrm{k}$ is the Boltzmann constant, and $\mathrm{T}$ is the temperature. In molecules with two local doublets that interact through bridging ligands, the two local spin states $S_{A}$ and $S_{B}$ have singlet and triplet coupling. As long as the isotropic interaction is dominant, the total spin quantum number $\mathrm{S}$ is a good quantum number. ${ }^{1}$ If the singlet $(\mathrm{S}=0)$ is the ground state $(\mathrm{J}<0)$, 
the interaction is antiferromagnetic; if the triplet $(S=1)$ is the ground state $(J>0)$, the interaction is ferromagnetic. When the interaction is antiferromagnetic, the magnetic susceptibility goes through a maximum (the Néel temperature) as the temperature decreases. The temperature $\mathrm{T}_{\max }$ at which this occurs is related to $\mathrm{J}$ by

$$
\mid 2 \mathrm{~J} / \mathrm{kT}_{\max }=1.599
$$

where $\mathrm{k}=0.695 \mathrm{~cm}^{-1} \mathrm{~K}^{-1}$. This relation may be used to compare experimentally observable susceptibility maxima with calculated isotropic interaction parameters.

If the isotropic interaction is small, other magnetic properties such as the dipolar interaction and anisotropic interaction (also called the pseudodipolar interaction) may become important. This may have especially important effects on the magnetic properties of the system if the triplet state is the ground state. In a dinuclear complex such as $\mathrm{D}_{2 \mathrm{~h}} \mathrm{Ti}_{2} \mathrm{X}_{2} \mathrm{Y}_{4}$, the interaction of the two local doublets leads to a zero-field splitting (ZFS) of the triplet state. The electron paramagnetic resonance (EPR) spectrum of the triplet state may be described by the Hamiltonian

$$
\mathcal{H}=\beta S \cdot \mathbf{g} \cdot H+S \cdot \mathbf{D} \cdot S
$$

where the first term accounts for the Zeeman perturbation due to the magnetic field $H$ and the g-tensor, and the second term accounts for the dipolar and anisotropic interactions, where $\mathbf{D}$ is the ZFS tensor. ${ }^{10}$ The zero-field splitting parameters are calculated from the principal values of $\mathbf{D}$ by ${ }^{10}$

$$
\begin{aligned}
& \mathrm{D}=3 \mathrm{D}_{\mathrm{z}} / 2 \\
& \mathrm{E}=\left(\mathrm{D}_{\mathrm{x}}-\mathrm{D}_{\mathrm{y}}\right) / 2
\end{aligned}
$$


where $D$ is the axial splitting parameter and $E$ is the nonaxial (rhombic) splitting parameter. The dipolar term is often the minor contribution to $\mathbf{D}$ and is often reasonably estimated from the point dipole approximation. ${ }^{1}$ The anisotropic (pseudodipolar) exchange interaction results from the synergistic effects of the local spin-orbit coupling (SOC) perturbations and the exchange interaction between the ground state of one magnetic center with the excited states of the other. ${ }^{1.35}$ In a symmetric dimer, the zero-field splitting parameters $\mathrm{D}$ and $\mathrm{E}$ are composed of the dipolar contributions $\mathrm{D}_{\mathrm{d}}$ and $\mathrm{E}_{\mathrm{d}}$ and the pseudodipolar contributions $\mathrm{D}_{\mathrm{e}}$ and $\mathrm{E}_{\mathrm{e}}$ according to ${ }^{35}$

$$
\begin{aligned}
& D=D_{d}+D_{c} \\
& E=E_{d}+E_{c}
\end{aligned}
$$

When the rhombic exchange parameter $\left|E_{e}\right|$ is larger than the axial exchange parameter $\left|D_{e}\right|$, SOC effects are larger perpendicular to the Ti-Ti axis than along it.

\section{Computational Details}

A triple-zeta with polarization (14s11p6d/10s8p3d) basis set was adopted for titanium, consisting of Wachter's basis set ${ }^{41}$ with two additional sets of $p$ functions ${ }^{42}$ and an additional set of diffuse $d$ functions. ${ }^{43}$ In this notation $(\mathrm{A} / \mathrm{B}), \mathrm{A}$ and $\mathrm{B}$ refer to the primitive and contracted basis sets, respectively. For hydrogen, Dunning's (5s $1 \mathrm{p} / 3 \mathrm{~s} 1 \mathrm{p})$ basis set was used. ${ }^{44}$ For fluorine, the triple-zeta (10s6p/5s3p) basis set of Dunning was employed; $;{ }^{45}$ for chlorine, the triple-zeta (12s9p/6s5p) basis set of McLean and Chandler was employed; ${ }^{46}$ and for bromine, the triple-zeta $(14 \mathrm{~s} 11 \mathrm{p} 5 \mathrm{~d} / 9 \mathrm{~s} 6 \mathrm{p} 2 \mathrm{~d})$ basis set of Binning and Curtiss was employed.$^{47}$ Collectively, this basis set is referred to as TZV(p). All geometry optimizations were performed with this basis set. 
In order to predict reasonable energy-related quantities, polarization functions were added to the $\operatorname{TZV}(\mathrm{p})$ basis set. The basis set referred to as $\operatorname{TZVP}(\mathrm{f})$ adds $f$ functions to the titanium $(\alpha=0.40),{ }^{48}$ two sets of $d$ polarization functions to the halides, and diffuse $s$ and $p$ functions to the halides as well. The $2 \mathrm{~d}$ polarization and diffuse $\mathrm{sp}$ function exponents are the default values in GAMESS. ${ }^{49}$ The basis set called TZVP(fg) retains the halide basis set from TZVP $(f)$ and adds one set of $f(\alpha=0.591)$ and $g(\alpha=0.390)$ functions and a set of diffuse $\mathrm{s}(\alpha=0.035), \mathrm{p}(\alpha=0.239)$, and $\mathrm{d}(\alpha=0.0207)$ functions to the TZV(p) titanium basis. These exponents are optimized for correlated titanium atoms. ${ }^{50}$

For the singlet homodinuclear titanium(III) molecules, preliminary geometry optimizations were carried out at the RHF level of theory. After convergence, modified virtual orbitals (MVOs) were generated by removing six electrons in the usual manner. ${ }^{51}$ The resulting orbitals were used as a starting point for a two configuration self-consistent field (TCSCF) geometry optimization. For the doublet and triplet states, geometry optimizations were performed at the ROHF level of theory.

Stationary points were characterized by calculating and diagonalizing the energy second-derivative (Hessian) matrix. Unless otherwise stated, these stationary points have no imaginary frequencies, so they are minima on their respective potential energy surfaces.

Dynamic electron correlation effects were included by carrying out multireference second-order perturbation theory (MRMP2) ${ }^{52}$ single-point energy calculations at the TCSCF singlet geometries and ROHF triplet geometries. These single-point energy calculations were repeated with the TZVP( $f)$ and $\operatorname{TZVP}(f g)$ basis sets as a test of basis set convergence. 
In order to obtain reasonable energies for the doublet states, $Z$-averaged perturbation theory $(\text { ZAPT2 })^{53}$ and MRMP2(1,1) calculations were carried out at the ROHF geometries.

Excited state calculations require fully optimized reaction space (FORS) multiconfigurational SCF (MCSCF) calculations ${ }^{54}$ (also called CASSCF), in this case with an active space consisting of two electrons in ten orbitals. Spin-orbit coupling effects (SOC) are determined in three ways: a one-electron spin-orbit coupling operator method (HSO1), ${ }^{55}$ a partial two electron and full one electron method (P2E) ${ }^{56}$ and the full Pauli-Breit operator method (HSO2) ${ }^{56}$ Both the complete active space SCF (CASSCF-SOC) and multiconfiguration quasi-degenerate perturbation spin-orbit coupling (MCQDPT-SOC) ${ }^{57}$ techniques are used with each of the three methods.

All calculations were done using the electronic structure code GAMESS. ${ }^{49}$ Molecules and orbitals were visualized using MacMolPlot, ${ }^{58}$ a graphical interface to GAMESS.

\section{Results and Discussion}

Electronic Structure and Energetics. As noted in the earlier work on $\mathrm{Ti}_{2} \mathrm{H}_{6}$, the ground-state minima are either triplets or they are singlets with a high degree of diradical character. The lowest energy singlet and triplet states are ${ }^{1} \mathrm{~A}_{\mathrm{g}}$ and ${ }^{3} \mathrm{~B}_{\mathrm{lu}}$, respectively. The lowest energy structures for $\mathrm{Ti}_{2} \mathrm{~F}_{2} \mathrm{H}_{4}$ are an exception to the general pattern, and are discussed in the next section. The natural orbital analysis of the TCSCF/TZV(p) wave functions (Figure 1) shows that the lowest energy singlets all have at least 0.87 electrons in the lowest virtual orbitals. This suggests that these states are essentially singlet diradicals, probably with very small bonding interactions.

Dynamic electron correlation is required for calculating quantitatively accurate energy gaps between the singlet and triplet states (Table 1). At the TCSCF/TZV(p) level of 
theory, five of the triplet states are predicted to lie slightly $(<0.2 \mathrm{kcal} / \mathrm{mol})$ below the singlet states. However, inclusion of dynamic electron correlation via second order perturbation theory lowers most of the singlet states preferentially. At the MRMP2/TZV(p) level of theory, three of the triplet states lie below the corresponding singlet states. As the basis set size is increased, the singlet-triplet splitting increases by up to $0.3 \mathrm{kcal} / \mathrm{mol}$ on going from $\mathrm{TZV}(\mathrm{p})$ to TZVP(f) and by up to an additional $0.6 \mathrm{kcal} / \mathrm{mol}$ from TZVP(f) to TZVP(fg).

The lowest energy singlet and triplet state geometries are shown in Table 2. Mulliken populations for the MCSCF and ROHF wavefunctions (Table 3) with the TZV(p) basis show positively charged Ti's, as expected with the anionic ligands. Charges on Ti range from +0.73 to +1.78 , indicating highly polarized bonds. The Ti positive charges increase with the electronegativity of the ligands and with the number of electronegative ligands.

Although the orbitals for the $\mathrm{Ti}_{2} \mathrm{X}_{2} \mathrm{Y}_{4}$ molecules are in principle able to form a direct Ti-Ti bond, there is apparently little such bonding based on the natural orbital occupation numbers (Figure 1). A similar conclusion was reached for singlet $\mathrm{Ti}_{2} \mathrm{H}_{6}$.

Lowest energy structures for $\mathrm{Ti}_{2} \mathbf{F}_{2} \mathbf{H}_{4}$. As for the other molecules in the series, the lowest energy $\mathrm{D}_{2 \mathrm{~h}}$ singlet state for $\mathrm{Ti}_{2} \mathrm{~F}_{2} \mathrm{H}_{4}$ is a ${ }^{1} \mathrm{~A}_{\mathrm{g}}$ state, while the lowest energy triplet state is a ${ }^{3} \mathrm{~B}_{1 u}$ state. Two low-lying orbital configurations can contribute to these states. For the singlet, these are $\left[(\sigma)\left(\sigma^{*}\right)\right]^{2}$ and $\left[(\delta)\left(\delta^{*}\right)\right]^{2}$. For the other molecules in the series, the $\left[(\sigma)\left(\sigma^{*}\right)\right]^{2}$ configuration dominates the ground state, while $\left[(\delta)\left(\delta^{*}\right)\right]^{2}$ is an excited singlet state. However, the $\left[(\delta)\left(\delta^{*}\right)\right]^{2}$ configuration dominates the $\mathrm{Ti}_{2} \mathrm{~F}_{2} \mathrm{H}_{4}$ ground state, while the $\left[(\sigma)\left(\sigma^{*}\right)\right]^{2}$ configuration, at $0.9 \mathrm{kcal} / \mathrm{mol}$, dominates the first excited singlet state at the $\operatorname{TCSCF} / \mathrm{TZV}(\mathrm{p})$ level of theory. $\operatorname{MCSCF}(2,10)$ calculations show that there is essentially no 
mixing between the two configurations. The Generalized Valence Bond Perfect Pairing (GVB-PP(1) $)^{59}$ method (equivalent to TCSCF) was used to calculate the analytical Hessian for the two states, and both have two imaginary frequencies. Displacements along the imaginary modes lead to a common $\mathrm{C}_{2 \mathrm{~h}}$ structure (Figure 3 ). This structure is 0.3 and 1.2 $\mathrm{kcal} / \mathrm{mol}$ lower than the two $\mathrm{D}_{2 \mathrm{n}}$ states at the TCSCF/TZV(p) level of theory (Table 4). GVB-PP analytic Hessian calculations show that it is a minimum on the potential energy surface. Vibrational frequencies are reported in Table 5. The plane containing the Ti and F atoms makes an angle of $83.3^{\circ}$ with the plane containing the $\mathrm{Ti}$ and $\mathrm{H}$ atoms. Other geometrical parameters are reported in Table 2.

Monomer Structures and Vibrational Frequencies. A $D_{3 \mathrm{~h}}$ structure $\left({ }^{2} \mathrm{~A}_{1}{ }^{2}\right.$ state $)$ is found to be the lowest energy minimum for the titanium trihalides, $\operatorname{TiX}_{3} . \mathrm{A} \mathrm{C}_{2 \mathrm{v}}$ structure $\left({ }^{2} \mathrm{~A}_{1}\right.$ state) is found to be the lowest energy minimum for both the $\mathrm{TiX}_{2} \mathrm{H}$ and the $\mathrm{TiXH}_{2}$ species. The $\mathrm{C}_{2 \mathrm{v}}$ state labels assume that $\mathrm{z}$ is the principal rotation axis and that the molecule lies in the yz plane. The ROHF/TZV(p) optimized geometries are given in Table 6.

In $\mathrm{TiF}_{3}$, the calculated Ti-F distance of $1.819 \AA$ is close to previously reported distances of $1.79,{ }^{60} 1.7978,{ }^{61}$ and $1.83^{62} \AA$. The computed vibrational frequencies agree well with prior estimates, calculations, and matrix isolation studies (see Table 7). This data provides additional evidence that the $v_{3}$ band originally assigned to $\mathrm{TiF}_{2}$ belongs to $\mathrm{TiF}_{3}{ }^{63,64}$ In addition, the weak $v_{1}$ symmetric stretch initially assigned to $\mathrm{TiF}_{2}^{63}$ appears to belong to $\mathrm{TiF}_{3}$. The confusion seems to have occurred because $\mathrm{TiF}_{3}$ both disproportionates and sublimes unchanged upon heating; ${ }^{64}$ this results in a spectrum that contains bands due to both $\mathrm{TiF}_{4}$ and $\mathrm{TiF}_{3}$ rather than $\mathrm{TiF}_{3}$ and $\mathrm{TiF}_{2}$ as assigned. 
For $\mathrm{TiCl}_{3}$, the calculated Ti-Cl distance of $2.272 \AA$ differs considerably $(\sim 0.1 \AA)$ from previously obtained Ti-Cl distances of $2.183^{65}$ and $2.178^{60} \AA$. Much of the available vibrational frequency data for $\mathrm{TiCl}_{3}$ is for the solid state ${ }^{6670}$. The few gas phase studies are summarized here. As seen in Table 7, the computed vibrational frequencies are similar to those found previously. $v_{4}$ in this work is $38 \mathrm{~cm}^{-1}$ lower than $v_{4}$ from Ref. 71 , but is similar . to that in references 60 and $65 . v_{1}$ is $5-59 \mathrm{~cm}^{-1}$ higher than previously reported values, while $v_{2}$ and $v_{3}$ are within $\pm 28 \mathrm{~cm}^{-1}$. Since the errors are not systematic and the previously reported frequencies vary significantly, the calculated frequencies have not been scaled.

For $\mathrm{TiBr}_{3}$, the metal-halide distance and vibrational frequencies have previously been estimated from the equilibrium structures, force fields, and vibrational frequencies of $\mathrm{TiCl}_{3}$ and $\mathrm{TiI}_{3}{ }^{60}$ The previously estimated distance of $2.34 \AA$ is $0.07 \AA$ lower than the calculated distance of $2.414 \AA$. The vibrational frequencies differ from the previously estimated frequencies by $12,8,23$, and $15 \mathrm{~cm}^{-1}$ for $\nu_{1}-v_{4}$ (see Table 7 ).

Since the vibrational frequencies calculated for the titanium trihalides are in reasonable agreement with prior estimates, calculations, and matrix isolation studies, it is reasonable to assume a similar level of agreement for the predicted frequencies for the $\mathrm{TiX}_{2} \mathrm{H}$ and $\mathrm{TiXH}_{2}$ species (Table 8).

Of the $\mathrm{TiX}_{2} \mathrm{H}$ and $\mathrm{TiXH}_{2}$ species studied here, only calculations on $\mathrm{TiHF}_{2}$ and $\mathrm{TiHCl}_{2}$ have been reported in the literature to date. For TiHF, Zakharov, et. al. found a Ti-H distance of $1.703 \AA$ and a Ti-F distance of $1.741 \AA$ with a calculated F-Ti-F angle of $129.0^{\circ}$ using a $3-21 G^{*}$ basis set at the Hartree-Fock level of theory. ${ }^{73}$ Vibrational data was not reported, although the stationary point was confirmed by diagonalizing the Hessian. ${ }^{73}$ 
Determination of the ground state of this molecule is elusive. The occupation of $\mathrm{ad}_{\mathrm{x}}{ }^{74}$ orbital by a single electron on the Ti leads to a ${ }^{2} A_{1}$ state while the occupation of a $d_{x z}$ orbital leads to $\mathrm{a}^{2} \mathrm{~B}_{1}$ state. At the ROHF/TZV(p) level, the $\mathrm{C}_{2 \mathrm{v}}{ }^{2} \mathrm{~B}_{1}$ state is $0.4 \mathrm{kcal} / \mathrm{mol}$ lower in energy than the $\mathrm{C}_{2 \mathrm{v}}{ }^{2} \mathrm{~A}_{1}$ state. At this level of theory, the ${ }^{2} \mathrm{~B}_{1}$ state has a positive definite Hessian, while the ${ }^{2} \mathrm{~A}_{1}$ state does not. At the ZAPT2/TZV(p)//ROHF/TZV(p) level of theory, the ${ }^{2} \mathrm{~A}_{1}$ state is lower than the ${ }^{2} \mathrm{~B}_{1}$ state by $1.2 \mathrm{kcal} / \mathrm{mol}$. UHF/TZV(p) calculations predict that the ${ }^{2} \mathrm{~B}_{1}$ state is $0.2 \mathrm{kcal} / \mathrm{mol}$ lower in energy than the ${ }^{2} \mathrm{~A}_{1}$ state and that both are minima. However, at the UMP2/TZV(p) level of theory, the ${ }^{2} \mathrm{~A}_{1}$ state is lower than the ${ }^{2} \mathrm{~B}_{1}$ state by 1.0 $\mathrm{kcal} / \mathrm{mol}$. At this level of theory, the ${ }^{2} \mathrm{~A}_{1}$ state has a positive definite Hessian while the ${ }^{2} \mathrm{~B}_{1}$ state does not. The imaginary frequencies from the ROHF/TZV $(p){ }^{2} \mathrm{~A}_{1}$ and UMP2/TZV(p) ${ }^{2} \mathrm{~B}_{1}$ state are out-of-plane bending modes. Calculations done in $\mathrm{C}_{s}$ symmetry show that these states end up converging to the lowest energy planar structures for the given level of theory.

For $\mathrm{TiHCl}_{2}$, previous calculations using generalized valance bond methods and $\mathrm{ECP}$ basis sets predict a planar compound with a Ti-H distance of $1.68-1.70 \AA$, a Ti-Cl distance of 2.32-2.33 $\AA$, and a Cl-Ti-Cl angle of $140-148^{\circ} .75,76$ The electronic state was not reported. In contrast, the Cl-Ti-Cl angle calculated in this work is $128.4^{\circ}$. In order to determine the origin of this difference, the minimum energy structures for the ${ }^{2} A_{2},{ }^{2} B_{1}$, and ${ }^{2} B_{2}$ states were calculated. The reported geometrical parameters in Ref. 75 agree well with our calculated geometry for the ${ }^{2} \mathrm{~B}_{2}$ state, which is $24.6 \mathrm{kcal} / \mathrm{mol}$ higher in energy than the ${ }^{2} \mathrm{~A}_{1}$ state at the ROHF level of theory and $27.4 \mathrm{kcal} / \mathrm{mol}$ higher at the ZAPT2/ROHF level of theory (See Table 9).

Vibrational Frequencies for Dimers. Vibrational frequencies for the Raman and IR active bands of the $\mathrm{Ti}_{2} \mathrm{X}_{2} \mathrm{Y}_{4}$ molecules are listed in Table 5. Very little experimental data is 
available for these compounds. Hastie, Hauge, and Margrave report an IR band at $745.5 \mathrm{~cm}^{-}$ ${ }^{1}$, which they attribute to a polymeric species such as $\left(\mathrm{TiF}_{3}\right)_{2} \cdot{ }^{63}$ Two of our calculated frequencies for $D_{2 h} F_{2} T i(\mu-F)_{2} T_{i F}$ fall within a reasonable range of this band. For the triplet state, a peak at $747 \mathrm{~cm}^{-1}\left(745 \mathrm{~cm}^{-1}\right.$ for the slightly higher energy singlet state) appears to be a likely candidate, but due to the symmetry of the vibration it is a Raman active peak and should not be IR active. A different peak at $764 \mathrm{~cm}^{-1}\left(762 \mathrm{~cm}^{-1}\right.$ for the singlet) is within 19 $\mathrm{cm}^{-1}$ of the reported IR band and should be IR active. After correcting for matrix shift effects of up to $20 \mathrm{~cm}^{-1}{ }^{63}$ these values could be even closer.

Dimerization Energies. The calculated $\mathrm{TiX}_{3}, \mathrm{TiX}_{2} \mathrm{H}$, and $\mathrm{TiXH}_{2}$ dimerization energies are listed in Table 10. Sørlie and Øye report the presence of $\mathrm{Ti}_{2} \mathrm{Cl}_{6}$ in hightemperature absorption spectroscopy. ${ }^{n}$ They suggest a distorted tetrahedral structure for $\mathrm{Ti}_{2} \mathrm{Cl}_{6}$, in which two deformed tetrahedra share one edge. This structure would imply either $C_{2 v}$ or $D_{2 h}$ symmetry. Sørlie and Øye found the enthalpy of dimerization to be in the range of -32.7 to $34.2 \mathrm{kcal} / \mathrm{mol}^{\pi}{ }^{\pi}$ Previous experiments in other laboratories found the enthalpy of dimerization to be $-31.9 \mathrm{kcal} / \mathrm{mol}^{78}$ and $-40.6 \mathrm{kcal} / \mathrm{mol}^{79}$ The former values agree well with our calculated energy of dimerization of $-32.8 \mathrm{kcal} / \mathrm{mol}$ for the $\mathrm{D}_{2 \mathrm{~h}}$ structure using second order perturbation theory. In general, the $\mathrm{D}_{2 \mathrm{~h}}$ structures of $\mathrm{Ti}_{2} \mathrm{X}_{2} \mathrm{Y}_{4}$ are $32.7-54.4 \mathrm{kcal} / \mathrm{mol}$ lower in energy than their separated monomers (see Table 10). Dimerization energies were calculated from the lowest energy monomer structure to the lowest energy dimer structure at the MRMP2/TZV(p) level of theory.

Previous theoretical calculations were done by Martinsky and Minot, who found a dimerization energy of $-73.4 \mathrm{kcal} / \mathrm{mol}$ for their lowest energy $\mathrm{C}_{\mathrm{s}} \mathrm{Ti}_{2} \mathrm{Cl}_{6}$ structure using density functional theory. ${ }^{80}$ This is more than twice our predicted value. Their dibridged 
compound lies $3.1 \mathrm{kcal} / \mathrm{mol}$ above the $\mathrm{C}_{\mathrm{s}}$ compound. ${ }^{80}$ The dimer spin state was not specified.

\section{Magnetic Properties.}

\section{A. Isotropic interaction}

Magnetic properties of dinuclear complexes with a single unpaired electron on each magnetic center depend on the intramolecular interaction between the two metal centers. This interaction is affected by both the bridging ligands and the terminal ligands. As the bridging ligand changes from $\mathrm{H}$ to $\mathrm{Br}$ to $\mathrm{Cl}$ to $\mathrm{F}$, the MRMP2/TZVP(fg) interaction becomes more ferromagnetic ( $\mathrm{J}$ becomes less negative) (Table 11). As the terminal ligand changes from $\mathrm{H}$ to $\mathrm{Br}$ to $\mathrm{Cl}$ to $\mathrm{F}$, the interaction becomes more antiferromagnetic ( $\mathrm{J}$ becomes more negative). The isotropic interactions for the halide series range from $41 \mathrm{~cm}^{-1}$ to $-367 \mathrm{~cm}^{-1}$ at the MRMP2/TZVP(fg) level of theory. Note that dynamic correlation and larger basis sets have important effects on these predictions.

Experimentally observed $\mathrm{J}$ values for planar ring Ti compounds fall within the range predicted by MRMP2 calculations. For example, for $\left(\left(\mathrm{C}_{5} \mathrm{H}_{5}\right)_{2} \mathrm{TiCl}\right)_{2}$ and $\left(\left(\mathrm{C}_{5} \mathrm{H}_{5}\right)_{2} \mathrm{TiBr}\right)_{2}$, observed $\mathrm{J}$ values are -70 to $-85 \mathrm{~cm}^{-1}$ and $-125 \mathrm{~cm}^{-1}$, respectively, after adjusting for the difference in the isotropic interaction parameter definition. ${ }^{32}$ These are similar to the corresponding values in Table 11 . Based on a susceptibility maximum at $170 \mathrm{~K}$, $\left(\left(\mathrm{C}_{5} \mathrm{H}_{5}\right)_{2} \mathrm{TiCl}\right)_{2}$ has an observed $\mathrm{J}$ value of $-96 \mathrm{~cm}^{-1}{ }^{30.31}$ Stucky, et. al. found $\mathrm{J}$ values of -111 , -160 , and $-138 \mathrm{~cm}^{-1}$ for $\left(\left(\mathrm{C}_{5} \mathrm{H}_{5}\right)_{2} \mathrm{TiCl}\right)_{2},\left(\left(\mathrm{CH}_{3} \mathrm{C}_{4} \mathrm{H}_{5}\right)_{2} \mathrm{TiCl}\right)_{2}$, and $\left(\left(\mathrm{CH}_{3} \mathrm{C}_{4} \mathrm{H}_{5}\right)_{2} \mathrm{TiBr}\right)_{2}$, respectively. ${ }^{27}$ Although the halide terminal ligands may have isotropic interactions that are different from the organic terminal ligands, the predicted trend of increasing antiferromaticity for a given terminal ligand as the bridging ligand changes from chloride to bromide is 
consistent with the experiments. ${ }^{27,32}$ Also of note is the observation that no susceptibility maximum for $\left(\left(\mathrm{C}_{5} \mathrm{H}_{5}\right)_{2} \mathrm{TiF}\right)_{2}$ was observed experimentally between 80 and $380 \mathrm{~K} .^{32}$ The susceptibility maximum may be used experimentally to determine the antiferromagneticity of a compound. Since the theoretical calculations show that fluoride is a more ferromagnetic bridging ligand than chloride or bromide, this suggests that the isotropic interaction for $\left(\left(\mathrm{C}_{5} \mathrm{H}_{5}\right)_{2} \mathrm{TiF}\right)_{2}$ is either slightly antiferromagnetic with $0>\mathrm{J}>-44 \mathrm{~cm}^{-1}(80 \mathrm{~K})$ or that the interaction is ferromagnetic.

An interesting correlation may be noted between the natural orbital occupation numbers for a series of compounds and the ferromagneticity of these compounds by comparing Figure 1 and Table 11. As the diradical character of the compound becomes more pronounced and the NOON becomes closer to one, the ferromagneticity of the compound increases. This is consistent with the increase in electronegativity of the bridging ligand.

\section{B. Spin-Orbit Coupling Calculations}

An initial state-averaged 2 electron, 10 orbital MCSCF calculation at the $\mathrm{TCSCF} / \mathrm{TZV}(\mathrm{p}){ }^{1} \mathrm{~A}_{\mathrm{g}}$ ground state geometry was used to obtain a set of starting orbitals. Then, a second 2 electron, 10 orbital MCSCF calculation was carried out with no orbital symmetry constraints and with each of the first 20 singlet states weighted equally. Using this wave function as a starting point, a 2 electron, 10 orbital MCSCF calculation with the core and virtual orbitals frozen was run at the same geometry to obtain the first 20 triplet states. The singlet and triplet state orbitals were used in the CASSCF spin-orbit coupling (CASSCFSOC) calculations. The orbitals from the 20 singlet state calculation were used in the MCQDPT spin-orbit coupling (MCQDPT-SOC) calculations. The order and energies of the 
excited states vary slightly for the different $\mathrm{Ti}_{2} \mathrm{X}_{2} \mathrm{Y}_{4}$ molecules but are qualitatively similar to those reported for $\mathrm{Ti}_{2} \mathrm{H}_{6}{ }^{40}$

Inspection of the eigenvectors of the spin-mixed states allows the identification of those adiabatic states that mix with the predominant state, as well as that angular momentum operator which is responsible for the mixing. These adiabatic states and operators are exactly the same as those previously reported for $\mathrm{Ti}_{2} \mathrm{H}_{6}$, although the weightings vary slightly. ${ }^{40}$ It is interesting to compare the performance of the three alternative methods for spin-orbit coupling calculations: the full two-electron (HSO2), partial two-electron (P2E) and the oneelectron method with effective nuclear charges (HSO1). Compared with HSO2, for CASSCF-SOC and MCQDPT-SOC, the coefficients in the eigenvectors of the spin states are within \pm 0.00002 for $\mathrm{P} 2 \mathrm{E}$ and \pm 0.002 for HSO1. Except for $\mathrm{Ti}_{2} \mathrm{~F}_{2} \mathrm{H}_{4}$, the energy levels calculated by $\mathrm{P} 2 \mathrm{E}$ and $\mathrm{HSO} 2$ are practically the same and differ by no more than $0.008 \mathrm{~cm}-1$. The principal axes $\mathrm{X}, \mathrm{Y}$, and $\mathrm{Z}$ for the $\mathrm{T}_{1}$ (lowest triplet state) components can be determined from the coefficients of the eigenvectors. Then, the axial and rhombic pseudodipolar parameters $\mathrm{D}_{\mathrm{c}}$ and $\mathrm{E}_{\mathrm{c}}$ can be calculated as described previously. ${ }^{40}$ These values are summarized in Table 12 for the six different methods used for determining spinorbit coupling effects.

For the compounds with both bridging and terminal halide ligands, the spin-mixed triplet states are lower in energy than the lowest energy singlet state for all calculations except $\mathrm{Ti}_{2} \mathrm{Br}_{6}$ MCQDPT-SOC. This mirrors the pattern in singlet-triplet splitting for the TCSCF/TZV(p) and MRMP2/TZV(p) calculations, as expected. For most of the calculations, the magnitude of $E_{c}$ is slightly larger than the magnitude of $D_{c}$ by up to 0.014 $\mathrm{cm}^{-1}$. The one exception occurs for MCQDPT-SOC calculations on $\mathrm{Ti}_{2} \mathrm{~F}_{6}$, for which $\mid \mathrm{D}_{\mathrm{c}} \mathrm{l}$ is 
$0.015 \mathrm{~cm}^{-1}$ larger than $\left|E_{e}\right|$ In general, the magnitudes of $D_{c}$ and $E_{c}$ increase slightly as the method is improved from HSO1 to P2E to HSO2. For these compounds, the magnitudes of $\mathrm{D}_{\mathrm{c}}$ and $\mathrm{E}_{\mathrm{c}}$ decrease slightly as we go from CASSCF-SOC to MCQDPT-SOC calculations.

For the compounds with terminal halide ligands, all singlet states are lower in energy than the corresponding triplet states, as expected. In general, the magnitudes of $D_{e}$ and $E_{e}$ are similar. For the most part, $\left|\mathrm{D}_{\mathrm{e}}\right|$ is slightly larger than $\left|\mathrm{E}_{\mathrm{c}}\right|$ by up to $0.009 \mathrm{~cm}^{-1}$ for CASSCFSOC or $0.031 \mathrm{~cm}^{-1}$ for MCQDPT-SOC. $\mathrm{D}_{\mathrm{c}}$ becomes more negative and $\mathrm{E}_{\mathrm{a}}$ becomes more positive for $\mathrm{HSO} 2$ relative to $\mathrm{HSO} 1$ and for MCQDPT-SOC relative to CASSCF-SOC.

For $\mathrm{Ti}_{2} \mathrm{Cl}_{2} \mathrm{H}_{4}$ and $\mathrm{Ti}_{2} \mathrm{Br}_{2} \mathrm{H}_{4}$, the magnitude of $\mathrm{E}_{\mathrm{e}}$ is larger than the magnitude of $\mathrm{D}_{\mathrm{c}}$ by up to $0.053 \mathrm{~cm}^{-1}$ for CASSCF-SOC calculations. However, this trend is reversed for MCQDPT-SOC calculations, for which $\left|D_{e}\right|$ is up to $0.071 \mathrm{~cm}^{-1}$ larger than $\mid E_{e} l . D_{c}$ becomes more negative and $\mathrm{E}_{\mathrm{e}}$ becomes more positive as the method improves from HSO1 to $\mathrm{HSO}$.

$\mathrm{Ti}_{2} \mathrm{~F}_{2} \mathrm{H}_{4}$ is the only compound that does not follow the general spin-orbit coupling patterns for $\mathrm{Ti}_{2} \mathrm{X}_{2} \mathrm{Y}_{4}$ molecules. Its $\mathrm{D}_{\mathrm{c}}$ values are an order of magnitude larger than other $\mathrm{D}_{\mathrm{e}}$ values.

\section{Spin-Orbit Coupling Timings}

The relative times required for the various methods are given in Tables 13 and 14 . Only timings for the $\sigma, \sigma *$ configuration of $\mathrm{Ti}_{2} \mathrm{~F}_{2} \mathrm{H}_{4}$ are included in the tables since this structure is analogous to the other $\mathrm{Ti}_{2} \mathrm{X}_{2} \mathrm{Y}_{4}$ molecules. In general, the CASSCF-SOC method requires less time than the MCQDPT-SOC method. For the CASSCF-SOC calculations, the P2E state energies are almost exactly the same as the HSO2 energies, but the method requires roughly $46 \%$ of the CPU time required for the HSO2 method on a Sun UltraSPARC2 300 $\mathrm{MHz}$ processor. This is approximately the same whether or not the setup time is included in 
the timings. For the MCQDPT-SOC calculations, the total time required for the P2E method is approximately $89 \%$ of the time required for the HSO2 method on a Compaq AXP EV6 500 $\mathrm{MHz}$ processor. However, the setup time for MCQDPT-SOC calculations is much greater than for CASSCF-SOC calculations. If only the times for the spin-orbit coupling parts of the calculations are compared, the P2E method requires only about $63 \%$ of the time required for the HSO2 method. For both CASSCF-SOC and MCQDPT-SOC calculations, the HSO1 method requires much less time than either the HSO2 or P2E method. As discussed in the previous section, the state energies vary slightly but the $D_{e}$ and $E_{e}$ values calculated by the HSO1 method are close to those calculated by the other two methods. There is a slight accuracy trade-off for a large computational time savings.

\section{Conclusions}

The compounds studied in this work have a high degree of diradical character. Dynamic electron correlation is required for calculating quantitatively accurate energy gaps between the singlet and triplet states. As the bridging ligand changes from $\mathrm{H}$ to $\mathrm{Br}$ to $\mathrm{Cl}$ to $\mathrm{F}$, the interaction becomes more ferromagnetic; as the terminal ligand changes from $\mathrm{H}$ to $\mathrm{Br}$ to $\mathrm{Cl}$ to $\mathrm{F}$, the interaction becomes more antiferromagnetic. Vibrational frequencies calculated for the monomers and dimers should help experimentalists determine whether these species are present in experiments. All dimers are predicted to be lower in energy than the corresponding separated monomers.

With the exception of $\mathrm{Ti}_{2} \mathrm{~F}_{2} \mathrm{H}_{4}$, spin-orbit coupling effects for these dinuclear titanium molecules are very similar to those for $\mathrm{Ti}_{2} \mathrm{H}_{6}$. Energies calculated by the $\mathrm{HSO} 2$ and $\mathrm{P} 2 \mathrm{E}$ methods are virtually the same, even though the latter method requires significantly less computer time for CASSCF-SOC and MCQDPT-SOC calculations. 
Acknowledgment. CMA wishes to thank the National Science Foundation for a

Predoctoral Fellowship. CMA and MSG also wish to thank the National Science Foundation for providing a computer cluster to the Iowa State University Chemistry Department.

\section{References and Notes}

(1) Kahn, O. Molecular Magnetism; VCH: New York, 1993; Chapters 6-9.

(2) Kahn, O. Angew. Chem. Int. Ed. Engl. 1985, 24, 834.

(3) Hatfield, W. E. In Magneto-Structural Correlations in Exchange Coupled Systems;

Willett, R.D.; Gatteschi, D.; Kahn, O. Eds., NATO ASI Series: Reidel: Dordrecht. 1985; pp. $555-602$.

(4) Rodríguez-Fortea, A.; Alemany, P.; Alvarez, S.; Ruiz, E. Chem. Eur. J. 2001, 7, 627.

(5) Escuer, A.; Mautner, F. A.; Peñalba, E.; Vicente, R. Inorg. Chem. 1998, 37, 4190.

(6) Acevedo-Chávez, R.; Costas, M. E.; Escudero, R. Inorg. Chem. 1996, 35, 7430.

(7) Slangen, P. M.; van Koningsbruggen, P. J.; Goubitz, K.; Haasnoot, J. G.; Reedijk, J. Inorg. Chem. 1994, 33, 1121.

(8) Emori, S.; Todoko, K. Bull. Chem. Soc. Jpn. 1993, 66, 3513.

(9) Oshio, H.; Nagashima, U.; Inorg. Chem. 1990, 29, 3321.

(10) Boillot, M-L.; Journaux, Y.; Bencini, A.; Gatteschi, D.; Kahn, O. Inorg. Chem. 1985, $24,263$.

(11) Charlot, M. F.; Verdaguer, M.; Joumaux, Y.; de Loth, P.; Daudey, J. P. Inorg. Chem. 1984, 23,3802 .

(12) Julve, M;; Verdaguer, M.; Gleizes, A.; Philoche-Levisalles, M.; Kahn, O. Inorg. Chem. $1984,23,3808$. 
(13) Charlot, M. F.; Jeannin, S.; Jeannin, Y.; Kahn, O.; Lucrece-Abaul, J.; Martin-Frere, J. Inorg. Chem. 1979, 18, 1675.

(14) Charlot, M. F.; Kahn, O.; Jeannin, S.; Jeannin, Y. Inorg. Chem. 1980, 19, 1411.

(15) Crawford, V.H.; Richardson, H. W.; Wasson, J. R.; Hodgson, D. J.; Hatfield, W. E; Inorg. Chem. 1976, 15, 2107.

(16) Solomon, E. I. In Copper Proteins, Spiro, T. G., Ed.; Wiley-Interscience: New York. 1981; Chapter 2.

(17) Calzado, C. J.; Cabrero, J.; Malrieu, J. P.; Caballol, R. J. Chem. Phys. 2002, 116, 2728.

(18) Fernandes, J. C.; Guimaraes, R. B.; Continentino, M. A.; Borges, H. A.; Valarelli, J. V.; Lacerda, A. Phys. Rev. B 1994, 50, 16754.

(19) Machin, D. J.; Murray, K. S.; Walton, R. A. J. Chem. Soc. A 1968, 1, 195.

(20) Fowles, G. W. A.; Lester, T. E.; Walton, R. A.; J. Chem. Soc. A 1968, 1, 198.

(21) DeSavage, B. F.; Goff, J. F. J. Appl. Phys. 1967, 38, 1337.

(22) Strnat,K. J. AIP Conf. Proc. 1972, 5 (No. 2), 1047.

(23) Manjusri, G.; Mohan Babu, T. V. S. M.; Kaul, S. N.; Lucinski, T. J. Phys.: Condens. Matter 1997, 9, 2085.

(24) Lukens, W. W., Jr.; Andersen, R. A. Inorg. Chem. 1995, 34, 3440.

(25) (a) Fink, K.; Fink, R.; Staemmler, V.; Inorg. Chem. 1994, 33, 6219. (b) Kolczewski, Ch.; Fink, K.; Staemmler, V. Int. J. Quant. Chem. 2000, 76, 137.

(26) Ren, Q.; Chen, Z.; Ren, J.; Wei, H.; Feng, W.; Zhang, L. J. Phys. Chem. A 2002, 106, 6161.

(27) Jungst, R.; Sekutowski, D.; Davis, J.; Luly, M.; Stucky, G. Inorg. Chem. 1977, I6, 1645. (28) Fieselmann, B. F.; Hendrickson, D. N.; Stucky, G. D. Inorg. Chem., 1978, 17, 1841. 
(29) Lukens, W. W. Jr.; Matsunaga, P. T.; Andersen, R. A. Organometallics 1998, 17, 5240.

(30) Martin, R. L.; Winter, G. J. Chem. Soc. 1965, 4709.

(31) Canty, A. J.; Coutts, R. S. P.; Wailes, P. C. Aust. J. Chem. 1968, $21,807$.

(32) Coutts, R. S. P.; Wailes, P. C.; Martin, R. L. J. Organomet. Chem. 1973, 47, 375.

(33) (a) Fieselmann, B. F.; Stucky, G. D. Inorg. Chem. 1978, 17, 2074. (b) Fieselmann, B. F.;

Hendrickson, D. N.; Stucky, G. D. Inorg. Chem. 1978, 17, 2078.

(34) Francesconi, L. C.; Corbin, D. R.; Hendrickson, D. N.; Stucky, G. D. Inorg. Chem. $1979,18,3074$

(35) Samuel, E.; Harrod, J. F.; Gourier, D.; Dromzee, Y.; Robert, F.; Jeannin, Y. Inorg.

Chem. 1992, 31, 3252 .

(36) Xin, S.; Harrod, J. F.; Samuel, E. J. Am. Chem. Soc. 1994, 116, 11562.

(37) Dick, D. G.; Stephan, D. W. Can. J. Chem. 1991, 69, 1146.

(38) Chen, L.; Cotton, F. A.; Dunbar, K. R.; Feng, X.; Heintz, R. A.; Uzelmeir, C. Inorg. Chem. 1996, 35, 7358.

(39) Webb, S. P.; Gordon, M. S. J. Am. Chem. Soc. 1998, 120, 3846.

(40) Webb, S. P.; Gordon, M. S. J. Chem. Phys. 1998, 109, 919.

(41) Wachters, A. J. H. J. Chem. Phys. 1970, 52, 1033.

(42) Hood, D. M.; Pitzer, R. M.; Schaefer, H. F., III. J. Chem. Phys. 1979, 71, 705.

(43) Rappe, A. K; Smedley, T. A.; Goddard, W. A., III. J. Phys. Chem. 1981,85, 2607.

(44) Dunning, T. H.; Hay P. J. In Methods of Electronic Structure Theory, Schaefer H. F., III., Ed.; Plenum Press: New York. 1977; pp 1-27.

(45) Dunning, T. H. J. Chem. Phys. 1971, 55, 716.

(46) McLean, A. D.; Chandler, G. S. J. Chem. Phys. 1980, 72, 5639. 
(47) (a) Binning, R. C.; Curtiss, L. A. J. Comp. Chem. 1990, II, 1206. (b) Dunning, T. H., Jr. J. Chem. Phys. 1977, 66, 1382.

(48) Webb, S. P.; Gordon, M. S. J. Am. Chem. Soc. 1995, 117, 7197.

(49) Schmidt, M. W.; Baldridge, K. K.; Boatz, J. A.; Jensen, J. H.; Koseki, S.; Matsunaga, N.; Gordon, M. S.; Nguyen, K. A.; Su, S.; Windus, T. L.; Elbert, S. T.; Montgomery, J.; Dupuis, M. J. Comput. Chem. 1993, 14, 1347.

(50) Glezakou, V.-A.; Gordon, M. S. J. Phys. Chem. 1997, 101, 8714.

(51) Bauschlicher, C. W. J. Chem. Phys. 1980, 72, 880.

(52) (a) Hirao, K. Chem. Phys. Lett. 1992, 190, 374. (b) Hirao, K. Chem. Phys. Lett. 1992, 196, 397. (c) Hirao, K. Int. J. Quant. Chem. 1992, S26, 517. (d) Hirao, K. Chem. Phys. Lett. $1993,201,59$.

(53) (a) Jayatilaka, D.; Lee, T. J.; Chem. Phys. Lett. 1992, 199, 211. (b) Lee, T. J.; Jayatilaka, D. Chem. Phys. Lett. 1993, 201, 1.

(54) (a) Sunberg, K. R.; Ruedenberg, K. In Quantum Science, Calais, J. L.; Goscinski, O.; Linderberg, J.; Öhrn Y. Eds.; Plenum Press: New York. 1976; p 505; (b) Cheung, L. M.; Sunberg, K. R.; Ruedenberg, K. Int. J. Quantum Chem. 1979, 16, 1103; (c) Ruedenberg, K.; Schmidt, M.; Gilbert, M. M.; Elbert, S. T.; Chem. Phys. 1982, 71, 41; (d) Roos, B. O.; Taylor, P.; Siegbahn, P. E. M. Chem. Phys. 1980, 48, 157.

(55) Koseki, S.; Gordon, M. S.; Schmidt, M. W.; Matsunaga, N. J. Phys. Chem. 1995, 99, 12764.

(56) Fedorov, D. G.; Gordon, M. S. J. Chem. Phys. 2000, 112, 5611.

(57) Fedorov, D. G.; Finley, J. P. Phys. Rev. A 2001, 64, 042502.

(58) Bode B. M.; Gordon, M. S. J. Mol. Graphics. Mod. 1998, 16, 133. 
(59) Hunt, W. J.; Hay, P. J.; Goddard, W. A. J. Chem. Phys. 1972, 57, 738.

(60) Giricheva, N. I.; Girichev, G. V.; Shlykov, S. A. J. Struct. Chem. 1991, 32, 602.

(61) Solomonik, V. G.; Sliznev, V. V.; Balabanov, N. B. Russ. J. Inorg. Chem. 1997, 42, 430.

(62) Yates, J. H.; Pitzer, R. M.; J. Chem. Phys. 1979, 70, 4049.

(63) Hastie, J. W.; Hauge, R. H.; Margrave, J. L. J. Chem. Phys. 1969, 51, 2648.

(64) Beattie I. R.; Jones, P. J.; Young, N. A. Angew. Chem. Int. Ed. Engl. 1989, 28, 313.

(65) Mamaeva, G. I.; Romanov, G. V.; Spiridonov, V. P.; Troyanov, S. I. J. Struct. Chem. $1987,28,846$.

(66) Fraser, G. V.; Chalmers, J. M.; Charlton, V.; Cudby, M. E. A. Solid State Commun. $1977,21,933$.

(67) Kanesaka, I.; Kawai, K.; Miyatake, T.; Kakugo, M. Spectrochim. Acta, Part A 1984, $40 A, 705$.

(68) Kanesaka, I.; Yonezawa, M.; Kawai, K.; Miyatake, T.; Kakugo, M. Spectrochim. Acta, Part A 1986, 42A 1415.

(69) Miyaoka, H.; Hasebe, K.; Sawada, M.; Sano, H.; Mori, H.; Mizutani, G.; Ushioda, S.; Otsuka, N.; Terano, M. Vib. Spectrosc. 1998, 17, 183.

(70) Miyaoka, H.; Kuze, T.; Sano, H.; Mori, H.; Mizutani, G.; Ushioda, S.; Otsuka, N.; Terano, M. J. Lumin. 2000, 87-89, 709.

(71) Hastie, J. W.; Hauge, R. H.; Margrave, J. L. High Temp. Sci. 1971, 3, 257.

(72) Andersen, B.; Seip, H. M.; Strand, T. G.; Stolevik, R. Acta Chem. Scand. 1969, 23, 3224.

(73) Zakharov, I. I.; Zhidomirov, G. M.; Zakharov, V. A. J. Mol. Catal. 1991, 68, 149. 
(74) This is referred to as $d_{x^{2}}$ instead of $d_{z^{2}}$ because of our choice of axis system.

(75) Bierwagen, E. P.; Bercaw, J. E.; Goddard, W. A., III. J. Am. Chem. Soc. 1994,I16, 1481.

(76) Steigerwald, M. L.; Goddard, W. A., III. J. Am. Chem. Soc. 1984, 106, 308.

(77) Sørlie, M.; Øye, H. A. Inorg. Chem. 1978, 17, 2473.

(78) Polyachenok, L. D.; Novikov, G. I.; Polyachenok, O. G.; Obshch. Prikl. Khim. 1972, 45.

(79) Sibbing E.; Schäfer, H. Z. Anorg. Allg. Chem. 1974, 410, 67.

(80) Martinsky, C.; Minot, C. Surf. Sci. 2000, 467, 152. 
TABLE 1: Calculated Singlet - Triplet Energy Gap (E(triplet) - E(singlet)) in kcal/mol method/basis set for singlet/triplet calculation

\begin{tabular}{lllll} 
molecule & TCSCF/TZV(p) & MRMP2/TZV(p) & MRMP2/TZVP(f) & MRMP2/TZVP(fg) \\
\cline { 2 - 5 }
\end{tabular}

\begin{tabular}{|c|c|c|c|c|}
\hline $\mathrm{Ti}_{2} \mathrm{H}_{6}^{\mathrm{n}}$ & 0.56 & 1.33 & 1.40 & 1.43 \\
\hline $\mathrm{Ti}_{2} \mathrm{~F}_{6}$ & -0.12 & -0.18 & -0.23 & -0.23 \\
\hline $\mathrm{Ti}_{2} \mathrm{Cl}_{6}$ & -0.09 & -0.01 & 0.27 & 0.90 \\
\hline $\mathrm{Ti}_{2} \mathrm{Br}_{6}$ & -0.02 & 0.34 & 0.61 & 0.45 \\
\hline $\mathrm{Ti}_{2} \mathrm{H}_{2} \mathrm{~F}_{4}$ & 0.83 & 1.93 & 2.06 & 2.10 \\
\hline $\mathrm{Ti}_{2} \mathrm{H}_{2} \mathrm{Cl}_{4}$ & 0.59 & 1.62 & 1.79 & 1.82 \\
\hline $\mathrm{Ti}_{2} \mathrm{H}_{2} \mathrm{Br}_{4}$ & 0.52 & 1.53 & 1.68 & 1.70 \\
\hline $\mathrm{Ti}_{2} \mathrm{~F}_{2} \mathrm{H}_{4}^{\mathrm{b}}$ & -0.11 & -0.18 & -0.20 & -0.2 \\
\hline $\mathrm{Ti}_{2} \mathrm{~F}_{2} \mathrm{H}_{4}{ }^{\mathrm{c}}$ & 0.12 & 0.24 & 0.28 & 0.2 \\
\hline $\mathrm{Ti}_{2} \mathrm{~F}_{2} \mathrm{H}_{4}{ }^{\mathrm{d}}$ & 0.08 & 0.17 & 0.21 & 0.24 \\
\hline $\mathrm{Ti}_{2} \mathrm{Cl}_{2} \mathrm{H}_{4}$ & -0.04 & 0.06 & 0.34 & 0.3 \\
\hline $\mathrm{Ti}_{2} \mathrm{Br}_{2} \mathrm{H}_{4}$ & 0.02 & 0.30 & 0.57 & 0.87 \\
\hline
\end{tabular}

${ }^{a}$ Values from Reference $39 .{ }^{b} \mathrm{D}_{2 \mathrm{~b}}{ }^{1} \mathrm{~A}_{\mathrm{g}}\left[(\sigma)\left(\sigma^{*}\right)\right]^{2 \beta} \mathrm{B}_{\mathrm{lu}}\left(\sigma, \sigma^{*}\right)$ state. ${ }^{\mathrm{c}} \mathrm{D}_{2 \mathrm{~h}}{ }^{1} \mathrm{~A}_{\mathrm{g}}\left[(\delta)\left(\delta^{*}\right)\right]^{2 \beta} \mathrm{B}_{\mathrm{lu}}\left(\delta, \delta^{*}\right)$ state, ${ }^{d} \mathrm{C}_{2 \mathrm{~h}}{ }^{1} \mathrm{~A}_{\mathrm{u}}$ state. 
TABLE 2: Geometrical Parameters for Lowest Energy Singlet and Triplet States"

\begin{tabular}{|c|c|c|c|c|c|c|}
\hline \multirow[b]{2}{*}{ singlet states } & \multicolumn{4}{|c|}{ distances (angstroms) } & \multicolumn{2}{|c|}{ bond angles (degrees) } \\
\hline & Ti-Ti & Ti-X & Ti-Y & $\mathrm{Y}-\mathrm{Y}$ & $\mathrm{Y}-\mathrm{Ti}-\mathrm{Y}$ & $\mathrm{X}-\mathrm{T} \mathrm{i}-\mathrm{X}$ \\
\hline $\mathrm{Ti}_{2} \mathrm{~F}_{6}$ & 3.249 & 2.020 & 1.814 & 3.289 & 130.1 & 72.9 \\
\hline $\mathrm{Ti}_{2} \mathrm{Cl}_{6}$ & 3.703 & 2.491 & 2.267 & 4.038 & 125.9 & 84.0 \\
\hline $\mathrm{Ti}_{2} \mathrm{Br}_{6}$ & 3.835 & 2.643 & 2.411 & 4.260 & 124.1 & 87.0 \\
\hline $\mathrm{Ti}_{2} \mathrm{H}_{2} \mathrm{~F}_{4}$ & 2.963 & 1.905 & 1.815 & 3.322 & 132.4 & 77.9 \\
\hline $\mathrm{Ti}_{2} \mathrm{H}_{2} \mathrm{Cl}_{4}$ & 2.968 & 1.888 & 2.280 & 4.143 & 130.7 & 76.4 \\
\hline $\mathrm{Ti}_{2} \mathrm{H}_{2} \mathrm{Br}_{4}$ & 2.975 & 1.887 & 2.425 & 4.388 & 129.6 & 75.9 \\
\hline $\mathrm{Ti}_{2} \mathrm{~F}_{2} \mathrm{H}_{4}^{\mathrm{b}}$ & 3.269 & 2.030 & 1.759 & 3.075 & 121.9 & 72.8 \\
\hline $\mathrm{Ti}_{2} \mathrm{~F}_{2} \mathrm{H}_{4}{ }^{\mathrm{c}}$ & 3.279 & 2.029 & 1.745 & 2.853 & 109.7 & 72.1 \\
\hline $\mathrm{Ti}_{2} \mathrm{~F}_{2} \mathrm{H}_{4}{ }^{\mathrm{d}}$ & 3.274 & 2.029 & 1.748 & 2.914 & 112.9 & 72.4 \\
\hline $\mathrm{Ti}_{2} \mathrm{Cl}_{2} \mathrm{H}_{4}$ & 3.746 & 2.527 & 1.743 & 3.037 & 121.2 & 84.3 \\
\hline \multirow[t]{2}{*}{$\mathrm{Ti}_{2} \mathrm{Br}_{2} \mathrm{H}_{4}$} & 3.876 & 2.684 & 1.741 & 3.032 & 121.0 & 87.5 \\
\hline & \multicolumn{4}{|c|}{ distances (angstroms) } & \multicolumn{2}{|c|}{ bond angles (degrees) } \\
\hline triplet states & Ti-Ti & Ti-X & $T i-Y$ & $\overline{Y-Y}$ & Y-Ti-Y & $\mathrm{X}-\mathrm{Ti}-\mathrm{X}$ \\
\hline $\mathrm{Ti}_{2} \mathrm{~F}_{6}$ & 3.246 & 2.019 & 1.814 & 3.289 & 130.1 & 73.0 \\
\hline $\mathrm{Ti}_{2} \mathrm{Cl}_{6}$ & 3.712 & 2.491 & 2.268 & 4.039 & 125.9 & 83.7 \\
\hline $\mathrm{Ti}_{2} \mathrm{Br}_{6}$ & 3.853 & 2.644 & 2.412 & 4.264 & 124.2 & 86.5 \\
\hline $\mathrm{Ti}_{2} \mathrm{H}_{2} \mathrm{~F}_{4}$ & 2.989 & 1.909 & 1.815 & 3.317 & 132.1 & 77.0 \\
\hline $\mathrm{Ti}_{2} \mathrm{H}_{2} \mathrm{Cl}_{4}$ & 2.987 & 1.892 & 2.280 & 4.136 & 130.2 & 75.7 \\
\hline $\mathrm{Ti}_{2} \mathrm{H}_{2} \mathrm{Br}_{4}$ & 2.992 & 1.889 & 2.425 & 4.381 & 129.2 & 75.3 \\
\hline $\mathrm{Ti}_{2} \mathrm{~F}_{2} \mathrm{H}_{4}{ }^{\mathrm{a}}$ & 3.268 & 2.030 & 1.759 & 3.075 & 121.9 & 72.8 \\
\hline $\mathrm{Ti}_{2} \mathrm{~F}_{2} \mathrm{H}_{4}^{\mathrm{b}}$ & 3.280 & 2.029 & 1.745 & 2.853 & 109.7 & 72.1 \\
\hline $\mathrm{Ti}_{2} \mathrm{~F}_{2} \mathrm{H}_{4}{ }^{\mathrm{c}}$ & 3.274 & 2.029 & 1.749 & 2.922 & 113.3 & 72.4 \\
\hline $\mathrm{Ti}_{2} \mathrm{Cl}_{2} \mathrm{H}_{4}$ & 3.758 & 2.527 & 1.743 & 3.038 & 121.3 & 83.9 \\
\hline $\mathrm{Ti}_{2} \mathrm{Br}_{2} \mathrm{H}_{4}$ & 3.895 & 2.685 & 1.742 & 3.033 & 121.1 & 87.0 \\
\hline
\end{tabular}

${ }^{a} \mathrm{X}$ is the bridging ligand in and $\mathrm{Y}$ is the terminal ligand in $\mathrm{Ti}_{2} \mathrm{X}_{2} \mathrm{Y}_{4}$

${ }^{b} \mathrm{D}_{2 \mathrm{~h}}{ }^{1} \mathrm{~A}_{\mathrm{g}}\left[(\sigma)\left(\sigma^{*}\right)\right]^{2 / \beta} \mathrm{B}_{1 \mathrm{u}}\left(\sigma, \sigma^{*}\right)$ state. ${ }^{\mathrm{c}} \mathrm{D}_{2 \mathrm{~b}}{ }^{1} \mathrm{~A}_{\mathrm{g}}\left[(\delta)\left(\delta^{*}\right)\right]^{2 \beta} \mathrm{B}_{1 \mathrm{u}}\left(\delta, \delta^{*}\right)$ state. ${ }^{d} \mathrm{C}_{2 \mathrm{~b}}{ }^{1} \mathrm{~A}_{\mathrm{v}}$ state. 
TABLE 3: Mulliken Charges on Ti

\begin{tabular}{lll}
\hline molecule & singlet & triplet \\
\hline $\mathrm{Ti}_{2} \mathrm{~F}_{6}$ & 1.78 & 1.78 \\
$\mathrm{Ti}_{2} \mathrm{Cl}_{6}$ & 0.93 & 0.94 \\
$\mathrm{Ti}_{2} \mathrm{Br}_{6}$ & 0.75 & 0.75 \\
$\mathrm{Ti}_{2} \mathrm{H}_{2} \mathrm{~F}_{4}$ & 1.46 & 1.46 \\
$\mathrm{Ti}_{2} \mathrm{H}_{2} \mathrm{Cl}_{4}$ & 0.89 & 0.89 \\
$\mathrm{Ti}_{2} \mathrm{H}_{2} \mathrm{Br}_{4}$ & 0.73 & 0.73 \\
$\mathrm{Ti}_{2} \mathrm{~F}_{2} \mathrm{H}_{4}{ }^{3}$ & 1.12 & 1.12 \\
$\mathrm{Ti}_{2} \mathrm{~F}_{2} \mathrm{H}_{4}{ }^{\mathrm{b}}$ & 1.10 & 1.10 \\
$\mathrm{Ti}_{2} \mathrm{~F}_{2} \mathrm{H}_{4}{ }^{\mathrm{c}}$ & 1.11 & 1.11 \\
$\mathrm{Ti}_{2} \mathrm{Cl}_{2} \mathrm{H}_{4}$ & 0.85 & 0.85 \\
$\mathrm{Ti}_{2} \mathrm{Br}_{2} \mathrm{H}_{4}$ & 0.79 & 0.79 \\
& \\
${ }^{2} \mathrm{D}_{2 \mathrm{k}}{ }^{1} \mathrm{~A}_{\mathrm{g}}\left[(\sigma)\left(\sigma^{*}\right)\right]^{2} \beta \mathrm{B}_{1 \mathrm{u}}\left(\sigma, \sigma^{*}\right)$ & state. ${ }^{\mathrm{b}} \mathrm{D}_{2 \mathrm{~b}}{ }^{1} \mathrm{~A}_{\mathrm{g}}\left[(\delta)\left(\delta^{*}\right)\right]^{2} \beta \mathrm{B}_{\mathrm{lu}}\left(\delta, \delta^{*}\right)$ state. ${ }^{\mathrm{c}} \mathrm{C}_{2 \mathrm{~b}}{ }^{1} \mathrm{~A}_{\mathrm{u}}$ state.
\end{tabular}


TABLE 4: Relative Energies ( $\mathrm{kcal} / \mathrm{mol})$ from lowest energy singlet $\left(\mathbf{C}_{\mathrm{zb}}\right)$ for each basis set

\begin{tabular}{|c|c|c|c|c|}
\hline & TCSCF/TZV(p) & MRMP2/TZV(p) & MRMP2/TZVP(f) & MRMP2/TZVP(fg) \\
\hline${ }^{1} \mathrm{Ti}_{2} \mathrm{~F}_{2} \overline{\mathrm{H}}_{4}{ }^{\mathrm{n}}$ & 1.17 & 1.77 & 2.64 & 3.06 \\
\hline${ }^{3} \mathrm{Ti}_{2} \mathrm{~F}_{2} \mathrm{H}_{4}{ }^{3}$ & 1.05 & 1.59 & 2.44 & 2.86 \\
\hline${ }^{1} \mathrm{Ti}_{2} \mathrm{~F}_{2} \mathrm{H}_{4}^{\mathrm{b}}$ & 0.30 & 0.46 & 0.28 & 0.18 \\
\hline${ }^{3} \mathrm{Ti}_{2} \mathrm{~F}_{2} \mathrm{H}_{4}{ }^{\mathrm{b}}$ & 0.41 & 0.70 & 0.55 & 0.47 \\
\hline${ }^{1} \mathrm{Ti}_{2} \mathrm{~F}_{2} \mathrm{H}_{4}{ }^{\mathrm{c}}$ & 0.00 & 0.00 & 0.00 & 0.00 \\
\hline${ }^{3} \mathrm{Ti}_{2} \mathrm{~F}_{2} \mathrm{H}_{4}{ }^{c}$ & 0.08 & 0.17 & 0.21 & 0.24 \\
\hline
\end{tabular}



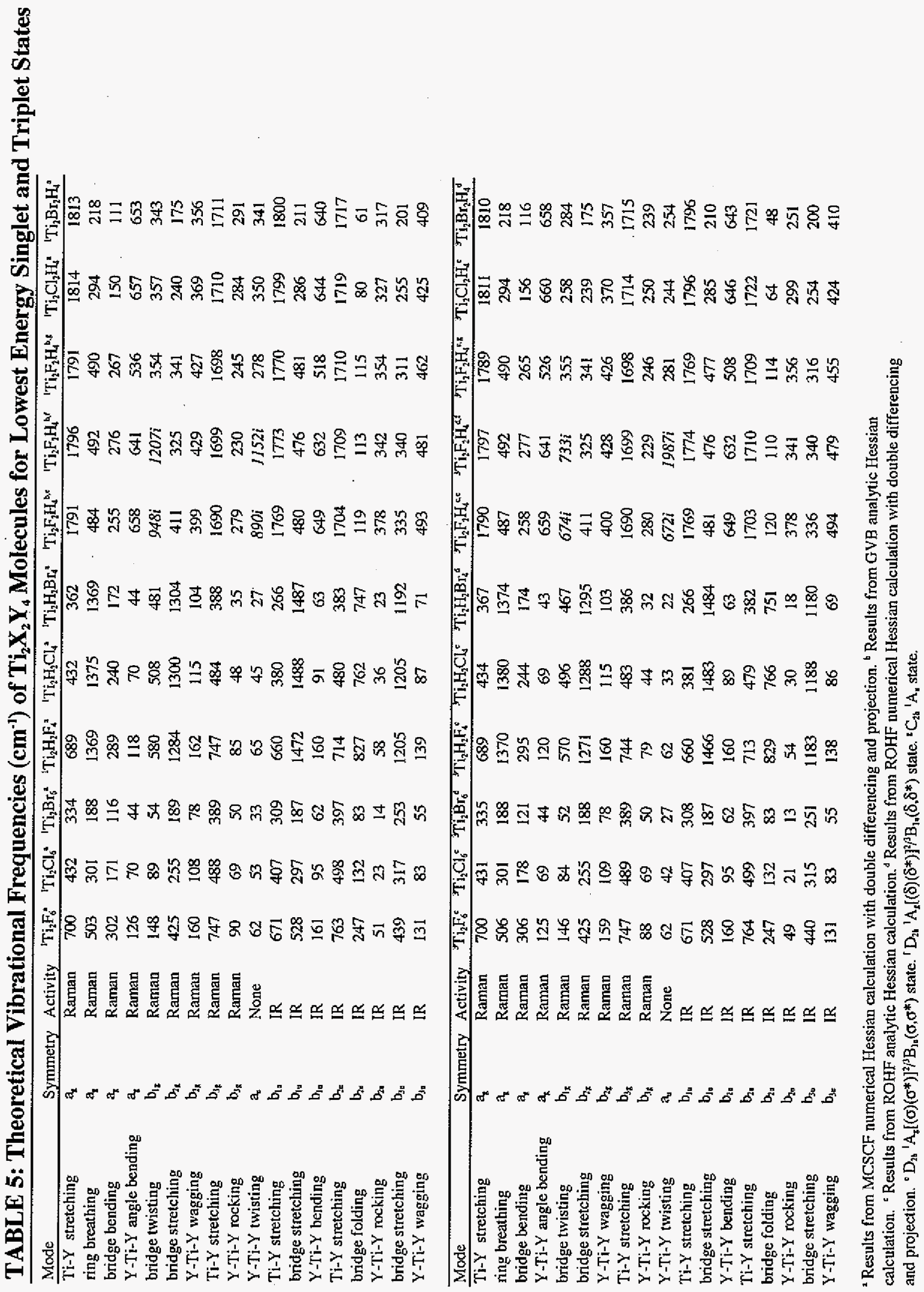
TABLE 6: ROHF/TZV(p) Geometries for the Titanium Monomers

\begin{tabular}{|c|c|c|c|c|}
\hline Molecule & Symmetry/State & $T i-X^{a}$ & Ti-H $H^{2}$ & $\mathrm{X}$-Ti-X or H-Ti-H angle \\
\hline $\mathrm{TiF}_{3}$ & $\mathrm{D}_{3 \mathrm{~h}}{ }^{\prime} \mathrm{A}_{\mathrm{I}}^{\prime}$ & 1.819 & & 120.0 \\
\hline $\mathrm{TiHF}_{2}$ & $\mathrm{C}_{2} \sqrt{\rho} \mathrm{A}_{1}$ & 1.821 & 1.754 & 127.6 \\
\hline $\mathrm{TiH}_{2} \mathrm{~F}$ & $\mathrm{C}_{2 \mathrm{v}}{ }^{2} \mathrm{~A}_{1}$ & 1.824 & 1.764 & 116.5 \\
\hline $\mathrm{TiCl}_{3}$ & $D_{3 b}{ }^{2} A_{1}^{\prime}$ & 2.272 & & 120.0 \\
\hline $\mathrm{TiHCl}_{2}$ & $\mathrm{C}_{2 v} \mathrm{v}^{2} \mathrm{~A}_{1}$ & 2.292 & 1.723 & 128.4 \\
\hline $\mathrm{TiH}_{2} \mathrm{Cl}$ & $\mathrm{C}_{2 \mathrm{r}} \mathrm{r}^{2} \mathrm{~A}_{1}$ & 2.315 & 1.749 & 116.0 \\
\hline $\mathrm{TiBr}_{3}$ & $\mathrm{D}_{31}{ }^{2} \mathrm{~A}_{1}^{\prime}$ & 2.414 & & 120.0 \\
\hline $\mathrm{TiHBr}_{2}$ & $\mathrm{C}_{2 v} v^{2} \mathrm{~A}_{1}$ & 2.436 & 1.720 & 129.2 \\
\hline $\mathrm{TiH}_{2} \mathrm{Br}$ & $\mathrm{C}_{2}{ }^{2}{ }^{\mathrm{A}} \mathrm{A}_{1}$ & 2.461 & 1.748 & 116.0 \\
\hline
\end{tabular}

${ }^{a}$ bond distances in angstroms ${ }^{b}$ bond angles in degrees 
TABLE 7: Theoretical and Experimental Vibrational Frequencies $\left(\mathrm{cm}^{-1}\right)$ of $\mathrm{TiX}_{3}$ molecules $\left(\mathbf{D}_{3 \mathrm{~h}}\right)$

\begin{tabular}{lcccc}
\hline Mode & sym stretch & out-of-plane & asym stretch & asym bend \\
& $\mathrm{A}_{1}{ }^{\prime}$ & $\mathrm{A}_{2}{ }^{\prime \prime}$ & $\mathrm{E}^{\prime}$ & $\mathrm{E}^{\prime}$ \\
Molecule & $\mathrm{v}_{1}$ & $\mathrm{v}_{2}$ & $\mathrm{v}_{3}$ & $\mathrm{v}_{4}$ \\
\hline $\mathrm{TiF}_{3}$ & 639 & 142 & 738 & 164 \\
& $630^{\mathrm{a}}$ & $150^{\mathrm{a}}$ & $735^{\mathrm{a}}$ & $160^{\mathrm{a}}$ \\
& $643^{\mathrm{b}}$ & & $740.6^{\mathrm{b}, \mathrm{c}}$ & \\
& & $140.6^{\mathrm{c}}$ & & \\
& $665^{\mathrm{d}}$ & $146^{\mathrm{a}}$ & $764^{\mathrm{d}}$ & $172^{\mathrm{d}}$ \\
$\mathrm{TiCl}_{3}$ & 355 & 101 & & \\
& $296(15)^{\mathrm{a}}$ & $120(6)^{\mathrm{a}}$ & 584 & 97 \\
& $338(17)^{\mathrm{a}}$ & $118(6)^{\mathrm{a}}$ & $465(24)^{\mathrm{a}}$ & $95(5)^{\mathrm{a}}$ \\
& & $110 \pm 12^{\mathrm{d}}$ & $505 \pm 10^{\mathrm{d}}$ & $135 \pm 1)^{\mathrm{a}}$ \\
& $350 \pm 30^{\mathrm{s}}$ & $110 \pm 15^{\mathrm{s}}$ & $500 \pm 10^{\mathrm{a}}$ & $135 \pm 15^{\mathrm{s}}$ \\
& $320(30)^{\mathrm{h}}$ & $129(20)^{\mathrm{h}}$ & $498(16)^{\mathrm{h}}$ & $107(7)^{\mathrm{h}}$ \\
$\mathrm{TiBr}_{3}$ & & & & \\
& 218 & 88 & 388 & 63 \\
& $230^{\mathrm{a}}$ & $80^{\mathrm{a}}$ & $355^{\mathrm{a}}$ & $58^{\mathrm{a}}$
\end{tabular}

${ }^{\mathrm{D} E s t i m a t e d ~ i n ~ R e f . ~ 60 . ~}{ }^{\mathrm{b}}$ Reference 63. ${ }^{\mathrm{C}}$ Reference 64. ${ }^{\mathrm{d}}$ Reference 61. ${ }^{\mathrm{C}}$ Reference 62.

Reference 71. ${ }^{\text {sReference } 65,72 .}{ }^{\circ}$ Reference 65. 
TABLE 8. Theoretical Vibrational Frequencies $\left(\mathrm{cm}^{-1}\right)$ of $\mathrm{TiHX}_{2}$ and $\mathrm{TiH}_{2} \mathrm{X}$ molecules $\left(\mathbf{C}_{2 v}\right)$

\begin{tabular}{lcccccc}
\hline Mode & Ti-H stretch & Ti-X stretch & X-Ti-X bend & Ti-F stretch & angle bend \\
Symmetry & $a_{1}$ & $a_{1}$ & $a_{1}$ & $b_{1}$ & $\begin{array}{c}\text { out-of-plane } \\
b_{2}\end{array}$ \\
\hline $\mathrm{TiHF}_{2}$ & 1646 & 647 & 163 & 755 & 519 & 89 \\
$\mathrm{TiHCl}_{2}$ & 1689 & 358 & 85 & 411 & 534 & 213 \\
$\mathrm{TiHBr}_{2}$ & 1683 & 240 & 62 & 348 & 489 & 248 \\
\hline $\mathrm{Mode}$ & $\mathrm{Ti}-\mathrm{H}$ stretch & $\mathrm{Ti}-\mathrm{X}$ stretch & H-Ti-H bend & Ti-H stretch & angle bend & out-of-plane \\
Symmetry & $\mathrm{a}_{1}$ & $\mathrm{a}_{1}$ & $\mathrm{a}_{1}$ & $\mathrm{~b}_{1}$ & $\mathrm{~b}_{1}$ & $\mathrm{~b}_{2}$ \\
$\mathrm{TiH}_{2} \mathrm{~F}$ & 1737 & 584 & 727 & 1684 & 375 & 293 \\
$\mathrm{TiH}_{2} \mathrm{Cl}$ & 1759 & 396 & 611 & 1732 & 369 & 309 \\
$\mathrm{TiH}_{2} \mathrm{Br}$ & 1716 & 298 & 610 & 1682 & 288 & 268
\end{tabular}


TABLE 9: ROHF/TZV(p) Geometries for the Different States of $\mathrm{TiHCl}_{2}$

\begin{tabular}{lcccc}
\hline State & Ti-X & Ti-H & X-Ti-X angle relative energy $(\mathrm{kcal} / \mathrm{mol})$ \\
\hline${ }^{2} \mathrm{~A}_{1}$ (ground) & 2.292 & 1.723 & 128.4 & 0.00 \\
${ }^{2} \mathrm{~B}_{1}$ & 2.296 & 1.710 & 136.7 & 1.72 \\
${ }^{2} \mathrm{~A}_{2}$ & 2.316 & 1.723 & 120.8 & 5.29 \\
${ }^{2} \mathrm{~B}_{2}$ & 2.335 & 1.689 & 147.4 & 24.63 \\
& $2.32^{\mathrm{a}}$ & $1.68^{\mathrm{a}}$ & $147.8^{\mathrm{a}}$ &
\end{tabular}

${ }^{a}$ values from reference 75 
TABLE 10: Energy of Dimerization (kcal/mol) using TZV(p) basis

\begin{tabular}{lccc}
\hline Molecule & $\Delta \mathrm{E}_{\text {clec }}$ MRMP2 & $\Delta$ ZPE (MCSCF) & $\Delta \mathrm{H}_{\text {dimcizatioo }}$ (MRMP2) \\
\hline $\mathrm{Ti}_{2} \mathrm{~F}_{6}{ }^{2}$ & -42.3 & 1.5 & -40.7 \\
$\mathrm{Ti}_{2} \mathrm{Cl}_{6}{ }^{2}$ & -33.7 & 0.9 & -32.8 \\
$\mathrm{Ti}_{2} \mathrm{Br}_{6}$ & -33.3 & 0.6 & -32.7 \\
$\mathrm{Ti}_{2} \mathrm{H}_{6} \mathrm{~F}_{4}$ & -45.7 & 4.1 & -41.6 \\
$\mathrm{Ti}_{2} \mathrm{H}_{2} \mathrm{Cl}_{4}$ & -34.3 & 3.2 & -31.1 \\
$\mathrm{Ti}_{2} \mathrm{H}_{2} \mathrm{Br}_{4}$ & -34.8 & 3.0 & -31.8 \\
$\mathrm{Ti}_{2} \mathrm{~F}_{2} \mathrm{H}_{4}{ }^{6}$ & -53.9 & 2.2 & -51.6 \\
$\mathrm{Ti}_{2} \mathrm{Cl}_{2} \mathrm{H}_{4}$ & -54.0 & 2.2 & -51.8 \\
$\mathrm{Ti}_{2} \mathrm{Br}_{2} \mathrm{H}_{4}$ & -56.3 & 2.0 & -54.3
\end{tabular}

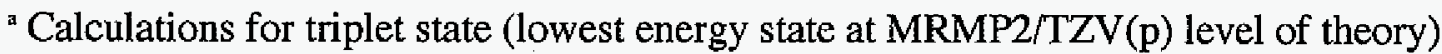

${ }^{b}$ Calculations for $\mathrm{C}_{2 \mathrm{~h}}$ structure 
TABLE 11: $\mathbf{J}\left(\mathrm{cm}^{-1}\right)=\mathrm{E}$ (singlet) - E(triplet)

\begin{tabular}{|c|c|c|c|c|}
\hline Molecule & TCSCF/TZV(p) & MRMP2/TZV(p) & MRMP2/TZVP(f) & MRMP2/TZVP(fg) \\
\hline $\mathrm{Ti}_{2} \mathrm{H}_{6}$ & -98 & -233 & -246 & -250 \\
\hline $\mathrm{Ti}_{2} \mathrm{~F}_{6}$ & 20 & 32 & 40 & 41 \\
\hline $\mathrm{Ti}_{2} \mathrm{Cl}_{6}$ & 15 & 2 & -47 & -157 \\
\hline $\mathrm{Ti}_{2} \mathrm{Br}_{6}$ & 4 & -59 & -107 & -78 \\
\hline $\mathrm{Ti}_{2} \mathrm{H}_{2} \mathrm{~F}_{4}$ & -144 & -337 & -360 & -367 \\
\hline $\mathrm{Ti}_{2} \mathrm{H}_{2} \mathrm{Cl}_{4}$ & -103 & -283 & -313 & -318 \\
\hline $\mathrm{Ti}_{2} \mathrm{H}_{2} \mathrm{Br}_{4}$ & -90 & -268 & -294 & -298 \\
\hline $\mathrm{Ti}_{2} \mathrm{~F}_{2} \mathrm{H}_{4}{ }^{\mathrm{a}}$ & 20 & 32 & 35 & 35 \\
\hline $\mathrm{Ti}_{2} \mathrm{~F}_{2} \mathrm{H}_{4}^{\mathrm{b}}$ & -20 & -42 & -49 & -50 \\
\hline $\mathrm{Ti}_{2} \mathrm{~F}_{2} \mathrm{H}_{4}{ }^{\mathrm{c}}$ & -14 & -30 & -37 & -41 \\
\hline $\mathrm{Ti}_{2} \mathrm{Cl}_{2} \mathrm{H}_{4}$ & 7 & -10 & -59 & -60 \\
\hline $\mathrm{Ti}_{2} \mathrm{Br}_{2} \mathrm{H}_{4}$ & -4 & -52 & -100 & -153 \\
\hline
\end{tabular}


TABLE 12: Spin-Orbit Coupling

\begin{tabular}{|c|c|c|c|c|c|c|c|}
\hline \multirow{2}{*}{ molecule } & & \multicolumn{3}{|c|}{ CASSCF-SOC/TZV(p) } & \multicolumn{3}{|c|}{ MCQDPT-SOC/TZV(p) } \\
\hline & & $\mathrm{HSO} 1$ & $\mathrm{HSO} 2 \mathrm{P}$ & $\mathrm{HSO} 2$ & HSO1 & $\mathrm{HSO} 2 \mathrm{P}$ & $\mathrm{HSO} 2$ \\
\hline \multirow[t]{6}{*}{$\overline{\mathrm{Ti}_{2} \mathrm{~F}_{6}}$} & $\mathrm{~S}_{0}$ & -7.491 & -8.355 & -8.355 & -6.706 & -7.589 & -7.589 \\
\hline & $\mathrm{T}_{1} \mathrm{X}$ & -52.848 & -53.697 & -53.693 & -45.358 & -46.202 & -46.198 \\
\hline & $\mathrm{T}_{1} \mathrm{Y}$ & -52.915 & -53.771 & -53.771 & -45.415 & -46.270 & -46.269 \\
\hline & $\mathrm{T}_{1} \mathrm{Z}$ & -52.911 & -53.766 & -53.770 & -45.430 & -46.268 & -46.271 \\
\hline & $\mathrm{D}_{e}$ & -0.030 & -0.032 & -0.038 & -0.044 & -0.032 & -0.038 \\
\hline & $\mathrm{E}_{\mathrm{e}}$ & 0.034 & 0.037 & 0.039 & 0.029 & 0.034 & 0.035 \\
\hline \multirow[t]{6}{*}{$\mathrm{Ti}_{2} \mathrm{Cl}_{6}$} & $\mathrm{~S}_{0}$ & -8.927 & -9.995 & -9.995 & -7.557 & -8.686 & -8.687 \\
\hline & $\mathrm{T}_{1} \mathrm{X}$ & -48.611 & -49.658 & -49.655 & -37.103 & -38.211 & -38.208 \\
\hline & $\mathrm{T}_{1} \mathrm{Y}$ & -48.689 & -49.745 & -49.744 & -37.159 & -38.279 & -38.278 \\
\hline & $T_{1} Z$ & -48.676 & -49.731 & -49.734 & -37.147 & -38.265 & -38.268 \\
\hline & $\mathrm{D}_{\mathrm{c}}$ & -0.026 & -0.030 & -0.035 & -0.016 & -0.020 & -0.025 \\
\hline & $\mathrm{E}_{\mathrm{c}}$ & 0.039 & 0.043 & 0.044 & 0.028 & 0.034 & 0.035 \\
\hline \multirow[t]{6}{*}{$\mathrm{Ti}_{2} \mathrm{Br}_{6}$} & $S_{0}$ & -6.663 & -7.774 & -7.774 & -5.460 & -6.592 & -6.592 \\
\hline & $\mathrm{T}_{1} \mathrm{X}$ & -18.562 & -19.651 & -19.649 & 19.473 & 18.350 & 18.352 \\
\hline & $T_{1} Y$ & -18.619 & -19.718 & -19.717 & 19.429 & 18.295 & 18.296 \\
\hline & $T_{1} Z$ & -18.607 & -19.704 & -19.707 & 19.439 & 18.307 & 18.305 \\
\hline & $\mathrm{D}_{\mathrm{e}}$ & -0.016 & -0.020 & -0.024 & -0.012 & -0.016 & -0.019 \\
\hline & $\mathrm{E}_{\mathrm{e}}$ & 0.028 & 0.034 & 0.034 & 0.022 & 0.027 & 0.028 \\
\hline \multirow[t]{6}{*}{$\mathrm{Ti}_{2} \mathrm{H}_{2} \mathrm{~F}_{4}$} & $\mathrm{~S}_{0}$ & $=-6.072$ & -6.622 & -6.622 & -5.872 & -6.599 & -6.599 \\
\hline & $\mathrm{T}_{1} \mathrm{X}$ & 304.086 & 303.563 & 303.566 & 491.004 & 490.447 & 490.450 \\
\hline & $\mathrm{T}_{1} \mathrm{Y}$ & 303.914 & 303.380 & 303.380 & 490.792 & 490.212 & 490.213 \\
\hline & $T_{1} Z$ & 303.913 & 303.378 & 303.374 & 490.786 & 490.207 & 490.203 \\
\hline & $\mathrm{D}_{\mathrm{c}}$ & -0.087 & -0.094 & -0.099 & -0.112 & -0.123 & -0.129 \\
\hline & $\mathrm{E}_{\mathrm{s}}$ & 0.086 & 0.091 & 0.093 & 0.106 & 0.118 & 0.118 \\
\hline \multirow[t]{6}{*}{$\mathrm{Ti}_{2} \mathrm{H}_{2} \mathrm{Cl}_{4}$} & $\mathrm{~S}_{0}$ & -7.709 & -8.483 & -8.484 & -6.901 & -7.881 & -7.882 \\
\hline & $T_{1} X$ & 215.218 & 214.450 & 214.457 & 446.386 & 445.533 & 445.538 \\
\hline & $\mathrm{T}_{1} \mathrm{Y}$ & 215.044 & 214.261 & 214.266 & 446.154 & 445.265 & 445.268 \\
\hline & $T_{1} Z$ & 215.045 & 214.262 & 214.257 & 446.133 & 445.242 & 445.237 \\
\hline & $D_{c}$ & -0.086 & -0.093 & -0.104 & -0.137 & -0.157 & -0.166 \\
\hline & $\mathrm{E}_{c}$ & 0.087 & 0.094 & 0.096 & 0.116 & 0.134 & 0.135 \\
\hline \multirow[t]{6}{*}{$\mathrm{Ti}_{2} \mathrm{H}_{2} \mathrm{Br}_{4}$} & $\mathrm{~S}_{0}$ & -7.234 & -8.042 & -8.043 & -6.706 & -7.703 & -7.704 \\
\hline & $\mathrm{T}_{1} \mathrm{X}$ & 188.937 & 188.106 & 188.114 & 416.105 & 415.191 & 415.197 \\
\hline & $T_{1} Y$ & 188.760 & 187.918 & 187.923 & 415.875 & 414.930 & 414.933 \\
\hline & $\mathrm{T}_{1} \mathrm{Z}$ & 188.761 & 187.920 & 187.914 & 415.853 & 414.904 & 414.900 \\
\hline & $\mathrm{D}_{\mathrm{c}}$ & -0.088 & -0.092 & -0.105 & -0.137 & -0.156 & -0.165 \\
\hline & $\mathrm{E}_{c}$ & 0.089 & 0.094 & 0.096 & 0.115 & 0.130 & 0.132 \\
\hline
\end{tabular}

$S_{0}, T, X, T_{1} Y$, and $T_{1} Z$ are the energies $\left(\mathrm{cm}^{-1}\right)$ of the spin-mixed states for the lowest energy singlet and $X, Y$, and $Z$ components of the lowest energy triplet state, respectively. $\mathrm{D}_{\mathrm{c}}$ and $\mathrm{E}_{\mathrm{o}}\left(\mathrm{cm}^{-1}\right)$ are the axial and rhombic ZFS parameters, respectively.

${ }^{\mathrm{a}} \mathrm{D}_{2 \mathrm{~h}}{ }^{1} \mathrm{~A}_{\mathrm{g}}\left[(\sigma)\left(\sigma^{*}\right)\right]^{2} \beta \mathrm{B}_{1 \mathrm{u}}\left(\sigma, \sigma^{*}\right)$ state. ${ }^{\mathrm{b}} \mathrm{D}_{2 \mathrm{~h}}{ }^{1} \mathrm{~A}_{\mathrm{g}}\left[(\delta)\left(\delta^{*}\right)\right]^{2 \beta} \mathrm{B}_{1 \mathrm{u}}\left(\delta, \delta^{*}\right)$ state. ${ }^{\mathrm{c}} \mathrm{C}_{2 \mathrm{~h}}{ }^{1} \mathrm{~A}_{\mathrm{v}}$ state. 
TABLE 12: (cont.)

\begin{tabular}{|c|c|c|c|c|c|c|c|}
\hline \multirow{2}{*}{\multicolumn{2}{|c|}{ molecule }} & \multicolumn{3}{|c|}{ CASSCF-SOC/TZV(p) } & \multicolumn{3}{|c|}{ MCQDPT-SOC/TZV(p) } \\
\hline & & HSO1 & HSO2P & $\mathrm{HSO} 2$ & $\mathrm{HSOl}$ & HSO2P & HSO2 \\
\hline \multirow[t]{6}{*}{$\mathrm{Ti}_{2} \mathrm{~F}_{2} \mathrm{H}_{4}{ }^{2}$} & $\mathrm{~S}_{0}$ & -53.091 & -56.216 & -56.232 & -98.661 & -105.397 & -105.420 \\
\hline & $T_{1} X$ & -91.490 & -94.270 & -94.226 & -49.704 & -57.300 & -57.223 \\
\hline & $T_{1} Y$ & -91.567 & -94.358 & -94.317 & -49.634 & -57.142 & -57.064 \\
\hline & $T_{1} Z$ & -90.612 & -93.364 & -93.381 & -47.979 & -55.561 & -55.588 \\
\hline & $D_{e}$ & 0.916 & 0.950 & 0.890 & 1.690 & 1.660 & 1.556 \\
\hline & $\mathrm{E}_{\mathrm{c}}$ & 0.038 & 0.044 & 0.045 & -0.035 & -0.079 & -0.079 \\
\hline \multirow[t]{6}{*}{$\mathrm{Ti}_{2} \mathrm{~F}_{2} \mathrm{H}_{4}^{\mathrm{b}}$} & $S_{0}$ & -28.829 & -30.636 & -30.644 & -19.192 & -21.147 & -21.152 \\
\hline & $T_{1} X$ & 11.685 & 9.742 & 9.772 & 58.295 & 56.227 & 56.246 \\
\hline & $T_{1} Y$ & 11.683 & 9.740 & 9.768 & 58.253 & 56.125 & 56.145 \\
\hline & $T_{1} Z$ & 12.205 & 10.289 & 10.278 & 58.494 & 56.433 & 56.426 \\
\hline & $D_{c}$ & 0.521 & 0.548 & 0.508 & 0.220 & 0.257 & 0.230 \\
\hline & $\mathrm{E}_{\varepsilon}$ & 0.001 & 0.001 & 0.002 & 0.021 & 0.051 & 0.050 \\
\hline \multirow[t]{6}{*}{$\mathrm{Ti}_{2} \mathrm{~F}_{2} \mathrm{H}_{4}{ }^{\mathrm{c}}$} & $\mathrm{S}_{0}$ & -29.488 & -31.381 & -31.39 & -21.186 & -23.351 & -23.358 \\
\hline & $T_{1} X$ & 2.680 & 0.668 & 0.697 & 59.049 & 56.375 & 56.396 \\
\hline & $T_{1} Y$ & 2.672 & 0.659 & 0.686 & 59.285 & 56.839 & 56.861 \\
\hline & $T_{1} Z$ & 3.213 & 1.227 & 1.215 & 59.418 & 56.767 & 56.758 \\
\hline & $D_{c}$ & 0.537 & 0.564 & 0.524 & 0.251 & 0.160 & 0.130 \\
\hline & $\mathrm{E}_{e}$ & 0.004 & 0.005 & 0.005 & -0.118 & -0.232 & -0.232 \\
\hline \multirow[t]{6}{*}{$\mathrm{Ti}_{2} \mathrm{Cl}_{2} \mathrm{H}_{4}$} & $S_{0}$ & -12.999 & -14.299 & -14.299 & -14.334 & -16.292 & -16.293 \\
\hline & $T_{1} X$ & -30.231 & -31.506 & -31.501 & -36.987 & -38.759 & -38.753 \\
\hline & $T_{1} Y$ & -30.327 & -31.615 & -31.613 & -37.076 & -38.874 & -38.871 \\
\hline & $\mathrm{T}, \mathrm{Z}$ & -30.271 & -31.556 & -31.560 & -36.953 & -38.74 & -38.745 \\
\hline & $\mathrm{D}_{\mathrm{c}}$ & 0.008 & 0.004 & -0.003 & 0.078 & 0.076 & 0.067 \\
\hline & $E_{c}$ & 0.048 & 0.054 & 0.056 & 0.044 & 0.058 & 0.059 \\
\hline \multirow[t]{6}{*}{$\mathrm{Ti}_{2} \mathrm{Br}_{2} \mathrm{H}_{4}$} & $\mathrm{~S}_{0}$ & -11.483 & -12.813 & -12.814 & -12.727 & -14.424 & -14.425 \\
\hline & $T_{t} X$ & -0.004 & -1.307 & -1.303 & 5.237 & 3.569 & 3.573 \\
\hline & $T_{1} Y$ & -0.077 & -1.397 & -1.396 & 5.172 & 3.483 & 3.485 \\
\hline & $\mathrm{T}_{1} \mathrm{Z}$ & -0.019 & -1.336 & -1.340 & 5.308 & 3.626 & 3.622 \\
\hline & $D_{c}$ & 0.022 & 0.016 & 0.009 & 0.104 & 0.100 & 0.093 \\
\hline & $\mathrm{E}_{c}$ & 0.037 & 0.045 & 0.047 & 0.033 & 0.043 & 0.044 \\
\hline
\end{tabular}


TABLE 13: CASSCF-SOC Timings

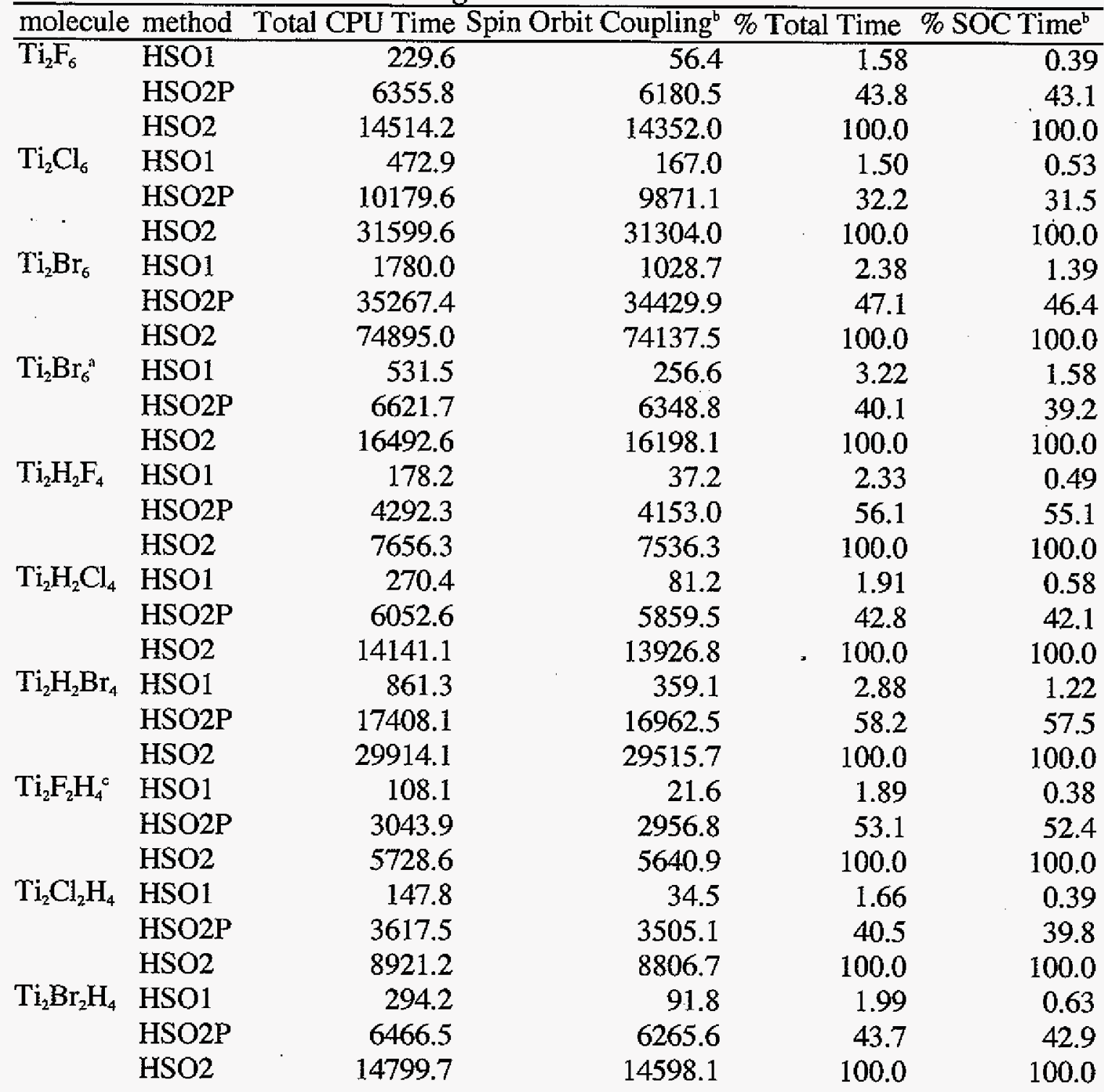

Timings for a $300 \mathrm{MHz}$ UltraSPARC2 computer. " Timings for a $500 \mathrm{MHz}$ AXP EV6 computer. ' This category includes time required for integral transformations and spin-orbit matrix element calculation. ${ }^{c} D_{2 h}\left[(\sigma)\left(\sigma^{*}\right)\right]^{2}$ state. 
TABLE 14: MCQDPT-SOC Timings

\begin{tabular}{|c|c|c|c|c|c|}
\hline molecule & method & Total CPU Time & Spin Orbit Coupling ${ }^{2}$ & $\%$ Total Time & $\%$ SOC Time \\
\hline $\mathrm{T}_{2}^{2} \mathrm{~F}_{6}$ & HSO1 & 3863.2 & 90.3 & 62.6 & 3.7 \\
\hline & $\mathrm{HSO} 2 \mathrm{P}$ & 5111.1 & 1500.7 & 82.8 & 62.2 \\
\hline & $\mathrm{HSO} 2$ & 6174.1 & 2412.8 & 100.0 & 100.0 \\
\hline $\mathrm{Ti}_{2} \mathrm{Cl}_{6}$ & HSO1 & 9560.4 & 181.9 & 73.3 & 4.2 \\
\hline & $\mathrm{HSO} 2 \mathrm{P}$ & 11137.3 & 2471.3 & 85.4 & 56.5 \\
\hline & $\mathrm{HSO} 2$ & 13048.7 & 4374.7 & 100.0 & 100.0 \\
\hline $\mathrm{Ti}_{2} \mathrm{Br}_{6}$ & HSO1 & 50172.1 & 800.1 & 81.7 & 7.1 \\
\hline & $\mathrm{HSO} 2 \mathrm{P}$ & 63878.7 & 6745.2 & 104.1 & 59.7 \\
\hline & $\mathrm{HSO}_{2}$ & 61380.2 & 11304.2 & 100.0 & 100.0 \\
\hline $\mathrm{Ti}_{2} \mathrm{H}_{2} \mathrm{~F}_{4}$ & HSO1 & 2191.8 & 58.1 & 59.4 & 3.8 \\
\hline & $\mathrm{HSO} 2 \mathrm{P}$ & 3170.8 & 1022.4 & 85.9 & 67.3 \\
\hline & $\mathrm{HSO} 2$ & 3692.1 & 1519.2 & 100.0 & 100.0 \\
\hline $\mathrm{Ti}_{2} \mathrm{H}_{2} \mathrm{Cl}_{4}$ & HSOl & 4471.8 & 105.3 & 68.4 & 4.6 \\
\hline & $\mathrm{HSO} 2 \mathrm{P}$ & 6022.4 & 1579.2 & 92.2 & 68.8 \\
\hline & $\mathrm{HSO} 2$ & 6533.6 & 2296.9 & 100.0 & 100.0 \\
\hline $\mathrm{Ti}_{2} \mathrm{H}_{2} \mathrm{Br}_{4}$ & HSO1 & 18638.0 & 363.9 & 81.0 & 6.4 \\
\hline & $\mathrm{HSO} 2 \mathrm{P}$ & 20682.6 & 3366.0 & 89.9 & 59.2 \\
\hline & $\mathrm{HSO} 2$ & 22996.9 & 5682.4 & 100.0 & 100.0 \\
\hline $\mathrm{Ti}_{2} \mathrm{~F}_{2} \mathrm{H}_{4}{ }^{\mathrm{b}}$ & HSO1 & 1620.4 & 42.7 & 60.2 & 3.9 \\
\hline & $\mathrm{HSO} 2 \mathrm{P}$ & 2320.5 & 711.9 & 86.1 & 65.5 \\
\hline & $\mathrm{HSO} 2$ & 2693.6 & 1086.2 & 100.0 & 100.0 \\
\hline $\mathrm{Ti}_{2} \mathrm{Cl}_{2} \mathrm{H}_{4}$ & HSO1 & 2103.7 & 56.5 & 62.8 & 4.3 \\
\hline & $\mathrm{HSO} 2 \mathrm{P}$ & 2908.5 & 859.7 & 86.8 & 65.8 \\
\hline & $\mathrm{HSO} 2$ & 3350.1 & 1307.2 & 100.0 & 100.0 \\
\hline $\mathrm{Ti}_{2} \mathrm{Br}_{2} \mathrm{H}_{4}$ & HSO1 & 4797.0 & 111.8 & 67.1 & 4.7 \\
\hline & $\mathrm{HSO} 2 \mathrm{P}$ & 6212.8 & 1538.0 & 86.9 & 64.4 \\
\hline & $\mathrm{HSO} 2$ & 7150.8 & 2388.1 & 100.0 & 100.0 \\
\hline
\end{tabular}

Timings for a $500 \mathrm{MHz}$ AXP EV6 computer. " This category includes time required for integral transformations and spin-orbit matrix element calculation. ${ }^{b} \mathrm{D}_{2 \mathrm{~h}}\left[(\sigma)\left(\sigma^{*}\right)\right]^{2}$ state. 


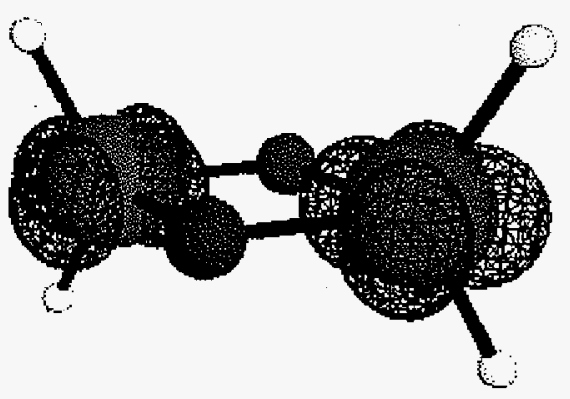

$\stackrel{\mathrm{a}_{\mathrm{g}}}{\mathrm{\sigma}} \mathrm{\sigma}$

$\begin{array}{ll}\mathrm{Ti}_{2} \mathrm{H}_{2} \mathrm{~F}_{4} & 1.13 \\ \mathrm{Ti}_{2} \mathrm{H}_{2} \mathrm{Cl}_{4} & 1.11 \\ \mathrm{Ti}_{2} \mathrm{H}_{2} \mathrm{Br}_{4} & 1.10 \\ \mathrm{Ti}_{2} \mathrm{~F}_{2} \mathrm{H}_{4} & 1.00 \\ \mathrm{Ti}_{2} \mathrm{Cl}_{2} \mathrm{H}_{4} & 1.04 \\ \mathrm{Ti}_{2} \mathrm{Br}_{2} \mathrm{H}_{4} & 1.05 \\ \mathrm{Ti}_{2} \mathrm{~F}_{6} & 1.01 \\ \mathrm{Ti}_{2} \mathrm{Cl}_{6} & 1.03 \\ \mathrm{Ti}_{2} \mathrm{Br}_{6} & 1.05\end{array}$

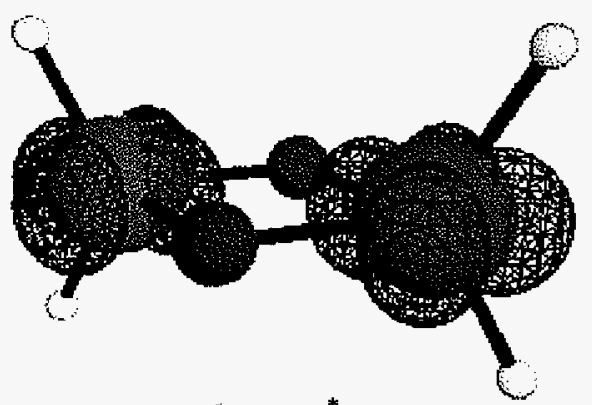

$\mathrm{b}_{1 \mathrm{u}} \sigma^{*}$

0.87

0.89

0.90

1.00

0.96

0.95

0.99

0.97

0.95

Figure 1. Three-dimensional plots of the natural orbitals from a 2 electron, 2 orbital MCSCF/TZV (p) calculation. The orbital contour value for the plots is 0.06 bohr $^{3 / 2}$. The z-axis is defined by the Ti-Ti axis. The orbital s shown are for $\mathrm{Ti}_{2} \mathrm{~F}_{2} \mathrm{H}_{4}$. Natural orbital occupations numbers (NOON's) are shown above. 


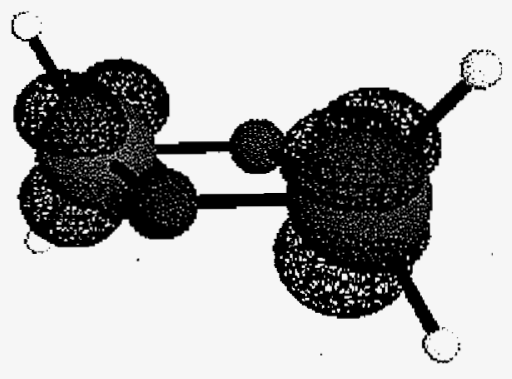

$\stackrel{a_{\mathrm{w}}}{\delta^{*}}$

1.04

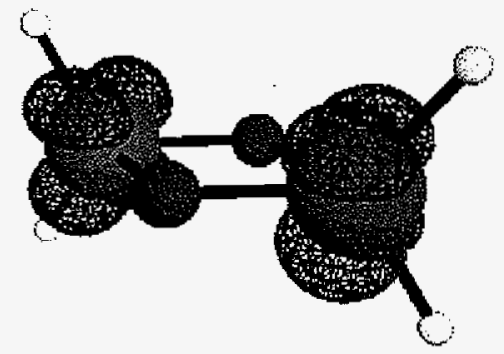

$b_{1 g} \delta$

0.96

Figure 2. Three-dimensional plots of the natural orbitals for singlet $\mathrm{Ti}_{2} \mathrm{~F}_{2} \mathrm{H}_{4}$ from a 2 electron, 2 orbital MCSCF/TZV (p) calculation. The orbital contour value for the plots is 0.06 bohr $^{3 / 2}$. The z-axis is defined by the Ti-Ti axis. Natural orbital occupations numbers (NOON's) are shown above.

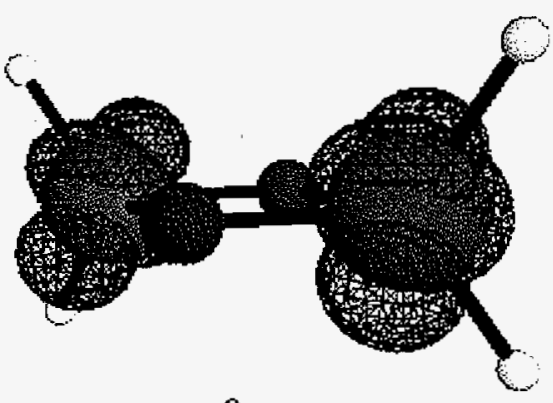

$a_{u}$

NOON

1.04

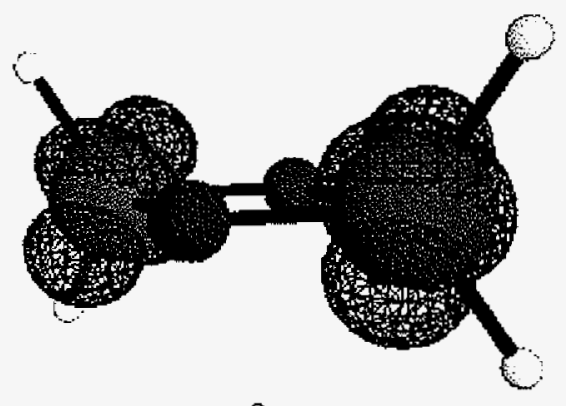

NOON

0.96

Figure 3. Three-dimensional plots of the natural orbitals for singlet $\mathrm{Ti}_{2} \mathrm{~F}_{2} \mathrm{H}_{4}$ with $\mathrm{C}_{2 \mathrm{~h}}$ symmetry from a 2 electron, 2 orbital MCSCF/TZV(p) calculation. The orbital contour value for the plots is 0.06 bohr $^{3 / 2}$. The z-axis is defined by the Ti-Ti axis. Natural orbital occupations numbers (NOON's) are shown above. 


\section{CHAPTER 3. INFLUENCE OF MULTI-ATOM BRIDGING LIGANDS ON THE ELECTRONIC STRUCTURE AND MAGNETIC PROPERTIES OF HOMODINUCLEAR TITANIUM MOLECULES}

A paper submitted to The Journal of Physical Chemistry A

Christine M. Aikens and Mark S. Gordon

The electronic structure and magnetic properties of homodinuclear titanium(III) molecules with bridging ligands from groups 14,15 , and 16 are examined. Single- and multireference methods with triple- $\zeta$ plus polarization basis sets are employed. Dynamic electron correlation effects are included via second-order multireference perturbation theory. Isotropic interaction parameters are calculated, and two of the complexes studied are predicted to be ferromagnetic based on multi-reference second-order perturbation (MRMP2) theory, using the TZVP(fg) basis set. Zero-field splitting parameters are determined using spin-orbit coupling obtained from complete active space (CAS) SCF and multiconfigurational quasidegenerate perturbation theory (MCQDPT) wave functions. Three Breit-Pauli-based spin coupling methods were employed: Full Breit-Pauli (HSO2), the partial two-electron method (P2E), and the semi-empirical one-electron method (HSO1). Timings for these three methods are compared.

\section{Introduction}

The interaction of multiple metal centers in molecular complexes, solid-state compounds, and enzymes has become a rapidly expanding field of study over the last few years. ${ }^{1-6}$ In particular, the design of single-molecule ferromagnets and antiferromagnetic superconductors with high critical temperatures are significant challenges in the area of 
materials science. The relationship between magnetic and electronic properties is also a growing field of study in bioinorganic chemistry. ${ }^{7}$

The magnetization of a material depends on the magnetic field acting on it. The magnetic susceptibility, $\chi$, is a property of the material and relates the magnetization, $\mathrm{M}$, to the strength of the magnetic field, $H$. For relatively low values of $H$, $\mathbf{M}=\chi \mathrm{H}$.

If the magnetic susceptibility is negative, it is independent of temperature and the material is diamagnetic. If the susceptibility is positive, it varies with temperature. This is the case for paramagnetic, ferromagnetic, antiferromagnetic, and ferrimagnetic materials. In ferromagnetic materials, the susceptibility increases as the temperature decreases. In antiferromagnetic materials, the magnetic susceptibility passes through a maximum at the Néel temperature and goes to zero as the temperature approaches absolute zero.

The magnetic behavior of transition metal complexes in which more than one metal atom has unpaired electrons depends on the strength of the interaction between the metal centers. When strong metal-metal bonds occur in a dimer, the molecule will be diamagnetic. If the metal centers do not interact, the magnetic properties of the dimer are unchanged from those of the monomer. In a weakly interacting complex, the weak coupling of the electrons leads to low-lying excited states of different spin. In dinuclear complexes with one unpaired electron on each metal center, the two local spin states $S_{A}$ and $S_{B}$ can interact through the bridging ligands with either singlet or triplet coupling. If singlet coupling is favored, the interaction is antiferromagnetic; if triplet coupling is favored, the interaction is 
ferromagnetic. If this isotropic interaction is the dominant magnetic effect, the total spin quantum number $S$ is a good quantum number. ${ }^{8}$

The Hamiltonian that describes the coupling between local spin operators $\mathbf{S}_{\mathbf{A}}$ and $\mathbf{S}_{\mathbf{B}}$ was introduced by Heisenberg. ${ }^{9}$ It may be written as

$$
\mathcal{H}=-2 \mathrm{JS}_{\mathrm{A}} \cdot \mathbf{S}_{\mathrm{B}},
$$

where the isotropic exchange interaction parameter $\mathrm{J}$ is defined by

$$
2 J=E(S=0)-E(S=1) \text {. }
$$

The isotropic interaction parameter is related to the magnetic susceptibility by

$$
\chi=\frac{2 N g^{2} \beta^{2}}{k T}\left[3+\exp \left(\frac{-2 J}{k T}\right)\right]^{-1}
$$

where $\mathrm{N}$ is Avogadro's number, $\mathrm{g}$ is the average electronic gyromagnetic ratio, $\beta$ is the Bohr magneton, $\mathrm{k}$ is the Boltzmann constant, and $\mathrm{T}$ is the temperature. Moreover, for antiferromagnetic compounds the isotropic interaction parameter is proportional to the Nél temperature $T_{\max }$ according to

$$
12 \mathrm{~J} / \mathrm{kT}_{\max }=1.599
$$

where $\mathrm{k}=0.695 \mathrm{~cm}^{-1} \mathrm{~K}^{-1}$. This relation may be used to compare calculated isotropic interaction parameters with experimentally observable susceptibility maxima.

The isotropic exchange interaction usually has a greater effect on the magnetic properties than other phenomena such as the spin-orbit coupling and the magnetic dipoledipole interaction. However, if the singlet-triplet splitting is small or if the triplet state is the ground state, these other interactions may become essential for an accurate description of the system. In addition, these effects may be seen in an electron paramagnetic resonance (EPR) 
spectrum of the triplet state, since they result in a zero-field splitting (ZFS) of the $M_{s}$ components. The Hamiltonian for these terms may be written

$$
\mathcal{H}=S \cdot \mathbf{D} \cdot S+\beta S \cdot \mathbf{g} \cdot H
$$

where the first term accounts for the dipolar and anisotropic exchange interactions due to the zero-field splitting tensor $\mathbf{D}$ and the second term accounts for the Zeeman perturbation with the $\mathbf{g}$ (gyromagnetic) tensor. The principal (diagonal) values of $\mathbf{D}$ and $\mathbf{g}$ are fit to the experimental data. The principal values of $\mathbf{D}$ are used to calculate the axial and nonaxial (rhombic) zero-field splitting parameters $D$ and $E$ according to ${ }^{10}$

$$
\begin{aligned}
& D=3 D_{z} / 2 \\
& E=\left(D_{x}-D_{y}\right) / 2
\end{aligned}
$$

The anisotropic exchange tensor $\mathbf{D}_{\mathbf{e}}$ may be found by

$$
\mathbf{D}_{\mathrm{e}}=\mathbf{D}-\mathbf{D}_{\mathrm{d}}
$$

where $\mathbf{D}_{\mathbf{d}}$ is the dipole-dipole interaction tensor. The dipolar term is often the minor contribution to $\mathbf{D}$ and can often be reasonably estimated from the point dipole approximation. ${ }^{8}$ The axial and rhombic exchange interaction parameters, $D_{e}$ and $E_{e}$, are related to the spin-orbit coupling and may be calculated by

$$
\begin{aligned}
& D=D_{d}+D_{e} \\
& E=E_{d}+E_{e}
\end{aligned}
$$

In 1934, Kramers introduced the idea of superexchange in order to explain how transition metal ions in solids could interact at long distances. ${ }^{11}$ He proposed that the neighboring non-magnetic atoms could play a role in the magnetic interaction mechanism through an exchange spin-coupling. In the 1950s, Anderson and Nesbet developed basic 
qualitative models of exchange interactions in solid-state materials. ${ }^{12-15}$ The Anderson model has been successful in predicting the sign of the magnetic interaction, but does not quantitatively reproduce its magnitude. Early ab initio calculations on the ionic solid $\mathrm{KNiF}_{3}$ confirmed the ideas of the Anderson model, but yielded a magnetic coupling value that was much too small. ${ }^{16}$

In 1952, Bleaney and Bowers discovered that superexchange is not limited to solids, but also occurs in binuclear or polynuclear metal complexes such as copper acetate. ${ }^{17}$ In the mid-1970s, Hay, Thibeault, and Hoffmann (HTH) ${ }^{18}$ and Kahn and Briat ${ }^{19.20}$ discussed a semiquantitative equivalent of the Anderson model for molecular complexes and other systems based on extended Hückel calculations. One reason that the Anderson and HTH models produce $\mathrm{J}$ values that are too small relative to experimental values is that they neglect dynamic correlation contributions. An important advance toward a quantitative examination of magnetic coupling came in 1981, when de Loth et al. used perturbation theory in order to include the effect of excited configuration state functions that contribute to the energy difference between the lowest energy singlet and triplet states. ${ }^{21}$ Since this time, perturbation theory methods built on a multireference zeroth-order wavefunction have been used to examine the magnetic coupling in a variety of metal complexes and materials. ${ }^{22.40}$ Other theoretical methods for calculating the magnetic coupling for biradicals and binuclear complexes have been discussed recently. ${ }^{41}$

$A b$ initio calculations can provide new insights into the interactions between metal centers and ligands. Homodinuclear complexes with one unpaired electron on each metal center, such as $\mathrm{d}^{1} \mathrm{Ti}(\mathrm{III})$ complexes, are some of the simplest model compounds for. investigating spin-spin interactions. Experimentally, dititanium(III) compounds with a linear 
oxo-bridge, ${ }^{42-45}$ organic bridge, ${ }^{46-57}$ face-sharing bioctahedral tribridge, ${ }^{58,59}$ or dibridge (ring) structure have been characterized. Complexes with a ring structure include hydrido-, ${ }^{60-62}$ halo- ${ }^{63-74}$ amido- ${ }^{75.78}$ hydroxy-,${ }^{74,79}$ alkoxy- ${ }^{76,80}$ phosphido- ${ }^{81}$ silyl- ${ }^{82}$ sulfato- ${ }^{83}$ and thiobridged species. ${ }^{76}$ Some of the rings are essentially planar ${ }^{63,66,77,80,81}$ while others are buckled. ${ }^{61,79}$

The magnetic properties of linear oxo-bridged compounds have been investigated using CASSCF, MC-CEPA, and ACPF calculations ${ }^{84,85}$ and density functional theory calculations. ${ }^{86}$ The Ti-Ti bonding interaction, isotropic interaction, and zero-field splitting parameters of $\mathrm{D}_{2 \mathrm{~h}} \mathrm{H}_{2} \mathrm{Ti}(\mu-\mathrm{H})_{2} \mathrm{TiH}_{2}$, a simple model of the flat ring compounds, were studied in detail using multireference methods. ${ }^{29,30}$ The effects of halide bridging and terminal ligands on the magnetic properties of homodinuclear titanium(III) compounds were also examined using multireference methods. ${ }^{34}$ In the present study, the effects of other bridging ligands such as $\mathrm{OH}, \mathrm{SH}, \mathrm{NH}_{2}, \mathrm{PH}_{2}, \mathrm{NNN}, \mathrm{CN}, \mathrm{OCN}, \mathrm{CNO}, \mathrm{SCN}, \mathrm{NO}$, and $\mathrm{NO}_{2}$ on the magnetic properties will be discussed.

\section{Computational Details}

Geometry optimizations for triplet states were carried out at the restricted open-shell Hartree-Fock (ROHF) level of theory. The triplet orbitals were used as a starting point for a two configuration self-consistent field (TCSCF) optimization for the singlet states. The basis set used in the geometry optimizations is denoted $\operatorname{TZV}(\mathrm{p})$. It consists of a triple- $\zeta$ with polarization (14s11p6d/10s8p3d) basis set for titanium, which is comprised of Wachter's basis set $^{87}$ with two additional sets of $\mathrm{p}$ functions ${ }^{88}$ and an additional set of diffuse $\mathrm{d}$ functions. ${ }^{89}$ In the notation $(\mathrm{A} / \mathrm{B}), \mathrm{A}$ is the primitive basis set and $\mathrm{B}$ is the contracted basis 
set. For hydrogen, Dunning's ( $5 \mathrm{~s} 1 \mathrm{p} / 3 \mathrm{~s} 1 \mathrm{p})$ basis set was employed; ${ }^{90}$ for carbon, nitrogen, and oxygen, the Dunning $(10 \mathrm{~s} 6 \mathrm{p} / 5 \mathrm{~s} 3 \mathrm{p})$ basis set was used. ${ }^{91}$ The McLean and Chandler $(12 \mathrm{~s} 9 \mathrm{p} / 6 \mathrm{~s} 5 \mathrm{p})$ basis set was utilized for phosphorus and sulfur. ${ }^{92}$

The energy second-derivative (Hessian) matrix was calculated and diagonalized at all stationary points. Unless otherwise stated, all stationary points have zero imaginary frequencies and are minima on their respective potential energy surfaces.

Two larger basis sets denoted TZVP(f) and TZVP(fg) were also used in this study. For both, diffuse $s$ and $\mathrm{p}$ functions and two sets of $\mathrm{d}$ polarization functions were added to the main group elements. The diffuse sp function and $2 \mathrm{~d}$ polarization function exponents are the default values in GAMESS. ${ }^{93,94}$ The basis set called TZVP( $\left.\mathrm{f}\right)$ adds an $\mathrm{f}$ function $(\alpha=0.40)^{95}$ to the titanium atom. The basis set referred to as TZVP( $f g)$ adds a set of $f(\alpha=0.591)$ and $g$ $(\alpha=0.390)$ polarization functions, as well as a set of diffuse $\mathrm{s}(\alpha=0.035), \mathrm{p}(\alpha=0.239)$, and $d(\alpha=0.0207)$ functions, to the TZV $(p)$ titanium basis. These exponents in the TZVP(fg) basis set are optimized for correlated titanium atoms. ${ }^{96}$

The effects of dynamic electron correlation were included by carrying out secondorder multireference perturbation theory (MRMP2) ${ }^{97-100}$ single-point energy calculations at the TCSCF and ROHF geometries. Single-point energy calculations were repeated with the TZVP(f) and TZVP(fg) basis sets as a test of basis set convergence.

For excited states, fully optimized reaction space (FORS) multiconfigurational SCF (MCSCF) calculations ${ }^{101-103}$ (also called complete active space SCF $(\mathrm{CASSCF})^{104}$ ) with an active space consisting of 2 electrons in 10 or more orbitals are required. Spin-orbit coupling (SOC) effects are determined using both the complete active space SCF (CASSCF-SOC) and 
multiconfiguration quasi-degenerate perturbation theory (MCQDPT-SOC) $)^{105}$ methods. Three different operators are used in the calculations: a semi-empirical one-electron spin-orbit coupling operator (HSO1), ${ }^{106}$ a partial two-electron/full one-electron operator $(\mathrm{P} 2 \mathrm{E}),{ }^{107}$ and the full Pauli-Breit operator (HSO2). ${ }^{107}$

The electronic structure code GAMESS ${ }^{93,94}$ was used for all calculations. Orbitals were visualized using MacMolPlt, ${ }^{108}$ a graphical interface to GAMESS.

\section{Results and Discussion}

Electronic Structure and Energetics

$\underline{\mathrm{OH}}$

The hydroxide ligand is isoelectronic with fluoride, so it provides a good first comparison with hydride and halide bridging ligands. Indeed, the complex $\mathrm{Ti}_{2}(\mu-\mathrm{OH})_{2} \mathrm{H}_{4}$ follows the electronic structure and energetic trends discussed in previous work on $\mathrm{Ti}_{2} \mathrm{H}_{6}{ }^{29}$ and $\mathrm{Ti}_{2} \mathrm{X}_{2} \mathrm{Y}_{4}(\mathrm{X}, \mathrm{Y}=\mathrm{H}, \mathrm{F}, \mathrm{Cl}, \mathrm{Br}){ }^{34}$ Mulliken populations (Table 1) for the TCSCF and $\mathrm{ROHF}$ wave functions with the TZV (p) basis show that the titanium atoms are positively charged. The lowest energy $D_{2 h}$ singlet and triplet states are determined to be ${ }^{1} A_{g}$ and ${ }^{3} B_{1 u}$, respectively. The molecular orbitals that create these states are primarily formed from the $\sigma$ and $\sigma^{*}$ combination of the $\mathrm{d}_{\mathrm{x} 2-22}$ orbitals on the two Ti atoms (Figure 1 ), where the Ti atoms lie along the $\mathrm{z}$-axis and the $\mathrm{OH}$ ligands lie along the $\mathrm{x}$-axis. The two configurations that are responsible for the singlet state may be expressed as $\left[(\sigma)\left(\sigma^{*}\right)\right]^{2}$, or:

$\begin{array}{lcc}\text { Config. \# } & \sigma & \sigma^{*} \\ 1 & 2 & 0 \\ 2 & 0 & 2\end{array}$


The singlet state has a high degree of diradical character; a natural orbital analysis of the TCSCF/TZV(p) wave function (Table 2) shows that there are 0.92 electrons in the lowest virtual orbital. This suggests that although the molecule is in principle able to form a direct Ti-Ti bond, the singlet state is essentially a singlet diradical with very little bonding interaction.

The TCSCF/TZV(p) energy difference between the singlet and triplet states is only $0.2 \mathrm{kcal} / \mathrm{mol}$ (Table 3). The inclusion of dynamic electron correlation via second-order perturbation theory lowers the singlet state preferentially. The MRMP2/TZV(p) energy difference increases to $0.7 \mathrm{kcal} / \mathrm{mol}$. As the basis set size is increased, the singlet-triplet splitting increases by an additional $0.1 \mathrm{kcal} / \mathrm{mol}$ to $0.8 \mathrm{kcal} / \mathrm{mol}$ at the MRMP2/TZVP(fg) level of theory, and is still very small.

\section{$\underline{\mathrm{SH}}$}

The hydrosulfido ligand is isoelectronic with chloride, so one might think that it would follow a similar electronic structure pattern. Unlike $\mathrm{Ti}_{2}(\mu-\mathrm{OH})_{2} \mathrm{H}_{4}$, the analogous $\mathrm{Ti}_{2}(\mu-\mathrm{SH})_{2} \mathrm{H}_{4} \mathrm{D}_{2 \mathrm{~h}}$ structure is not a local minimum. Imaginary frequencies lead to $\mathrm{C}_{2 \mathrm{v}}$ and $\mathrm{C}_{2 \mathrm{~h}}$ structures. The relative energies for these structures are shown in Table 4. The $C_{2 v}$ structure is lower in energy than the $\mathrm{C}_{2 \mathrm{~b}}$ structure by $1.1 \mathrm{kcal} / \mathrm{mol}$. Geometrical parameters are presented in Table 5. Although it has a lower symmetry, the general electronic structure of $\mathrm{Ti}_{2}\left(\mu-\mathrm{SH}_{2} \mathrm{H}_{4}\right.$ can be related to that of $\mathrm{Ti}_{2}(\mu-\mathrm{OH})_{2} \mathrm{H}_{4}$. The frontier molecular orbitals that create the ${ }^{1} \mathrm{~A}_{1}$ and ${ }^{3} \mathrm{~B}_{2}$ states are derived from the Ti $\mathrm{d}_{\mathrm{xz}-22}$ atomic orbitals. The "modified" $\sigma$ and $\sigma^{*}$ molecular orbitals have $a_{1}$ and $b_{2}$ symmetry, respectively. The singlet state is essentially a singlet diradical with 0.96 electrons in the lowest virtual orbital (Table 2). 
At the TCSCF/TZV(p) level of theory, the singlet state is predicted to be only 0.01 $\mathrm{kcal} / \mathrm{mol}$ lower in energy than the triplet state (Table 3). The inclusion of dynamic electron correlation at the MRMP2/TZV(p) level further stabilizes the singlet state by $0.2 \mathrm{kcal} / \mathrm{mol}$. As the basis set is improved, the singlet-triplet splitting grows to $0.5 \mathrm{kcal} / \mathrm{mol}$ at the MRMP2/TZVP(fg) level of theory.

$\underline{\mathrm{NH}}_{2}$

For $\mathrm{D}_{2 \mathrm{~h}} \mathrm{Ti}_{2}\left(\mu-\mathrm{NH}_{2}\right)_{2} \mathrm{H}_{4}$, the $\left[(\sigma)\left(\sigma^{*}\right)\right]^{2}$ orbital configuration is not the dominant configuration in the ground state. Instead, the $\left[(\delta)\left(\delta^{*}\right)\right]^{2}$ orbital configuration (Figure 2) created from the $\mathrm{Ti} \mathrm{d}_{x y}$ atomic orbitals dominates the ground state and the $\left[(\sigma)\left(\sigma^{*}\right)\right]^{2}$ orbital configuration corresponds to an excited state. This behavior was noted earlier for $\mathrm{Ti}_{2}(\mu-$ $\mathrm{F}_{2} \mathrm{H}_{4} \cdot{ }^{34} \operatorname{MCSCF}(2,10)$ calculations show that the $\left[(\sigma)\left(\sigma^{*}\right)\right]^{2}$ and $\left[(\delta)\left(\delta^{*}\right)\right]^{2}$ configurations essentially do not mix, even though they belong to the same irreducible representation. However, the singlet state comprised of $\sigma$ orbitals and the triplet state dominated by $\delta$ orbitals are not local minima. Imaginary frequencies lead to $\mathrm{a}_{2 \mathrm{~h}}$ structure for both singlet and triplet states (Figure 3). At the MRMP2/TZV(p) level of theory, this structure is 0.3 and $5.7 \mathrm{kcal} / \mathrm{mol}$ lower in energy than the singlet $\mathrm{D}_{2 \mathrm{~h}}$ states with orbital configurations $\left[(\delta)\left(\delta^{*}\right)\right]^{2}$ and $\left[(\sigma)\left(\sigma^{*}\right)\right]^{2}$, respectively (Table 4$)$.

$\underline{\mathrm{PH}}_{2}$

The lowest energy singlet and triplet states for $\mathrm{Ti}_{2}\left(\mu-\mathrm{PH}_{2}\right)_{2} \mathrm{H}_{4}$ with $\mathrm{D}_{2 h}$ symmetry are ${ }^{1} \mathrm{~A}_{\mathrm{g}}$ and ${ }^{3} \mathrm{~B}_{1 \mathrm{u}}$. The $\mathrm{D}_{2 \mathrm{~b}}$ triplet state is not a minimum on the potential energy surface. The imaginary frequency $\left(38 i \mathrm{~cm}^{-1}\right)$ leads to a structure with $\mathrm{C}_{2 \mathrm{v}}$ symmetry. The lowest energy $C_{2 v}$ singlet is $1.0 \mathrm{kcal} / \mathrm{mol}$ lower in energy than the lowest energy $D_{2 \mathrm{~b}}$ singlet (Table 4). The 
ground state of this molecule is more similar to $\mathrm{SH}$ than $\mathrm{NH}_{2}$. The molecular orbitals are formed primarily from the $\mathrm{Ti} \mathrm{d}_{\mathrm{x} 2.42}$ orbitals, similar to $\mathrm{OH}$ and $\mathrm{SH}$, rather than the $\mathrm{d}_{\mathrm{xy}}$ orbitals seen in $\mathrm{NH}_{2}$.

NNN

The azido ligand can act as a bridge between the titanium atoms in two ways: a $\mu-1,1$ ("end-on") mode or a $\mu-1,3$ ("linear") mode. These bridging modes are shown in Figure 4. Both of these bridging modes have been seen experimentally in copper(II) dinuclear compounds. ${ }^{8}$ For both modes, the $\mathrm{D}_{2 h}$ structure is a local minimum. The ground state of these molecules is ${ }^{1} \mathrm{~A}_{\mathrm{g}}$, and the lowest energy triplet state is ${ }^{3} \mathrm{~B}_{1 \mathrm{u}}$. The molecular orbitals follow the pattern established for hydroxide. According to a natural orbital analysis of the $\operatorname{TCSCF} / T Z V(p)$ wave function, there are 0.85 electrons in the lowest virtual orbital of the end-on structure and 0.95 electrons in the lowest virtual orbital of the linear structure (Table 2). The TCSCF/TZV(p) singlet-triplet splitting for the end-on structure is calculated to be $1.1 \mathrm{kcal} / \mathrm{mol}$, and increases to $3.2 \mathrm{kcal} / \mathrm{mol}$ at the MRMP2/TZVP(fg) level (Table 3 ). For the linear structure, the TCSCF/TZV(p) singlet-triplet splitting is $0.2 \mathrm{kcal} / \mathrm{mol}$ and $0.5 \mathrm{kcal} / \mathrm{mol}$ at the MRMP2/TZVP(fg) level. The MRMP2/TZVP(fg) end-on structure is more stable than the linear structure by $1.7 \mathrm{kcal} / \mathrm{mol}$.

Experimentally for the copper compounds, the end-on azido-bridged structures are ferromagnetic, while the linear structures are strongly antiferromagnetic. ${ }^{109,110}$ In contrast, the end-on $\mathrm{Ti}_{2}(\mu-1,1-\mathrm{NNN})_{2} \mathrm{H}_{4}$ is very antiferromagnetic and the linear $\mathrm{Ti}_{2}(\mu-1,3-\mathrm{NNN})_{2} \mathrm{H}_{4}$ is slightly antiferromagnetic. The atomic orbitals available to form metal-metal bonds are different on copper and titanium. For copper, the unpaired electron density is in the $\mathrm{d}_{\mathrm{xz}}$ 
orbital, rather than $d_{x 2-22}$. This difference may be used to explain the dramatic difference in the magnetic coupling observed for the two bonding modes with the different metals. The HOMO and LUMO orbitals for titanium complexes are oriented along the Ti-Ti axis, whereas the orbitals in copper complexes are oriented along the $\mathrm{Cu}$-ligand bonds.

CN

The cyano ligand can bridge the titanium atoms in three ways: two end-on structures ( $\mu-1,1-\mathrm{CN}$ and $\mu-1,1-\mathrm{NC})$ and one linear structure $(\mu-1,2-\mathrm{CN})$ (Figure 5). Experimentally, the cyano ligand has been observed to bind in a bidentate fashion using both the carbon and nitrogen, or preferentially through the carbon when it bonds in an end-on fashion. ${ }^{111}$ The end-on structure with $\mathrm{D}_{2 \mathrm{~h}}$ symmetry is predicted to be a local minimum. For the linear structure, the highest possible symmetry is $C_{2 h}$. (A structure with equally high $C_{2 v}$ symmetry could be imagined. However, since the two titanium atoms are in different environments, the $\mathrm{C}_{2 \mathrm{v}}$ structures were not considered in this study.) For all three structures, the active orbitals are composed primarily of $\mathrm{Ti}_{\mathrm{k} 2-22}$ orbitals, as discussed for the $\mathrm{OH}$ bridging ligand. Regardless of basis set, the MRMP2 calculations predict that the $\mu-1,2$ arrangement is lower in energy than the $\mu-1,1-\mathrm{N}$ structure by approximately $18 \mathrm{kcal} / \mathrm{mol}$. The $\mu-1,1-\mathrm{C}$ arrangement is the highest energy bridging structure. These calculations suggest that the linear bonding structure will be preferred for the cyano ligand in this type of system.

\section{OCN/ONC}

The cyanato and fulminato ligands also have three available bridging modes. Experimentally, when it bonds in an end-on fashion the cyanato ligand tends to bind through the nitrogen atom ${ }^{12}$ and the fulminato ligand tends to bind through the carbon atom. ${ }^{111}$ For all 
of these structures, the usual $\mathrm{D}_{2 \mathrm{~h}}$ or $\mathrm{C}_{2 \mathrm{~h}}$ structure is a local minimum. The singlet states are essentially diradicals, with 0.85 to 1.00 electrons in the lowest virtual orbital (Table 2). For most of these compounds, the singlet state is the lowest in energy. However, the MRMP2 triplet state of $\mathrm{Ti}_{2}(\mu-1,3-\mathrm{ONC})_{2} \mathrm{H}_{4}$ is predicted to be $0.03 \mathrm{kcal} / \mathrm{mol}$ lower in energy than the lowest energy singlet state (Table 3).

Larger basis sets and dynamic electron correlation also affect the isomeric orderings of these ligands. For the cyanato compounds at the MRMP2/TZV(p) level, $\operatorname{Ti}_{2}(\mu-1,1-$ $\mathrm{NCO}_{2} \mathrm{H}_{4}$ is $1.9 \mathrm{kcal} / \mathrm{mol}$ lower in energy than $\mathrm{Ti}_{2}(\mu-1,3-\mathrm{OCN})_{2} \mathrm{H}_{4}$. The inclusion of higher polarization functions also stabilizes $\mathrm{Ti}_{2}(\mu-1,1-\mathrm{NCO})_{2} \mathrm{H}_{4}$ with respect to $\mathrm{Ti}_{2}(\mu-1,3-\mathrm{OCN})_{2} \mathrm{H}_{4}$. At the MRMP2/TZVP(fg) level, the relative energy is $9.6 \mathrm{kcal} / \mathrm{mol} . \mathrm{Ti}_{2}(\mu-1,1-\mathrm{OCN})_{2} \mathrm{H}_{4}$ is predicted to be much higher in energy than either of the other two compounds. For the fulminato compounds, at the MRMP2/TZV(p) level, the $\mathrm{Ti}_{2}(\mu-1,3-\mathrm{ONC})_{2} \mathrm{H}_{4}$ compound is $12.2 \mathrm{kcal} / \mathrm{mol}$ lower in energy than the $\mathrm{Ti}_{2}(\mu-1,1-\mathrm{ONC})_{2} \mathrm{H}_{4}$ compound. Multireference perturbation theory suggests that the $\mu-1,1-\mathrm{CNO}$ and $\mu-1,1-\mathrm{ONC}$ structures have similar energies. The calculations suggest that for this system, the cyanato ligand will bind through the nitrogen atom in an end-on fashion and the fulminato ligand will bind in a linear fashion. Many experimentally observed compounds with fulminato ligands are known to be explosive. ${ }^{111}$ Indeed, the calculations on the compounds in this study show that the fulminato-bridged compounds are over $140 \mathrm{kcal} / \mathrm{mol}$ higher in energy than the cyanatobridged compounds (Table 6), which suggests that the isomerization of these molecules would be highly exothermic. 


\section{SCN}

The thiocyanate ligand also has three possible bridging modes. All three bridging structures have been observed experimentally in metal complexes. ${ }^{113}$ The $\mu-1,3-S C N$ bridging structure has a $\mathrm{C}_{2 \mathrm{~h}}$ local minimum. The bond angles for this compound are quite different from the bond angles for OCN (Table 5). The $\mu-1,1-\mathrm{N}$ bridging mode has a local minimum with $\mathrm{D}_{2 \mathrm{~h}}$ symmetry. However, the compound with the $\mu-1,1-\mathrm{S}$ bridging mode in $\mathrm{D}_{2 h}$ symmetry has one imaginary frequency for the singlet state and two for the triplet state. The lowest energy singlet with $\mathrm{C}_{2 v}$ symmetry is $0.3 \mathrm{kcal} / \mathrm{mol}$ lower in energy than the related $C_{2 h}$ structure and $1.1 \mathrm{kcal} / \mathrm{mol}$ lower in energy than the $D_{2 h}$ structure (Table 6). The molecular orbitals in the active space are formed primarily from the $\mathrm{Ti} \mathrm{d}_{\mathrm{x} 2 \mathrm{-z} 2}$ orbitals, as noted for the SH ligand. At the MRMP2/TZV(p) level, the singlet state is predicted to lie 0.03 $\mathrm{kcal} / \mathrm{mol}$ below the triplet state (Table 3 ). As the basis set size is increased, the singlet is stabilized by a further $0.1 \mathrm{kcal} / \mathrm{mol}$. At the MRMP2/TZVP(fg) level, the $\mu-1,1-\mathrm{NCS}$ bridged structure is predicted to be $1.1 \mathrm{kcal} / \mathrm{mol}$ lower in energy. The $\mu-1,1-\mathrm{SCN}$ bridged structure is predicted to be the highest in energy.

$\underline{N O}$

Nitrosyl is an interesting ligand. Again, this ligand can bridge the titanium atoms in three possible ways. Two of these bridging modes ( $\mu-1,1-\mathrm{NO}$ and $\mu-1,2-\mathrm{NO})$ result in compounds with an electronic structure previously unseen in this study. The third bonding mode $(\mu-1,1-\mathrm{ON})$ has an electronic structure analogous to that described for the hydroxide complex. 
The lowest energy singlet and triplet states for $\mathrm{Ti}_{2}(\mu-1,1-\mathrm{NO})_{2} \mathrm{H}_{4}$ are ${ }^{\mathrm{t}} \mathrm{A}_{\mathrm{g}}$ and ${ }^{3} \mathrm{~B}_{3 \mathrm{u}}$. The frontier molecular orbitals that form these states have $b_{2 u}$ and $b_{1 g}$ symmetry and are shown in Figure 6. Rather than having unpaired electrons on the titanium atoms, this compound has the unpaired electron density mostly on the oxygen atoms. The two active molecular orbitals are principally formed from atomic $p_{y}$ orbitals on the oxygen atoms. There are 0.87 electrons in the lowest virtual orbital, so the molecule is essentially a singlet diradical. At the MRMP2/TZV(p) level of theory, this ground state singlet is $42.8 \mathrm{kcal} / \mathrm{mol}$ lower in energy than the first excited singlet state, which is composed of the normal titanium $\sigma / \sigma^{*}$ orbitals (Table 6$)$. MCSCF $(2,14)$ calculations show that these states do not mix. The lowest energy triplet state is $2.8 \mathrm{kcal} / \mathrm{mol}$ higher in energy than the ground state singlet at the MRMP2/TZV(p) level of theory. When the basis set size is increased, the state with the "normal" titanium $\sigma / \sigma^{*}$ orbitals is predicted to lie approximately $40 \mathrm{kcal} / \mathrm{mol}$ higher in energy than the state created by the oxygen $\mathrm{p}_{\mathrm{y}}$ orbitals. For $\mathrm{Ti}_{2}(\mu-1,2-\mathrm{NO})_{2} \mathrm{H}_{4}$, the lowest energy singlet and triplet states have ${ }^{1} \mathrm{~A}_{\mathrm{g}}$ and ${ }^{3} \mathrm{~B}_{\mathrm{v}}$ symmetry, respectively. The frontier molecular orbitals for these states have $b_{g}$ and $a_{n}$ symmetry and are shown in Figure 7. For this molecule, the unpaired electron density is located primarily on the nitrogen atoms. The two active molecular orbitals are formed from the nitrogen $p_{z}$ orbitals, where the $\mathrm{z}$-axis is the principal axis. At the MRMP2/TZV(p) level of theory, the triplet is predicted to be 0.1 $\mathrm{kcal} / \mathrm{mol}$ lower in energy than the singlet (Table 3).

Of the three bonding modes, the triplet state of $\mathrm{Ti}_{2}(\mu-1,2-\mathrm{NO})_{2} \mathrm{H}_{4}$ is predicted to be the lowest in energy. At the MRMP2/TZV(p) level, $\mathrm{Ti}_{2}(\mu-1,1-\mathrm{NO})_{2} \mathrm{H}_{4}$ and $\mathrm{Ti}_{2}(\mu-1,1-\mathrm{ON})_{2} \mathrm{H}_{4}$ are calculated to lie 14.0 and $96.8 \mathrm{kcal} / \mathrm{mol}$ above $\mathrm{Ti}_{2}(\mu-1,2-\mathrm{NO})_{2} \mathrm{H}_{4}$, respectively. With the 
larger basis set, the MRMP2 level of theory predicts that the $\mathrm{Ti}_{2}(\mu-1,2-\mathrm{NO})_{2} \mathrm{H}_{4}$ triplet structure will be lowest in energy. According to these calculations, the molecule is ferromagnetic and the magnetic susceptibility is predicted to increase as the temperature decreases. The effects of spin-orbit coupling on the singlet-triplet energy gap will be considered below.

$\underline{\mathrm{NO}}_{2}$

The nitrite ion is an electronegative ligand. While this ligand has many possible bonding modes (including $\mu-1,2-\mathrm{ONO}$ and $\mu-1,3-\mathrm{ONO}$ ), the lowest energy local minimum found in this study is shown in Figure 8. The lowest energy singlet and triplet states are ${ }^{1} \mathrm{~A}_{\mathrm{g}}$ and ${ }^{3} B_{31}$, respectively. The frontier molecular orbitals are also shown in Figure 8. As seen in the $\mu-1,2-\mathrm{NO}$ structure, the unpaired electron density is primarily located on the $\mathrm{p}_{\mathrm{y}}$ orbitals of nitrogen, where the titanium atoms lie along the $\mathrm{z}$-axis and the nitrogen atoms lie along the $\mathrm{x}$ axis. The lowest energy singlet state has 0.99 electrons in the lowest virtual orbital, based on a natural orbital occupation analysis of the TCSCF/TZV(p) wave function (Table 2), so it is essentially a singlet diradical. The singlet-triplet splitting is $0.03 \mathrm{kcal} / \mathrm{mol}$ at the MPMP2/TZVP(fg) level of theory (Table 3).

\section{Magnetic Properties}

\section{A. Isotropic Interaction}

The isotropic interaction between the titanium atoms in these dinuclear complexes is proportional to the calculated singlet-triplet energy gap, in the absence of spin-orbit coupling and magnetic dipole-magnetic dipole effects. The isotropic interaction parameters for these compounds are shown in Table 7. As noted earlier, ${ }^{34}$ as the diradical character of the 
dinuclear complex becomes more pronounced and the natural orbital occupation numbers of the HOMO and LUMO approach 1, the ferromagneticity of the complex increases. At the . MRMP2/TZVP(fg) level of theory, the interaction becomes more ferromagnetic ( $\mathrm{J}$ becomes more positive) in the order $\mathrm{Ti}_{2}(\mu-1,1-\mathrm{NO})_{2} \mathrm{H}_{4}<\mathrm{Ti}_{2}(\mu-1,1-\mathrm{CNO})_{2} \mathrm{H}_{4}<\mathrm{Ti}_{2}\left(\mu-1,1-\mathrm{NNN}_{2} \mathrm{H}_{4}<\right.$ $\mathrm{Ti}_{2}(\mu-1,1-\mathrm{NCO})_{2} \mathrm{H}_{4}<\mathrm{Ti}_{2}(\mu-1,1-\mathrm{NCS})_{2} \mathrm{H}_{4}<\mathrm{Ti}_{2}(\mu-1,1-\mathrm{CN})_{2} \mathrm{H}_{4}<\mathrm{Ti}_{2}\left(\mu-1,1-\mathrm{NC}_{2} \mathrm{H}_{4}<\mathrm{Ti}_{2}(\mu-\right.$ $\mathrm{H}_{2} \mathrm{H}_{4}{ }^{29}<\mathrm{Ti}_{2}(\mu-\mathrm{Br})_{2} \mathrm{H}_{4}{ }^{34}<\mathrm{Ti}_{2}(\mu-\mathrm{OH})_{2} \mathrm{H}_{4}<\mathrm{Ti}_{2}(\mu-1,2-\mathrm{CN})_{2} \mathrm{H}_{4}<\mathrm{Ti}_{2}(\mu-\mathrm{SH})_{2} \mathrm{H}_{4}<\mathrm{Ti}_{2}(\mu-1,3-$ $\mathrm{NNN})_{2} \mathrm{H}_{4}<\mathrm{Ti}_{2}(\mu-1,1-\mathrm{OCN})_{2} \mathrm{H}_{4}<\mathrm{Ti}_{2}(\mu-1,1-\mathrm{ONC})_{2} \mathrm{H}_{4}<\mathrm{Ti}_{2}\left(\mu-\mathrm{PH}_{2}\right)_{2} \mathrm{H}_{4}<\mathrm{Ti}_{2}(\mu-\mathrm{Cl})_{2} \mathrm{H}_{4}{ }^{34}<$ $\mathrm{Ti}_{2}(\mu-1,1-\mathrm{ON})_{2} \mathrm{H}_{4}<\mathrm{Ti}_{2}(\mu-1,1-\mathrm{SCN})_{2} \mathrm{H}_{4}<\mathrm{Ti}_{2}\left(\mu-\mathrm{NH}_{2}\right)_{2} \mathrm{H}_{4}<\mathrm{Ti}_{2}(\mu-1,3-\mathrm{SCN})_{2} \mathrm{H}_{4}<\mathrm{Ti}_{2}(\mu-1,3-$ $\mathrm{OCN})_{2} \mathrm{H}_{4}<\mathrm{Ti}_{2}\left(\mu-\mathrm{NO}_{2}\right)_{2} \mathrm{H}_{4}<\mathrm{Ti}_{2}(\mu-1,3-\mathrm{ONC})_{2} \mathrm{H}_{4}<\mathrm{Ti}_{2}\left(\mu-1,2-\mathrm{NO}_{2} \mathrm{H}_{4} \cdot<\mathrm{Ti}_{2}\left(\mu-\mathrm{F}_{2} \mathrm{H}_{4}{ }^{34}\right.\right.$.

For copper compounds, an experimentally-determined linear relationship was found between the isotropic interaction parameter $\mathrm{J}$ and the metal-ligand-metal angle. ${ }^{114}$ However, the homodinuclear titanium compounds examined in this study show no such relationship (Table 8).

\section{B. Spin-Orbit Coupling Calculations}

For the homodinuclear titanium molecules of interest in this study, it is necessary to consider 2 electrons in at least 10 orbitals in order to develop correct descriptions of the excited states. ${ }^{30}$ The Ti-Ti bonding and antibonding interactions of the $\sigma \sigma^{*}, \pi \pi^{*}$, and $\delta \delta^{*}$ type arising from the atomic $\mathrm{d}$ orbitals must be treated. For all molecules except those with $\mathrm{NO}$ and $\mathrm{NO}_{2}$ bridging ligands, an initial state-averaged 2-electron, 10-orbital MCSCF calculation was carried out at the ground state geometry. For $\mathrm{Ti}_{2}(\mu-1,3-\mathrm{ONC})_{2} \mathrm{H}_{4}$, the ground state is predicted to be a triplet based on the TCSCF and MRMP2 calculations reported above, so the ROHF/TZV(p) geometry was used. For the other molecules, the 
calculations were performed at the TCSCF/TZV(p) singlet geometry. The resulting orbitals were used in a second state-averaged 2-electron, 10-orbital MCSCF calculation with no orbital symmetry restraints and with each of the first 20 states weighted equally. These orbitals were used in both the CASSCF spin-orbit coupling (CASSCF-SOC) and MCQDPT spin-orbit coupling (MCQDPT-SOC) calculations.

For most of the homodinuclear titanium molecules considered in this study, the excited states and spin-orbit coupling effects are qualitatively similar to those previously reported for hydride and halide ligands ${ }^{30,34}$ However, the complexes with $\mu-1,1-\mathrm{NO}, \mu-1,2-$ $\mathrm{NO}$, and $\mu-\mathrm{NO}_{2}$ ligands do not follow the customary trends. For the $\mathrm{NO}$ and $\mathrm{NO}_{2}$ bridging ligands, more than 10 orbitals are needed to treat the low-lying excited states. To obtain starting orbitals, modified virtual orbitals were generated by removing six electrons in the usual manner. ${ }^{115}$ For the $\mu-1,1-N O$ case, molecular orbitals formed primarily from atomic $p$ orbitals on the oxygen atoms and antibonding molecular orbitals on NO were used in addition to the Ti d orbitals (see Figure 9). At the CASSCF-SOC level, the primary adiabatic states that mix to form the first spin state are $S_{0}, T_{2}, T_{9}$, and $T_{7}$ (see Table 9). $T_{1}$ is the primary component of spin states 2,3 , and 4 . However, the inclusion of dynamic electron correlation dramatically alters these results. At the MCQDPT-SOC level, the first spin state is produced by a nearly equal mixture of $S_{8}$ and $S_{0}$. The principal adiabatic state that creates spin states 2,3 , and 4 is $T_{6}$. The primary configuration state functions (CSF's) (and their weightings) that contribute to these states are shown in Table 10. In Table 10, the occupancy of the 14 active orbitals (molecular orbitals $39-53$, where orbital 39 is the HOMO) in each CSF is represented by an ordered pair of numbers. A 2 or a 0 indicates that the orbital is 
doubly occupied or unoccupied, respectively. A + or a-indicates that a single electron occupies the orbital. The antisymmetric spin function (for the singlet state) is donoted by a + and $a-$, while the symmetric spin function (for the triplet state) is donoted by ++ .

For $\mathrm{Ti}_{2}(\mu-1,2-\mathrm{NO})_{2} \mathrm{H}_{4}$, the ground state is predicted to be a triplet based on the TCSCF and MRMP2 calculations, so the ROHF/TZV(p) geometry was used. The 14 orbitals used in the SOC calculations are shown in Figure 10. The CASSCF-SOC calculations predict that the first spin state is primarily formed from the $S_{0}$ adiabatic state, while the next three spin states are primarily formed from the $\mathrm{T}_{1}$ adiabatic state (see Table 11). At the MCQDPT-SOC level, the first spin state is composed of adiabatic states $S_{0}, S_{15}, S_{7}$, and $S_{14}$, while the next three spin states are composed of $T_{1}, T_{4}, T_{20}$, and $T_{5}$. The configuration state functions that create these states are shown in Table 12 .

For $\mathrm{Ti}_{2}\left(\mu-\mathrm{NO}_{2}\right)_{2} \mathrm{H}_{4}$, the ground state is predicted to be a triplet based on the TCSCF calculations, so the ROHF/TZV(p) geometry was used. The 16 orbitals used in the SOC calculations are shown in Figure 11 . These include 10 orbitals primarily created from the $\mathrm{Ti}$ d atomic orbitals, two orbitals formed from $\mathrm{N}$ p orbitals, and four antibonding $\mathrm{NO}_{2}$ orbitals. As shown in Table 13, the principal adiabatic states that form the first four spin states are $\mathrm{S}_{0}$ and $\Upsilon_{1}$ for CASSCF-SOC, and $S_{0}$ and $\Upsilon_{7}$ for MCQDPT-SOC. CSF's for these states are shown in Table 14.

The principal axes $\mathrm{X}, \mathrm{Y}$, and $\mathrm{Z}$ for the $\mathrm{T}_{1}$ (lowest energy triplet state) components can then be determined from the coefficients of the eigenvectors. The axial and rhombic pseudodipolar parameters $D_{c}$ and $E_{c}$ can be calculated as discussed previously. ${ }^{30}$ These values are presented in Table 15. In general, the one-electron operator (HSO1) and the 
partial two-electron operator (P2E) track the full two-electron operator (HSO2) closely. The magnitude of the state energies for the lowest singlet and triplet states calculated by HSO1 varies from $\mathrm{HSO} 2$ by up to $2.5 \mathrm{~cm}^{-1}$, but details of the splittings are qualitatively correct. The energies calculated by $\mathrm{P} 2 \mathrm{E}$ are practically the same as those of HSO2, and differ by no more than $0.021 \mathrm{~cm}^{-1}$. In general, the magnitude of $D_{c}$ and $E_{e}$ increases as the spin-orbit coupling operator varies from $\mathrm{HSO} 1$ to $\mathrm{P} 2 \mathrm{E}$ to $\mathrm{HSO} 2$. The magnitude of the zero-field splitting parameters from MCQDPT-SOC calculations is usually larger than the magnitude from CASSCF-SOC calculations. In general, the effect of dynamic correlation on the SOC parameters is much larger than is the effect of the SOC method.

\section{Spin-Orbit Coupling Timings}

The CPU time required for spin-orbit coupling calculations on a Sun UltraSPARC3 $900 \mathrm{MHz}$ processor is reported in Tables 16 and 17. For CASSCF-SOC, the one-electron operator method requires only $2.1-3.5 \%$ of the time needed for a full two-electron calculation. Most of this time is due to the setup routines; the actual integral transformations and spin-orbit coupling calculations with HSO1 take only $4.2-15.6$ seconds for the molecules in this study. The partial two-electron operator calculation requires $46.6-71.6 \%$ of the time for a full two-electron calculation. The average savings is approximately $36 \%$.

Overall, the MCQDPT-SOC method requires more time than the CASSCF-SOC method. The setup for MCQDPT is much more expensive. In addition, the cost of the spinorbit coupling computation increases somewhat, particularly for the HSO2 method. For MCQDPT-SOC, the one-electron operator requires $50 \%$ of the time needed for a full twoelectron operator calculation. When the setup time is not considered, HSO1 requires 2.5 $3.8 \%$ and $\mathrm{P} 2 \mathrm{E}$ requires $43.0-67.9 \%$ of the time required for $\mathrm{HSO} 2$. 


\section{Conclusions}

The influence of multi-atom bridging ligands from groups 14,15 , and 16 of the periodic table on the magnetic properties of homodinuclear titanium complexes has been examined. These compounds are prototypes for many experimentally observed compounds. The compounds studied in this work have a high degree of diradical character, and there is little or no Ti-Ti bonding. Dynamic electron correlation is required for accurate predictions of the singlet-triplet splitting. In contrast to most of the ligands, $\mathrm{NO}^{-}$and $\mathrm{NO}_{2}^{-}$have the unpaired density on the ligands rather than the titanium atoms. The ferromagneticity of the complexes studied in this work is closely related to the natural orbital occupation numbers of the HOMO and LUMO, but is not related to the titanium-ligand-titanium angle. The addition of dynamic correlation via second order perturbation theory greatly increases the mixing of spin states, but there is very little singlet-triplet splitting.

The partial two-electron operator method tracks the full two-electron operator closely in the spin-orbit coupling calculations while dynamic correlation has a very large effect. The zero-field splitting parameters calculated by each operator method are very similar, although the magnitude tends to increase in the order $\mathrm{HSO} 1<\mathrm{P} 2 \mathrm{E}<\mathrm{HSO} 2$. The zero-field splitting parameters from MCQDPT-SOC calculations are slightly larger than those from CASSCFSOC calculations. The time required for MCQDPT-SOC calculations is much greater than CASSCF-SOC calculations. HSO1 requires only 2-3\% of the time required for $\mathrm{HSO} 2$, while P2E requires $50-70 \%$ of the time. 


\section{Acknowledgement}

This work was supported by a grant from the Air Force Office of Scientific Research.

C. M. A. thanks the National Science Foundation for a Predoctoral Fellowship (2000-2003).

\section{References}

(1) Gatteschi, D.; Sessoli, R. J. Magnetism and Magnetic Materials 2004, 272$276,1030$.

(2) Coronado, E.; Forment-Aliaga, A.; Galán-Mascarós, J. R.; Giménez-Saiz, C.; Gómez-García, C. J.; Martinéz-Ferrero, E.; Nuez, A.; Romero, F. M. Solid State Sci. 2003, 5, 917.

(3) Magnetism: Molecules to Materials IV; Miller, J. S.; Drillon, M., Eds.; WLEEY-VCH: Weinheim, 2003.

(4) Miller, J. S.; Epstein, A. J. MRS Bulletin 2000, 25, 21.

(5) Metal-Organic and Organic Molecular Magnets; Day, P.; Underhill, A. E., Eds.; The Royal Society of Chemistry: Cambridge, 1999.

(6) Molecular Magnetism: New Magnetic Materials; Itoh, K.; Kinoshita, M., Eds.; Gordon and Breach: Amsterdam (Kodansha: Tokyo), 2000.

(7) Girerd, J.-J.; Journaux, Y. Molecular Magnetism in Bioinorganic Chemistry. In Physical Methods in Bioinorganic Chemistry; Que Jr., L., Ed.; University Science Books: Saưsalito, CA, 2000; pp 321.

(8) Kahn, O. Molecular Magnetism; VCH: New York, 1993.

(9) Heisenberg, W. Z. Phys. 1928, 49, 619.

(10) Boillot, M.-L.; Journaux, Y:; Bencini, A.; Gatteschi, D.; Kahn, O. Inorg. Chem. 1985, 24, 263. 
(11) Kramers, H. A. Physica 1934, $l, 182$.

(12) Anderson, P. W. Phys. Rev. 1950, 79, 350.

(13) Nesbet, R. K. Ann. Phys. 1958, 4, 87.

(14) Anderson, P. W. Phys. Rev. 1959, 115, 2.

(15) Nesbet, R. K. Phys. Rev. 1960, 119, 658.

(16) Wachters, A. J. H.; Nieuwpoort, W. C. Cryṣtalfield Splitting and Magnetic Interaction in KNiF3. In Selected Topics in Molecular Physics; Clementi, E., Ed.; VerlagChemie: Weinheim, Germany, 1972; pp 135.

(17) Bleaney, B.; Bowers, K. D. Proc. Royal Soc. London A 1952, 214, 451.

(18) Hay, P. J.; Thibeault, J. C.; Hoffmann, R. J. Am. Chem. Soc. 1975, 97, 4884.

(19) Kahn, O.; Briat, B. J. Chem. Soc., Faraday Trans. II 1976, 72, 268.

(20) Kahn, O.; Briat, B. J. Chem. Soc., Faraday Trans. II 1976, 72, 1441.

(21) de Loth, P.; Cassoux, P.; Daudey, J. P.; Malrieu, J. P. 1981.

(22) Illas, F.; Casanovas, J.; García-Bach, M. A.; Caballol, R.; Castell, O. Phys.

Rev. Lett. 1993, 71, 3549.

(23) Pierloot, K.; Van Praet, E.; Vanquickenborne, L. G. J. Phys. Chem. 1993, 97, 12220.

(24) Casanovas, J.; Illas, F. J. Chem. Phys. 1994, 100, 8257.

(25) de Graaf, C.; Illas, F.; Broer, R.; Nieuwpoort, W. C. J. Chem. Phys. 1996, 106,3287 .

(26) Sousa, C.; de Jong, W. A.; Broer, R.; Nieuwpoort, W. C. J. Chem. Phys. 1997, 106,7162 .

(27) de Graaf, C.; Broer, R.; Nieuwpoort, W. C. Chem. Phys. Lett. 1997, 271, 372. 
(28) Moed, M.; Povill, A.; Rubio, J.; Illas, F. J. Phys. Chem. A 1997, 101, 1526.

(29) Webb, S. P.; Gordon, M. S. J. Am. Chem. Soc. 1998, 120, 3846.

(30) Webb, S. P.; Gordon, M. S. J. Chem. Phys. 1998, 109, 919.

(31) de Graaf, C.; de P. R. Moreira, I.; Illas, F.; Martin, R. L. Phys. Rev. B 1999, $60,3457$.

(32) Suaud, N.; Bolvin, H.; Daudey, J. P. Inorg. Chem. 1999, 38, 6089.

(33) de Graaf, C.; Sousa, C.; de P. R. Moreira, I.; Illas, F. J. Phys. Chem. A 2001, $105,11371$.

(34) Aikens, C. M.; Gordon, M. S. J. Phys. Chem. A 2003, 107, 104.

(35) Taratiel, D; Cabrero, J.; de Graaf, C.; Caballol, R. Polyhedron 2003, 22, 2409.

(36) Herebian, D.; Wieghardt, K. E.; Neese, F. J. Am. Chem. Soc. 2003, 125, 10997.

(37) de Graaf, C.; Hozoi, L.; Broer, R. J. Chem. Phys. 2004, 120, 961.

(38) Wang, B.; Chen, Z. Chem. Phys. Lett. 2004, 387, 395.

(39) Muñoz, D.; de Graaf, C.; Illas, F. J. Comp. Chem. 2004, 25, 1234.

(40) Paulovic, J.; Cimpoesu, F.; Ferbinteanu, M.; Hirao, K. J. Am. Chem. Soc. $2004,126,3321$.

(41) Illas, F.; de P. R. Moreira, I.; de Graaf, C.; Barone, V. Theor. Chem. Acc. $2000,104,265$.

(42) Bodner, A.; Jeske, P.; Weyhermueller, T.; Wieghardt, K. E.; Dubler, E; Schmalle, H.; Nuber, B. Inorg. Chem. 1992, 31, 3737.

(43) Jeske, P.; Wieghardt, K. E.; Nuber, B. Inorg. Chem. 1994, 33, 47. 
(44) Lukens Jr., W. W.; Andersen, R. A. Inorg. Chem. 1995, 34, 3440.

(45) Kempe, R.; Spannenberg, A.; Penlecke, N.; Rosenthal, U. Z. Kristallogr. $1998,213,423$.

(46) Carr, S. G.; Boyd, P. D. W.; Smith, T. D. J. Chem. Soc., Dalton Trans. 1972, 1491.

(47) Cookson, D. J.; Smith, T. D.; Pilbrow, J. R. J. Chem. Soc, Dalton Trans. $1974,1396$.

(48) Fieselmann, B. F.; Hendrickson, D. N.; Stucky, G. D. Inorg. Chem. 1978, 17, 1841.

(49) Fieselmann, B. F.; Stucky, G. D. Inorg. Chem. 1978, 17, 2074.

(50) Fieselmann, B. F.; Hendrickson, D. N.; Stucky, G. D. Inorg. Chem. 1978, 17, 2078.

(51) Francesconi, L. C.; Corbin, D. R.; Hendrickson, D. N.; Stucky, G. D. Inorg. Chem. 1979, 18, 3074.

(52) Fachinetti, G.; Biran, C.; Floriani, C.; Villa, A. C.; Guastini, C. J. Chem. Soc., Dalton Trans. 1979, 5.

(53) Corbin, D. R.; Atwood, J. L.; Stucky, G. D. Inorg. Chem. 1986, 25, 98.

(54) Harris, H. A.; Rae, A. D.; Dahl, L. F. J. Am. Chem. Soc. 1987, 109, 4739.

(55) Harris, H. A.; Kanis, D. R.; Dahl, L. F. J. Am. Chem. Soc. 1991, 113, 8602.

(56) Rosenthal, U.; Goerls, H. J. Organomet. Chem. 1992, 439, C36.

(57) Cotton, F. A.; Dikarev, E. V.; Murillo, C. A.; Petrukhina, M. A. Inorg. Chim. Acta 2002, 332, 41. 
(58) Briat, B.; Kahn, O.; Morgenstern-Badarau, I.; Rivoal, J. C. Inorg. Chem. $1981,20,4193$.

(59) Chen, L.; Cotton, F. A.; Dunbar, K. R.; Feng, X.; Heintz, R. A.; Uzelmeir, C. Inorg. Chem. 1996, 35, 7358 .

(60) Bercaw, J. E.; Brintzinger, H. H. J. Am. Chem. Soc. 1969, 91, 7301.

(61) Brintzinger, H. H.; Bercaw, J. E. J. Am. Chem. Soc. 1970, 92, 6182.

(62) Xin, S.; Harrod, J. F.; Samuel, E. J. Am. Chem. Soc. 1994, 116, 11562.

(63) Martin, R. L.; Winter, G. J. Chem. Soc. 1965, 4709.

(64) Canty, A. J.; Coutts, R. S. P.; Wailes, P. C. Aust. J. Chem. 1968, 21, 807.

(65) Coutts, R. S. P.; Wailes, P. C.; Martin, R. L. J. Organomet. Chem. 1973, 47, 375.

(66) Jungst, R.; Sekutowski, D.; Davis, J.; Luly, M.; Stucky, G. Inorg. Chem. $1977,16,1645$.

(67) Olthof, G. J. J. Organomet. Chem. 1977, 128, 367.

(68) Perevalova, E. G.; Urazowski, I. F.; I..emenovskii, D. A.; Slovokhotov, Y. L.; Struchkov, Y. T. J. Organomet. Chem. 1985, 289, 319.

(69) Hill, J. E.; Nash, J. M.; Fanwick, P. E.; Rothwell, I. P. Polyhedron 1990, 9, 1617.

(70) Sobota, P.; Ejfler, J.; Utko, J.; Lis, T. J. Organomet. Chem. 1991, 410, 149.

(71) Cotton, F. A.; Wojtczak, W. A. Gazz. Chim. Ital. 1993, 123, 499.

(72) Yu, P.; Murphy, E. F.; Roesky, H. W.; Lubini, P.; Schmidt, H.-G.;

Noltemeyer, M. Organomet. 1997, 16, 313.

(73) Hao, S.; Feghali, K.; Gambarotta, S. Inorg. Chem. 1997, 36, 1745. 
(74) Smith, S. B.; Stephan, D. W. In Comprehensive Coordination Chemistry II;

McCleverty, J. A., Meyer, T. J., Eds.; Elsevier: Oxford, 2004; Vol. 4; pp 31.

(75) Lappert, M. F.; Sanger, A. R. J. Chem. Soc. A 1971, 874.

(76) Lappert, M. F.; Sanger, A. R. J. Chem. Soc. A 1971, 1314.

(77) Armor, J. N. Inorg. Chem. 1978, 17, 203.

(78) Vroegop, C. T.; Teuben, J. H.; van Bolhuis, F.; van der Linden, J. G. M. J.

Chem. Soc. Chem. Commun. 1983, 550.

(79) Guggenberger, L. J.; Tebbe, F. N. J. Am. Chem. Soc. 1976, 98, 4137.

(80) Samuel, E.; Harrod, J. F.; Gourier, D.; Dromzee, Y.; Robert, F.; Jeannin, Y. Inorg. Chem. 1992, 31, 3252.

(81) Dick, D. G.; Stephan, D. W. Can. J. Chem. 1991, 69, 1146.

(82) Heneken, G.; Weiss, E. Chem. Ber, 1973, 106, 1747.

(83) Thewalt, U.; Schinnerling, P. J. Organomet. Chem. 1991, 418, 191.

(84) Fink, K.; Fink, R.; Staemmler, V. Inorg. Chem. 1994, 33, 6219.

(85) Kolczewski, C.; Fink, K.; Staemmler, V. Int. J. Quant. Chem. 2000, 76, 137.

(86) Ren, Q.; Chen, Z.; Ren, J.; Wei, H.; Feng, W.; Zhang, L. J. Phys. Chem. A $2002,106,6161$.

(87) Wachters, A. J. H. J. Chem. Phys. 1970, 52, 1033.

(88) Hood, D. M.; Pitzer, R. M.; Schaefer III, H. F. J. Chem. Phys. 1979, 7I, 705.

(89) Rappe, A. K.; Smedley, T. A.; Goddard III, W. A. J. Phys. Chem. 1981, 85, 2607.

(90) Dunning, T. H.; Hay, P. J. In Methods of Electronic Structure Theory; Schaefer III, H. F., Ed.; Plenum Press: New York, 1977; pp 1. 
(91) Dunning, T. H. J. Chem. Phys. 1971, 55, 716.

(92) McLean, A. D.; Chandler, G. S. J. Chem. Phys. 1980, 72, 5639.

(93) Schmidt, M. W.; Baldridge, K. K.; Boatz, J. A.; Elbert, S. T.; Gordon, M. S.; Jensen, J. H.; Koseki, S.; Matsunaga, N.; Gordon, M. S.; Nguyen, K. A.; Su, S.; Windus, T. L.; Dupuis, M.; Montgomery Jr., J. A. J. Comp. Chem. 1993, 14, 1347.

(94) Gordon, M. S.; Schmidt, M. W. J. Mol. Struct. (THEOCHEM) in press.

(95) Webb, S. P.; Gordon, M. S. J. Am. Chem. Soc. 1995, 117, 7197.

(96) Glezakou, V.-A.; Gordon, M. S. J. Phys. Chem. A 1997, 101, 8714.

(97) Hirao, K. Chem. Phys. Lett. 1992, 190, 374.

(98) Hirao, K. Chem. Phys. Lett. 1992, 196, 397.

(99) Hirao, K. Int. J. Quant. Chem. 1992, S26, 517.

(100) Hirao, K. Chem. Phys. Lett. 1993, 201, 59.

(101) Sunberg, K. R; Ruedenberg, K. MCSCF Studies of Chemical Reactions: Natural Reaction Orbitals and Localized Reaction Orbitals. In Quantum Science; Calais, J.L., Goscinski, O., Linderberg, J., Öhrn, Y., Eds.; Plenum: New York, 1976; pp 505.

(102) Cheung, L. M.; Sunberg, K. R.; Ruedenberg, K. J. Quant. Chem. 1979, 16, 1103.

(103) Ruedenberg, K.; Schmidt, M. W.; Gilbert, M. M.; Elbert, S. T. Chem. Phys. $1982,71,41$.

(104) Roos, B. O.; Taylor, P.; Siegbahn, P. E. M. Chem. Phys. 1980, 48, 157.

(105) Fedorov, D. G.; Finley, J. P. Phys. Rev. A 2001, 64, 042502.

(106) Koseki, S.; Gordon, M. S.; Schmidt, M. W.; Matsunaga, N. J. Phys. Chem. $1995,99,12764$. 
(107) Fedorov, D. G.; Gordon, M. S. J. Chem. Phys. 2000, 112, 5611.

(108) Bode, B. M.; Gordon, M. S. J. Mol. Graphics and Modeling 1998, 16, 133.

(109) Comarmond, J.; Plumere, P.; Lehn, J. M.; Agnus, Y.; Louis, R.; Weiss, R.;

Kahn, O. J. Am. Chem. Soc. 1982, 104, 6330.

(110) Sikorav, S.; Bkouche-Waksman, I.; Kahn, O. Inorg. Chem. 1984, 23, 490.

(111) Sharpe, A. G. In Comprehensive Coordination Chemistry; Wilkinson, G., Ed.;

Pergamon Press: Oxford, 1987; Vol. 2; pp 7.

(112) Schönherr, T. Inorg. Chem. 1986, 25, 171.

(113) Vrieze, K.; Van Koten, G. In Comprehensive Coordination Chemistry;

Wilkinson, G., Ed.; Pergamon Press: Oxford, 1987; Vol. 2; pp 189.

(114) Crawford, V. M.; Richardson, H. W.; Wasson, J. R.; Hodgson, D. J.; Hatfield, W. E. Inorg. Chem. 1976, 15, 3175.

(115) Bauschlicher, C. W. J. Chem. Phys. 1980, 72, 880. 
TABLE 1: Mulliken Charges on Ti for the Lowest-Energy Singlet and Triplet States

\begin{tabular}{llll}
\hline molecule & bonding mode & singlet & triplet \\
\hline $\mathrm{Ti}_{2}(\mathrm{OH})_{2} \mathrm{H}_{4}$ & $1,1-\mu-\mathrm{O}$ & 1.10 & 1.11 \\
$\mathrm{Ti}_{2}(\mathrm{SH})_{2} \mathrm{H}_{4}$ & $1,1-\mu-\mathrm{S}$ & 0.87 & 0.88 \\
$\mathrm{Ti}_{2}\left(\mathrm{NH}_{2}\right)_{2} \mathrm{H}_{4}$ & $1,1-\mu-\mathrm{N}$ & 1.06 & 1.06 \\
$\mathrm{Ti}_{2}\left(\mathrm{PH}_{2}\right)_{2} \mathrm{H}_{4}$ & $1,1-\mu-\mathrm{P}$ & 0.79 & 0.79 \\
$\mathrm{Ti}_{2}(\mathrm{NNN})_{2} \mathrm{H}_{4}$ & $1,1-\mu$ & 1.07 & 1.07 \\
$\mathrm{Ti}_{2}(\mathrm{NNN})_{2} \mathrm{H}_{4}$ & $1,3-\mu$ & 0.96 & 0.96 \\
$\mathrm{Ti}_{2}(\mathrm{CN})_{2} \mathrm{H}_{4}$ & $1,1-\mu-\mathrm{C}$ & 1.11 & 1.12 \\
$\mathrm{Ti}_{2}(\mathrm{CN})_{2} \mathrm{H}_{4}$ & $1,1-\mu-\mathrm{N}$ & 1.09 & 1.09 \\
$\mathrm{Ti}_{2}(\mathrm{CN})_{2} \mathrm{H}_{4}$ & $1,2-\mu$ & 1.03 & 1.03 \\
$\mathrm{Ti}_{2}(\mathrm{OCN})_{2} \mathrm{H}_{4}$ & $1,1-\mu-\mathrm{O}$ & 1.14 & 1.14 \\
$\mathrm{Ti}_{2}(\mathrm{OCN})_{2} \mathrm{H}_{4}$ & $1,1-\mu-\mathrm{N}$ & 1.07 & 1.07 \\
$\mathrm{Ti}_{2}(\mathrm{OCN})_{2} \mathrm{H}_{4}$ & $1,3-\mu$ & 1.10 & 1.10 \\
$\mathrm{Ti}_{2}(\mathrm{ONC})_{2} \mathrm{H}_{4}$ & $1,1-\mu-\mathrm{O}$ & 1.07 & 1.07 \\
$\mathrm{Ti}_{2}(\mathrm{ONC})_{2} \mathrm{H}_{4}$ & $1,1-\mu-\mathrm{C}$ & 1.12 & 1.13 \\
$\mathrm{Ti}_{2}(\mathrm{ONC})_{2} \mathrm{H}_{4}$ & $1,3-\mu$ & 1.01 & 1.01 \\
$\mathrm{Ti}_{2}(\mathrm{SCN})_{2} \mathrm{H}_{4}$ & $1,1-\mu-\mathrm{S}$ & 0.87 & 0.87 \\
$\mathrm{Ti}_{2}(\mathrm{SCN})_{2} \mathrm{H}_{4}$ & $1,1-\mu-\mathrm{N}$ & 1.05 & 1.05 \\
$\mathrm{Ti}_{2}(\mathrm{SCN})_{2} \mathrm{H}_{4}$ & $1,3-\mu$ & 0.83 & 0.83 \\
$\mathrm{Ti}_{2}(\mathrm{NO})_{2} \mathrm{H}_{4}$ & $1,1-\mu-\mathrm{N}^{\mathrm{a}}$ & 1.16 & 1.16 \\
$\mathrm{Ti}_{2}(\mathrm{NO})_{2} \mathrm{H}_{4}$ & $1,1-\mu-\mathrm{N}^{\mathrm{b}}$ & 1.00 & 1.00 \\
$\mathrm{Ti}_{2}(\mathrm{NO})_{2} \mathrm{H}_{4}$ & $1,1-\mu-\mathrm{O}$ & 1.08 & 1.08 \\
$\mathrm{Ti}_{2}(\mathrm{NO})_{2} \mathrm{H}_{4}$ & $1,2-\mu$ & 1.09 & 1.09 \\
$\mathrm{Ti}_{2}(\mathrm{NO})_{2} \mathrm{H}_{4}$ & $1,3-\mu-\mathrm{ONO}$ & 1.31 & 1.31 \\
& & & \\
${ }^{\mathrm{a}} \mathrm{b}_{2 u}$ and $\mathrm{b}_{1 \mathrm{~s}}$ frontier molecular orbitals. ${ }^{\circ} \mathrm{a}_{\mathrm{g}}$ and $\mathrm{b}_{1 \mathrm{u}}$ frontier molecular orbitals.
\end{tabular}


TABLE 2: Natural Orbital Occupation Numbers (NOONs) from a Natural Orbital Analysis of the $\operatorname{MCSCF}(2,2)$ Wavefunction HOMO LUMO

\begin{tabular}{|c|c|c|c|c|c|}
\hline molecule & bonding mode & NOON & sym & NOON & sym \\
\hline $\mathrm{Ti}_{2}(\mathrm{OH})_{2} \mathrm{H}_{4}$ & $1,1-\mu-O$ & 1.08 & $a_{g}$ & 0.92 & $b_{1 u}$ \\
\hline $\mathrm{Ti}_{2}(\mathrm{SH})_{2} \mathrm{H}_{4}$ & $1,1-\mu-S$ & 1.04 & $a_{1}$ & 0.96 & $b_{2}$ \\
\hline $\mathrm{Ti}_{2}\left(\mathrm{NH}_{2}\right)_{2} \mathrm{H}_{4}$ & $1,1-\mu-\mathrm{N}$ & 1.02 & $a_{u}$ & 0.98 & $a_{\mathrm{g}}$ \\
\hline $\mathrm{Ti}_{2}\left(\mathrm{PH}_{2}\right)_{2} \mathrm{H}_{4}$ & $1,1-\mu-P$ & 1.05 & $a_{1}$ & 0.95 & $b_{2}$ \\
\hline $\mathrm{Ti}_{2}(\mathrm{NNN})_{2} \mathrm{H}_{4}$ & $1,1-\mu$ & 1.15 & $a_{\mathrm{B}}$ & 0.85 & $b_{1 u}$ \\
\hline $\mathrm{Ti}_{2}(\mathrm{NNN})_{2} \mathrm{H}_{4}$ & $1,3-\mu$ & 1.05 & $\mathrm{a}_{\mathrm{g}}$ & 0.95 & $b_{1 u}$ \\
\hline $\mathrm{Ti}_{2}(\mathrm{CN})_{2} \mathrm{H}_{4}$ & $1,1-\mu-C$ & 1.12 & $a_{\mathrm{g}}$ & 0.88 & $b_{1 u}$ \\
\hline $\mathrm{Ti}_{2}(\mathrm{CN})_{2} \mathrm{H}_{4}$ & $1,1-\mu-N$ & 1.12 & $a_{\mathrm{s}}$ & 0.88 & $\mathrm{~b}_{\mathrm{Iu}}$ \\
\hline $\mathrm{Ti}_{2}(\mathrm{CN})_{2} \mathrm{H}_{4}$ & $1,2-\mu$ & 1.06 & $b_{u}$ & 0.94 & $a_{s}$ \\
\hline $\mathrm{Ti}_{2}(\mathrm{OCN})_{2} \mathrm{H}_{4}$ & $1,1-\mu-O$ & 1.06 & $a_{B}$ & 0.94 & $b_{1 v}$ \\
\hline $\mathrm{Ti}_{2}(\mathrm{OCN})_{2} \mathrm{H}_{4}$ & $1,1-\mu-\mathrm{N}$ & 1.15 & $a_{g}$ & 0.85 & $b_{10}$ \\
\hline $\mathrm{Ti}_{2}(\mathrm{OCN})_{2} \mathrm{H}_{4}$ & $1,3-\mu$ & 1.02 & $\mathrm{a}_{\mathrm{g}}$ & 0.98 & $b_{u}$ \\
\hline $\mathrm{Ti}_{2}(\mathrm{ONC})_{2} \mathrm{H}_{4}$ & $1,1-\mu-O$ & 1.05 & $a_{\mathrm{g}}$ & 0.95 & $b_{t u}$ \\
\hline $\mathrm{Ti}_{2}(\mathrm{ONC})_{2} \mathrm{H}_{4}$ & $1,1-\mu-C$ & 1.13 & $\mathrm{a}_{\mathrm{g}}$ & 0.87 & $b_{1 u}$ \\
\hline $\mathrm{Ti}_{2}(\mathrm{ONC})_{2} \mathrm{H}_{4}$ & $1,3-\mu$ & 1.00 & $a_{B}$ & 1.00 & $b_{n}$ \\
\hline $\mathrm{Ti}_{2}(\mathrm{SCN})_{2} \mathrm{H}_{4}$ & $1,1-\mu-S$ & 1.03 & $a_{1}$ & 0.97 & $b_{2}$ \\
\hline $\mathrm{Ti}_{2}(\mathrm{SCN})_{2} \mathrm{H}_{4}$ & $1,1-\mu-\mathrm{N}$ & 1.13 & $\mathrm{a}_{\mathrm{g}}$ & 0.87 & $b_{\mathrm{su}}$ \\
\hline $\mathrm{Ti}_{2}(\mathrm{SCN})_{2} \mathrm{H}_{4}$ & $1,3-\mu$ & 1.02 & $b_{u}$ & 0.98 & $\mathrm{a}_{\mathrm{g}}$ \\
\hline $\mathrm{Ti}_{2}(\mathrm{NO})_{2} \mathrm{H}_{4}$ & $1,1-\mu-\mathrm{N}^{\mathrm{a}}$ & 1.13 & $b_{2 u}$ & 0.87 & $b_{1 g}$ \\
\hline $\mathrm{Ti}_{2}(\mathrm{NO})_{2} \mathrm{H}_{4}$ & $1,1-\mu-N^{b}$ & 1.05 & $a_{\mathrm{g}}$ & 0.95 & $\mathrm{~b}_{1 \mathrm{u}}$ \\
\hline $\mathrm{Ti}_{2}(\mathrm{NO})_{2} \mathrm{H}_{4}$ & $1,1-\mu-O$ & 1.05 & $a_{\mathrm{g}}$ & 0.95 & $b_{10}$ \\
\hline $\mathrm{Ti}_{2}(\mathrm{NO})_{2} \mathrm{H}_{4}$ & $1,2-\mu$ & 1.03 & $\mathrm{~b}_{\mathrm{g}}$ & 0.97 & $a_{u}$ \\
\hline $\mathrm{Ti}_{2}\left(\mathrm{NO}_{2}\right)_{2} \mathrm{H}_{4}$ & $1,3-\mu-\mathrm{ONO}$ & 1.01 & $\mathrm{~b}_{\mathrm{ig}}$ & 0.99 & $b_{2 u}$ \\
\hline
\end{tabular}

${ }^{a} b_{2 u}$ and $b_{1 g}$ frontier molecular orbitals. ${ }^{b} a_{g}$ and $b_{1 u}$ frontier molecular orbitals. 
TABLE 3: Calculated Singlet-Triplet Energy Gap (E(triplet) - E(singlet)) in $\mathrm{kcal} / \mathrm{mol}$

\begin{tabular}{|c|c|c|c|c|c|c|c|}
\hline molecule & bonding mode & $\begin{array}{c}\mathrm{MCSCF} / \\
\mathrm{TZV}(\mathrm{p})\end{array}$ & $\begin{array}{l}\text { MCSCF/ } \\
\text { TZVP(f) }\end{array}$ & $\begin{array}{l}\mathrm{MCSCF} / \\
\mathrm{TZVP}(\mathrm{fg})\end{array}$ & $\begin{array}{c}\text { MRMP2/ } \\
\text { TZV(p) }\end{array}$ & $\begin{array}{l}\text { MRMP2/ } \\
\text { TZVP(f) }\end{array}$ & $\begin{array}{l}\text { MRMP2/ } \\
\text { TZVP(fg) }\end{array}$ \\
\hline $\mathrm{Ti}_{2}(\mathrm{OH})_{2} \mathrm{H}_{4}$ & $1,1-\mu-O$ & 0.2 & 0.2 & 0.2 & 0.7 & 0.8 & 0.8 \\
\hline $\mathrm{Ti}_{2}(\mathrm{SH})_{2} \mathrm{H}_{4}$ & $1,1-\mu-S$ & 0.01 & 0.3 & 0.3 & 0.2 & 0.5 & 0.5 \\
\hline $\mathrm{Ti}_{2}\left(\mathrm{NH}_{2}\right)_{2} \mathrm{H}_{4}$ & $1,1-\mu-N$ & 0.03 & 0.03 & 0.03 & 0.05 & 0.07 & 0.07 \\
\hline $\mathrm{Ti}_{2}\left(\mathrm{PH}_{2}\right)_{2} \mathrm{H}_{4}$ & $1,1-\mu-P$ & 0.01 & 0.04 & 0.03 & 0.2 & 0.4 & 0.4 \\
\hline $\mathrm{Ti}_{2}(\mathrm{NNN})_{2} \mathrm{H}_{4}$ & $1,1-\mu$ & 1.0 & 1.0 & 0.9 & 3.0 & 3.2 & 3.2 \\
\hline $\mathrm{Ti}_{2}(\mathrm{NNN})_{2} \mathrm{H}_{4}$ & $1,3-\mu$ & 0.2 & 0.07 & 0.08 & 0.6 & 0.5 & 0.5 \\
\hline $\mathrm{Ti}_{2}(\mathrm{CN})_{2} \mathrm{H}_{4}$ & $1,1-\mu-C$ & 0.8 & 0.8 & 0.8 & 2.2 & 2.4 & 2.5 \\
\hline $\mathrm{Ti}_{2}(\mathrm{CN})_{2} \mathrm{H}_{4}$ & $1,1-\mu-N$ & 0.8 & 0.6 & 0.6 & 1.9 & 2.1 & 2.1 \\
\hline $\mathrm{Ti}_{2}(\mathrm{CN})_{2} \mathrm{H}_{4}$ & $1,2-\mu$ & 0.2 & 0.1 & 0.1 & 0.7 & 0.6 & 0.6 \\
\hline $\mathrm{Ti}_{2}(\mathrm{OCN})_{2} \mathrm{H}_{4}$ & $1,1-\mu-O$ & 0.2 & 0.1 & 0.1 & 0.5 & 0.5 & 0.5 \\
\hline $\mathrm{Ti}_{2}(\mathrm{OCN})_{2} \mathrm{H}_{4}$ & $1,1-\mu-N$ & 1.1 & 0.9 & 0.9 & 3.0 & 3.1 & 3.1 \\
\hline $\mathrm{Ti}_{2}(\mathrm{OCN})_{2} \mathrm{H}_{4}$ & $1,3-\mu$ & 0.03 & 0.00 & 0.01 & 0.09 & 0.06 & 0.06 \\
\hline $\mathrm{Ti}_{2}(\mathrm{ONC})_{2} \mathrm{H}_{4}$ & $1,1-\mu-O$ & 0.08 & 0.08 & 0.08 & 0.3 & 0.4 & 0.4 \\
\hline $\mathrm{Ti}_{2}(\mathrm{ONC})_{2} \mathrm{H}_{4}$ & $1,1-\mu-C$ & 0.9 & 1.0 & 1.0 & 3.0 & 3.3 & 3.3 \\
\hline $\mathrm{Ti}_{2}(\mathrm{ONC})_{2} \mathrm{H}_{4}$ & $1,3-\mu$ & -0.01 & -0.01 & -0.01 & -0.03 & -0.03 & -0.03 \\
\hline $\mathrm{Ti}_{2}(\mathrm{SCN})_{2} \mathrm{H}_{4}$ & $1,1-\mu-S$ & -0.02 & 0.02 & 0.02 & 0.03 & 0.1 & 0.1 \\
\hline $\mathrm{Ti}_{2}(\mathrm{SCN})_{2} \mathrm{H}_{4}$ & $1,1-\mu-\mathrm{N}$ & 0.9 & 0.8 & 0.7 & 2.6 & 2.8 & 2.8 \\
\hline $\mathrm{Ti}_{2}(\mathrm{SCN})_{2} \mathrm{H}_{4}$ & $1,3-\mu$ & 0.01 & 0.02 & 0.02 & 0.02 & 0.06 & 0.06 \\
\hline $\mathrm{Ti}_{2}(\mathrm{NO})_{2} \mathrm{H}_{4}$ & $1,1-\mu-\mathrm{N}^{\mathrm{a}}$ & 0.9 & 1.6 & 1.6 & 3.2 & 4.8 & 4.7 \\
\hline $\mathrm{Ti}_{2}(\mathrm{NO})_{2} \mathrm{H}_{4}$ & $1,1-\mu-\mathrm{N}^{\mathrm{b}}$ & 0.06 & 0.06 & 0.06 & 0.3 & 0.3 & 0.3 \\
\hline $\mathrm{Ti}_{2}(\mathrm{NO})_{2} \mathrm{H}_{4}$ & $1,1-\mu-O$ & 0.06 & 0.04 & 0.04 & 0.2 & 0.2 & 0.2 \\
\hline $\mathrm{Ti}_{2}(\mathrm{NO})_{2} \mathrm{H}_{4}$ & $1,2-\mu$ & -0.05 & -0.1 & -0.1 & -0.1 & -0.2 & -0.2 \\
\hline $\mathrm{Ti}_{2}\left(\mathrm{NO}_{2}\right)_{2} \mathrm{H}_{4}$ & $1,3-\mu$-ONO & -0.02 & -0.03 & -0.03 & 0.02 & 0.04 & 0.03 \\
\hline
\end{tabular}


TABLE 4: Relative MRMP2/TZV(p) Energies (kcal/mol) for Ligands without Local Minimum $D_{2 h} \sigma, \sigma^{*}$ Structure

\begin{tabular}{ccc}
\hline Ligand/Structure & \multicolumn{2}{c}{ State } \\
\hline$\mu-\mathrm{SH}$ & singlet & triplet \\
$\mathrm{D}_{2 \mathrm{~b}}$ & 2.3 & 2.3 \\
$\mathrm{C}_{2 \mathrm{~b}}$ & 1.1 & 1.1 \\
$\mathrm{C}_{2 \mathrm{r}}$ & 0.0 & 0.2 \\
& & \\
$\mu-\mathrm{NH}_{2}$ & singlet & triplet \\
$\mathrm{D}_{2 \mathrm{~b}} \sigma, \sigma^{*}$ & 5.7 & 7.8 \\
$\mathrm{D}_{2 \mathrm{~h}} \delta, \delta^{*}$ & 0.3 & 0.4 \\
$\mathrm{C}_{2 \mathrm{~b}}$ & 0.0 & 0.05 \\
$\mu-\mathrm{PH}_{2}$ & singlet & triplet \\
$\mathrm{D}_{2 \mathrm{~b}}$ & 1.0 & 1.2 \\
$\mathrm{C}_{2 \mathrm{r}}$ & 0.0 & 0.2 \\
& & \\
$1,1-\mu-\mathrm{SCN}$ & singlet & triplet \\
$\mathrm{D}_{2 \mathrm{~b}}$ & 2.2 & 2.2 \\
$\mathrm{C}_{2 \mathrm{~h}}$ & 0.8 & 0.7 \\
$\mathrm{C}_{2 \mathrm{r}}$ & 0.0 & 0.03
\end{tabular}



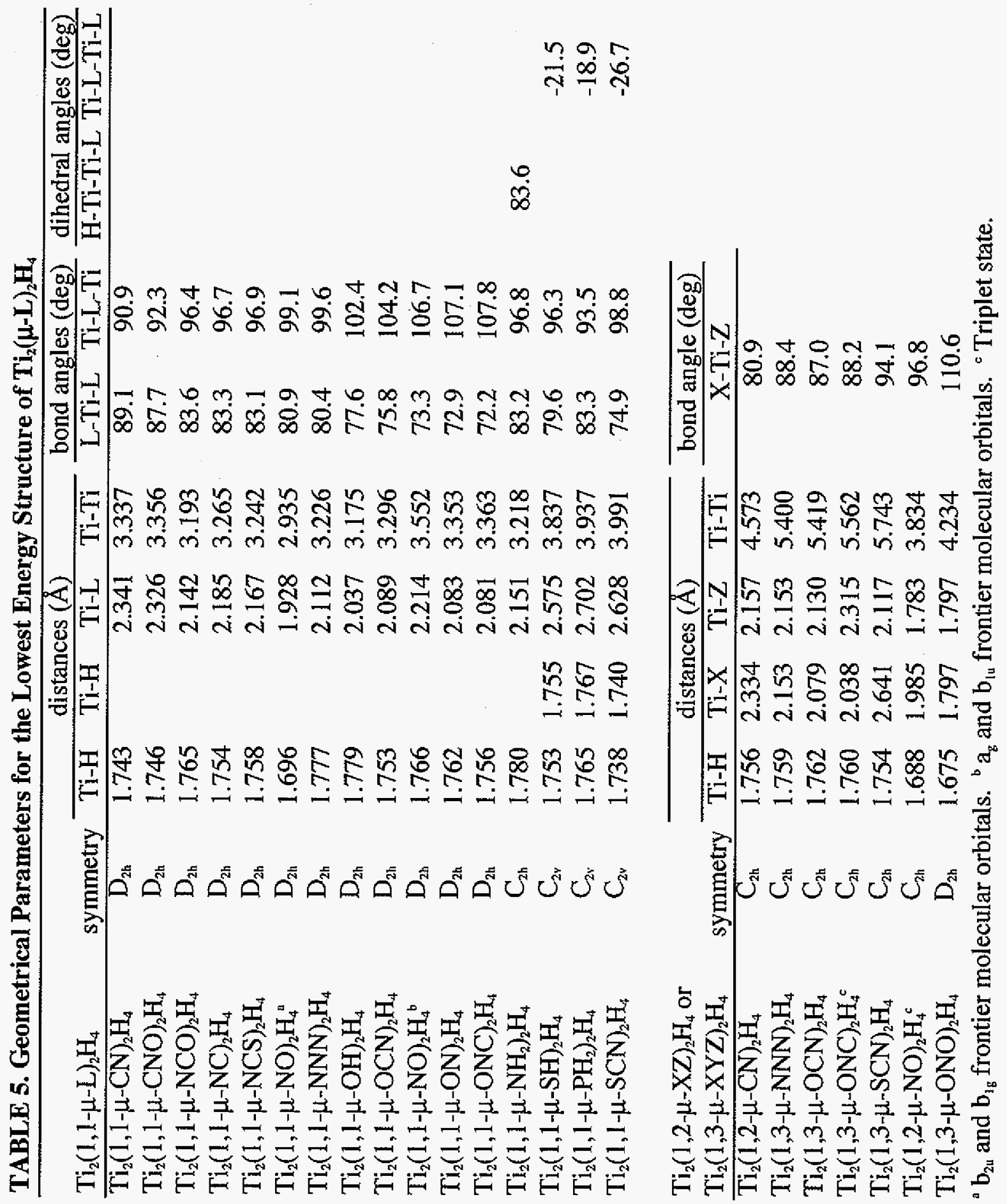
TABLE 6: Relative Energies (kcal/mol) for Lowest-Energy Singlet and Triplet States

\begin{tabular}{|c|c|c|c|c|c|c|}
\hline \multirow[b]{2}{*}{ compound } & \multicolumn{3}{|c|}{ singlet } & \multicolumn{3}{|c|}{ triplet } \\
\hline & $\begin{array}{c}\text { MRMP2/ } \\
\text { TZV(p) }\end{array}$ & $\begin{array}{l}\text { MRMP2/ } \\
\text { TZVP(f) }\end{array}$ & $\begin{array}{l}\text { MRMP2/ } \\
\text { TZVP(fg) }\end{array}$ & $\begin{array}{c}\text { MRMP2/ } \\
\text { TZV(p) }\end{array}$ & $\begin{array}{c}\text { MRMP2/ } \\
\text { TZVP(f) }\end{array}$ & $\begin{array}{l}\text { MRMP2/ } \\
\text { TZVP(fg) }\end{array}$ \\
\hline$\overline{\mathrm{H}_{2} \mathrm{Ti}(1,1-\mu-\mathrm{NNN})_{2} \mathrm{TiH}_{2}}$ & 0.0 & 0.0 & 0.0 & 3.0 & 3.2 & 3.2 \\
\hline $\mathrm{H}_{2} \mathrm{Ti}(1,3-\mu-\mathrm{NNN})_{2} \mathrm{TiH}_{2}$ & 5.1 & 1.1 & 1.7 & 5.7 & 1.6 & 2.2 \\
\hline $\mathrm{H}_{2} \mathrm{Ti}(1,1-\mu-\mathrm{CN})_{2} \mathrm{TiH}_{2}$ & 30.3 & 30.7 & 30.5 & 32.5 & 33.1 & 33.0 \\
\hline $\mathrm{H}_{2} \mathrm{Ti}(1,1-\mu-\mathrm{NC})_{2} \mathrm{TiH}_{2}$ & 17.3 & 18.9 & 18.4 & 19.2 & 20.9 & 20.4 \\
\hline $\mathrm{H}_{2} \mathrm{Ti}(1,2-\mu-\mathrm{CN})_{2} \mathrm{TiH}_{2}$ & 0.0 & 0.0 & 0.0 & 0.7 & 0.6 & 0.6 \\
\hline $\mathrm{H}_{2} \mathrm{Ti}(1,1-\mu-\mathrm{OCN})_{2} \mathrm{TiH}_{2}$ & 26.3 & 49.5 & 49.4 & 26.8 & 50.0 & 49.9 \\
\hline $\mathrm{H}_{2} \mathrm{Ti}(1,1-\mu-\mathrm{NCO})_{2} \mathrm{TiH}_{2}$ & 0.0 & 0.0 & 0.0 & 3.0 & 3.1 & 3.1 \\
\hline $\mathrm{H}_{2} \mathrm{Ti}(1,3-\mu-\mathrm{OCN})_{2} \mathrm{TiH}_{2}$ & 1.9 & 9.3 & 9.6 & 2.0 & 9.3 & 9.7 \\
\hline $\mathrm{H}_{2} \mathrm{Ti}(1,1-\mu-\mathrm{ONC})_{2} \mathrm{TiH}_{2}$ & 152.2 & 178.6 & 178.4 & 152.6 & 179.0 & 178.7 \\
\hline $\mathrm{H}_{2} \mathrm{Ti}(1,1-\mu-\mathrm{CNO})_{2} \mathrm{TiH}_{2}$ & 170.7 & 176.6 & 177.0 & 173.7 & 179.9 & 180.3 \\
\hline $\mathrm{H}_{2} \mathrm{Ti}(1,1-\mu-\mathrm{ONC})_{2} \mathrm{TiH}_{2}$ & 140.0 & 157.5 & 157.8 & 140.0 & 157.4 & 157.8 \\
\hline $\mathrm{H}_{2} \mathrm{Ti}(1,1-\mu-\mathrm{SCN})_{2} \mathrm{TiH}_{2}$ & 47.4 & 46.7 & 47.1 & 47.5 & 46.8 & 47.2 \\
\hline $\mathrm{H}_{2} \mathrm{Ti}(1,1-\mu-\mathrm{NCS})_{2} \mathrm{TiH}_{2}$ & 2.7 & 0.0 & 0.0 & 5.3 & 2.8 & 2.8 \\
\hline $\mathrm{H}_{2} \mathrm{Ti}(1,3-\mu-\mathrm{SCN})_{2} \mathrm{TiH}_{2}$ & 0.0 & 0.7 & 1.1 & 0.0 & 0.7 & 1.1 \\
\hline $\mathrm{H}_{2} \mathrm{Ti}(1,1-\mu-\mathrm{NO})_{2} \mathrm{TiH}_{2}{ }^{\mathrm{n}}$ & 14.0 & 13.0 & 13.3 & 17.2 & 17.8 & 18.1 \\
\hline $\mathrm{H}_{2} \mathrm{Ti}(1,1-\mu-\mathrm{NO})_{2} \mathrm{TiH}_{2}{ }^{\mathrm{b}}$ & 56.8 & 55.0 & 57.3 & 57.1 & 55.3 & 57.6 \\
\hline $\mathrm{H}_{2} \mathrm{Ti}(1,1-\mu-\mathrm{ON})_{2} \mathrm{TiH}_{2}$ & 96.8 & 111.5 & 113.6 & 97.0 & 111.8 & 113.8 \\
\hline $\mathrm{H}_{2} \mathrm{Ti}(1,2-\mu-\mathrm{NO})_{2} \mathrm{TiH}_{2}$ & 0.1 & 0.2 & 0.2 & 0.0 & 0.0 & 0.0 \\
\hline
\end{tabular}

${ }^{\mathrm{a}} \mathrm{b}_{\mathrm{z} u}$ and $\mathrm{b}_{\mathrm{sg}}$ frontier molecular orbitals. ${ }^{\mathrm{b}} \mathrm{a}_{\mathrm{g}}$ and $\mathrm{b}_{\mathrm{tu}}$ frontier molecular orbitals. 
TABLE 7: Isotropic Interaction Parameter J $\left(\mathrm{cm}^{-1}\right)$

\begin{tabular}{|c|c|c|c|c|c|c|c|}
\hline molecule & bonding mode & $\begin{array}{l}\mathrm{MCSCF} / \\
\mathrm{TZV}(\mathrm{p})\end{array}$ & $\begin{array}{l}\text { MCSCF/ } \\
\operatorname{TZVP(f)} \\
\end{array}$ & $\begin{array}{l}\text { MCSCF/ } \\
\text { TZVP(fg) }\end{array}$ & $\begin{array}{c}\text { MRMP2/ } \\
\text { TZV(p) }\end{array}$ & $\begin{array}{l}\text { MRMP2/ } \\
\text { TZVP(f) }\end{array}$ & $\begin{array}{l}\text { MRMP2/ } \\
\text { TZVP(fg) }\end{array}$ \\
\hline $\mathrm{Ti}_{2}(\mathrm{OH})_{2} \mathrm{H}_{4}$ & $1,1-\mu-\mathrm{O}$ & -40 & -43 & -41 & -118 & -137 & -135 \\
\hline $\mathrm{Ti}_{2}(\mathrm{SH})_{2} \mathrm{H}_{4}$ & $1,1-\mu-S$ & -1 & -47 & -47 & -32 & -87 & -87 \\
\hline $\mathrm{Ti}_{2}\left(\mathrm{NH}_{2}\right)_{2} \mathrm{H}_{4}$ & $1,1-\mu-N$ & -5 & -5 & -6 & -8 & -12 & -12 \\
\hline $\mathrm{Ti}_{2}\left(\mathrm{PH}_{2}\right)_{2} \mathrm{H}_{4}$ & $1,1-\mu-P$ & -2 & -6 & -6 & -34 & -62 & -62 \\
\hline $\mathrm{Ti}_{2}(\mathrm{NNN})_{2} \mathrm{H}_{4}$ & $1,1-\mu$ & -183 & -166 & -164 & -526 & -566 & -566 \\
\hline $\mathrm{Ti}_{2}(\mathrm{NNN})_{2} \mathrm{H}_{4}$ & $1,3-\mu$ & -34 & -13 & -13 & -103 & -84 & -86 \\
\hline $\mathrm{Ti}_{2}(\mathrm{CN})_{2} \mathrm{H}_{4}$ & $1,1-\mu-C$ & -146 & -133 & -133 & -391 & -425 & -430 \\
\hline $\mathrm{Ti}_{2}(\mathrm{CN})_{2} \mathrm{H}_{4}$ & $1,1-\mu-N$ & -142 & -99 & -98 & -337 & -359 & -362 \\
\hline $\mathrm{Ti}_{2}(\mathrm{CN})_{2} \mathrm{H}_{4}$ & $1,2-\mu$ & -40 & -21 & -21 & -115 & -108 & -110 \\
\hline $\mathrm{Ti}_{2}(\mathrm{OCN})_{2} \mathrm{H}_{4}$ & $1,1-\mu-O$ & -29 & -17 & -17 & -88 & -84 & -85 \\
\hline $\mathrm{Ti}_{2}(\mathrm{OCN})_{2} \mathrm{H}_{4}$ & $1,1-\mu-\mathrm{N}$ & -198 & -162 & -160 & -518 & -546 & -547 \\
\hline $\mathrm{Ti}_{2}(\mathrm{OCN})_{2} \mathrm{H}_{4}$ & $1,3-\mu$ & -6 & -1 & -1 & -16 & -10 & -10 \\
\hline $\mathrm{Ti}_{2}(\mathrm{ONC})_{2} \mathrm{H}_{4}$ & $1,1-\mu-O$ & -13 & -14 & -14 & -55 & -62 & -63 \\
\hline $\mathrm{Ti}_{2}\left(\mathrm{ONC}_{2} \mathrm{H}_{4}\right.$ & $1,1-\mu-C$ & -163 & -175 & -175 & -528 & -575 & -581 \\
\hline $\mathrm{Ti}_{2}(\mathrm{ONC})_{2} \mathrm{H}_{4}$ & $1,3-\mu$ & 2 & 2 & 2 & 5 & 5 & 5 \\
\hline $\mathrm{Ti}_{2}(\mathrm{SCN})_{2} \mathrm{H}_{4}$ & $1,1-\mu-S$ & $\mathbf{3}$ & -4 & -4 & -6 & -24 & -24 \\
\hline $\mathrm{Ti}_{2}(\mathrm{SCN})_{2} \mathrm{H}_{4}$ & $1,1-\mu-\mathrm{N}$ & -155 & -131 & -130 & -446 & -490 & -492 \\
\hline $\mathrm{Ti}_{2}(\mathrm{SCN})_{2} \mathrm{H}_{4}$ & $1,3-\mu$ & -1 & -3 & -3 & -4 & -11 & -11 \\
\hline $\mathrm{Ti}_{2}(\mathrm{NO})_{2} \mathrm{H}_{4}$ & $1,1-\mu-N^{a}$ & -158 & -276 & -276 & -558 & -831 & -828 \\
\hline $\mathrm{Ti}_{2}(\mathrm{NO})_{2} \mathrm{H}_{4}$ & $1,1-\mu-N^{b}$ & -11 & -10 & -10 & -49 & -57 & -57 \\
\hline $\mathrm{Ti}_{2}(\mathrm{NO})_{2} \mathrm{H}_{4}$ & $1,1-\mu-O$ & -11 & -7 & -6 & -35 & -42 & -42 \\
\hline $\mathrm{Ti}_{2}(\mathrm{NO})_{2} \mathrm{H}_{4}$ & $1,2-\mu$ & 8 & 24 & 24 & 26 & 34 & 35 \\
\hline $\mathrm{Ti}_{2}\left(\mathrm{NO}_{2}\right)_{2} \mathrm{H}_{4}$ & $1,3-\mu$-ONO & 4 & 5 & 5 & -3 & -6 & -6 \\
\hline
\end{tabular}

${ }^{a} b_{2 u}$ and $b_{1 \mathrm{f}}$ frontier molecular orbitals. ${ }^{\mathrm{b}} \mathrm{a}_{\mathrm{q}}$ and $\mathrm{b}_{\mathrm{lu}}$ frontier molecular orbitals. 
TABLE 8: Comparison of Metal-Ligand-Metal Angle and Isotropic Interaction Parameters for $\mathbf{D}_{2 \mathrm{~b}}$ Structures at the TCSCF/TZV(p) Level of Theory

\begin{tabular}{lcc}
\hline & Ti-L-Ti angle & $\mathrm{J}\left(\mathrm{cm}^{-1}\right)$ \\
\hline $\mathrm{Ti}_{2}(1,1-\mu-\mathrm{NCO})_{2} \mathrm{H}_{4}$ & 96.4 & -198 \\
$\mathrm{Ti}_{2}(1,1-\mu-\mathrm{NNN})_{2} \mathrm{H}_{4}$ & 99.6 & -183 \\
$\mathrm{Ti}_{2}(1,1-\mu-\mathrm{CNO})_{2} \mathrm{H}_{4}$ & 92.3 & -163 \\
$\mathrm{Ti}_{2}(1,1-\mu-\mathrm{NO})_{2} \mathrm{H}_{4}{ }^{\mathrm{a}}$ & 99.1 & -158 \\
$\mathrm{Ti}_{2}(1,1-\mu-\mathrm{NCS})_{2} \mathrm{H}_{4}$ & 96.9 & -155 \\
$\mathrm{Ti}_{2}(1,1-\mu-\mathrm{CN})_{2} \mathrm{H}_{4}$ & 90.9 & -146 \\
$\mathrm{Ti}_{2}\left(1,1-\mu-\mathrm{NC}_{2} \mathrm{H}_{4}\right.$ & 96.7 & -142 \\
$\mathrm{Ti}_{2}(\mu-\mathrm{H})_{2} \mathrm{H}_{4}^{\mathrm{b}}$ & 103.7 & -98 \\
$\mathrm{Ti}_{2}(\mu-\mathrm{OH})_{2} \mathrm{H}_{4}$ & 102.4 & -40 \\
$\mathrm{Ti}_{2}(1,1-\mu-\mathrm{OCN})_{2} \mathrm{H}_{4}$ & 104.2 & -29 \\
$\mathrm{Ti}_{2}(1,1-\mu-\mathrm{ONC})_{2} \mathrm{H}_{4}$ & 107.8 & -13 \\
$\mathrm{Ti}_{2}(1,1-\mu-\mathrm{ON})_{2} \mathrm{H}_{4}$ & 107.1 & -11 \\
$\mathrm{Ti}_{2}(1,1-\mu-\mathrm{NO})_{2} \mathrm{H}_{4}{ }^{\mathrm{c}}$ & 106.7 & -11 \\
$\mathrm{Ti}_{2}(\mu-\mathrm{Br})_{2} \mathrm{H}_{4}{ }^{\mathrm{c}}$ & 92.5 & -4 \\
$\mathrm{Ti}_{2}(\mu-\mathrm{Cl})_{2} \mathrm{H}_{4}{ }^{\mathrm{d}}$ & 95.7 & 7
\end{tabular}

${ }^{\mathrm{a}} \mathrm{b}_{2 \mathrm{u}}$ and $\mathrm{b}_{\mathrm{ig}}$ frontier molecular orbitals. ${ }^{\mathrm{b}}$ Values from Reference 29.

${ }^{c} a_{8}$ and $b_{14}$ frontier molecular orbitals. ${ }^{~}$ Values from Reference 34. 
TABLE 9: The First Four Spin States Obtained from the 20 Singlet, 20 Triplet SOC Calculation for $\mathrm{Ti}_{2}(\mu-1,1-\mathrm{NO})_{2} \mathrm{H}_{4}$. Adiabatic State Weightings are from the Eigenvectors Resulting from the Diagonalization of the SOC Matrix.

CASSCF-SOC with HSO2 operator

\begin{tabular}{|c|c|c|c|c|}
\hline spin state & $\begin{array}{l}\text { principal } \\
\text { axes }\end{array}$ & $\begin{array}{c}\text { energy relative } \\
\text { to adiabatic } \\
\text { ground state } \\
S_{0}\left(\mathrm{~cm}^{-1}\right)\end{array}$ & $\begin{array}{c}\text { CASSCF } \\
\text { adiabatic state }\end{array}$ & $\begin{array}{l}\text { eigenvector } \\
\text { weighting }\end{array}$ \\
\hline \multirow[t]{4}{*}{1} & & -12 & $\mathrm{~S}_{0}$ & 0.9790 \\
\hline & & & $\mathrm{T}_{2}$ & 0.0206 \\
\hline & & & $\mathrm{T}_{9}$ & 0.0002 \\
\hline & & & $\mathrm{T}_{7}$ & 0.0001 \\
\hline \multirow[t]{4}{*}{2} & $\mathrm{X}$ & 237 & $\mathrm{~T}_{1}$ & 0.9951 \\
\hline & & & $\Gamma_{3}$ & 0.0045 \\
\hline & & & $\mathrm{T}_{6}$ & 0.0002 \\
\hline & & & $\mathrm{T}_{10}$ & 0.0002 \\
\hline \multirow[t]{4}{*}{3} & $\mathrm{Y}$ & 237 & $\mathrm{~T}_{1}$ & 0.9952 \\
\hline & & & $\mathrm{T}_{3}$ & 0.0045 \\
\hline & & & $T_{10}$ & 0.0002 \\
\hline & & & $\mathrm{S}_{6}$ & 0.0001 \\
\hline \multirow[t]{4}{*}{4} & Z & 237 & $\mathrm{~T}_{1}$ & 0.9956 \\
\hline & & & $S_{3}$ & 0.0039 \\
\hline & & & $\mathrm{T}_{6}$ & 0.0002 \\
\hline & & & $\mathrm{S}_{1 \mathrm{t}}$ & 0.0002 \\
\hline \multicolumn{5}{|c|}{ MCQDPT-SOC with HSO2 operator } \\
\hline spin state & $\begin{array}{l}\text { principal } \\
\text { axes }\end{array}$ & $\begin{array}{c}\text { energy relative } \\
\text { to adiabatic } \\
\text { ground state } \\
\mathrm{S}_{0}\left(\mathrm{~cm}^{-1}\right)\end{array}$ & $\begin{array}{c}\text { CASSCF } \\
\text { adiabatic state }\end{array}$ & $\begin{array}{l}\text { eigenvector } \\
\text { weighting }\end{array}$ \\
\hline \multirow[t]{5}{*}{1} & & -2 & $\mathrm{~S}_{8}$ & 0.5436 \\
\hline & & & $\mathrm{S}_{0}$ & 0.4502 \\
\hline & & & $\mathrm{S}_{10}$ & 0.0049 \\
\hline & & & $\mathrm{S}_{2}$ & 0.0013 \\
\hline & & & $\mathrm{T}_{7}$ & 0.0001 \\
\hline \multirow[t]{3}{*}{2} & $\mathrm{Z}$ & 9387 & $\mathrm{~T}_{6}$ & 0.9996 \\
\hline & & & $\mathrm{S}_{4}$ & 0.0002 \\
\hline & & & $\mathrm{S}_{15}$ & 0.0001 \\
\hline \multirow[t]{3}{*}{3} & $\mathrm{Y}$ & 9387 & $\mathrm{~T}_{6}$ & 0.9996 \\
\hline & & & $\mathrm{T}_{5}$ & 0.0002 \\
\hline & & & $\mathrm{T}_{13}$ & 0.0001 \\
\hline \multirow[t]{3}{*}{4} & $X$ & 9388 & $\mathrm{~T}_{6}$ & 0.9997 \\
\hline & & & $\mathrm{T}_{s}$ & 0.0002 \\
\hline & & & $T_{13}$ & 0.0001 \\
\hline
\end{tabular}


TABLE 10: Principal Configuration State Functions in CASSCF Adiabatic States for $\mathrm{Ti}_{2}(\mu-1,1-\mathrm{NO})_{2} \mathrm{H}_{4}$.

\begin{tabular}{crl}
\hline State & Coefficient & Active Orbital Occupancy \\
\hline $\mathrm{S}_{0}$ & & \\
& 0.172679 & 20000000000000 \\
& -0.056019 & $+0000000000-00$ \\
& -0.439273 & 02000000000000 \\
0.509953 & $0+0000000-000$ \\
0.640762 & 00020000000000 \\
& -0.317496 & 00000000002000 \\
$\mathrm{~S}_{8}$ & -0.756819 & 20000000000000 \\
& 0.468181 & $+0000000000-00$ \\
& 0.098792 & 02000000000000 \\
& 0.147722 & $0+00000000-000$ \\
& 0.174700 & 00020000000000 \\
& 0.345678 & 00000020000000 \\
& -0.098964 & 00000000002000 \\
& -0.118790 & 00000000000200 \\
$\mathrm{~T}_{1}$ & & \\
& 0.749618 & $0+0+0000000000$ \\
$\mathrm{~T}_{6}$ & 0.661282 & $000+000000+000$ \\
& -0.692251 & ++000000000000 \\
& 0.449596 & $+000000000+000$ \\
& -0.253080 & $0+000000000+00$ \\
& 0.464420 & $000+00+0000000$ \\
& 0.197247 & $0000000000++00$
\end{tabular}

The occupancy of the 14 active orbitals in the primary CSF's is shown for four CASSCF adiabatic states. A 2 indicates that the orbital is doubly occupied in the CSF. A + or a indicates that a single electron occupies the orbital. 
TABLE 11: The First Four Spin States Obtained from the 20 Singlet, 20 Triplet SOC Calculation for $\mathrm{Ti}_{2}(\mu-1,2-\mathrm{NO})_{2} \mathrm{H}$. Adiabatic State Weightings are from the Eigenvectors Resulting from the Diagonalization of the SOC Matrix. CASSCF-SOC with HSO2 operator

\begin{tabular}{|c|c|c|c|c|}
\hline spin state & $\begin{array}{l}\text { principal } \\
\text { axes }\end{array}$ & $\begin{array}{l}\text { energy relative } \\
\text { to adiabatic } \\
\text { ground state } \\
\mathrm{S}_{0}\left(\mathrm{~cm}^{-1}\right)\end{array}$ & $\begin{array}{c}\text { CASSCF } \\
\text { adiabatic state }\end{array}$ & $\begin{array}{l}\text { eigenvector } \\
\text { weighting }\end{array}$ \\
\hline \multirow[t]{3}{*}{1} & & -2.870 & $\mathrm{~S}_{0}$ & 0.9997 \\
\hline & & & $\mathrm{T}_{2}$ & 0.0002 \\
\hline & & & $\mathrm{T}_{6}$ & 0.0001 \\
\hline \multirow[t]{3}{*}{2} & $\mathrm{Y}$ & 887.082 & $\mathrm{~T}_{1}$ & 0.9997 \\
\hline & & & $\mathrm{T}_{3}$ & 0.0001 \\
\hline & & & $T_{7}$ & 0.0001 \\
\hline \multirow[t]{3}{*}{3} & $\mathrm{X}$ & 887.089 & $T_{1}$ & 0.9997 \\
\hline & & & $\mathrm{S}_{2}$ & 0.0001 \\
\hline & & & $\mathrm{S}_{5}$ & 0.0001 \\
\hline \multirow[t]{3}{*}{4} & $\mathrm{Z}$ & 887.110 & $T_{1}$ & 0.9997 \\
\hline & & & $T_{3}$ & 0.0002 \\
\hline & & & $T_{7}$ & 0.0001 \\
\hline \multicolumn{5}{|c|}{ MCQDPT-SOC with HSO2 operator } \\
\hline & $\begin{array}{c}\text { principal } \\
\text { axes }\end{array}$ & $\begin{array}{l}\text { energy relative } \\
\text { to adiabatic } \\
\text { ground state } \\
\mathrm{S}_{0}\left(\mathrm{~cm}^{-1}\right)\end{array}$ & $\begin{array}{c}\text { CASSCF } \\
\text { adiabatic state } \\
\end{array}$ & $\begin{array}{c}\text { eigenvector } \\
\text { weighting }\end{array}$ \\
\hline \multirow[t]{4}{*}{1} & & -0.730 & $\mathrm{~S}_{0}$ & 0.5106 \\
\hline & & & $S_{15}$ & 0.3281 \\
\hline & & & $S_{7}$ & 0.1425 \\
\hline & & & $S_{14}$ & 0.0179 \\
\hline \multirow[t]{4}{*}{2} & $\mathrm{X}$ & 246.512 & $T_{1}$ & 0.4628 \\
\hline & & & $\mathrm{T}_{4}$ & 0.4238 \\
\hline & & & $\mathrm{T}_{20}$ & 0.109 \\
\hline & & & $\mathrm{T}_{s}$ & 0.0044 \\
\hline \multirow[t]{4}{*}{3} & Y & 246.630 & $\mathrm{~T}_{1}$ & 0.4628 \\
\hline & & & $\mathrm{T}_{4}$ & 0.4238 \\
\hline & & & $\mathrm{T}_{20}$ & 0.109 \\
\hline & & & $\mathrm{T}_{5}$ & 0.0044 \\
\hline \multirow[t]{4}{*}{4} & Z & 246.735 & $\mathrm{~T}_{1}$ & 0.4628 \\
\hline & & & $\mathrm{T}_{4}$ & 0.4238 \\
\hline & & & $\mathrm{T}_{20}$ & 0.109 \\
\hline & & & $\mathrm{T}_{5}$ & 0.0044 \\
\hline
\end{tabular}


TABLE 12: Principal Configuration State Functions in CASSCF Adiabatic States for $\mathrm{Ti}_{2}(\mu-1,2-\mathrm{NO})_{2} \mathrm{H}_{4}$.

\begin{tabular}{crl}
\hline State & Coefficient & Active Orbital Occupancy \\
\hline$S_{0}$ & 0.203232 & 20000000000000 \\
& -0.313720 & $+000-000000000$ \\
0.072045 & $+0000000000-00$ \\
-0.530604 & 02000000000000 \\
0.147667 & $0+00000-000000$ \\
-0.496062 & $0+0000000-0000$ \\
0.472163 & 00002000000000 \\
-0.115934 & $0000+000000-00$ \\
0.101962 & $0000000+0-0000$ \\
-0.239314 & 00000000020000 \\
& \\
& -0.382972 & 20000000000000 \\
0.318757 & $+000-000000000$ \\
& -0.308719 & $+0000000000-00$ \\
-0.460314 & $0+00000-000000$ \\
& -0.238212 & $0+0000000-0000$ \\
& 0.352217 & 00002000000000 \\
& 0.298433 & $0000+000000-00$ \\
& 0.179306 & 00000002000000 \\
& -0.309574 & $0000000+0-0000$ \\
& -0.191792 & 00000000020000 \\
-0.095493 & 00000000000200 \\
& \\
& 0.076820 & 20000000000000 \\
& 0.060769 & $+000-000000000$ \\
& 0.059639 & $+0000000000-00$ \\
0.106808 & 00200000000000 \\
-0.618625 & $00+00000-00000$ \\
& 0.113697 & $00+0000000000-$ \\
0.074314 & $000+00-0000000$ \\
0.593462 & $000+000000-000$ \\
-0.088849 & $000+00000000-0$ \\
-0.280126 & $00000+00-00000$ \\
-0.253416 & $000000+000-000$ \\
-0.054223 & 00000002000000 \\
-0.142897 & 00000000200000 \\
-0.159228 & $00000000+0000-$ \\
0.080294 & 00000000002000 \\
& & \\
& &
\end{tabular}

The occupancy of the 14 active orbitals in the primary CSF's is shown for eight CASSCF adiabatic states. A 2 indicates that the orbital is doubly occupied in the CSF. A + or a-indicates that a single electron occupies the orbital. 
TABLE 12: cont.

\begin{tabular}{|c|c|c|}
\hline State & Coefficient & Active Orbital Occupancy \\
\hline \multicolumn{3}{|l|}{$\mathrm{S}_{15}$} \\
\hline & 0.508497 & 20000000000000 \\
\hline & 0.395347 & $+000-000000000$ \\
\hline & 0.389969 & $+0000000000-00$ \\
\hline & -0.167991 & 02000000000000 \\
\hline & -0.196134 & $0+00000-000000$ \\
\hline & 0.054622 & $0+0000000-0000$ \\
\hline & 0.091912 & $00+00000-00000$ \\
\hline & -0.092015 & $000+000000-000$ \\
\hline & 0.304653 & $0000+000000-00$ \\
\hline & -0.362371 & 00000002000000 \\
\hline & -0.295368 & $0000000+0-0000$ \\
\hline & 0.165713 & 00000000000200 \\
\hline \multicolumn{3}{|l|}{$T_{1}$} \\
\hline & -0.458774 & ++000000000000 \\
\hline & 0.102646 & $+000000+000000$ \\
\hline & -0.280084 & $+00000000+0000$ \\
\hline & -0.636168 & $0+00+000000000$ \\
\hline & 0.156088 & $0+000000000+00$ \\
\hline & -0.186759 & $0000+00+000000$ \\
\hline & 0.474139 & $0000+0000+0000$ \\
\hline & 0.102556 & $000000000+0+00$ \\
\hline \multicolumn{3}{|r|}{ 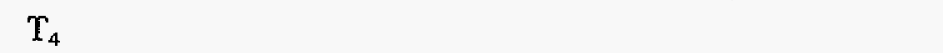 } \\
\hline & 0.524968 & ++000000000000 \\
\hline & -0.234767 & $+000000+000000$ \\
\hline & 0.207394 & $+00000000+0000$ \\
\hline & -0.395514 & $0+00+000000000$ \\
\hline & -0.302571 & $0+000000000+00$ \\
\hline & 0.067400 & $00++0000000000$ \\
\hline & 0.364747 & $0000+00+000000$ \\
\hline & 0.440483 & $0000+0000+0000$ \\
\hline & 0.114145 & $0000000+000+00$ \\
\hline & -0.176248 & $000000000+0+00$ \\
\hline \multicolumn{3}{|r|}{ (2) } \\
\hline & -0.801000 & $00++0000000000$ \\
\hline & 0.306229 & $00+000+0000000$ \\
\hline & -0.067194 & $00+0000000+000$ \\
\hline & -0.068473 & $00+000000000+0$ \\
\hline & 0.376414 & $000+0+00000000$ \\
\hline & 0.125356 & $000+0000+00000$ \\
\hline & 0.223942 & $000+000000000+$ \\
\hline & 0.161946 & $00000++0000000$ \\
\hline & -0.092945 & $000000+000000+$ \\
\hline
\end{tabular}


TABLE 12: (continued)

\begin{tabular}{crl}
\hline State & Coefficient & Active Orbital Occupancy \\
\hline $\mathrm{T}_{20}$ & & \\
& -0.104177 & ++000000000000 \\
-0.739346 & $+000000+000000$ \\
& -0.197710 & $+00000000+0000$ \\
& -0.231158 & $0000+00+000000$ \\
& -0.074468 & $0000+0000+0000$ \\
0.573987 & $0000000+000+00$ \\
& 0.113080 & $000000000+0+00$
\end{tabular}


TABLE 13: The First Four Spin States Obtained from the 20 Singlet, 20 Triplet SOC Calculation for $\mathrm{Ti}_{2}\left(\mu-\mathrm{NO}_{2}\right)_{2} \mathrm{H}_{4}$. Adiabatic State Weightings are from the Eigenvectors Resulting from the Diagonalization of the SOC Matrix. CASSCF-SOC with HSO2 operator

\begin{tabular}{|c|c|c|c|c|}
\hline spin state & $\begin{array}{l}\text { principal } \\
\text { axes }\end{array}$ & $\begin{array}{c}\text { energy relative } \\
\text { to adiabatic } \\
\text { ground state } \\
\mathrm{S}_{0}\left(\mathrm{~cm}^{-1}\right)\end{array}$ & $\begin{array}{c}\text { CASSCF } \\
\text { adiabatic state }\end{array}$ & $\begin{array}{l}\text { eigenvector } \\
\text { weighting }\end{array}$ \\
\hline \multirow[t]{3}{*}{1} & & -4.358 & $\mathrm{~S}_{0}$ & 0.9995 \\
\hline & & & $T_{5}$ & 0.0004 \\
\hline & & & $\mathrm{T}_{8}$ & 0.0001 \\
\hline \multirow[t]{5}{*}{2} & $\mathrm{Y}$ & 1281.284 & $T_{1}$ & 0.9993 \\
\hline & & & $\mathrm{T}_{6}$ & 0.0005 \\
\hline & & & $\mathrm{T}_{3}$ & 0.0001 \\
\hline & & & $T_{7}$ & 0.0001 \\
\hline & & & $\mathrm{S}_{7}$ & 0.0001 \\
\hline \multirow[t]{5}{*}{3} & $\mathrm{X}$ & 1281.292 & $T_{1}$ & 0.9993 \\
\hline & & & $\mathrm{T}_{6}$ & 0.0005 \\
\hline & & & $\mathrm{T}_{3}$ & 0.0001 \\
\hline & & & $T_{9}$ & 0.0001 \\
\hline & & & $S_{10}$ & 0.0001 \\
\hline \multirow[t]{5}{*}{4} & Z & 1281.295 & $\mathrm{~T}_{1}$ & 0.9993 \\
\hline & & & $S_{s}$ & 0.0005 \\
\hline & & & $\mathrm{S}_{2}$ & 0.0001 \\
\hline & & & $T_{7}$ & 0.0001 \\
\hline & & & $\mathrm{T}_{9}$ & 0.0001 \\
\hline \multicolumn{5}{|c|}{ MCQDPT-SOC with HSO2 operator } \\
\hline \multirow[b]{2}{*}{ spin state } & & energy relative & & \\
\hline & $\begin{array}{l}\text { principal } \\
\text { axes }\end{array}$ & $\begin{array}{l}\text { to adiabatic } \\
\text { ground state } \\
\mathrm{S}_{0}\left(\mathrm{~cm}^{-1}\right)\end{array}$ & $\begin{array}{c}\text { CASSCF } \\
\text { adiabatic } \\
\text { state }\end{array}$ & $\begin{array}{l}\text { eigenvector } \\
\text { weighting }\end{array}$ \\
\hline \multirow[t]{2}{*}{1} & & -2.862 & $\mathrm{~S}_{0}$ & 0.9998 \\
\hline & & & $T_{5}$ & 0.0001 \\
\hline \multirow[t]{3}{*}{2} & $\mathrm{Z}$ & 1650.370 & $T_{7}$ & 0.9998 \\
\hline & & & $T_{1}$ & 0.0001 \\
\hline & & & $\mathrm{T}_{3}$ & 0.0001 \\
\hline \multirow[t]{3}{*}{3} & $\mathrm{Y}$ & 1650.378 & $\mathrm{~T}_{7}$ & 0.9998 \\
\hline & & & $\mathrm{S}_{2}$ & 0.0001 \\
\hline & & & $T_{1}$ & 0.0001 \\
\hline \multirow[t]{2}{*}{4} & $\mathrm{X}$ & 1651.108 & $\mathrm{~T}_{7}$ & 0.9999 \\
\hline & & & $T_{3}$ & 0.0001 \\
\hline
\end{tabular}


TABLE 14: Principal Configuration State Functions in

CASSCF Adiabatic States for $\mathrm{Ti}_{2}\left(\mu-\mathrm{NO}_{2}\right)_{2} \mathbf{H}_{4}$.

\begin{tabular}{crl}
\hline State & Coefficient & Active Orbital Occupancy \\
\hline $\mathrm{S}_{0}$ & 0.383051 & 2000000000000000 \\
& -0.560557 & $+0000000-0000000$ \\
& -0.063039 & 0200000000000000 \\
& -0.606029 & 0000020000000000 \\
& 0.409274 & 0000000020000000 \\
& & \\
$\mathrm{~T}_{1}$ & 0.654701 & $+0000+0000000000$ \\
& 0.755765 & $00000+00+0000000$ \\
& & \\
$\mathrm{~T}_{7}$ & 0.481309 & ++00000000000000 \\
& -0.397813 & $+0000000000+0000$ \\
& 0.404633 & $0+000000+0000000$ \\
& -0.541849 & $00000+000+000000$ \\
& 0.390828 & $00000000+00+0000$
\end{tabular}

The occupancy of the 16 active orbitals in the primary CSF's is shown for three CASSCF adiabatic states. A 2 indicates that the orbital is doubly occupied in the CSF. A + or aindicates that a single electron occupies the orbital. 
TABLE 15: Spin-Orbit Coupling

\begin{tabular}{|c|c|c|c|c|c|c|c|}
\hline & \multicolumn{3}{|c|}{ CASSCF-SOC/TZV(p) } & \multicolumn{3}{|c|}{ MCQDPT-SOC/TZV(p) } \\
\hline & & HSO1 & P2E & $\mathrm{HSO} 2$ & HSO1 & P2E & $\mathrm{HSO} 2$ \\
\hline \multirow[t]{6}{*}{$\mathrm{Ti}_{2}(\mathrm{OH})_{2} \mathrm{H}_{4}$} & $\mathrm{~s}$ & -12.563 & -13.581 & -13.584 & -11.905 & -13.413 & -13.415 \\
\hline & $\mathrm{T} X$ & 84.555 & 83.399 & 83.412 & 129.866 & 128.280 & 128.292 \\
\hline & $\mathrm{T} Y$ & 84.507 & 83.345 & 83.355 & 129.847 & 128.279 & 128.288 \\
\hline & $\mathrm{T} Z$ & 84.865 & 83.726 & 83.719 & 130.431 & 128.913 & 128.906 \\
\hline & $D_{e}$ & 0.334 & 0.354 & 0.335 & 0.575 & 0.634 & 0.616 \\
\hline & $\mathrm{E}_{\mathrm{c}}$ & 0.024 & 0.027 & 0.029 & 0.010 & 0.001 & 0.002 \\
\hline \multirow[t]{6}{*}{$\mathrm{Ti}_{2}(\mathrm{SH})_{2} \mathrm{H}_{4}$} & $\mathrm{~s}$ & -10.554 & -11.521 & -11.522 & -10.229 & -11.515 & -11.516 \\
\hline & $\mathrm{T} X$ & -4.436 & -5.397 & -5.400 & 8.088 & 6.832 & 6.829 \\
\hline & T $Y$ & -4.475 & -5.439 & -5.437 & 8.030 & 6.759 & 6.761 \\
\hline & $\mathrm{T} Z$ & -4.439 & -5.400 & -5.396 & 8.085 & 6.848 & 6.851 \\
\hline & $D_{e}$ & 0.016 & 0.018 & 0.023 & 0.026 & 0.052 & 0.056 \\
\hline & $E_{c}$ & 0.019 & 0.021 & 0.019 & 0.029 & 0.036 & 0.034 \\
\hline \multirow[t]{6}{*}{$\mathrm{Ti}_{2}\left(\mathrm{NH}_{2}\right)_{2} \mathrm{H}_{4}$} & $\mathrm{~S}$ & -7.831 & -8.486 & -8.488 & -7.454 & -8.413 & -8.414 \\
\hline & $\mathrm{T} X$ & 6.814 & 6.132 & 6.138 & 22.425 & 21.408 & 21.414 \\
\hline & $\mathrm{T} Y$ & 6.816 & 6.135 & 6.142 & 22.413 & 21.390 & 21.397 \\
\hline & $\mathrm{T} Z$ & 6.932 & 6.259 & 6.256 & 22.539 & 21.558 & 21.555 \\
\hline & $\mathrm{D}_{\mathrm{e}}$ & 0.117 & 0.126 & 0.116 & 0.120 & 0.159 & 0.150 \\
\hline & $E_{0}$ & -0.001 & -0.002 & -0.002 & 0.006 & 0.009 & 0.009 \\
\hline \multirow[t]{6}{*}{$\mathrm{Ti}_{2}\left(\mathrm{PH}_{2}\right)_{2} \mathrm{H}_{4}$} & $\mathrm{~S}$ & -11.862 & -12.953 & -12.954 & -12.488 & -14.118 & -14.119 \\
\hline & $\mathrm{T} X$ & -3.208 & -4.280 & -4.284 & 10.070 & 8.497 & 8.494 \\
\hline & $\mathrm{T} Y$ & -3.264 & -4.341 & -4.339 & 9.969 & 8.373 & 8.376 \\
\hline & $\mathrm{T} Z$ & -3.221 & -4.293 & -4.289 & 10.006 & 8.424 & 8.428 \\
\hline & $\mathrm{D}_{\mathrm{c}}$ & 0.015 & 0.018 & 0.023 & -0.013 & -0.011 & -0.007 \\
\hline & $E_{c}$ & 0.028 & 0.031 & 0.028 & 0.051 & 0.062 & 0.059 \\
\hline \multirow[t]{6}{*}{$\mathrm{Ti}_{2}(\mathrm{NNN})_{2} \mathrm{H}_{4} \quad 1,1-\mu$} & $\mathrm{S}$ & -7.402 & -8.058 & -8.058 & -7.225 & -8.020 & -8.021 \\
\hline & $\mathrm{T} X$ & 461.455 & 460.679 & 460.684 & 828.690 & 827.341 & 827.347 \\
\hline & $\mathrm{T} Y$ & 461.412 & 460.632 & 460.634 & 828.648 & 827.253 & 827.255 \\
\hline & T $Z$ & 461.549 & 460.779 & 460.775 & 829.038 & 827.682 & 827.677 \\
\hline & $D_{e}$ & 0.115 & 0.124 & 0.116 & 0.369 & 0.385 & 0.376 \\
\hline & $\mathrm{E}_{\mathrm{c}}$ & 0.022 & 0.023 & 0.025 & 0.021 & 0.044 & 0.046 \\
\hline \multirow[t]{6}{*}{$\mathrm{Ti}_{2}(\mathrm{NNN})_{2} \mathrm{H}_{4} \quad 1,3-\mu$} & $\mathrm{S}$ & -11.649 & -12.601 & -12.601 & -12.457 & -13.903 & -13.903 \\
\hline & $\mathrm{T} X$ & 67.021 & 66.044 & 66.046 & 128.215 & 126.546 & 126.548 \\
\hline & Т $Y$ & 66.993 & 66.013 & 66.014 & 128.122 & 126.450 & 126.451 \\
\hline & $\mathrm{T} Z$ & 67.001 & 66.021 & 66.019 & 128.097 & 126.423 & 126.421 \\
\hline & $\mathrm{D}_{c}$ & -0.006 & -0.008 & -0.011 & -0.072 & -0.075 & -0.078 \\
\hline & $E_{c}$ & 0.014 & 0.015 & 0.016 & 0.046 & 0.048 & 0.049 \\
\hline
\end{tabular}

${ }^{\mathrm{a}} \mathrm{b}_{2 \mathrm{u}}$ and $\mathrm{b}_{1 \mathrm{~g}}$ frontier molecular orbitals. ${ }^{\mathrm{b}} \mathrm{a}_{\mathrm{g}}$ and $\mathrm{b}_{\mathrm{lu}}$ frontier molecular orbitals. 
TABLE 15: (continued)

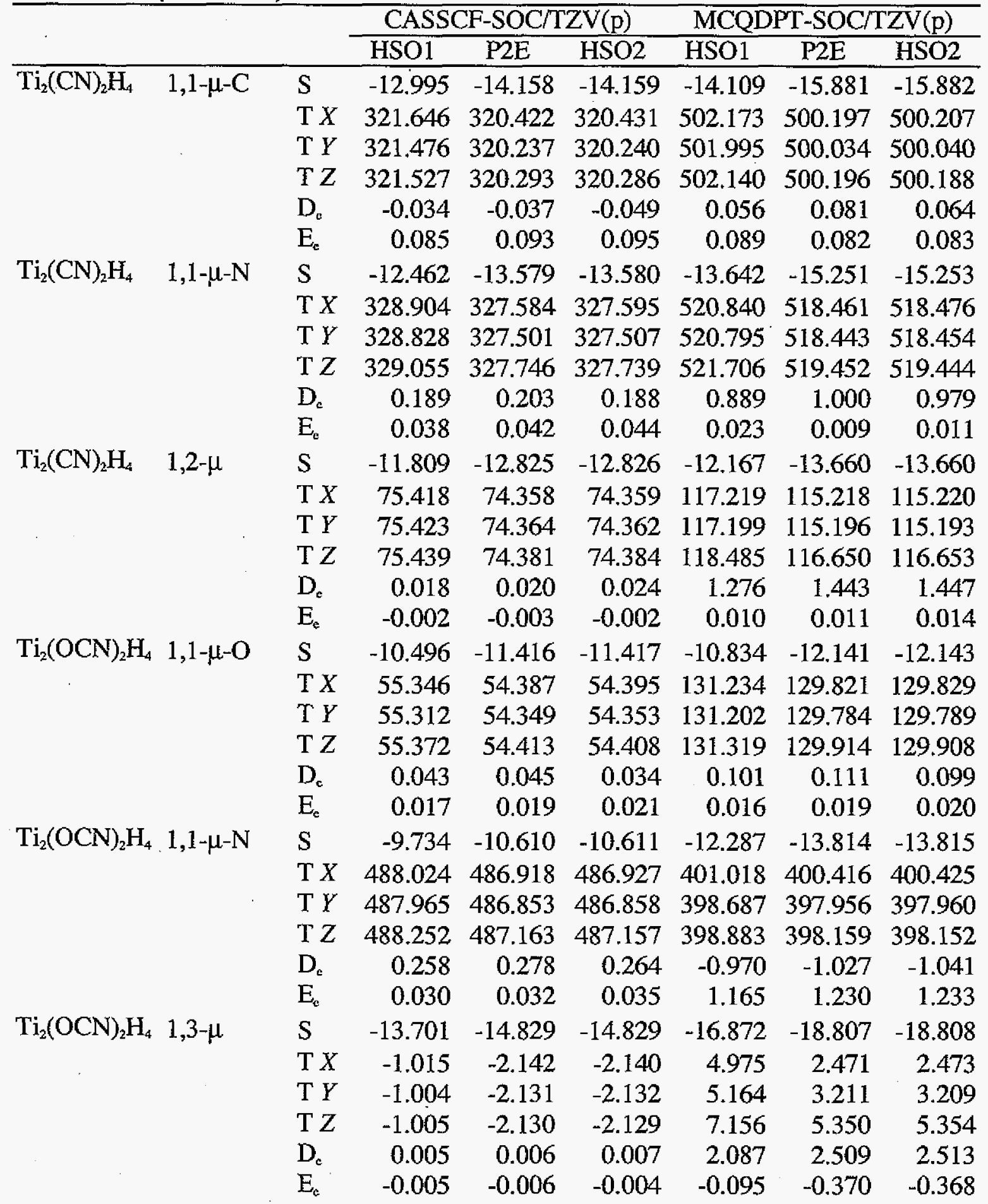


TABLE 15: (continued)

\begin{tabular}{|c|c|c|c|c|c|c|c|}
\hline & & \multicolumn{3}{|c|}{ CASSCF-SOC/TZV(p) } & \multicolumn{3}{|c|}{ MCQDPT-SOC/TZV(p) } \\
\hline & & $\mathrm{HSO} 1$ & P2E & $\mathrm{HSO} 2$ & HSO1 & $\mathrm{P} 2 \mathrm{E}$ & HSO2 \\
\hline \multirow[t]{6}{*}{$\mathrm{Ti}_{2}\left(\mathrm{ONC}_{2} \mathrm{H}_{4} \quad 1,1-\mu-\mathrm{O}\right.$} & $\mathrm{S}$ & -9.700 & -10.545 & -10.547 & -9.542 & -10.683 & -10.684 \\
\hline & $\mathrm{T} X$ & 17.453 & 16.586 & 16.593 & 70.534 & 69.318 & 69.325 \\
\hline & $\mathrm{T} Y$ & 17.425 & 16.555 & 16.559 & 70.518 & 69.318 & 69.323 \\
\hline & $\mathrm{T} Z$ & 17.459 & 16.592 & 16.587 & 70.563 & 69.368 & 69.364 \\
\hline & $\mathrm{D}_{\mathrm{e}}$ & 0.020 & 0.021 & 0.011 & 0.037 & 0.050 & 0.040 \\
\hline & $\mathrm{E}_{\mathrm{c}}$ & 0.014 & 0.015 & 0.017 & 0.008 & 0.000 & 0.001 \\
\hline \multirow[t]{6}{*}{$\mathrm{Ti}_{2}(\mathrm{ONC})_{2} \mathrm{H}_{4} \quad 1,1-\mu-\mathrm{C}$} & $\mathrm{S}$ & -11.744 & -12.792 & -12.792 & -12.287 & -13.814 & -13.815 \\
\hline & $\mathrm{T} X$ & 379.475 & 378.345 & 378.352 & 401.018 & 400.416 & 400.425 \\
\hline & $\mathrm{T} Y$ & 379.338 & 378.195 & 378.198 & 398.687 & 397.956 & 397.960 \\
\hline & $\mathrm{T} Z$ & 379.403 & 378.266 & 378.260 & 398.883 & 398.159 & 398.152 \\
\hline & $D_{c}$ & -0.004 & -0.004 & -0.015 & -0.970 & -1.027 & -1.041 \\
\hline & $\mathrm{E}_{c}$ & 0.069 & 0.075 & 0.077 & 1.165 & 1.230 & 1.233 \\
\hline \multirow[t]{6}{*}{$\mathrm{Ti}_{2}(\mathrm{ONC})_{2} \mathrm{H}_{4} \quad 1,3-\mu$} & $\mathrm{S}$ & -10.414 & -11.322 & -11.322 & -11.883 & -13.484 & -13.484 \\
\hline & $\mathrm{T} X$ & -15.050 & -15.955 & -15.955 & -17.540 & -19.094 & -19.094 \\
\hline & T $Y$ & -15.042 & -15.947 & -15.948 & -17.529 & -19.107 & -19.108 \\
\hline & $\mathrm{T} Z$ & -15.043 & -15.948 & -15.946 & -17.539 & -19.120 & -19.118 \\
\hline & $\mathrm{D}_{\varepsilon}$ & 0.003 & 0.003 & 0.006 & -0.005 & -0.020 & -0.017 \\
\hline & $\mathrm{E}_{*}$ & -0.004 & -0.004 & -0.003 & -0.005 & 0.006 & 0.007 \\
\hline \multirow[t]{6}{*}{$\mathrm{Ti}_{2}(\mathrm{SCN})_{2} \mathrm{H}_{4} \quad 1,1-\mu-\mathrm{S}$} & $\mathrm{S}$ & -10.252 & -11.198 & -11.198 & -10.260 & -11.554 & -11.554 \\
\hline & $\mathrm{T} X$ & -16.854 & -17.796 & -17.799 & -1.767 & -3.059 & -3.062 \\
\hline & $\mathrm{T} Y$ & -16.875 & -17.818 & -17.817 & -1.780 & -3.076 & -3.075 \\
\hline & $\mathrm{T} Z$ & -16.848 & -17.789 & -17.786 & -1.748 & -3.028 & -3.024 \\
\hline & $\mathrm{D}_{\mathrm{c}}$ & 0.017 & 0.018 & 0.022 & 0.026 & 0.040 & 0.045 \\
\hline & $\mathrm{E}_{c}$ & 0.011 & 0.011 & 0.009 & 0.007 & 0.008 & 0.007 \\
\hline \multirow[t]{6}{*}{$\mathrm{Ti}_{2}(\mathrm{SCN})_{2} \mathrm{H}_{4} \quad 1,1-\mu-\mathrm{N}$} & $\mathrm{S}$ & -10.913 & -11.898 & -11.900 & -11.318 & -12.619 & -12.620 \\
\hline & $\mathrm{T} X$ & 370.799 & 369.618 & 369.627 & 634.494 & 632.402 & 632.414 \\
\hline & $\mathrm{T} Y$ & 370.738 & 369.552 & 369.557 & 634.483 & 632.371 & 632.379 \\
\hline & $\mathrm{T} Z$ & 370.950 & 369.780 & 369.774 & 635.265 & 633.240 & 633.233 \\
\hline & $\mathrm{D}_{\mathrm{c}}$ & 0.182 & 0.195 & 0.182 & 0.776 & 0.853 & 0.836 \\
\hline & $E_{c}$ & 0.030 & 0.033 & 0.035 & 0.006 & 0.016 & 0.017 \\
\hline \multirow[t]{6}{*}{$\mathrm{Ti}_{2}(\mathrm{SCN})_{2} \mathrm{H}_{4} \quad 1,3-\mu$} & $\mathrm{S}$ & -9.990 & -10.885 & -10.885 & -9.973 & -11.178 & -11.178 \\
\hline & $T X$ & -8.571 & -9.466 & -9.466 & -1.810 & -3.039 & -3.039 \\
\hline & T $Y$ & -8.562 & -9.455 & -9.456 & -1.786 & -3.013 & -3.014 \\
\hline & $\mathrm{T} Z$ & -8.559 & -9.452 & -9.451 & -1.658 & -2.853 & -2.852 \\
\hline & $\mathrm{D}_{\varepsilon}$ & 0.008 & 0.008 & 0.010 & 0.140 & 0.173 & 0.175 \\
\hline & $\mathrm{E}_{\varepsilon}$ & -0.005 & -0.005 & -0.005 & -0.012 & -0.013 & -0.013 \\
\hline
\end{tabular}


TABLE 15: (continued)

\begin{tabular}{|c|c|c|c|c|c|c|c|c|}
\hline & \multicolumn{3}{|c|}{ CASSCF-SOCTTZV(p) } & \multicolumn{3}{|c|}{ MCQDPT-SOC/TZV(p) } \\
\hline & & & $\mathrm{HSO} 1$ & P2E & $\mathrm{HSO} 2$ & $\mathrm{HSOI}$ & $\mathrm{P} 2 \mathrm{E}$ & $\mathrm{HSO} 2$ \\
\hline \multirow[t]{6}{*}{$\mathrm{Ti}_{2}(\mathrm{NO})_{2} \mathrm{H}_{4}$} & $1,1-\mu-\mathrm{N}^{\mathfrak{a}}$ & $\mathrm{S}$ & -10.529 & -11.705 & -11.710 & -1.362 & -2.193 & -2.193 \\
\hline & & $\mathrm{T} X$ & 237.869 & 237.282 & 237.290 & 9388.05 & 9387.80 & 9387.80 \\
\hline & & $\mathrm{T} Y$ & 237.631 & 237.034 & 237.042 & 9387.54 & 9387.21 & 9387.20 \\
\hline & & $\mathrm{T} Z$ & 237.935 & 237.372 & 237.369 & 9387.38 & 9386.90 & 9386.90 \\
\hline & & $\mathrm{D}_{\mathrm{c}}$ & 0.185 & 0.214 & 0.203 & -0.419 & -0.602 & -0.599 \\
\hline & & $\mathrm{E}_{\mathrm{c}}$ & 0.119 & 0.124 & 0.124 & 0.255 & 0.296 & 0.2965 \\
\hline \multirow[t]{6}{*}{$\mathrm{Ti}_{2}(\mathrm{NO})_{2} \mathrm{H}_{4}$} & $1,1-\mu-\mathrm{N}^{b}$ & $S$ & -13.672 & -14.858 & -14.861 & -22.868 & -25.789 & -25.795 \\
\hline & & $\mathrm{T} X$ & 12.587 & 11.379 & 11.389 & 68.302 & 65.277 & 65.297 \\
\hline & & $\mathrm{T} Y$ & 12.556 & 11.344 & 11.352 & 68.268 & 65.23 & 65.248 \\
\hline & & $\mathrm{T} Z$ & 12.644 & 11.439 & 11.434 & 68.255 & 65.211 & 65.203 \\
\hline & & $\mathrm{D}_{\mathrm{e}}$ & 0.0725 & 0.0775 & 0.0635 & -0.03 & -0.0425 & -0.0695 \\
\hline & & $\mathrm{E}_{\mathrm{e}}$ & 0.0155 & 0.0175 & 0.0185 & 0.017 & 0.0235 & 0.0245 \\
\hline \multirow[t]{6}{*}{$\mathrm{Ti}_{2}(\mathrm{NO})_{2} \mathrm{H}_{4}$} & $1,1-\mu-O$ & $\mathrm{~S}$ & -13.718 & -14.865 & -14.868 & -15.753 & -17.59 & -17.594 \\
\hline & & $\mathrm{T} X$ & 7.204 & 6.012 & 6.024 & 54.265 & 52.184 & 52.199 \\
\hline & & $\mathrm{T} Y$ & 7.176 & 5.982 & 5.991 & 54.227 & 52.138 & 52.151 \\
\hline & & T $Z$ & 7.268 & 6.08 & 6.074 & 54,418 & 52.347 & 52.34 \\
\hline & & $\mathrm{D}_{\mathrm{e}}$ & 0.078 & 0.083 & 0.0665 & 0.172 & 0.186 & 0.165 \\
\hline & & $\mathrm{E}_{\mathrm{e}}$ & 0.014 & 0.015 & 0.0165 & 0.019 & 0.023 & 0.024 \\
\hline \multirow[t]{6}{*}{$\mathrm{Ti}_{2}(\mathrm{NO})_{2} \mathrm{H}_{4}$} & $1,2-\mu$ & $\mathrm{S}$ & -2.692 & -2.87 & -2.87 & -0.684 & -0.73 & -0.73 \\
\hline & & $\mathrm{T} X$ & 887.267 & 887.088 & 887.089 & 246.625 & 246.511 & 246.512 \\
\hline & & $\mathrm{T} Y$ & 887.261 & 887.081 & 887.082 & 246.678 & 246.63 & 246.63 \\
\hline & & $\mathrm{T} Z$ & 887.288 & 887.108 & 887.109 & 246.827 & 246.735 & 246.735 \\
\hline & & $\mathrm{D}_{e}$ & 0.024 & 0.0235 & 0.0235 & 0.1755 & 0.1645 & 0.164 \\
\hline & & $\mathrm{E}_{\mathrm{e}}$ & 0.003 & 0.0035 & 0.0035 & -0.0265 & -0.0595 & -0.059 \\
\hline \multirow[t]{6}{*}{$\mathrm{Ti}_{2}\left(\mathrm{NO}_{2}\right)_{2} \mathrm{H}_{4}$} & $1,3-\mu-\mathrm{ONO}$ & $S$ & -4.102 & -4.357 & -4.358 & -2.539 & -2.861 & -2.862 \\
\hline & & $\mathrm{T} X$ & 1281.62 & 1281.29 & 1281.29 & 1651.12 & 1651.11 & 1651.11 \\
\hline & & $\mathrm{T} Y$ & 1281.61 & 1281.28 & 1281.28 & 1650.49 & 1650.38 & 1650.38 \\
\hline & & $\mathrm{T} Z$ & 1281.62 & 1281.3 & 1281.3 & 1650.49 & 1650.37 & 1650.37 \\
\hline & & $\mathrm{D}_{\mathrm{e}}$ & 0.008 & 0.01 & 0.007 & -0.319 & -0.372 & -0.373 \\
\hline & & $\mathrm{E}_{\mathrm{e}}$ & 0.005 & 0.004 & 0.004 & 0.318 & 0.365 & 0.365 \\
\hline
\end{tabular}


TABLE 16: CASSCF-SOC Timings ${ }^{\mathrm{a}}$

\begin{tabular}{|c|c|c|c|c|c|}
\hline \multirow{2}{*}{$\begin{array}{l}\text { molecule } \\
\mathrm{Ti}_{2}(1, \mathrm{l}-\mathrm{H}-\mathrm{OH}), \mathrm{H}_{4}\end{array}$} & method & \multicolumn{4}{|c|}{ total CPU time spin-orbit coupling $\%$ total time $\%$ SOC time ${ }^{b}$} \\
\hline & HSO1 & 47.1 & 4.2 & 2.5 & 0.2 \\
\hline & $\mathrm{P} 2 \mathrm{E}$ & 1340.3 & 1296.7 & 71.6 & 70.9 \\
\hline & $\mathrm{HSO} 2$ & 1871.9 & 1829.0 & 100.0 & 100.0 \\
\hline \multirow[t]{3}{*}{$\mathrm{Ti}_{2}\left(1,1-\mu-\mathrm{SH}_{2} \mathrm{H}_{4}\right.$} & HSO1 & 75.6 & 6.7 & 2.9 & 0.3 \\
\hline & $\mathrm{P} 2 \mathrm{E}$ & 1609.2 & 1534.6 & 62.1 & 60.8 \\
\hline & $\mathrm{HSO} 2$ & 2591.4 & 2522.6 & 100.0 & 100.0 \\
\hline \multirow[t]{3}{*}{$\mathrm{Ti}_{2}\left(\mathrm{I}, 1-\mu-\mathrm{NH}_{2}\right)_{2} \mathrm{H}_{4}$} & HSO1 & 85.4 & 5.0 & 2.7 & 0.2 \\
\hline & P2E & 1910.9 & 1833.8 & 59.5 & 58.5 \\
\hline & $\mathrm{HSO} 2$ & 3212.9 & 3132.6 & 100.0 & 100.0 \\
\hline \multirow{3}{*}{$\mathrm{Ti}_{2}\left(1,1-\mu-\mathrm{PH}_{2}\right)_{2} \mathrm{H}_{4}$} & HSO1 & 94.0 & 7.7 & 2.7 & 0.2 \\
\hline & $\mathrm{P} 2 \mathrm{E}$ & 2025.7 & 1939.2 & 57.6 & 56.6 \\
\hline & $\mathrm{HSO} 2$ & 3515.0 & 3425.7 & 100.0 & 100.0 \\
\hline \multirow{3}{*}{$\mathrm{Ti}_{2}(1 ; 1-\mu-\mathrm{NNN})_{2} \mathrm{H}_{4}$} & $\mathrm{HSO} 1$ & 107.0 & 10.7 & 2.1 & 0.2 \\
\hline & P2E & 3406.5 & 3310.3 & 68.1 & 67.5 \\
\hline & $\mathrm{HSO} 2$ & 5000.2 & 4904.8 & 100.0 & 100.0 \\
\hline \multirow[t]{3}{*}{$\mathrm{Ti}_{2}(\mathrm{I}, 3-\mu-\mathrm{NNN})_{2} \mathrm{H}_{4}$} & HSO1 & 102.9 & 10.7 & 2.2 & 0.2 \\
\hline & $\mathrm{P} 2 \mathrm{E}$ & 3313.0 & 3222.8 & 69.5 & 68.9 \\
\hline & $\mathrm{HSO} 2$ & 4769.4 & 4674.5 & 100.0 & 100.0 \\
\hline \multirow[t]{3}{*}{$\mathrm{Ti}_{2}(1,1-\mu-\mathrm{CN})_{2} \mathrm{H}_{4}$} & $\mathrm{HSO} 1$ & 63.4 & 5.9 & 2.2 & 0.2 \\
\hline & $\mathrm{P} 2 \mathrm{E}$ & 2003.7 & 1944.0 & 68.3 & 67.6 \\
\hline & $\mathrm{HSO} 2$ & 2935.3 & 2877.0 & 100.0 & 100.0 \\
\hline \multirow[t]{3}{*}{$\mathrm{Ti}_{2}(1,1-\mu-\mathrm{NC})_{2} \mathrm{H}_{4}$} & HSO1 & 66.8 & 6.0 & 2.2 & 0.2 \\
\hline & $\mathrm{P} 2 \mathrm{E}$ & 2079.4 & 2019.2 & 67.7 & 67.0 \\
\hline & $\mathrm{HSO} 2$ & 3073.0 & 3012.3 & 100.0 & 100.0 \\
\hline \multirow[t]{3}{*}{$\mathrm{Ti}_{2}(1,2-\mu-\mathrm{CN})_{2} \mathrm{H}_{4}$} & HSO1 & · 99.4 & 5.9 & 3.3 & 0.2 \\
\hline & $\mathrm{P} 2 \mathrm{E}$ & 2010.0 & 1915.4 & 67.2 & 66.1 \\
\hline & $\mathrm{HSO} 2$ & 2990.8 & 2896.4 & 100.0 & 100.0 \\
\hline \multirow{3}{*}{$\mathrm{Ti}_{2}(1,1-\mu-\mathrm{OCN})_{2} \mathrm{H}_{4}$} & HSO1 & 109.8 & 10.7 & 2.1 & 0.2 \\
\hline & $\mathrm{P} 2 \mathrm{E}$ & 3457.5 & 3359.0 & 67.4 & 66.8 \\
\hline & $\mathrm{HSO} 2$ & 5131.9 & 5032.0 & 100.0 & 100.0 \\
\hline \multirow[t]{3}{*}{$\mathrm{Ti}_{2}(1,1-\mu-\mathrm{NCO})_{2} \mathrm{H}_{4}$} & HSO1 & 114.6 & 10.8 & 2.3 & 0.2 \\
\hline & $\mathrm{P} 2 \mathrm{E}$ & 3412.1 & 3314.3 & 67.3 & 66.6 \\
\hline & $\mathrm{HSO} 2$ & 5072.6 & 4975.3 & 100.0 & 100.0 \\
\hline \multirow[t]{3}{*}{$\mathrm{Ti}_{2}(1,3-\mu-\mathrm{OCN})_{2} \mathrm{H}_{4}$} & HSOI & 173.5 & 10.7 & 3.4 & 0.2 \\
\hline & $\mathrm{P} 2 \mathrm{E}$ & 3439.0 & 3276.6 & 68.0 & 66.9 \\
\hline & $\mathrm{HSO} 2$ & 5059.4 & 4897.1 & 100.0 & 100.0 \\
\hline \multirow[t]{3}{*}{$\mathrm{Ti}_{2}(1,1-\mu-\mathrm{ONC})_{2} \mathrm{H}_{4}$} & HSO1 & 110.4 & 10.6 & 2.2 & 0.2 \\
\hline & $\mathrm{P} 2 \mathrm{E}$ & 3473.6 & 3373.4 & 68.1 & 67.5 \\
\hline & $\mathrm{HSO} 2$ & 5098.4 & 4999.7 & 100.0 & 100.0 \\
\hline \multirow[t]{3}{*}{$\mathrm{Ti}_{2}(1,1-\mu-\mathrm{NCO})_{2} \mathrm{H}_{4}$} & $\mathrm{HSO} 1$ & 103.2 & 10.6 & 2.2 & 0.2 \\
\hline & $\mathrm{P} 2 \mathrm{E}$ & 3251.7 & 3159.2 & 68.9 & 68.2 \\
\hline & $\mathrm{HSO} 2$ & 4721.5 & 4629.6 & 100.0 & 100.0 \\
\hline
\end{tabular}

a Timings for a 900-MHz UltraSPARC3 computer. ${ }^{6}$ This category includes the time required for integral transformations and spin-orbit matrix element calculations.

${ }^{c} b_{2 u}$ and $b_{1 \mathrm{~g}}$ frontier molecular orbitals. ${ }^{d} a_{k}$ and $b_{1 u}$ frontier molecular orbitals. 
TABLE 16: (continued)

\begin{tabular}{|c|c|c|c|c|c|}
\hline molecule & method & total CPU time & spin-orbit coupling ${ }^{b}$ & $\%$ total time & \% SOC time $^{\mathrm{b}}$ \\
\hline \multirow[t]{3}{*}{$\mathrm{Ti}_{2}(1,3-\mu-\mathrm{ONC})_{2} \mathrm{H}_{4}$} & HSO1 & 171.8 & 10.6 & 3.5 & 0.2 \\
\hline & $\mathrm{P} 2 \mathrm{E}$ & 3374.0 & 3215.0 & 67.8 & 66.7 \\
\hline & $\mathrm{HSO} 2$ & 4976.6 & 4816.9 & 100.0 & 100.0 \\
\hline \multirow[t]{3}{*}{$\mathrm{Ti}_{2}(1,1-\mu-\mathrm{SCN})_{2} \mathrm{H}_{4}$} & HSO1 & 184.2 & 15.5 & 2.2 & 0.2 \\
\hline & $\mathrm{P} 2 \mathrm{E}$ & 3831.0 & 3661.0 & 46.6 & 45.6 \\
\hline & $\mathrm{HSO} 2$ & 8213.8 & 8034.6 & 100.0 & 100.0 \\
\hline \multirow[t]{3}{*}{$\mathrm{Ti}_{2}(1,1-\mu-\mathrm{NCS})_{2} \mathrm{H}_{4}$} & HSO1 & 133.8 & 15.5 & 1.9 & 0.2 \\
\hline & $\mathrm{P} 2 \mathrm{E}$ & 3943.5 & 3817.6 & 55.2 & 54.4 \\
\hline & $\mathrm{HSO} 2$ & 7141.0 & 7022.9 & 100.0 & 100.0 \\
\hline \multirow[t]{3}{*}{$\mathrm{Ti}_{2}(1,3-\mu-\mathrm{SCN})_{2} \mathrm{H}_{4}$} & HSO1 & 225.9 & 15.6 & 3.3 & 0.2 \\
\hline & P2E & 3910.1 & 3699.4 & 57.4 & 55.8 \\
\hline & $\mathrm{HSO} 2$ & 6816.8 & 6624.7 & 100.0 & 100.0 \\
\hline \multirow[t]{3}{*}{$\mathrm{Ti}_{2}(1,1-\mu-\mathrm{NO})_{2} \mathrm{H}_{4}{ }^{\mathrm{c}}$} & $\mathrm{HSOI}$ & 77.4 & 7.7 & 2.3 & 0.2 \\
\hline & $\mathrm{P} 2 \mathrm{E}$ & 2094.3 & 2024.7 & 61.6 & 60.8 \\
\hline & $\mathrm{HSO} 2$ & 3398.7 & 3328.3 & 100.0 & 100.0 \\
\hline \multirow[t]{3}{*}{$\mathrm{Ti}_{2}\left(1,1-\mu-\mathrm{NO}_{2} \mathrm{H}_{4}{ }^{d}\right.$} & $\mathrm{HSO} 1$ & 73.0 & 7.7 & 2.3 & 0.3 \\
\hline & $\mathrm{P} 2 \mathrm{E}$ & 1960.9 & 1895.2 & 63.0 & 62.2 \\
\hline & $\mathrm{HSO} 2$ & 3114.6 & 3048.5 & 100.0 & 100.0 \\
\hline \multirow[t]{3}{*}{$\mathrm{Ti}_{2}(1,1-\mu-\mathrm{ON})_{2} \mathrm{H}_{4}$} & HSO1 & 61.0 & 6.4 & 2.1 & 0.2 \\
\hline & $\mathrm{P} 2 \mathrm{E}$ & 1991.9 & 1938.5 & 68.6 & 68.0 \\
\hline & $\mathrm{HSO} 2$ & 2902.9 & 2848.8 & 100.0 & 100.0 \\
\hline \multirow[t]{3}{*}{$\mathrm{Ti}_{2}(1,2-\mu-\mathrm{NO})_{2} \mathrm{H}_{4}$} & HSO1 & 121.7 & 7.6 & 3.4 & 0.2 \\
\hline & $\mathrm{P} 2 \mathrm{E}$ & 2115.3 & 2002.7 & 59.6 & 58.3 \\
\hline & $\mathrm{HSO} 2$ & 3550.0 & 3437.8 & 100.0 & 100.0 \\
\hline \multirow[t]{3}{*}{$\mathrm{Ti}_{2}\left(\mu-\mathrm{NO}_{2}\right)_{2} \mathrm{H}_{4}$} & HSO1 & 130.3 & 14.1 & 2.2 & 0.2 \\
\hline & P2E & 3437.4 & 3317.7 & 56.8 & 55.9 \\
\hline & $\mathrm{HSO} 2$ & 6055.4 & 5936.6 & 100.0 & 100.0 \\
\hline
\end{tabular}


TABLE 17: MCQDPT-SOC Timings ${ }^{2}$

\begin{tabular}{|c|c|c|c|c|c|}
\hline \multirow{2}{*}{$\frac{\text { molecule }}{\mathrm{Ti}_{2}(1,1-\mu-\mathrm{OH})_{2} \mathrm{H}_{4}}$} & \multirow{2}{*}{$\frac{\text { method }}{\text { HSO1 }}$} & \multicolumn{4}{|c|}{ total CPU time spin-orbit coupling $\%$ total time \% SOC time $\mathrm{e}^{\mathrm{b}}$} \\
\hline & & 1953.6 & 64.2 & 49.2 & 3.1 \\
\hline & P2E & 3289.0 & 1408.4 & 82.9 & 67.9 \\
\hline & $\mathrm{HSO} 2$ & 3967.7 & 2074.5 & 100.0 & 100.0 \\
\hline \multirow[t]{3}{*}{$\mathrm{Ti}_{2}\left(1, \mathrm{l}-\mu-\mathrm{SH}_{2}\right)_{2} \mathrm{H}_{4}$} & $\mathrm{HSOl}$ & 3030.5 & 94.6 & 55.3 & 3.6 \\
\hline & P2E & 4548.4 & 1667.4 & 83.0 & 64.0 \\
\hline & $\mathrm{HSO} 2$ & 5481.2 & 2606.4 & 100.0 & 100.0 \\
\hline \multirow[t]{3}{*}{$\mathrm{Ti}_{2}\left(1,1-\mu-\mathrm{NH}_{2}\right)_{2} \mathrm{H}_{4}$} & HSO1 & 3082.4 & 92.4 & 50.8 & 2.9 \\
\hline & P2E & 4862.2 & 1949.4 & 80.2 & 60.6 \\
\hline & $\mathrm{HSO} 2$ & 6062.8 & 3218.8 & 100.0 & 100.0 \\
\hline \multirow[t]{3}{*}{$\mathrm{Ti}_{2}\left(1,1-\mu-\mathrm{PH}_{2}\right)_{2} \mathrm{H}_{4}$} & HSO1 & 4035.6 & 120.4 & 55.0 & 3.4 \\
\hline & P2E & 6036.4 & 2121.3 & 82.2 & 59.9 \\
\hline & $\mathrm{HSO} 2$ & 7342.0 & 3538.9 & 100.0 & 100.0 \\
\hline \multirow{3}{*}{$\mathrm{Ti}_{2}\left(1,1-\mu-\mathrm{NNN}_{2} \mathrm{H}_{4}\right.$} & HSO1 & 5256.9 & 163.0 & 45.4 & 2.5 \\
\hline & P2E & 8585.8 & 3489.0 & 74.2 & 53.8 \\
\hline & $\mathrm{HSO} 2$ & 11571.7 & 6486.2 & 100.0 & 100.0 \\
\hline \multirow[t]{3}{*}{$\mathrm{Ti}_{2}(1,3-\mu-\mathrm{NNN})_{2} \mathrm{H}_{4}$} & HSO1 & 5514.1 & 165.3 & 49.7 & 2.7 \\
\hline & P2E & 8399.8 & 3390.7 & 75.7 & 55.8 \\
\hline & $\mathrm{HSO} 2$ & 11091.0 & 6078.9 & 100.0 & 100.0 \\
\hline \multirow[t]{3}{*}{$\mathrm{Ti}_{2}(1,1-\mu-\mathrm{CN})_{2} \mathrm{H}_{4}$} & HSOl & 2802.8 & 92.1 & 46.6 & 2.9 \\
\hline & P2E & 4798.2 & 2094.6 & 79.8 & 65.0 \\
\hline & $\mathrm{HSO} 2$ & 6012.0 & 3221.1 & 100.0 & 100.0 \\
\hline \multirow[t]{3}{*}{$\mathrm{Ti}_{2}(1,1-\mu-N C)_{2} \mathrm{H}_{4}$} & HSOI & 2760.5 & 92.1 & 45.9 & 2.8 \\
\hline & P2E & 4861.0 & 2171.5 & 80.9 & 65.1 \\
\hline & $\mathrm{HSO} 2$ & 6011.0 & 3337.4 & 100.0 & 100.0 \\
\hline \multirow[t]{3}{*}{$\mathrm{Ti}_{2}(1,2-\mathrm{\mu}-\mathrm{CN})_{2} \mathrm{H}_{4}$} & HSOI & 2997.0 & 101.0 & 49.4 & 3.2 \\
\hline & P2E & 4968.1 & 2053.8 & 81.8 & 64.6 \\
\hline & $\mathrm{HSO} 2$ & 6072.3 & 3177.5 & 100.0 & 100.0 \\
\hline \multirow[t]{3}{*}{$\mathrm{Ti}_{2}(1,1-\mu-\mathrm{OCN})_{2} \mathrm{H}_{4}$} & HSO1 & 5683.1 & 164.9 & 46.7 & 2.4 \\
\hline & $\mathrm{P} 2 \mathrm{E}$ & 8821.1 & 3532.4 & 72.4 & 52.1 \\
\hline & $\mathrm{HSO} 2$ & 12180.0 & 6776.2 & 100.0 & 100.0 \\
\hline \multirow[t]{3}{*}{$\mathrm{Ti}_{2}(1,1-\mu-\mathrm{NCO})_{2} \mathrm{H}_{4}$} & HSO1 & 5380.7 & 163.6 & 48.2 & 2.7 \\
\hline & P2E & 8386.7 & 3341.4 & 75.1 & 55.3 \\
\hline & $\mathrm{HSO} 2$ & 11168.4 & 6045.0 & 100.0 & 100.0 \\
\hline \multirow[t]{3}{*}{$\mathrm{Ti}_{2}(1,3-\mu-\mathrm{OCN})_{2} \mathrm{H}_{4}$} & HSOl & 5832.5 & 176.6 & 46.4 & 2.7 \\
\hline & P2E & 9086.1 & 3463.1 & 72.3 & 52.6 \\
\hline & HSO2 & 12569.7 & 6586.3 & 100.0 & 100.0 \\
\hline \multirow[t]{3}{*}{$\mathrm{Ti}_{2}(1,1-\mu-\mathrm{ONC})_{2} \mathrm{H}_{4}$} & HSO1 & 5500.0 & 164.1 & 46.6 & 2.5 \\
\hline & P2E & 8865.8 & 3553.0 & 75.1 & 54.0 \\
\hline & $\mathrm{HSO} 2$ & 11799.5 & 6574.4 & 100.0 & 100.0 \\
\hline \multirow{3}{*}{$\mathrm{Ti}_{2}(1,1-\mu-\mathrm{NCO})_{2} \mathrm{H}_{4}$} & HSOI & 5296.0 & 164.3 & 45.9 & 2.7 \\
\hline & P2E & 8601.9 & 3347.4 & 74.6 & 54.1 \\
\hline & $\mathrm{HSO} 2$ & 11534.2 & 6182.5 & 100.0 & 100.0 \\
\hline
\end{tabular}

${ }^{a}$ Timings for a $900-\mathrm{MHz}$ UltraSPARC3 computer. ${ }^{\mathrm{b}}$ This category includes the time required for integral transformations and spin-orbit matrix element calculations.

${ }^{c} b_{2 u}$ and $b_{1 \mathrm{e}}$ frontier molecular orbitals. ${ }^{\mathrm{a}} \mathrm{a}_{\mathrm{g}}$ and $\mathrm{b}_{\mathrm{ku}}$ frontier molecular orbitals. 
TABLE 17: (continued)

\begin{tabular}{|c|c|c|c|c|c|}
\hline \multirow{2}{*}{$\frac{\text { molecule }}{\mathrm{Ti}_{2}(1,3-\mu-\mathrm{ONC})_{2} \mathrm{H}_{4}}$} & method & \multicolumn{4}{|c|}{ total CPU time spin-orbit coupling $\%$ total time $\%$ SOC time ${ }^{\mathrm{b}}$} \\
\hline & HSO1 & 6161.3 & 177.4 & 50.8 & 2.9 \\
\hline & P2E & 9421.7 & 3388.8 & 77.7 & 54.5 \\
\hline & $\mathrm{HSO} 2$ & 12119.5 & 6216.5 & 100.0 & 100.0 \\
\hline \multirow{3}{*}{$\mathrm{Ti}_{2}(1,1-\mu-\mathrm{SCN})_{2} \mathrm{H}_{4}$} & HSO1 & 9390.9 & 221.9 & 54.0 & 2.7 \\
\hline & $\mathrm{P} 2 \mathrm{E}$ & 12985.5 & 3961.1 & 74.7 & 47.6 \\
\hline & $\mathrm{HSO}_{2}$ & 17374.7 & 8318.0 & 100.0 & 100.0 \\
\hline \multirow[t]{3}{*}{$\mathrm{Ti}_{2}(1,1-\mu-\mathrm{NCS})_{2} \mathrm{H}_{4}$} & HSOI & 7343.0 & 207.2 & 50.3 & 2.8 \\
\hline & $\mathrm{P} 2 \mathrm{E}$ & 11226.6 & 4094.0 & 76.9 & 55.3 \\
\hline & $\mathrm{HSO} 2$ & 14607.0 & 7403.4 & 100.0 & 100.0 \\
\hline \multirow[t]{3}{*}{$\mathrm{Ti}_{2}(1,3-\mu-\mathrm{SCN})_{2} \mathrm{H}_{4}$} & HSO1 & 8370.3 & 220.9 & 56.3 & 3.2 \\
\hline & $\mathrm{P} 2 \mathrm{E}$ & 11819.0 & 3962.5 & 79.5 & 57.4 \\
\hline & $\mathrm{HSO} 2$ & 14868.5 & 6898.4 & 100.0 & 100.0 \\
\hline \multirow[t]{3}{*}{$\mathrm{Ti}_{2}(1,1-\mu-\mathrm{NO})_{2} \mathrm{H}_{4}^{\mathrm{c}}$} & HSO1 & 10992.8 & 119.6 & 75.0 & 3.2 \\
\hline & $\mathrm{P} 2 \mathrm{E}$ & 13051.1 & 2164.0 & 89.1 & 57.1 \\
\hline & $\mathrm{HSO} 2$ & 14653.3 & 3790.2 & 100.0 & 100.0 \\
\hline \multirow[t]{3}{*}{$\mathrm{Ti}_{2}(1,1-\mu-\mathrm{NO})_{2} \mathrm{H}_{4}{ }^{\mathrm{d}}$} & HSO1 & 11202.1 & 120.6 & 75.7 & 3.5 \\
\hline & $\mathrm{P} 2 \mathrm{E}$ & 13125.5 & 2021.4 & 88.7 & 58.1 \\
\hline & $\mathrm{HSO} 2$ & 14798.9 & 3478.0 & 100.0 & 100.0 \\
\hline \multirow[t]{3}{*}{$\mathrm{Ti}_{2}(1,1-\mu-\mathrm{ON})_{2} \mathrm{H}_{4}$} & HSO1 & 10554.0 & 118.9 & 74.7 & 3.3 \\
\hline & $\mathrm{P} 2 \mathrm{E}$ & 12605.1 & 2097.3 & 89.2 & 58.1 \\
\hline & HSO2 & 14126.0 & 3609.1 & 100.0 & 100.0 \\
\hline \multirow[t]{3}{*}{$\mathrm{Ti}_{2}(1,2-\mu-\mathrm{NO})_{2} \mathrm{H}_{4}$} & 'HSO1 & 11275.4 & 150.0 & 73.9 & 3.8 \\
\hline & $\mathrm{P} 2 \mathrm{E}$ & 13441.6 & 2191.7 & 88.1 & 55.0 \\
\hline & $\mathrm{HSO} 2$ & 15253.9 & 3985.7 & 100.0 & 100.0 \\
\hline \multirow[t]{3}{*}{$\mathrm{Ti}_{2}\left(\mu-\mathrm{NO}_{2}\right)_{2} \mathrm{H}_{4}$} & HSO1 & 29299.6 & 236.8 & 78.0 & 2.8 \\
\hline & $\mathrm{P} 2 \mathrm{E}$ & 32852.8 & 3630.9 & 87.5 & 43.0 \\
\hline & $\mathrm{HSO} 2$ & 37540.7 & 8437.5 & 100.0 & 100.0 \\
\hline
\end{tabular}



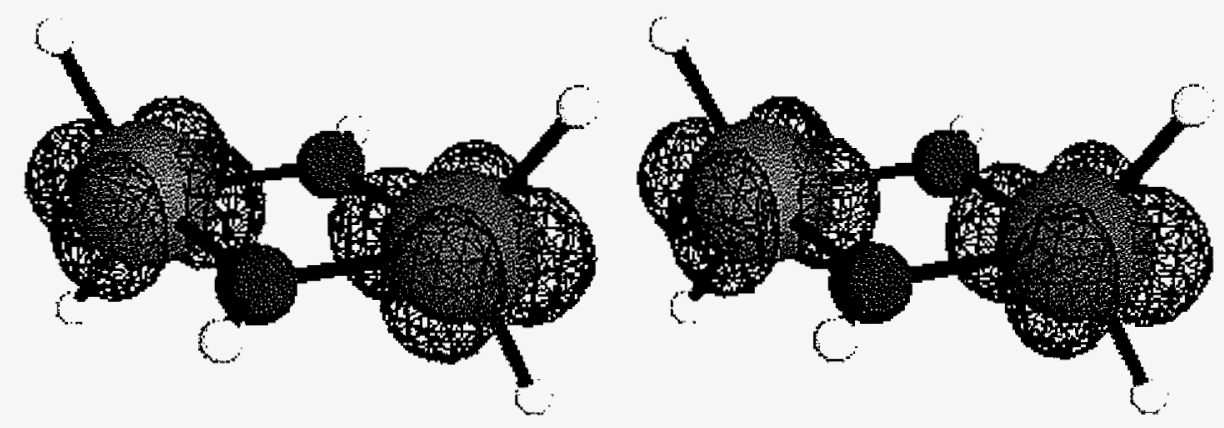

Figure 1. Three-dimensional plots of the $\sigma$ and $\sigma^{*}$ natural orbitals from a two-electron, two-orbital MCSCF/TZV (p) calculation for singlet $\mathrm{Ti}_{2}(\mathrm{OH})_{2} \mathrm{H}_{4}$. The orbital contour value for the plots is $0.06 \mathrm{bohr}^{3 / 2}$.
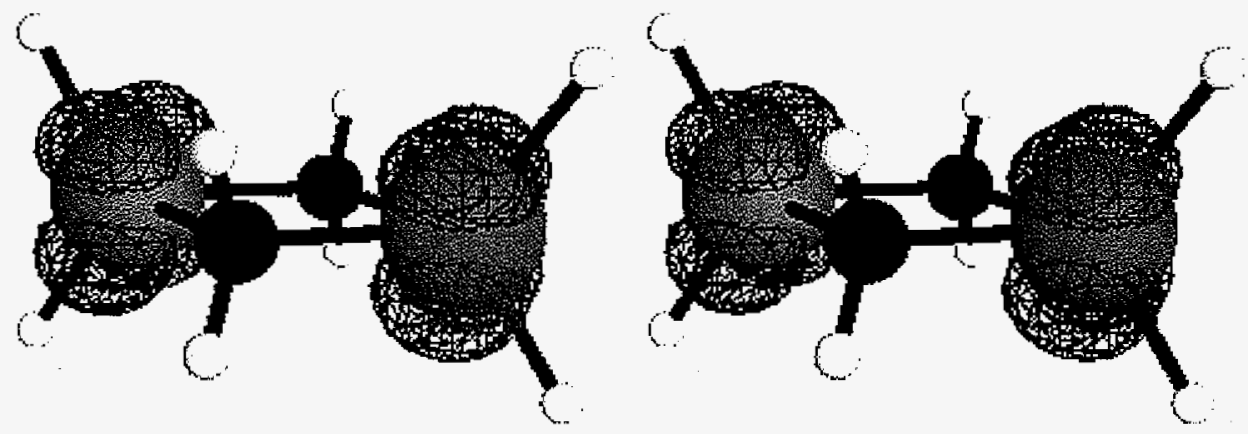

Fignre 2. Three-dimensional plots of the $\delta$ and $\delta^{*}$ natural orbitals for singlet $\mathrm{Ti}_{2}\left(\mathrm{NH}_{2}\right)_{2} \mathrm{H}_{4}$ from a two-electron, two-orbital MCSCF/TZV(p) calculation. The orbital contour value for the plots is $0.06 \mathrm{bohr}^{3 / 2}$.
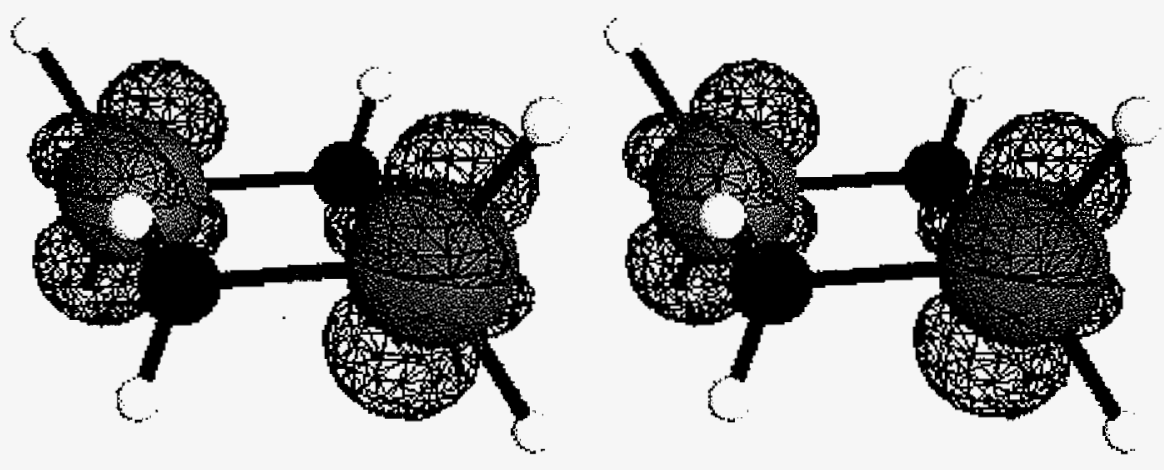

Figure 3. Three-dimensional plots of the natural orbitals for singlet $\mathrm{Ti}_{2}\left(\mathrm{NH}_{2}\right)_{2} \mathrm{H}_{4}$ with $C_{2 h}$ symmetry from a two-electron, two-orbital MCSCF/TZV(p) calculation. The orbital contour value for the plots is 0.06 

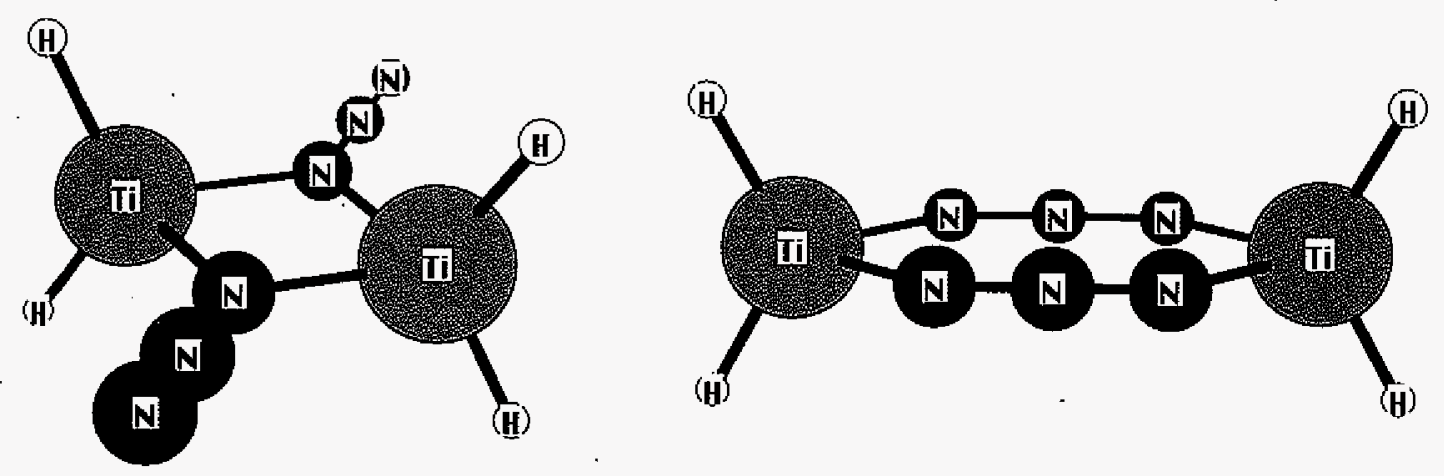

Figure 4. Three-dimensional plots of "end-on" $\mathrm{Ti}_{2}(\mu-1,1-\mathrm{NNN})_{2} \mathrm{H}_{4}$ and "linear" $\mathrm{Ti}_{2}(\mu-1,3-\mathrm{NNN})_{2} \mathrm{H}_{4}$ from a two-electron, two-orbital MCSCF/TZV(p) calculation.
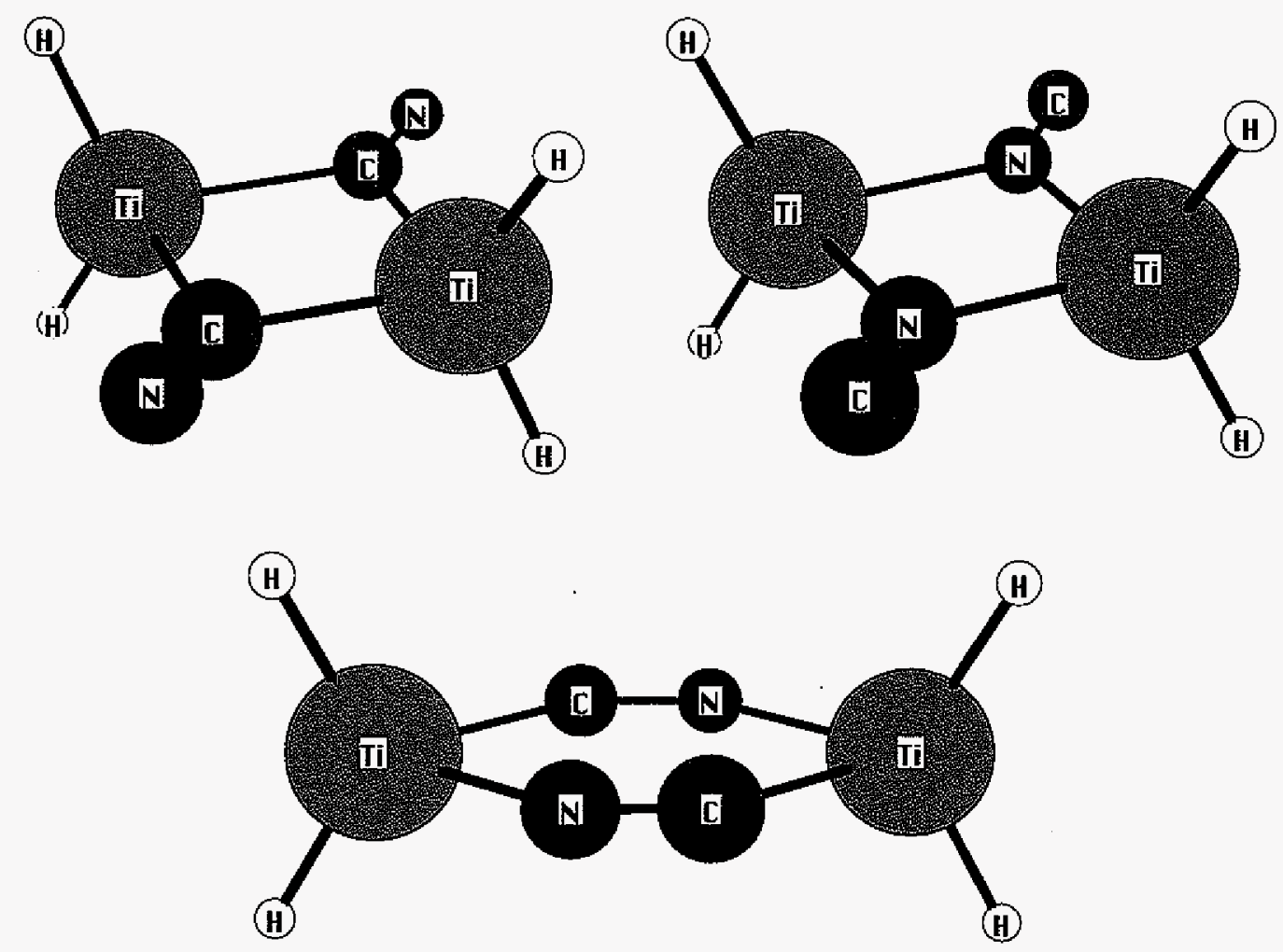

Figure 5. Three-dimensional plots of $\mathrm{Ti}_{2}(\mu-1,1-\mathrm{CN})_{2} \mathrm{H}_{4}, \mathrm{Ti}_{2}\left(\mu-1,1-\mathrm{NC}_{2} \mathrm{H}_{4}\right.$, and $\mathrm{Ti}_{2}(\mu-1,2-\mathrm{CN})_{2} \mathrm{H}_{4}$ from a two-electron, two-orbital MCSCF/TZV(p) calculation. 

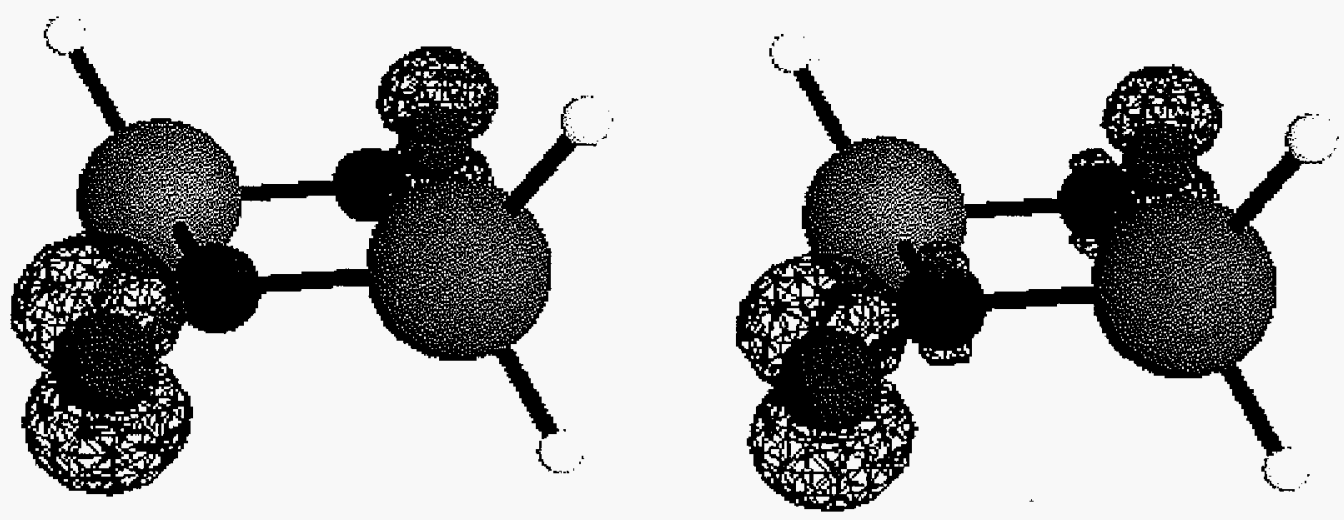

Figure 6. Three-dimensional plots of the natural orbitals for singlet $\mathrm{Ti}_{2}(\mu-1,1-$ $\mathrm{NO})_{2} \mathrm{H}_{4}$ from a two-electron, two-orbital MCSCF/TZV(p) calculation. The orbital contour value for the plots is $0.1 \mathrm{bohr}^{3 / 2}$.
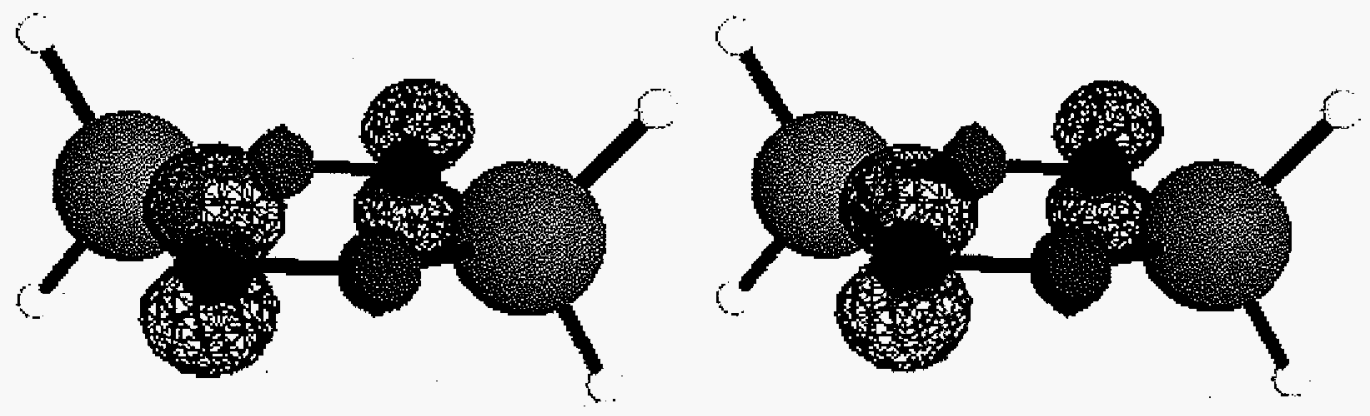

Figure 7. Three-dimensional plots of the frontier orbitals for triplet $\mathrm{Ti}_{2}(\mu-1,2-$ $\mathrm{NO})_{2} \mathrm{H}_{4}$ from a $\mathrm{ROHF} / \mathrm{TZV}(\mathrm{p})$ calculation. The orbital contour value for the plots is 0.1 bohr $^{3 / 2}$.
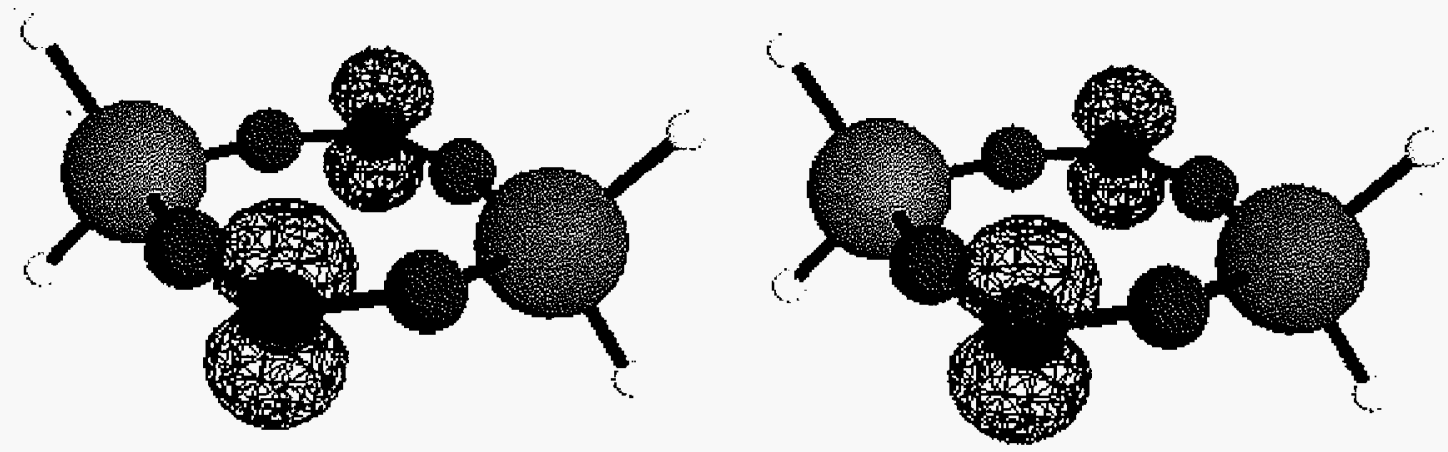

Figure 8. Three-dimensional plots of the natural orbitals from a two-electron, two-orbital MCSCF/TZV(p) calculation for singlet $\mathrm{Ti}_{2}\left(\mathrm{NO}_{2}\right)_{2} \mathrm{H}_{4}$. The orbital contour value for the plots is $0.1 \mathrm{bohr}^{3 / 2}$. 
Figure 9. Three-dimensional plots of the 14 active molecular orbitals for $\mathrm{Ti}_{2}(\mu$ $1,1-\mathrm{NO})_{2} \mathrm{H}_{4}$ used in the spin-orbit coupling calculations. Orbital 39 is the HOMO.

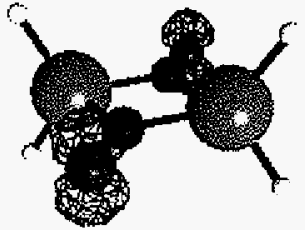

$39 \mathrm{~b}_{2 \mathrm{u}} \mathrm{p}_{\mathrm{y}}$

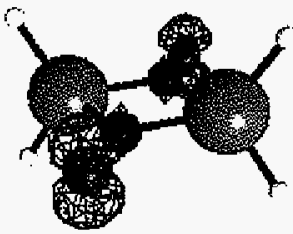

$40 \quad b_{1 g} p_{y}$

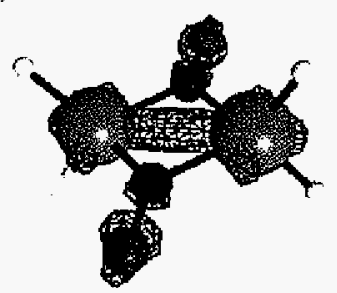

$41 \mathrm{a}_{\mathrm{g}} \sigma_{1}$

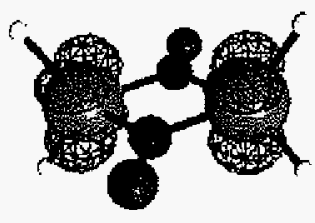

$42 a_{u} \delta^{*}$

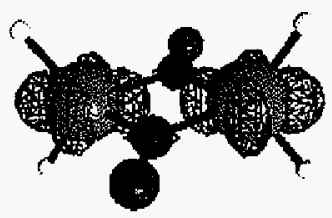

$43 \mathrm{~b}_{1 \mathfrak{u}} \sigma_{1}^{*}$

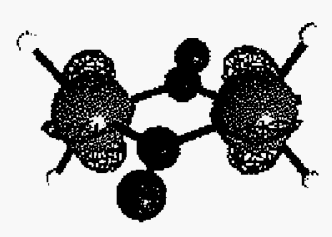

$44 \mathrm{a}_{\mathrm{g}} \sigma_{2}$

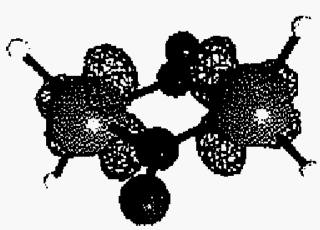

$45 \mathrm{~b}_{3 \mathrm{~g}} \pi_{2}^{*}$

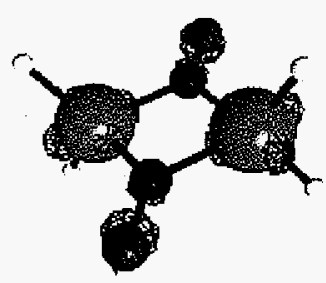

$46 b_{3 u} \pi_{1}$

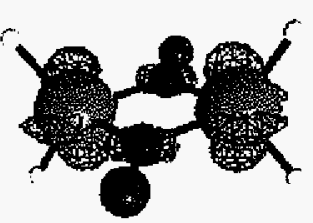

$47 \mathrm{~b}_{1 \mathrm{u}} \sigma_{2}^{*}$

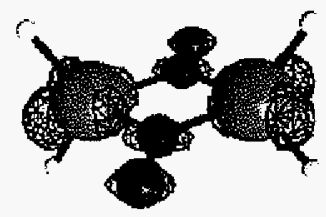

$48 \mathrm{~b}_{2 \mathrm{~g}} \pi_{1}^{*}$

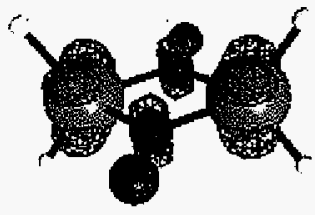

$49 \mathrm{~b}_{\mathrm{lg}} \delta$

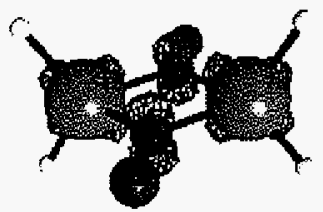

$50 b_{2 u} \pi_{2}$

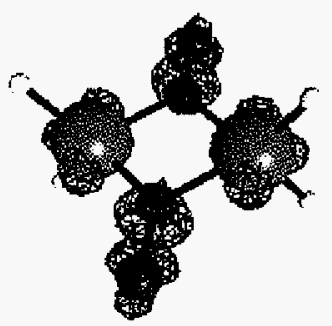

$51 \mathrm{a}_{\mathrm{g}} \mathrm{NO} \sigma^{*}$

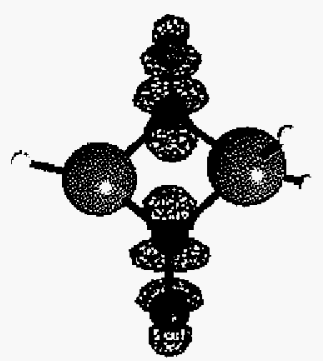

$52 b_{3 \mathrm{u}} \mathrm{NO} \sigma^{*}$ 
Figure 10. Three-dimensional plots of the 14 active molecular orbitals for $\mathrm{Ti}_{2}(\mu$ 1,2-NO $)_{2} \mathrm{H}_{4}$ used in the spin-orbit coupling calculations. Orbital 39 is the HOMO.

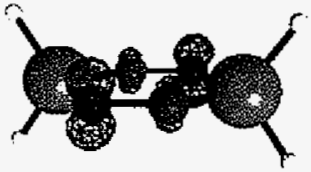

$39 \mathrm{~b}_{\mathrm{g}} \mathrm{p}_{\mathrm{y}}$

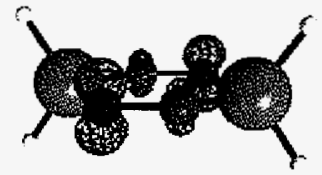

$40 \mathrm{a}_{\mathrm{u}} \mathrm{p}_{\mathrm{y}}$

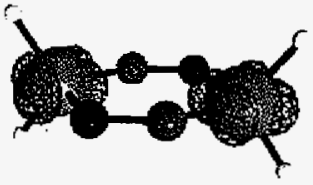

$41 b_{u} \sigma_{1}^{*}$

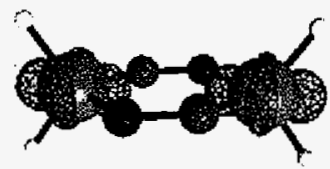

$42 \mathrm{a}_{\mathrm{g}} \sigma_{1}$

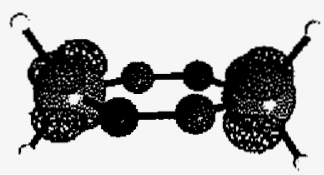

$43 \mathrm{~b}_{\mathrm{g}} \delta_{1}$

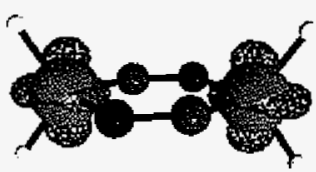

$44 b_{u}$

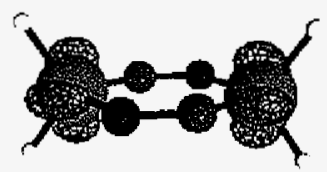

$45 \mathrm{a}_{\mathrm{g}}$

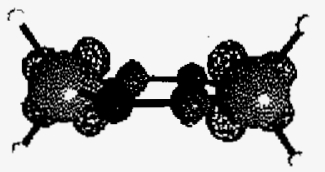

$46 \mathrm{a}_{\mathrm{u}} \pi_{1}$

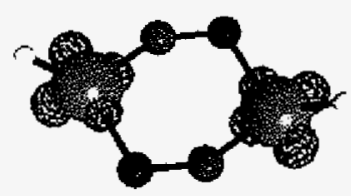

$47 \mathrm{~b}_{\mathrm{u}} \pi_{2}$

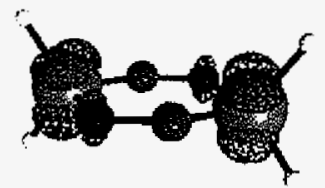

$48 \mathrm{a}_{\mathrm{u}} \delta_{1}^{*}$

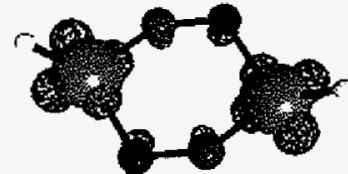

$49 \mathrm{a}_{\mathrm{g}} \pi_{2}^{*}$

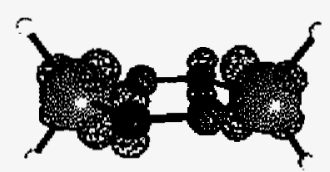

$50 \mathrm{~b}_{\mathrm{g}} \pi_{1}^{*}$

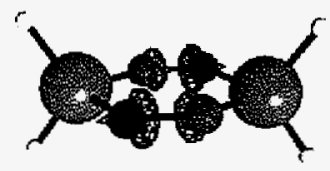

$51 \mathrm{a}_{\mathrm{g}} \mathrm{NO} \sigma^{*}$

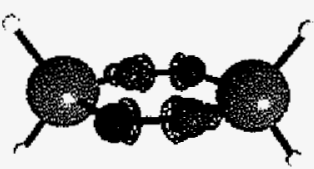

$52 b_{u}$ NO $\sigma^{*}$ 
Figure 11. Three-dimensional plots of the 16 active molecular orbitals for $\mathrm{Ti}_{2}(\mu$ $\left.\mathrm{NO}_{2}\right)_{2} \mathrm{H}_{4}$ used in the spin-orbit coupling calculations. Orbital 47 is the HOMO.
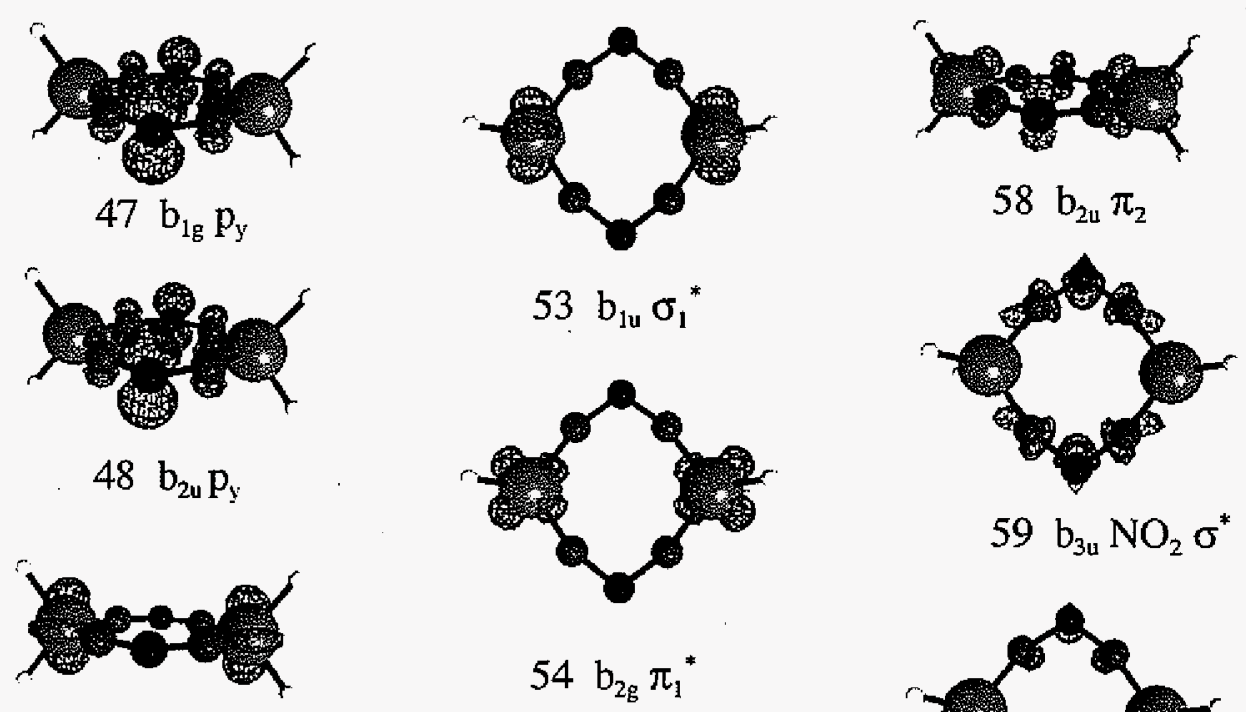

$49 \mathrm{a}_{\mathrm{g}} \sigma_{2}$
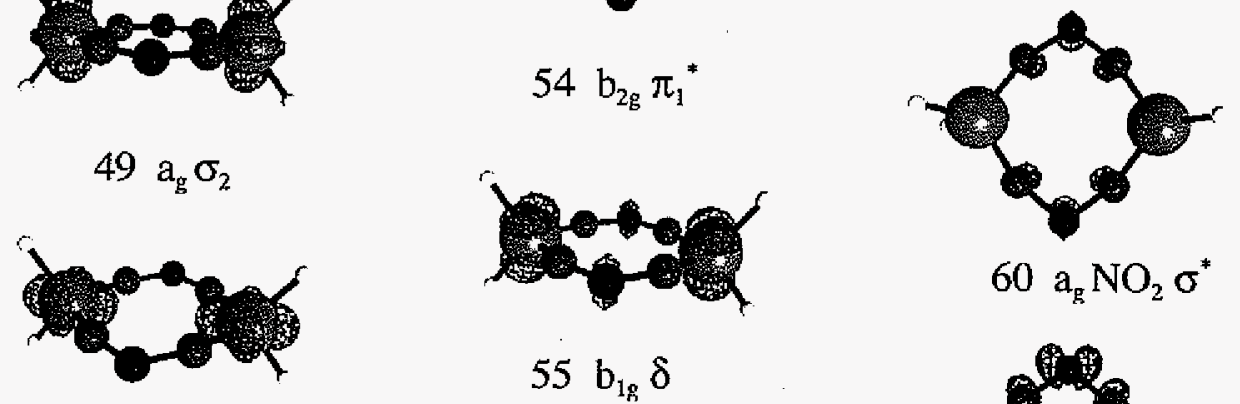

$55 \mathrm{~b}_{1 \mathrm{~g}} \delta$

$50 \mathrm{a}_{\mathrm{g}} \sigma_{1}$
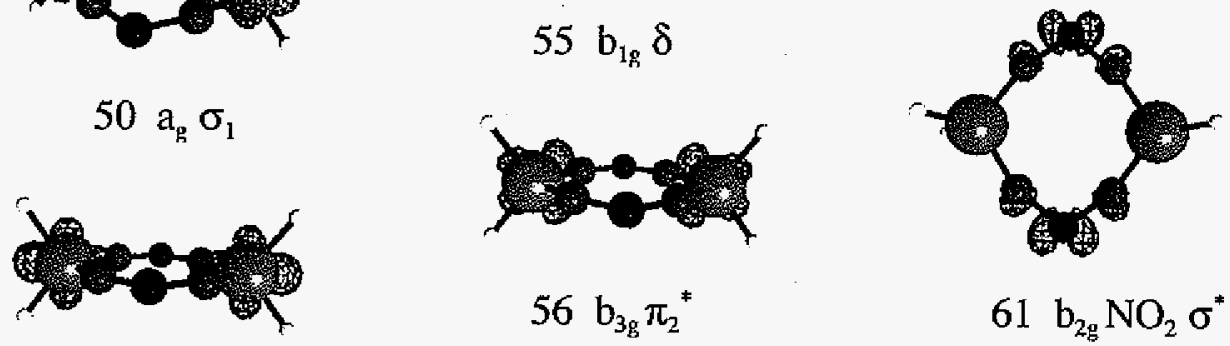

$61 \mathrm{~b}_{2 \mathrm{~g}} \mathrm{NO}_{2} \sigma^{*}$

$51 \mathrm{~b}_{1 \mathrm{u}} \sigma_{2}^{*}$
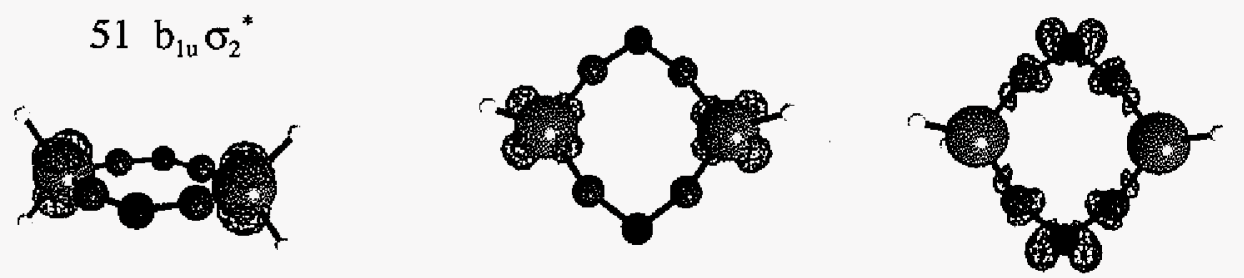

$52 \mathrm{a}_{\mathrm{u}} \delta^{*}$

$57 \mathrm{~b}_{3 \mathrm{u}} \pi_{1}$

$62 \mathrm{~b}_{\mathrm{Iu}} \mathrm{NO}_{2} \sigma^{*}$ 


\title{
CHAPTER 4. SYSTEMATIC INVESTIGATION OF THE SOLVATION OF NONIONIZED AND ZWITTERIONIC GLYCINE
}

\author{
A paper to be submitted to the Journal of the American Chemical Society \\ Christine M. Aikens and Mark S. Gordon
}

Microsolvation and combined microsolvation-continuum approaches are employed in order to examine the solvation of glycine. Glycine $\left(\mathrm{H}_{2} \mathrm{O}\right)_{\mathrm{n}}$ supermolecular clusters with $\mathrm{n}=1-7$ are studied with effective fragment potentials, Hartree-Fock, second-order perturbation theory, and the polarizable continuum model in order to determine the structures and relative energies of nonionized and zwitterionic glycine clusters. Bridging structures are predicted to be the global minima after 3-5 discrete water molecules are included in the calculations, depending on the level of theory. Second-order perturbation theory stabilizes the zwitterionic structures by about $8-9 \mathrm{kcal} / \mathrm{mol}$ relative to the nonionized structures regardless of the number of discrete water molecules considered. Continuum calculations stabilize the zwitterionic structures relative to nonionized structures, and this effect decreases as the number of discrete water molecules is increased. Seven water molecules do not fully solvate glycine.

\section{Introduction}

Since most chemical reactions and biological processes take place in solution, an accurate treatment of solvent effects is increasingly important in quantum chemistry. The two main approaches to solvation include dielectric continuum methods and discrete microsolvation methods, and each has its own advantages and disadvantages. Most common solvation models are based on a continuum approach, in which the solvent is treated in bulk 
as a polarizable medium. ${ }^{1}$ These models include the self-consistent reaction field (SCRF) or Onsager cavity model, ${ }^{2,3}$ the polarizable continuum model $(\mathrm{PCM}),{ }^{4}$ the $\mathrm{COSMO}{ }^{5}$ and $\mathrm{GCOSMO}^{6}$ models, the solvation model 5 (SM5) ${ }^{7.8}$, and other variants of these methods. Continuum methods are fast, relatively simple, and designed to satisfactorily reproduce bulk properties of the solvent. However, they can be very sensitive to the choice of the parameters such as the shape of the cavity in which the solute is embedded. Their description of important electronic effects is generally not adequate. In addition, they cannot describe the individual interactions between solute and solvent molecules, which may be particularly important when the solvent and solute can form hydrogen bonds.

In a discrete approach, individual solvent molecules are explicitly treated. This successfully accounts for the intermolecular solute-solvent interactions. However, if $a b$ initio solvent molecules are used, the calculation may be very computationally demanding. A number of quantum mechanical/molecular mechanical (QM/MM) methods have been developed in order to reduce the computational cost associated with discrete solvation approaches. ${ }^{9}$ A generalized potential derived from first principles known as the effective fragment potential method has been developed by Stevens, Jensen, Gordon, and coworkers. ${ }^{10,11}$ The original method (EFP1/HF) was designed specifically for water and is represented by a set of one-electron potentials that are added to the ab initio electronic Hamiltonian. ${ }^{10,11}$ It contains three energy terms, including Coulombic interactions, induction/polarization interactions, and charge-transfer/exchange-repulsion terms between solvent molecules and between solvent and solute molecules. Charge penetration is included to correct for the pointwise nature of the electrostatic expansion. The first two terms are determined from $a b$ initio calculations on the water monomer, and the third term is fit to a 
quantum mechanical water dimer potential, so the method can be systematically improved. The EFP1/HF method has been found to closely reproduce Hartree-Fock results for a variety of systems. Other effective fragment potential methods have been developed, including a density functional theory-based model (EFP1/DFT) that includes some short-range correlation effects, ${ }^{12}$ and an EFP1/MP2 model that incorporates dispersion effects and a second-order correction to polarization. ${ }^{13}$ A general effective fragment potential model (EFP2) has also been developed. ${ }^{14-17}$ This method is applicable to any solvent, and may be applied across covalent bonds. No fitting is used in this procedure, and the existing model includes terms for exchange repulsion, electrostatic interaction and charge penetration, polarization, dispersion ${ }^{18}$ and charge transfer. ${ }^{19}$

As the number of discrete solvent molecules increases, the number of degrees of freedom in the system also increases. Since numerous minima exist in the configuration space, methods such as molecular dynamics or Monte Carlo simulations must be employed in order to extensively sample this space. Some three-layer approaches have been developed that combine the microsolvation and continuum approaches.$^{20.26}$ These methods may reduce the number of explicit solvent molecules required (and hence the computational cost) and may allow for an accurate description of long-range interactions.

Interactions between water molecules and amino acids and the effects of hydrogen bonding between them are of significant interest to chemists, particularly with regard to structures and vibrational spectra. Depending on the $\mathrm{pH}$, amino acids such as glycine may be neutral, anionic, or cationic. Neutral amino acids exist predominantly in their nonionized form $(\mathrm{N})$ in the gas phase, while in solution or in crystals they occur in the zwitterionic form (Z). ${ }^{27,28}$ The relative stability of these two forms of glycine is of increasing interest. The 
intermolecular hydrogen bonding interaction leads to a considerably larger stability of the zwitterionic form compared to the nonionized form; consequently, the experimental free energy and enthalpy for the process $\mathrm{Z}(\mathrm{aq}) \rightarrow \mathrm{N}(\mathrm{aq})$ are 7.3 and $10.3 \mathrm{kcal} / \mathrm{mol}$, respectively. ${ }^{29}$

As the smallest amino acid, glycine has been the object of many theoretical investigations. The nonionized structure for glycine has three internal rotational degrees of freedom: the rotation of the amino group around the $\mathrm{C}-\mathrm{N}$ bond, the rotation of the $\mathrm{C}-\mathrm{C}$ bond, and the rotation of the hydroxyl group around the $\mathrm{C}-\mathrm{O}$ bond. Initial studies examined various $C_{s}$ and $C_{1}$ stationary points on the conformational potential energy surface of nonionized gas phase glycine, $\left({ }^{30,31}\right.$ and references therein) Continuum solvation models have been employed in several studies. Bonaccorsi et al. showed that electrostatic solute-solvent interactions stabilize zwitterionic glycine with respect to the nonionized form using continuum-only calculations. ${ }^{32}$ Tortonda et al. found that the combination of correlation energy and continuum calculations makes the zwitterionic form lower in energy than the nonionized form. ${ }^{33}$ In addition, they found that solvent effects change the relative stabilities of the gas phase conformers, and that the most stable conformer in solution is well-suited for intramolecular proton transfer..$^{33}$

Previous theoretical studies in the gas phase predicted that the zwitterion is not a minimum if basis sets including polarization functions on the hydrogen atoms are used ${ }^{34} \mathrm{~A}$ complex of zwitterionic glycine with one discrete water molecule is a minimum at the RHF level of theory, but is not a minimum at the MP2 level of theory. ${ }^{35,36}$ Two discrete water molecules are required in order for the zwitterion to be a minimum at the MP2 level of theory. ${ }^{35}$ Low energy structures for the zwitterion with one or two water molecules have also 
been of interest to other researchers. ${ }^{37,38}$ In addition, low energy structures have been examined for the nonionized form with one or two water molecules. ${ }^{35,37,39-41}$

The lowest energy zwitterionic structure with three waters was first reported by Kassab et al. in 2000 using DFT. ${ }^{42}$ This group also reported one nonionized structure relating to proton transfer. Bandyopadhyay et al. examined the energy difference between this structure and the global minima for zwitterionic and nonionized species using ab initio RHF and MP2 calculations, EFP1/HF potentials, and PCM. ${ }^{25}$ Adamovic et al. extended this work to consider the effects of DFT and EFP1/DFT potentials. ${ }^{\mathrm{I} 2}$ Other zwitterionic and nonionized tri-hydrated structures were examined by Ramaekers et al. ${ }^{41}$

A few other studies have explored supermolecular complexes with more than three discrete water molecules, but many of these did not fully sample the configuration space. Ramaekers et al. looked at nonionized and zwitterionic structures with four and five water molecules. ${ }^{41}$ Yamabe et al. examined intermolecular proton transfer pathways for glycine $\left(\mathrm{H}_{2} \mathrm{O}\right)_{\mathbf{n}}(\mathrm{n}=1-4,11,17)$ using density functional theory (DFT) and DFT+Onsager methods. ${ }^{43}$ They considered structures based on three conformers (N3, N5, and N8 defined below), which included the lowest energy structure in solution but did not include the lowest energy gas phase structure. Only bridged structures were examined, and no configurational sampling was reported.

Fernández-Ramos et al. examined the proton transfer reaction for a six-water complex in an Onsager dielectric continuum. ${ }^{24}$ They started with several arrangements of the sixwater complex and used the lowest energy configuration they found upon optimization at the $\mathrm{HF} / 6-31 \mathrm{G}(\mathrm{d})$ level. 
Rzepa and $\mathrm{Yi}$ found starting structures for complexes with 7 and 15 waters using Monte Carlo searches with a molecular mechanics force field, and then optimized these structures with semi-empirical models. ${ }^{21}$ They found that the zwitterionic form is more stable than the nonionized form for the glycine $\left(\mathrm{H}_{2} \mathrm{O}\right)_{15}$ supermolecular complex and for the glycine $\left(\mathrm{H}_{2} \mathrm{O}\right)_{7}$ complex in a self-consistent reaction field.

Bandyopadhyay et al. looked at the glycine $\left(\mathrm{H}_{2} \mathrm{O}\right)_{8}$ complex using three-layer models that combined the effective fragment potential with the Onsager and PCM models. ${ }^{23,25}$ In the first study, eight water molecules in the solvation shell were selected from a molecular dynamics calculation, and this structure was optimized. ${ }^{23}$ In the second study, MC with local minimization was used in order to find a low energy configuration. ${ }^{25}$ Cui used an approach similar to the former in order to examine the effects of TIP3P waters. ${ }^{26}$ Using the three-layer approach, the zwitterion is predicted to be more stable than the nonionized species when a reliable continuum method is used. ${ }^{23,25,26}$

Theoretically predicted spectra may be useful in the analysis of experimentally determined spectra of small hydrogen-bonded complexes such as the glycine-water complex. Theoretical methods have previously been applied to $\operatorname{Raman}^{24}$ and $\mathrm{IR}^{41}$ spectra. Anharmonic vibrational spectroscopy of the glycine $\left(\mathrm{H}_{2} \mathrm{O}\right)$ complex has also been considered. ${ }^{44}$ Neutral complexes of glycine and water molecules may be isolated in a matrix environment. Related ionic complexes may be segregated using mass spectrometric techniques. Xu et al. note that only [Gly $\left.\left(\mathrm{H}_{2} \mathrm{O}\right)_{\mathrm{n}}\right]^{-}$species with $\mathrm{n} \geq 5$ are seen in their mass spectrometry experiments, and they attribute this to the formation of a zwitterionic species. ${ }^{45}$ On the other hand, Diken et al. were later able to synthesize the bare glycine anion and the smaller hydrates $\mathrm{Gly} \bullet \cdot\left(\mathrm{H}_{2} \mathrm{O}\right)_{1-2 \cdot} \cdot{ }^{46}$ 
Theoretical calculations may be useful in determining at what point the zwitterionic species will become more stable than the nonionized form.

The goal of the present work is to determine the equilibrium structures for small glycine-water clusters and determine which conformers dominate as the size of the cluster increases. In addition, the present work will determine at what point the zwitterionic form is predicted to be more stable than the nonionized form, and how the inclusion of correlation energy affects this result. The convergence of the zwitterionic-nonionized energy difference will be considered. The effect of adding a bulk solvent will be discussed, as well as how this is affected by increasing the number of discrete water molecules. The number of waters needed to completely solvate glycine will be considered in an effort to determine the number of waters in the first solvent shell. Previous studies have investigated a first solvation shell consisting of $5,{ }^{47} 6,{ }^{21,24,48} 8,{ }^{23,26}$ or $11^{43}$ water molecules.

\section{Computational Methods}

Molecular structures for water and eight nonionized glycine minima were determined at the restricted Hartree-Fock (RHF) level of theory using the 6-31G(d,p) basis set. Four of the nonionized glycine structures have $C_{s}$ symmetry and four structures have $C_{I}$ symmetry. (See Ref. 30) MP2/6-31++G(d,p) single-point energies were used to refine the relative energies. For zwitterionic glycine, the Polarizable Continuum Model (PCM) was employed with a geometry optimization at the RHF/6-31G(d,p) level to calculate a minimum energy structure. General effective fragment potentials (EFP2's) that include exchange repulsion, electrostatic interaction and charge penetration effects were constructed for water, the eight nonionized minima, the zwitterionic minimum, and three other zwitterionic structures constructed by introducing torsion around the C-C bond. 
For 1-3 discrete water molecules, a Monte Carlo (MC) simulation with local minimization" "basin-hopping" approach was used to find minima on the potential energy surface. Starting structures for MC runs were constructed by adding a water molecule in various positions relative to structures determined from previous runs with one fewer water molecule. For complexes involving one water molecule, 30 steps were allowed in each local optimization. For two and three water molecules, 60 steps were allowed. General effective fragment potentials (EFP2's) were used for glycine and water in order to reduce the computational cost. Structures obtained from the MC runs were used as a starting point for geometry optimizations with glycine treated at the RHF/6-31++G(d,p) level of theory and water molecules treated with the EFP1/HF potential (this will be referred to as an efp-ab optimization). These structures were then fully optimized at the RHF/6-31++G(d,p) level of theory (this will be referred to as an ab-ab optimization). At each step, duplicate minima were removed. As a test of this two-part optimization, full $a b$ initio $\mathrm{RHF} / 6-31++\mathrm{G}(\mathrm{d}, \mathrm{p})$ optimizations were performed on selected structures from the MC runs with one discrete water molecule. Single point calculations incorporating the conductor-like polarizable continuum model (C-PCM) ${ }^{50}$ were performed on the efp-ab and $a b-a b$ optimized structures. For one and two water molecules, optimizations incorporating C-PCM were also run. Single point MP2 calculations were performed on the ab-ab optimized structures. In addition, single point MP2 energies were calculated using C-PCM orbitals and orbital energies to integrate correlation effects with bulk solvent effects. ${ }^{51-54} \mathrm{MP} 2$ and B3LYP geometry optimizations were performed for selected $a b$-ab structures. Imaginary frequencies were detected by diagonalizing the energy second-derivative (Hessian) matrix. 
For four discrete water molecules, a simulated annealing Monte Carlo with local minimization approach was used to find minima on the potential energy surface. ${ }^{55}$ Ab initio atoms were not allowed to move during the MC steps, but were allowed to move during the minimization procedure. Starting structures were generated by adding a water molecule to unique structures with three water molecules. The water molecules were represented by the EFP1/HF potential and the RHF/6-31++G(d,p) level of theory was used for glycine in order to allow the molecule to sample torsional degrees of freedom. The initial and final temperatures used in the simulation were $10000 \mathrm{~K}$ and $200 \mathrm{~K}$, respectively. Fifty temperatures were used in the simulation, and 300 geometries were evaluated at each temperature. Local optimizations were carried out after $150 \mathrm{MC}$ steps, with a maximum of 150 optimization steps. The maximum step size was held constant and the $a b$ initio atoms were not allowed to move during the MC steps. All structures within $3.0 \mathrm{kcal} / \mathrm{mol}$ of the global nonionized and zwitterionic minima were subjected to a full $\mathrm{RHF} / 6-31++\mathrm{G}(\mathrm{d}, \mathrm{p})$ geometry optimization. Single-point MP2 and C-PCM calculations were performed on the unique ab-ab minima.

For five or more discrete waters, a similar simulated annealing MC with local minimization approach was employed. The initial temperature was set at $5000 \mathrm{~K}$. Two hundred temperatures were used in the simulation and 200 geometries were evaluated at each temperature. Ten translational steps were permitted in each block. Three fragments were allowed to move during each MC step. The box dimensions for periodic boundary conditions were slightly increased to $23 \times 19.5 \times 20$. Local optimizations were performed after $100 \mathrm{MC}$ steps, with a maximum of 200 steps in each. Full RHF/6-31++G(d,p) geometry optimizations were performed on a few lowest energy nonionized and zwitterionic structures. Single-point MP2 and C-PCM calculations were performed on the ab-ab minima. 
All calculations were performed with the electronic structure code GAMESS, ${ }^{56}$ which is freely available from Iowa State University at www.msg.ameslab.gov. Structures were visualized with MacMolPlt, ${ }^{57}$ a graphical interface to GAMESS.

\section{Results and Discussion}

\section{Glycine}

The eight nonionized glycine conformers determined in the geometry optimizations correspond to the eight minima found in Ref. 30. These gas phase structures and their relative energies are shown in Figure 1.

$\operatorname{Glycine}\left(\mathrm{H}_{2} \mathrm{O}\right)$

A single water molecule can interact with each glycine conformer to form a wide variety of structures. It may interact with the carboxylic acid group, the amino group, or the saturated carbon, or it may act as a bridge between the carboxylic acid and amino groups. 66 distinct structures were observed for nonionized EFP2 glycine and 25 structures were found for zwitterionic EFP2 glycine interacting with a single EFP2 water molecule. Upon efp-ab optimization, there are 47 unique structures for the nonionized form ranging from 0.0 to 13.7 $\mathrm{kcal} / \mathrm{mol}$ relative to the lowest energy structure and 6 unique structures for the zwitterionic form ranging from 24.2 to $28.2 \mathrm{kcal} / \mathrm{mol}$ above the lowest energy nonionized minimum for glycine (see Table 1 and Figure 2). The reduction in the number of isomers may be due in part to relaxation from the frozen EFP2 geometries. After ab-ab optimization, 44 unique nonionized structures and 5 unique zwitterionic structures remain. These unique structures are named according to the following convention. The name of each structure has the form $m \mathrm{~N} n$-alpha or $m \mathrm{Z}$-alpha, where $m$ designates the number of water molecules surrounding the glycine core, $\mathrm{N} n$ represents the $n$th nonionized glycine conformer, $\mathrm{Z}$ indicates the zwitterion, 
and "alpha" is an alphabetical letter used to label the structures. The complexes are labeled alphabetically from the lowest energy structure at the mixed efp-ab level of theory, so structures close to " $\mathrm{a}$ " are relatively low in energy.

EFP1/HF waters do a good job of reproducing the RHF relative energy ordering, particularly for the lowest energy structures. In the six lowest energy structures (1N1-a, 1N2$a, 1 N 6-a, 1 N 6-b, 1 N 8-a$, and 1N8-b) (shown in Figure 2), the water interacts with the carboxylic acid functionality of the glycine molecule. The five zwitterionic structures found in this work (1Z-a, 1Z-b, 1Z-c, 1Z-d, and 1Z-e in Figure 3) are similar to those found in Ref. 35 (Zla, Zlb, and i, iv, and iii in Figure 2 of that reference). A frequency analysis shows that the four lowest energy structures are minima on the RHF/6-31++G(d,p) potential energy surface. The fifth structure has an imaginary frequency of $6 i \mathrm{~cm}^{-1}$. The two lowest energy structures have the water molecule bridging the protonated amino group and the carboxylate group. They differ in that the water molecule bonds to the oxygen that is $c i s$ to the nitrogen for $1 Z-a$, and to the oxygen trans to the nitrogen for $1 Z-b$.

Some of the nonionized structures found here have been previously reported in the literature. Most of these studies were largely concerned with a few conformers. Basch and Stevens examined five structures with $\mathrm{C}_{\mathrm{s}}$ symmetry, and as a result a few of their structures are saddle points. ${ }^{39}$ Their structures came from four gas phase conformers. Kwon et al. examined two monohydrated minima that were derived from the most stable gas phase conformer. ${ }^{37}$ Jensen and Gordon found eight nonionized minima from multiple conformers. ${ }^{35}$ Wang et al. examined four monohydrated structures based on a single gas phase conformer. ${ }^{40}$ Rameakers et al. determined 16 nonionized structures that were derived from three gas phase conformers. ${ }^{41}$ The present and previous studies agree that cyclic 1N1-a is the most stable 
structure. However, most 1:1 glycine-water complexes examined in this work have not been seen previously, including four of the five structures that lie within $3.0 \mathrm{kcal} / \mathrm{mol}$ of $1 \mathrm{~N} 1-\mathrm{a}$ at the RHF/6-31++G(d,p) level of theory. Six of the 47 nonionized structures found in this study have imaginary frequencies ranging from $5-67 i \mathrm{~cm}^{-1}$, so they are saddle points at this level of theory. Since the potential energy surface appears to be shallow and other levels of theory may predict slightly different results (as previously reported for gas phase glycine), these structures are retained here.

On average, the inclusion of correlation via MP2 single point energies lowers the energy of nonionized structures by $0.3 \mathrm{kcal} / \mathrm{mol}$ relative to the lowest energy $\mathrm{N}$ structure. The relative energies were raised by up to $0.7 \mathrm{kcal} / \mathrm{mol}$ or lowered by up to $2.4 \mathrm{kcal} / \mathrm{mol}$. This effect is more dramatic for zwitterionic structures, whose relative energies decrease by $8.1-9.2 \mathrm{kcal} / \mathrm{mol}$ relative to the lowest energy $\mathrm{N}$ structure. MP2 optimizations on zwitterions with only one discrete water result in proton transfer leading to nonionized structures, in agreement with Ref. 35. Optimizations of nonionized structures with second-order perturbation theory changed bond lengths slightly, but did not change energy orderings or general structure aspects substantially.

Single point calculations using C-PCM with the RHF/6-31++G(d,p) structures simulate the effect of adding a bulk solvent around the glycine $\left(\mathrm{H}_{2} \mathrm{O}\right)$ complex. These calculations stabilize the zwitterionic structures by $21.0-23.7 \mathrm{kcal} / \mathrm{mol}$ relative to the lowest energy nonionized structure; nonetheless, the nonionized form is predicted to be the lowest in energy. Although geometry optimization inside a continuum solvent has a negligible effect on the structure of the nonionized glycine, there are large effects on the zwitterionic structure. These effects have been seen previously. ${ }^{58}$ If one intends to determine structures 
of the zwitterion in solution rather than in small water clusters, optimization in the presence of solvent is important. Single point energy calculations at the combined C-PCM+MP2 level of theory predict that the zwitterionic species is $3.6 \mathrm{kcal} / \mathrm{mol}$ lower in energy than the nonionized species when one discrete water is considered inside the bulk. Glycine $\left(\mathrm{H}_{2} \mathrm{O}\right)_{2}$

For glycine with two water molecules, 238 nonionized and 86 zwitterionic structures were found in the EFP2 Monte Carlo simulations. After efp-ab optimization, 155 nonionized and 19 zwitterionic structures remain. Upon ab-ab optimization, 132 unique nonionized structures and 11 unique zwitterionic structures were found. Ten of the nonionized and two of the zwitterionic structures were found in previous studies (see Table 2 and Figures 4,5 ). As found in earlier studies, ${ }^{35,41}$ the water molecules bridge the $\mathrm{COO}^{-}$and $\mathrm{NH}_{3}{ }^{+}$groups in the lowest energy zwitterionic structures (Figure 5). Most levels of theory agree that a complex with a bridge consisting of two water molecules (such as $2 \mathrm{Z}-\mathrm{a}, 2 \mathrm{Z}-\mathrm{b}$, and $2 \mathrm{Z}$-c) is slightly lower in energy than a complex with two single-water bridges (such as $2 Z$-d and $2 Z$-e), although the $\mathrm{RHF} / 6-31++\mathrm{G}(\mathrm{d}, \mathrm{p})$ level of theory predicts that the latter is $0.1 \mathrm{kcal} / \mathrm{mol}$ lower in energy. The nonionized-zwitterion energy difference is $20.2 \mathrm{kcal} / \mathrm{mol}$ at the efp-ab level of theory, in very good agreement with the RHF energy differences of $19.7 \mathrm{kcal} / \mathrm{mol}$ for $2 Z-\mathrm{d}$ and $19.8 \mathrm{kcal} / \mathrm{mol}$ for $2 \mathrm{Z}-\mathrm{a}$. MP2 single point energies stabilize the zwitterionic form with respect to the nonionized glycine by $7.0-9.4 \mathrm{kcal} / \mathrm{mol}$. Nonetheless, the global minimum is found to be the nonionized species. Upon optimization at the MP2 level of theory, the two zwitterionic structures without a bridging water molecule ( $2 \mathrm{Z}-\mathrm{j}$ and $2 \mathrm{Z}-\mathrm{k}$ ) become nonionized structures. Structures $2 Z$-g and $2 Z$-h optimize to the same structure. After optimization at the MP2 level of theory, eight unique zwitterionic structures remain. 
C-PCM single point energies stabilize the zwitterion $\left(\mathrm{H}_{2} \mathrm{O}\right)_{2}$ complex by $16.0-23.1$ $\mathrm{kcal} / \mathrm{mol}$. This stabilization is less than that seen for the glycine $\left(\mathrm{H}_{2} \mathrm{O}\right)$ complex, but the inclusion of bulk solvent effects continues to have a dramatic consequence for the energy difference with two explicit water molecules. Combined C-PCM+MP2 single point energy calculations predict that the zwitterionic species is $4.7 \mathrm{kcal} / \mathrm{mol}$ lower in energy than the nonionized species, so the consideration of a second explicit water molecule inside the bulk increased the Z-N energy difference by $1.1 \mathrm{kcal} / \mathrm{mol}$.

In the lowest energy nonionized complexes (2N1-a, 2N1-b, 2N2-a, 2N6-a, 2N6-b, 2N2-b, 2N6-c, 2N8-a, 2N8-b, and 2N8-c), the water molecules form a ring with carboxylic acid end of glycine (Figure 4). This motif was found in an earlier study by Jensen and Gordon. $^{35}$ This structure may be visualized with the two oxygen atoms in glycine essentially substituting for two of the oxygen atoms in a cluster of four water molecules. The dihydrated nonionized structure found by Kwon et al. is either 2N1-e or 2N1-f; these structures lie 4.8 and 5.5-5.6 kcal/mol above the global minimum at the RHF/6-31++G(d,p) and MP2// RHF/6-31++G(d,p) levels of theory, respectively. The lowest energy structure reported by Rameakers et al. is $2 \mathrm{~N} 1-\mathrm{c}$, which is 4.5 and $4.8 \mathrm{kcal} / \mathrm{mol}$ above the global minimum at the RHF/6-31++G(d,p) and MP2//RHF/6-31++G(d,p) levels of theory, respectively. At the B3LYP/6-31++G(d,p) level of theory, $2 \mathrm{~N} 1-\mathrm{c}$ is $5.2 \mathrm{kcal} / \mathrm{mol}$ higher in energy than $2 \mathrm{~N} 1-\mathrm{a}$. $\operatorname{Grlycine}\left(\mathrm{H}_{2} \mathrm{O}\right)_{3}$

For the glycine complex with three water molecules, 824 nonionized and 212 zwitterionic structures were found in the EFP2 Monte Carlo calculations. After optimization with $a b$ initio glycine and EFP1/HF waters, 450 nonionized and 42 zwitterionic complexes were found. Full ab initio optimizations lead to 349 nonionized and 24 zwitterionic 
structures. 24 of the nonionized structures are predicted to lie within $3.0 \mathrm{kcal} / \mathrm{mol}$ of the global minimum (Table 3). The lowest energy structures fall, into two groups. The global minimum structure 1N1-a (see Figure 6) consists of three water molecules interacting with the carboxylic acid end of glycine in a ring similar to the water pentamer. This global minimum was previously reported by Bandyopadhyay and Gordon. ${ }^{25}$ The other primary motif seen in the low energy structures is a chain of three waters that bridges the carboxylic acid and amino groups (see 3N6-a and 3N6-c in Figure 6). A similar cyclic bridging structure was seen by Yamabe et al. ${ }^{43}$ This type of structure is stabilized by $2.0-3.0 \mathrm{kcal} / \mathrm{mol}$ relative to ring structures when electron correlation is included via MP2 single point energies. Optimization at the MP2 level of theory further stabilizes the cyclic structures. At the MP2/6-31++G(d,p) level of theory, 3N6-c is predicted to lie $0.8 \mathrm{kcal} / \mathrm{mol}$ lower in energy than 3N1-a, so it is predicted to be the global minimum at this level of theory. The B3LYP level of theory also stabilizes the cyclic structures relative to the ring structures with respect to RHF calculations, although not as dramatically as MP2 calculations. After optimization at the B3LYP/6-31++G(d,p) level of theory, 3N6-c is $1.4 \mathrm{kcal} / \mathrm{mol}$ higher in energy than 3N1-a.

The relative energies for the cyclic and the ring structures with $a b$ initio glycine and EFP1/HF waters are somewhat different than the energies from full ab initio calculations. Interestingly, the EFP1/HF water relative energies are closer to the MP2 single point values. For most other structures, the EFP and RHF relative energies agree to within $1.0 \mathrm{kcal} / \mathrm{mol}$.

Two other previous studies have examined minima for complexes with nonionized glycine and three water molecules. Kassab et al. were interested in the minimum that resulted from intramolecular proton transfer rather than the global minimum. ${ }^{42}$ This structure (3N3-h in Figure 6) is $6.5 \mathrm{kcal} / \mathrm{mol}$ higher in energy than the global minimum at the RHF/6- 
$31++G(d, p)$ level of theory. Rameakers et al. purport to find the global minimum. ${ }^{41}$

However, this structure (3N1-ar in Figure 6) is $7.1 \mathrm{kcal} / \mathrm{mol}$ higher than the global minimum at the RHF/6-31++G(d,p) level of theory. After optimizations at the B3LYP/6-31++G(d,p) level of theory, $3 \mathrm{~N} 1-\mathrm{ar}$ is $8.5 \mathrm{kcal} / \mathrm{mol}$ higher in energy than $3 \mathrm{~N} 1-\mathrm{a}$.

The lowest energy efp-ab zwitterionic glycine complex with three water molecules (3Z-a) is shown in Figure 7. At the RHF/6-31++G(d,p) level of theory, two structures found in this work (3Z-d and 3Z-f in Figure 7) are predicted to be $0.1 \mathrm{kcal} / \mathrm{mol}$ lower in energy than 3Z-a. Neither of these structures has been previously reported. Structure 3Z-a was previously reported in the literature, ${ }^{25,42}$ as were three higher energy structures. ${ }^{41.43}$ The energy ordering predicted by the MP2 single point energies suggests that 3Z-a is the global zwitterionic minimum. This structure is $14.7 \mathrm{kcal} / \mathrm{mol}$ higher in energy than the global nonionized minimum with EFP1/HF waters and RHF/6-31++G(d,p) glycine, $15.6 \mathrm{kcal} / \mathrm{mol}$ higher in energy at the RHF/6-31++G(d,p) level of theory, and $5.2 \mathrm{kcal} / \mathrm{mol}$ higher in energy at the MP2//RHF/6-31++G(d,p) level of theory. In general, MP2 single point calculations stabilize the zwitterionic structures by $6.7-10.4 \mathrm{kcal} / \mathrm{mol}$. C-PCM calculations stabilize the zwitterionic structures with respect to the nonionized structures by $12.1-18.7 \mathrm{kcal} / \mathrm{mol}$. C$\mathrm{PCM}+\mathrm{MP} 2$ calculations predict that the zwitterionic form is $6.9 \mathrm{kcal} / \mathrm{mol}$ lower in energy than the nonionized form, so the inclusion of a third explicit water molecule increases the Z$\mathrm{N}$ energy difference by $2.2 \mathrm{kcal} / \mathrm{mol}$. In general, the efp-ab method predicts relative energies that are in very good agreement with the fully RHF values. For three waters, the global minimum is predicted to be a nonionized structure at all levels of theory except C$\mathrm{PCM}+\mathrm{MP2}$. 
Glycine $\left(\mathrm{H}_{2} \mathrm{O}_{4}\right.$

In a glycine $\left(\mathrm{H}_{2} \mathrm{O}\right)_{4}$ complex, the number of low energy local minima increases substantially. This prompted the procedural change described in the Computational Methods section above. At least 26 nonionized complexes of gas phase glycine conformer 1 with four water molecules are predicted to lie within $3.0 \mathrm{kcal} / \mathrm{mol}$ of the global minimum based on the Monte Carlo calculations. The lowest energy RHF/6-31++G(d,p) nonionized structure (4N1a in Figure 8) is analogous to the water hexamer "book" structure. The lowest energy structure based on gas phase conformer 6 (4N6-a in Figure 8) has a cyclic structure similar to 3N6-a. At the RHF/6-31++G(d,p) level of theory, this structure is $0.8 \mathrm{kcal} / \mathrm{mol}$ higher in energy than 4N1-a. However, MP2 single point energies predict that it is $1.0 \mathrm{kcal} / \mathrm{mol}$ more stable. MP2 optimizations on these structures increase this energy difference in favor of the cyclic isomer to $1.7 \mathrm{kcal} / \mathrm{mol}$. Bond lengths for both structures decrease upon MP2 optimization.

The lowest energy zwitterionic complex is shown in Figure 8. At the RHF/6$31++\mathrm{G}(\mathrm{d}, \mathrm{p})$ level of theory, this structure is predicted to be $11.7 \mathrm{kcal} / \mathrm{mol}$ less stable than the global minimum nonionized structure. The inclusion of dynamic electron correlation via MP2 single point energies decreases this to $1.6 \mathrm{kcal} / \mathrm{mol}$. In general, MP2 single point energies stabilize zwitterionic structures with four waters by $8.5-11.7 \mathrm{kcal} / \mathrm{mol}$. C-PCM calculations stabilize the zwitterionic structures by $10.0-14.7 \mathrm{kcal} / \mathrm{mol}$. C-PCM+MP2 single point energy calculations predict that $4 \mathrm{Z}-\mathrm{a}$ is $7.7 \mathrm{kcal} / \mathrm{mol}$ lower in energy than $4 \mathrm{~N} 1-\mathrm{a}$ and $6.7 \mathrm{kcal} / \mathrm{mol}$ lower in energy than 4N6-a. The Z-N energy difference for four explicit waters is within $1 \mathrm{kcal} / \mathrm{mol}$ of the difference for three explicit waters, which suggests that the C- 
$\mathrm{PCM}+\mathrm{MP} 2 \mathrm{Z}-\mathrm{N}$ energy difference may be converging with respect to the number of discrete water molecules considered inside the bulk.

A previous investigation on the energy difference between the nonionized and zwitterionic structures predicted the zwitterion to be more stable when four discrete water molecules were considered in the calculations. ${ }^{41}$ However, this study did not sample the configuration space, so the "global minima" reported are in fact high energy structures. At the B3LYP/6-31++G(d,p) level of theory, 4N6-a is predicted to be $0.2 \mathrm{kcal} / \mathrm{mol}$ lower in energy than $4 \mathrm{Nl}$-a and $16.3 \mathrm{kcal} / \mathrm{mol}$ lower in energy than the structure reported in Ref. 41 ; $4 \mathrm{Z}$-a is predicted to lie $5.0 \mathrm{kcal} / \mathrm{mol}$ above $4 \mathrm{~N} 6-\mathrm{a}$, and the zwitterionic structure reported in Ref. 41 is predicted to lie $9.6 \mathrm{kcal} / \mathrm{mol}$ above 4 N6-a. In addition, the structures reported in the Yamabe et al. study on intermolecular proton transfer ${ }^{43}$ are somewhat higher in energy than the global minima reported here. All levels of theory examined here agree that the global minimum for the four water complex is a nonionized structure when it is not embedded in bulk water. As noted previously, relative energies obtained using EFP waters are in good agreement with those from fully quantum mechanical calculations. Glycine $\left(\mathrm{H}_{2} \mathrm{O}\right)_{5}$

With five water molecules, the number of low energy local minima escalates further. Only the global minimum and a few selected low energy minima from the Monte Carlo "basin-hopping" procedure are discussed here.

For the glycine $\left(\mathrm{H}_{2} \mathrm{O}\right)_{5}$ complex, the efp-ab method predicts relative energies that are in good agreement with the fully ab initio calculations. The $\mathrm{RHF} / 6-31++\mathrm{G}(\mathrm{d}, \mathrm{p})$ global minimum nonionized structure is predicted to be a bridge-like species (see 5N6-a in Figure 9) similar to 3N6-a and 4N6-a, rather than a structure consisting of a water cluster at the 
carboxylic acid end of glycine (see 5N1-a in Figure 9). This 5N6-a structure can be considered to be more solvated, as the waters are in closer proximity to the glycine molecule. The nonplanar gas phase conformer 6 can accept hydrogen bonds, and this appears to encourage bridge-like structures. The lowest energy zwitterionic structure is also a bridged structure. It is predicted to lie $9.5 \mathrm{kcal} / \mathrm{mol}$ higher than the global minimum at the RHF/6$31++G(d, p)$ level of theory. Incorporation of electron correlation reduces this value to 0.4 $\mathrm{kcal} / \mathrm{mol}$ at the MP2/RHF/6-31++G(d,p) level of theory. The use of C-PCM with RHF stabilizes the zwitterion by $8.7 \mathrm{kcal} / \mathrm{mol}$, but still predicts that it is $0.8 \mathrm{kcal} / \mathrm{mol}$ higher in energy than the global minimum. C-PCM+MP2 calculations predict that $5 Z$-a is 7.3 $\mathrm{kcal} / \mathrm{mol}$ lower in energy.than 5N6-a.

The only previous calculation we are aware of on this system predicted the zwitterion to be more stable by $6.6 \mathrm{kcal} / \mathrm{mol},{ }^{41}$ but the minima reported are not the lowest energy structures. The nonionized structure reported in Ref. 41 is predicted to lie $13.2 \mathrm{kcal} / \mathrm{mol}$ higher in energy than $5 \mathrm{~N} 6-\mathrm{a}$ at the $\mathrm{RHF} / 6-31++\mathrm{G}(\mathrm{d}, \mathrm{p})$ level of theory, and $18.0 \mathrm{kcal} / \mathrm{mol}$ higher in energy at the B3LYP/6-31++G(d,p) level of theory. The zwitterionic structure reported in Ref. 41 is predicted to lie $9.5 \mathrm{kcal} / \mathrm{mol}$ higher in energy than $5 \mathrm{N6}-\mathrm{a}$ at the B3LYP/6-31++G(d,p) level of theory. Glycine $\left(\mathrm{H}_{2} \mathrm{O}\right)_{6}$

The lowest energy nonionized complexes with six water molecules found in this study have a cubic structure (Figure 10). The lowest energy zwitterionic structure corresponds to the addition of the water labeled " $\mathrm{x}$ " to 5Z-a with subsequent expansion of the structure. At the RHF/6-31++G(d,p) level of theory, the zwitterion is predicted to be 8.4 $\mathrm{kcal} / \mathrm{mol}$ higher in energy than the global minimum. This energy difference is reduced to 0.8 
$\mathrm{kcal} / \mathrm{mol}$ at the MP2// RHF/6-31++G(d,p) level of theory. Addition of bulk solvent effects through the use of C-PCM single point energy calculations stabilizes the zwitterion by 8.6 $\mathrm{kcal} / \mathrm{mol}$, which means it is predicted to lie $0.2 \mathrm{kcal} / \mathrm{mol}$ lower in energy than the lowest energy nonionized structure. Integration of correlation energy via C-PCM+MP2 single point energy calculations increases this energy difference to $6.9 \mathrm{kcal} / \mathrm{mol}$.

Fernández-Ramos et al. examined the proton transfer energy difference for the glycine $\left(\mathrm{H}_{2} \mathrm{O}\right)_{6}$ complex using RHF and MP2 methods with and without an Onsager SCRF, and found that their zwitterionic structure lies lower in energy than their nonionized structure for all levels of theory. ${ }^{24}$ However, they only probed a few starting structures and did not report cubic structures.

$\operatorname{Glycine}\left(\mathrm{H}_{2} \mathrm{O}\right)_{7}$

Low energy nonionized and zwitterionic structures for the glycine $\left(\mathrm{H}_{2} \mathrm{O}\right)_{7}$ supermolecular complex are shown in Figure 11. The efp-ab method and the RHF/6$31++\mathrm{G}(\mathrm{d}, \mathrm{p})$ level of theory predict the global minimum to be a nonionized prismatic structure based on gas phase conformer $1(7 \mathrm{~N} 1-\mathrm{a})$. The lowest energy structure based on gas phase conformer $8(7 \mathrm{~N} 8-\mathrm{a})$ is $1.2 \mathrm{kcal} / \mathrm{mol}$ higher in energy at the $\mathrm{RHF} / 6-31++\mathrm{G}(\mathrm{d}, \mathrm{p})$ level of theory, while the lowest energy structure based on conformer $6(7 \mathrm{~N} 6-\mathrm{a})$ is $1.3 \mathrm{kcal} / \mathrm{mol}$ higher in energy. However, the inclusion of correlation energy via MP2 single point energy calculations stabilizes $7 \mathrm{~N} 8 \mathrm{-a}$ and $7 \mathrm{~N} 6-\mathrm{a}$ with respect to $7 \mathrm{N1}$-a. At this level of theory, 7N8-a and 7N6-a are predicted to lie 1.0 and $0.7 \mathrm{kcal} / \mathrm{mol}$ lower in energy than $7 \mathrm{~N} 1-\mathrm{a}$, respectively.

The efp-ab method predicts that the zwitterionic structures 7Z-a, 7Z-b, and 7Z-f lie $7.3,7.4$, and $8.9 \mathrm{kcal} / \mathrm{mol}$ higher in energy than $7 \mathrm{NI}$-a. However, this differs slightly from the full RHF/6-31++G(d,p) results. At this level of theory, the lowest energy zwitterionic 
structure is predicted to be $7 Z$-f, followed by $7 \mathrm{Z}-\mathrm{b}$ and $7 \mathrm{Z}$-a $(8.4,8.5$, and $9.0 \mathrm{kcal} / \mathrm{mol}$ higher than 7N1-a, respectively). With seven discrete water molecules, many structures fall within $1 \mathrm{kcal} / \mathrm{mol}$ of the lowest energy zwitterionic structure, so it may be necessary to examine multiple structures in order to interpret experimental results for this system.

MP2 single point energy calculations again stabilize the zwitterionic structures by about $9 \mathrm{kcal} / \mathrm{mol}$. These calculations predict that the global minimum structure will be $7 \mathrm{Z}-\mathrm{b}$. It lies $0.3 \mathrm{kcal} / \mathrm{mol}$ lower in energy than $7 \mathrm{~N} 8-\mathrm{a}$ at the $\mathrm{MP} 2 / \mathrm{RHF} / 6-31++\mathrm{G}(\mathrm{d}, \mathrm{p})$ level of theory. C-PCM single point energy calculations stabilize the zwitterionic structures by about $9 \mathrm{kcal} / \mathrm{mol}$. These calculations also predict that $7 \mathrm{Z}-\mathrm{b}$ will be the global minimum. The integration of correlation energy and C-PCM bulk solvation effects further stabilizes the zwitterionic structures. At this level of theory, $7 \mathrm{Z}-\mathrm{b}$ is predicted to lie $8.8 \mathrm{kcal} / \mathrm{mol}$ lower in energy than both $7 \mathrm{~N} 1$-a and $7 \mathrm{~N} 8$-a. Overall, $7 \mathrm{Z}$-b is predicted to be the global minimum for the correlated methods discussed here.

The zwitterionic structures seen in this work appear to be qualitatively similar to the PM3 and AM1 structures reported previously. ${ }^{21}$ The structures show a high degree of hydrogen bonding. In addition, the solvent molecules are asymmetrically clustered around the zwitterionic glycine solute, in contrast to the highly symmetrical ordering seen around the nonionized glycine. The $\mathrm{N}-\mathrm{H}^{\prime \prime} \mathrm{O}$ bond is effectively broken, and the $\mathrm{CO}_{2}^{-}$group is twisted with respect to the $\mathrm{NH}_{3}{ }^{+}$group. In addition, the semi-empirical calculations on the glycine $\left(\mathrm{H}_{2} \mathrm{O}\right)_{7}$ system predicted the nonionized structure to be lower in energy than the zwitterion by $4.0 \mathrm{kcal} / \mathrm{mol}$ and the combined semi-empirical $/ \mathrm{SCRF}$ approach predicted the zwitterionic structure to be lower in energy than the nonionized structure by $1.4 \mathrm{kcal} / \mathrm{mol}^{21}$ 
This is in good agreement with our combined RHF/C-PCM approach, which predicts 7Z-b to be $0.5 \mathrm{kcal} / \mathrm{mol}$ lower in energy than the nonionized structures.

\section{Conclusions}

In general, the EFP1/HF water potentials track RHF structures and energy orderings well. The global minimum structure is the same for both methods for the numbers of water molecules examined in this study. Since there are a large number of low energy structures, configurational sampling is important. Multiple gas phase conformers must be considered. These species are highly fluxional, so multiple structures will likely be important for a physical description of the system.

The effect of systematically increasing the level of solvation is observed. The convergence of each method as the number of water molecules increases is summarized in

Table 8 . As the number of discrete water molecules increases, a different, "more solvated," structure becomes the global minimum nonionized structure. The internal structure of glycine in this complex is not the lowest energy gas phase conformer. This change occurs for three water molecules at the MP2/6-31++G(d,p) level of theory and for five water molecules at the RHF/6-31++G(d,p) level of theory. When seven discrete water molecules are considered, the lowest energy structure at the RHF/6-31+tG(d,p) level of theory has an internal structure of gas phase conformer 1 ; however, the lowest energy nonionized structure at the MP2//RHF/6-3I++G(d,p) level of theory is based on gas phase conformer 8 .

Correlation effects included via second order perturbation theory typically stabilize the zwitterion about $8-9 \mathrm{kcal} / \mathrm{mol}$ with respect to the nonionized form. Even so, the nonionized form is lowest in energy for complexes with up to six water molecules. The zwitterionic structure is the global minimum for a supermolecular complex with seven 
discrete water molecules at the MP2//RHF/6-31++G(d,p) level of theory. As the number of discrete water molecules increases, the effect of a continuum solvent on the energy difference between the nonionized and zwitterionic forms decreases. However, it still has a significant effect for clusters with seven waters, so these clusters do not completely recover long-range interactions with bulk solvent. Seven water molecules do not fully solvate the glycine molecule. The integration of correlation with the continuum solvent effects through CPCM+MP2 single point energy calculations suggests that the zwitterionic species is 6.7-8.8 $\mathrm{kcal} / \mathrm{mol}$ lower in energy than the neutral species in solution, which agrees well with the experimental free energy. At least three discrete water molecules are needed in order to obtain converged results within this level of theory.

Acknowledgement. The authors are grateful to the Air Force Office of Scientific Research for funding. The authors would also like to thank Jamie Rintelman and Jonathan Mullin for helpful discussions.

\section{References}

(1) Cramer, C. J.; Truhlar, D. G. In Reviews in Computational Chemistry; Boyd, D. B., Lipkowitz, K. B., Eds.; VCH: New York, 1995; Vol. 6.

(2) Kirkwood, J. G. J. Chem. Phys. 1934, 2, 351.

(3) Onsager, L. J. Am. Chem. Soc. 1936, 58, 1486.

(4) Miertus, S.; Scrocco, E.; Tomasi, J. Chem. Phys. 1981, 55, 117.

(5) Klamt, A.; Schüürmann, G. J. Chem. Soc., Perkin Trans. 1993, II, 799.

(6) Truong, T. N.; Stefanovich, E. V. Chem. Phys. Lett. 1995, 240, 253.

(7) Li, J.; Hawkins, G. D.; Cramer, C. J.; Truhlar, D. G. Chem. Phys. Lett. 1998, $288,293$. 
(8) Hawkins, G. D.; Zhu, T.; Li, J.; Chambers, C. C.; Giesen, D. J.; Liotard, D. A.; Cramer, C. J.; Truhlar, D. G. In Combined Quantum Mechanical and Molecular Mechanical Methods; Gao, J., Thompson, M. A., Eds.; ACS: Washington DC, 1998; Vol. 712; pp 201.

(9) Gao, J. In Reviews in Computational Chemistry; Lipkowitz, K. B., Boyd, D. B., Eds.; VCH: New York, 1996; Vol. 7.

(10) Jensen, J. H.; Day, P. N.; Gordon, M. S.; Basch, H.; Cohen, D.; Garmer, D. R.; Krauss, M.; Stevens, W. J. Effective Fragment Method for Modeling Intermolecular Hydrogen-Bonding Effects on Quantum Mechanical Calculations. In Modeling the Hydrogen Bond; Smith, D. A., Ed.; ACS Symposium Series: Washington DC, 1994; Vol. 569; pp 139.

(11) Day, P. N.; Jensen, J. H.; Gordon, M. S.; Webb, S. P.; Stevens, W. J.; Krauss, M.; Garmer, D. R.; Basch, H.; Cohen, D. J. Chem. Phys. 1996, 105, 1968.

(12) Adamovic, I.; Freitag, M. A.; Gordon, M. S. J. Chem. Phys. 2003, 118, 6725.

(13) Song, J.; Gordon, M. S. manuscript in preparation.

(14) Jensen, J. H. J. Chem. Phys. 1996, 104, 7795.

(15) Jensen, J. H.; Gordon, M. S. Mol. Phys. 1996, 89, 1313.

(16) Jensen, J. H.; Gordon, M. S. J. Chem. Phys. 1998, 108, 4772.

(17) Gordon, M. S.; Freitag, M. A.; Bandyopadhyay, P.; Jensen, J. H.; Kairys, V.; Stevens, W. J. J. Phys. Chem. A 2001, 105, 293.

(18) Adamovic, I.; Gordon, M. S. Mol. Phys. 2005, 103, 379.

(19) Li, H.; Jensen, J. H.; Gordon, M. S. manuscript in preparation.

(20) Russell, S. T.; Warshel, A. J. Mol. Bio. 1985, 185, 389.

(21) Rzepa, H. S.; Yi, M. J. Chem. Soc., Perkin Trans. 1991, 2, 531. 
(22) De Vries, A. H.; Van Duijnen, P. T.; Juffer, A. H.; Rullmann, J. A. C.;

Dijkman, J. P.; Merenga, H.; Thole, B. T. J. Comp. Chem. 1995, 16, 37.

(23) Bandyopadhyay, P.; Gordon, M. S. J. Chem. Phys. 2000, 113, 1104.

(24) Fernández-Ramos, A.; Smedarchina, Z.; Siebrand, W.; Zgierski, M. Z. J.

Chem. Phys. 2000, 113, 9714.

(25) Bandyopadhyay, P.; Gordon, M. S.; Mennucci, B.; Tomasi, J. J. Chem. Phys. $2002,116,5023$.

(26) Cui, Q. J. Chem. Phys. 2002, 117, 4720.

(27) Albrecht, G.; Corey, R. B. J. Am. Chem. Soc. 1939, 61, 1087.

(28) Jonsson, P. G.; Kvick, A. Acta Crystallogr. B 1972, 28, 1827.

(29) Wada, G.; Tamura, E.; Okina, M.; Nakamura, M. Bull. Chem. Soc. Jpn. 1982, 55,3064 .

(30) Jensen, J. H.; Gordon, M. S. J. Am. Chem. Soc. 1991, 113, 7917.

(31) Hu, C.-H.; Shen, M.; Schaefer III, H. F. J. Am. Chem. Soc. 1993, 115, 2923.

(32) Bonaccorsi, R.; Palla, P.; Tomasi, J. J. Am. Chem. Soc. 1984, 106, 1945.

(33) Tortonda, F. R.; Pascual-Ahuir, J. L.; Silla, E.; Tuñón, I. Chem. Phys. Lett.

$1996,260,21$.

(34) Ding, Y.; Krogh-Jespersen, K. Chem. Phys. Lett. 1992, 199, 261.

(35) Jensen, J. H.; Gordon, M. S. J. Am. Chem. Soc. 1995, 117, 8159.

(36) Ding, Y.; Krogh-Jespersen, K. J. Comp. Chem. 1996, 17, 338.

(37) Kwon, O. Y.; Kim, S. Y.; No, K. T. Bull. Korean Chem. Soc. 1995, 16, 410.

(38) Wang, W.; Pu, X.; Zheng, W.; Wong, N.-B.; Tian, A. J. Mol. Struct.

Theochem. 2003, 626, 127. 
(39) Basch, H.; Stevens, W. J. Chem. Phys. Lett. 1990, 169, 275.

(40) Wang, W.; Zheng, W.; Pu, X.; Wong, N.-B.; Tian, A. J. Mol. Struct.

Theochem. 2002, 618, 235.

(41) Ramaekers, R.; Pajak, J.; Lambie, B.; Maes, G. J. Chem. Phys. 2004, 120 , 4182.

(42) Kassab, E.; Langlet, J.; Evleth, E.; Akacem, Y. J. Mol. Struct. Theochem. 2000, 531, 267.

(43) Yamabe, S.; Ono, N.; Tsuchida, N. J. Phys. Chem. A 2003, 107, 7915.

(44) Chaban, G. M.; Gerber, R. B. J. Chem. Phys. 2001, 115, 1340.

(45) Xu, S.; Nilles, J. M.; Bowen Jr., K. H. J. Chem. Phys. 2003, 119, 10696.

(46) Diken, E. G.; Hammer, N. I.; Johnson, M. A. J. Chem. Phys. 2004, 120, 9899.

(47) Kokpol, U.; Doungdee, P. B.; Hannongbua, S. V.; Rode, B. M. J. Chem. Soc., Faraday Trans. 2 1988, 84, 1789.

(48) Förner, W.; Otto, P.; Bernhart, J.; Ladik, J. Theor. Chim. Acta 1981, 60, 269.

(49) Li, Z.; Scheraga, H. A. Proc. Nat. Acad. Sci. 1987, 84, 6611.

(50) Barone, V.; Cossi, M. J. Phys. Chem. A 1998, 102, 1995.

(51) Olivares del Valle, F. J.; Tomasi, J. Chem. Phys. 1991, 150, 139.

(52) Aguilar, M. A.; Olivares del Valle, F. J.; Tomasi, J. Chem. Phys. 1991, 150, 151.

(53) Olivares del Valle, F. J.; Aguilar, M. A.; Tolosa, S. J. Mol. Struct. Theochem. $1993,279,223$.

(54) Olivares del Valle, F. J.; Aguilar, M. A. J. Mol. Struct. Theochem. 1993, 280, 25. 
(55) Kirkpatrick, S.; Gelatt, C. D.; Vecci, M. P. Science 1983, $220,671$.

(56) Schmidt, M. W.; Baldridge, K. K.; Boatz, J. A.; Elbert, S. T.; Gordon, M. S.; Jensen, J. H.; Koseki, S.; Matsunaga, N.; Gordon, M. S.; Nguyen, K. A.; Su, S.; Windus, T. L.; Dupuis, M.; Montgomery Jr., J. A. J. Comp. Chem. 1993, 14, 1347.

(57) Bode, B. M.; Gordon, M. S. J. Mol. Graphics and Modeling 1998, 16, 133.

(58) Truong, T. N.; Stefanovich, E. V. J. Chem. Phys. 1995, I03, 3709. 


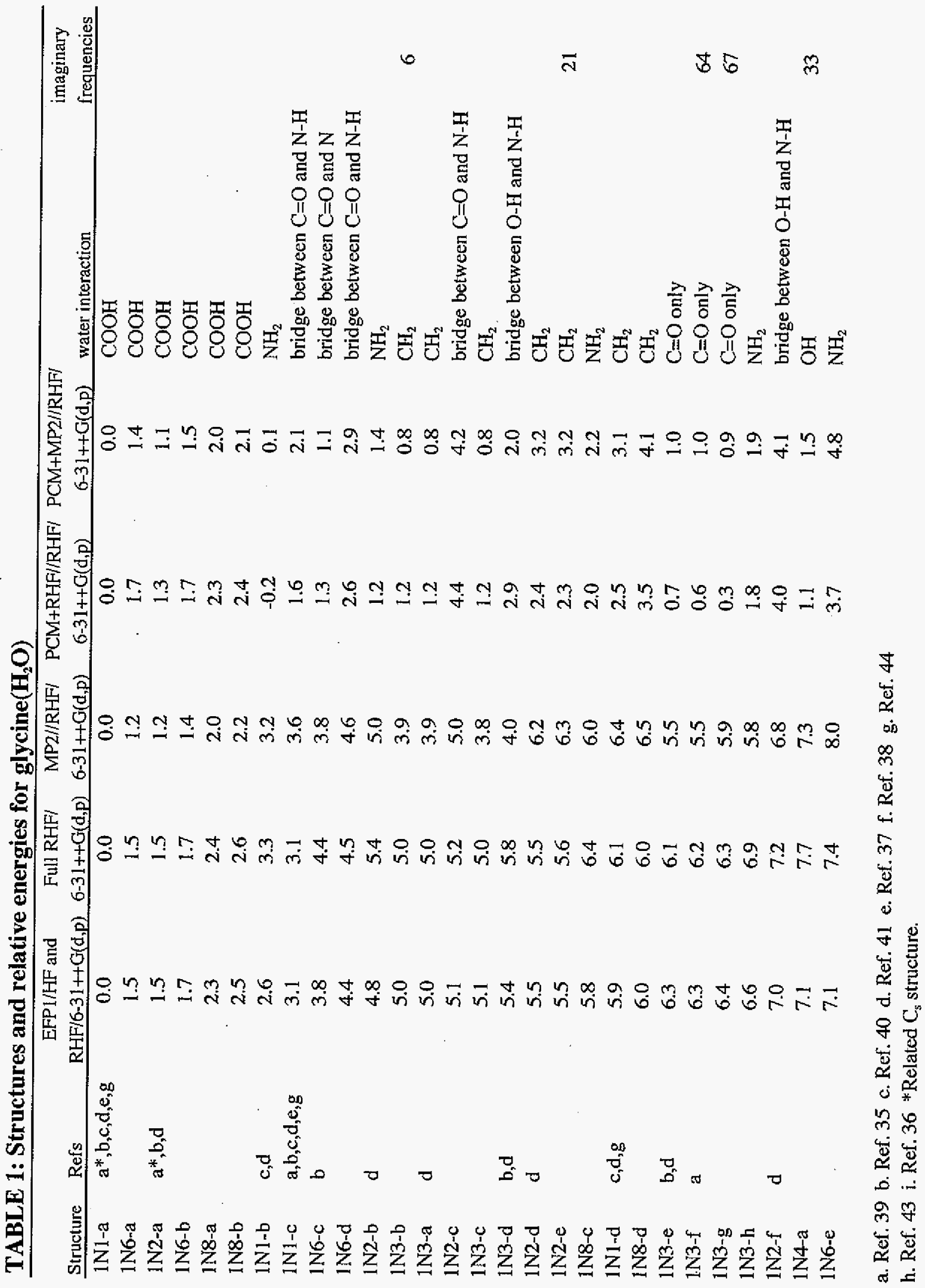




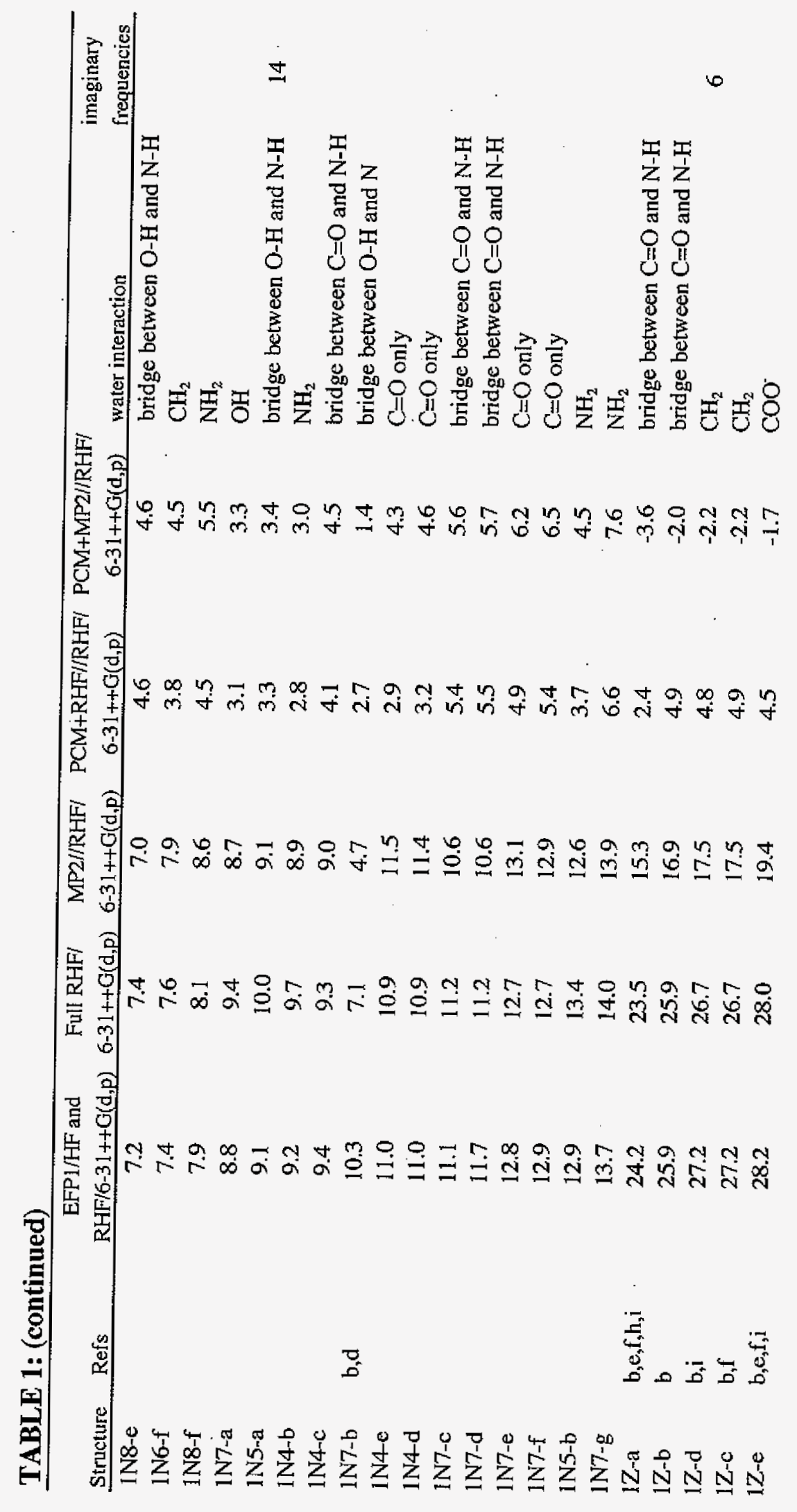




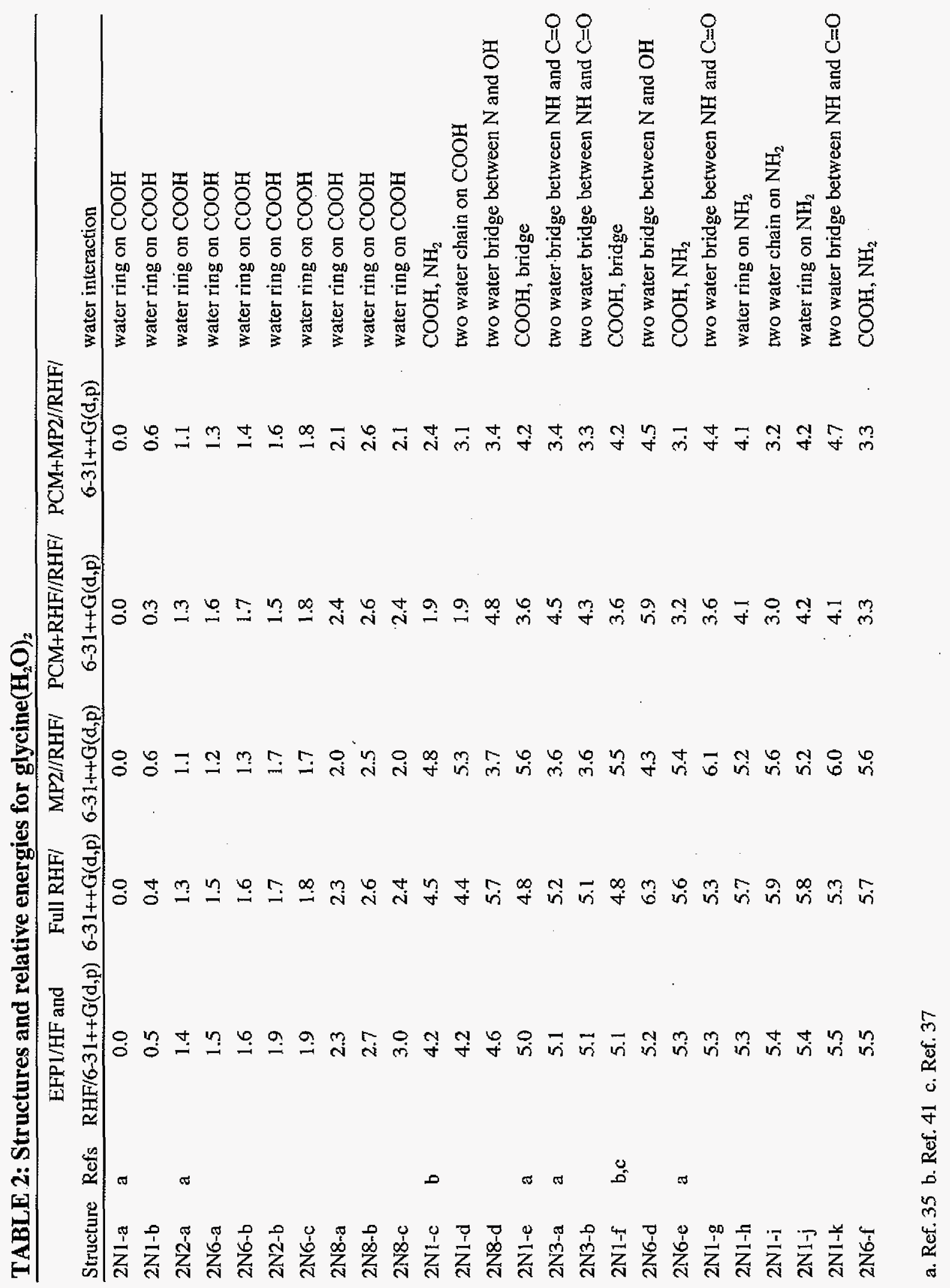




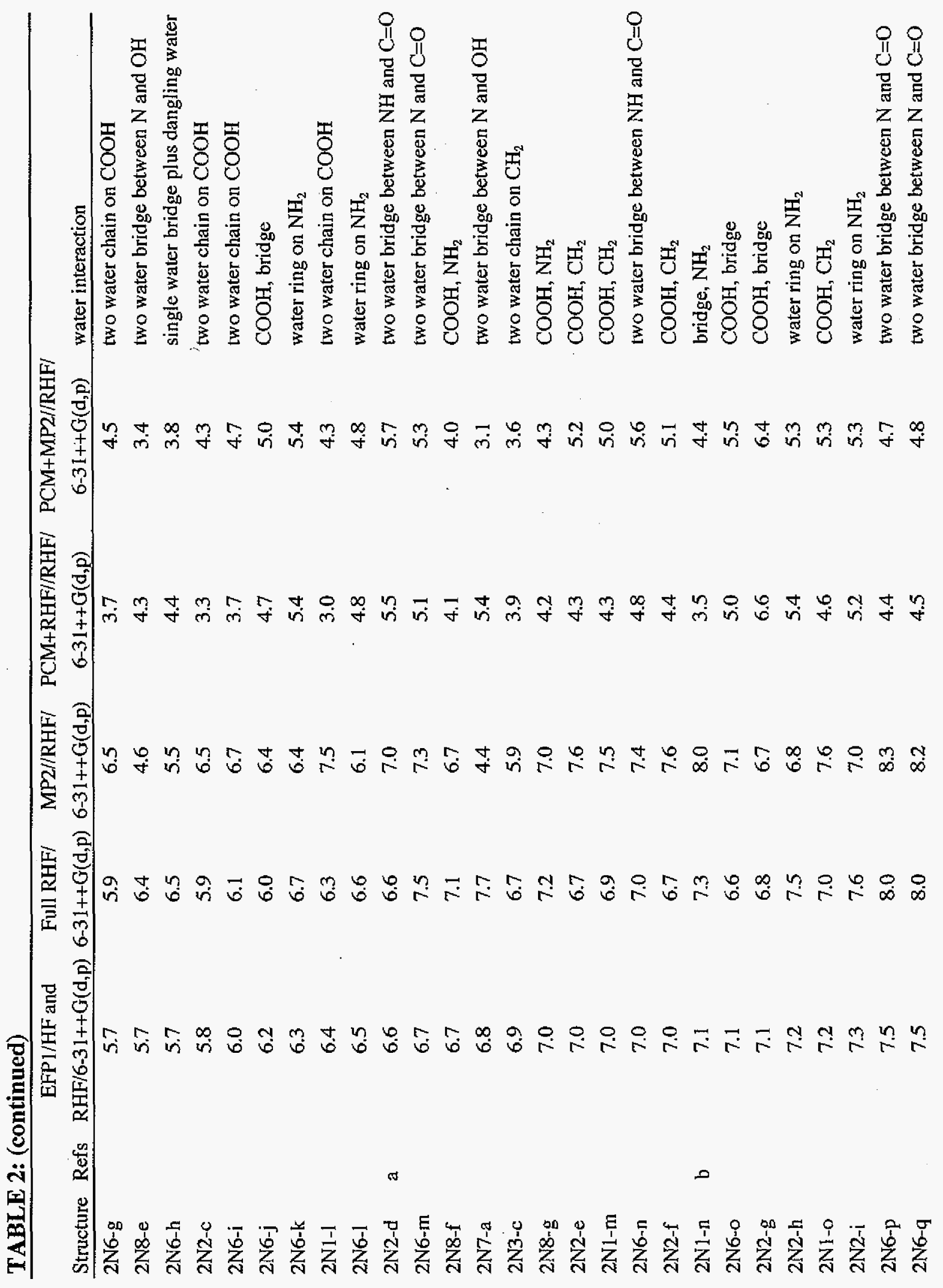




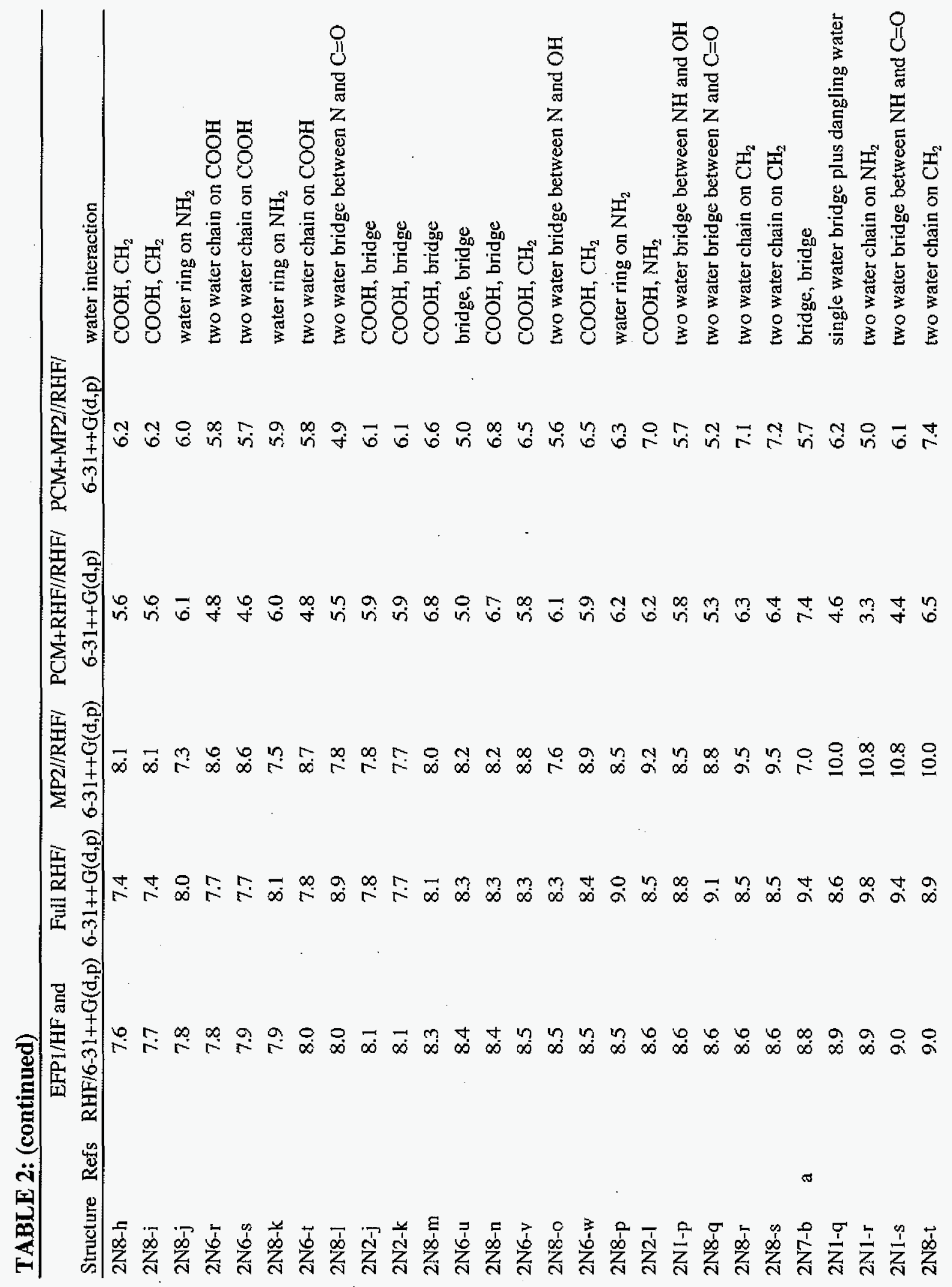




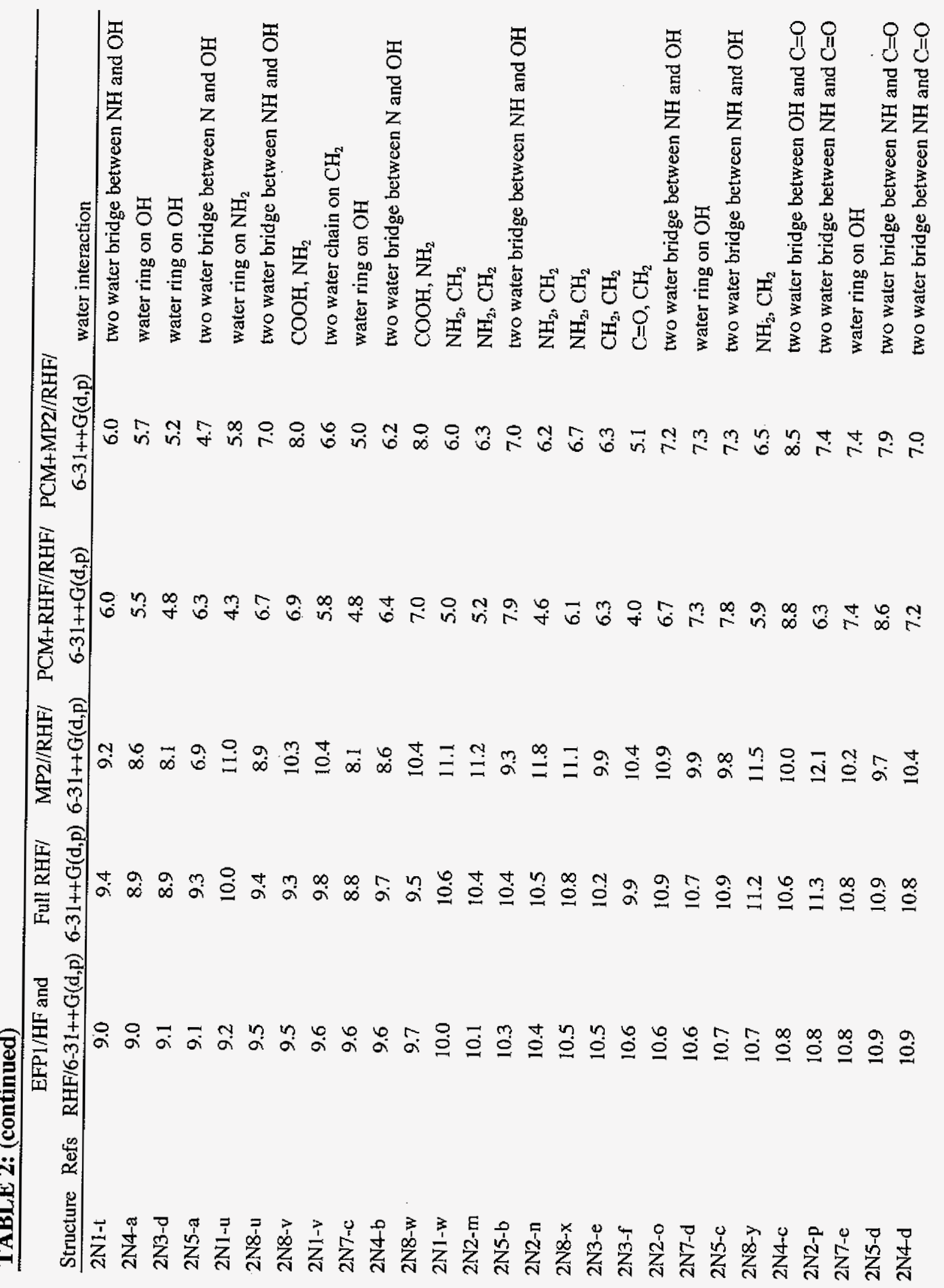




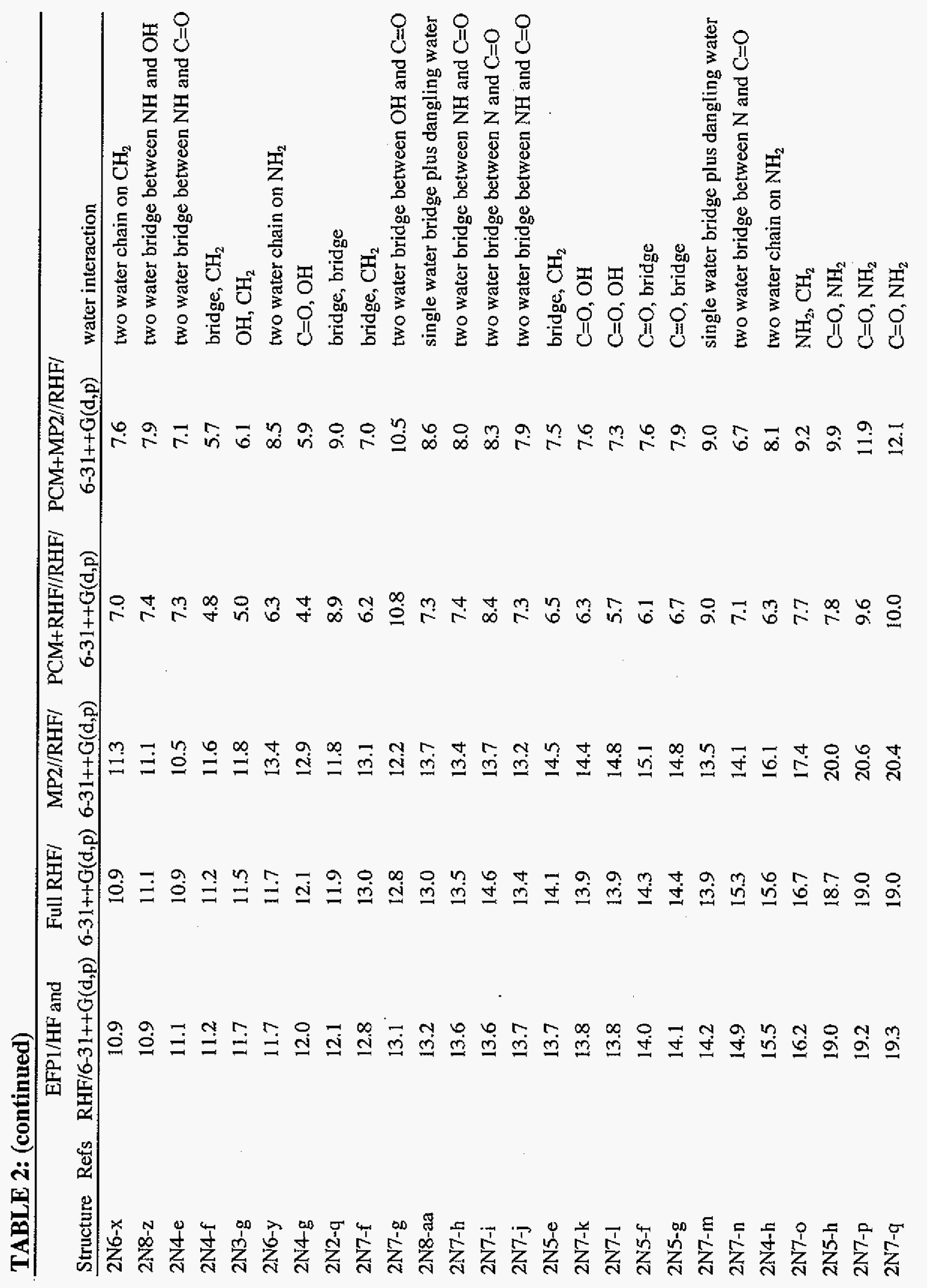




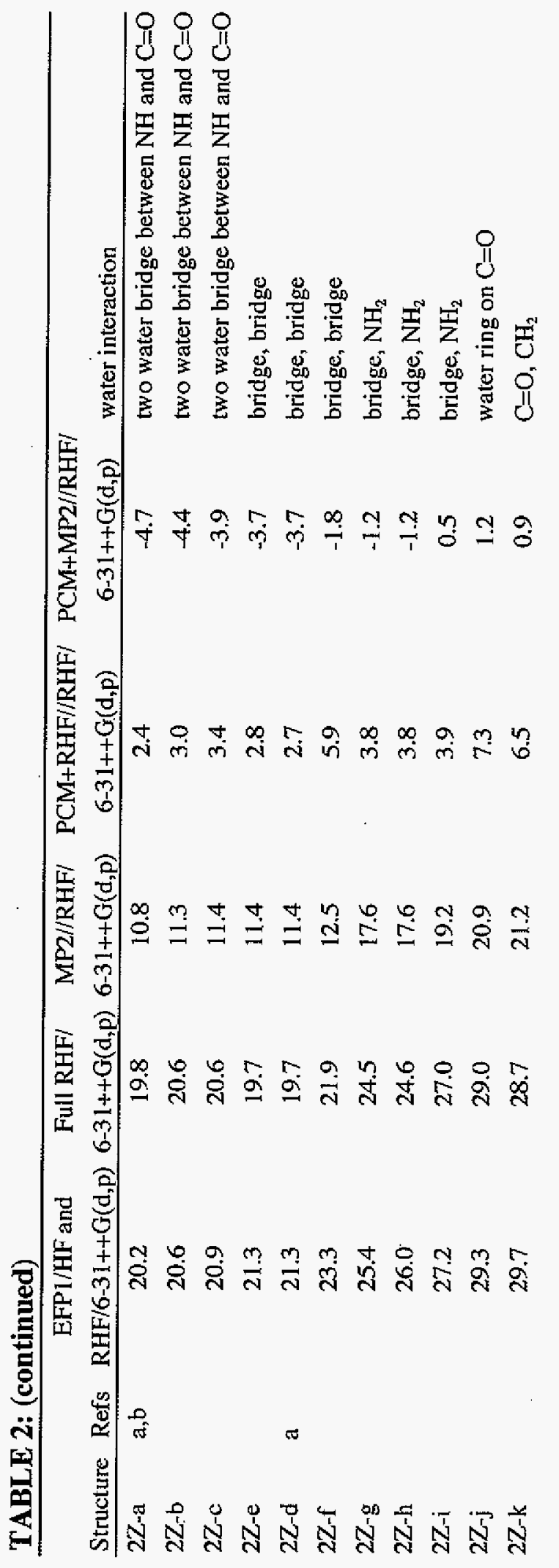


TABLE 3: Structures and relative energies for glycine $\left(\mathrm{H}_{2} \mathrm{O}\right)_{3}$

\begin{tabular}{|c|c|c|c|c|c|c|}
\hline Structure & Refs & $\begin{array}{c}\text { EFP1/HF and } \\
\text { RHF/6-31++G(d,p) }\end{array}$ & $\begin{array}{c}\text { Full RHF } / \\
6-31++G(d, p)\end{array}$ & $\begin{array}{c}\text { MP2//RHF/ } \\
6-31++\mathrm{G}(\mathrm{d}, \mathrm{p}) \\
\end{array}$ & $\begin{array}{c}\mathrm{PCM}+\mathrm{RHF} / / \mathrm{RHF} / \\
6-31++\mathrm{G}(\mathrm{d}, \mathrm{p}) \\
\end{array}$ & $\begin{array}{c}\mathrm{PCM}+\mathrm{MP} 2 / \mathrm{RHF} / \\
6-31++\mathrm{G}(\mathrm{d}, \mathrm{p}) \\
\end{array}$ \\
\hline $3 \mathrm{~N} 1-\mathrm{a}$ & $\mathrm{c}$ & 0.0 & 0.0 & 0.0 & 0.0 & 0.0 \\
\hline $3 \mathrm{N1}-\mathrm{b}$ & & 0.4 & 1.3 & 1.0 & 1.9 & 1.6 \\
\hline $3 N 6-a$ & & 1.1 & 2.9 & 0.2 & 2.3 & 0.1 \\
\hline 3N6-b & & 1.3 & 2.6 & 0.1 & 3.2 & 1.0 \\
\hline $3 N 8-a$ & & 1.3 & 3.1 & 0.3 & 2.0 & -0.1 \\
\hline $3 N 6-c$ & & 1.3 & 2.7 & 0.1 & 3.2 & 1.0 \\
\hline $3 N 6-d$ & & 1.4 & 2.9 & 0.9 & 3.7 & 2.0 \\
\hline $3 N 6-e$ & & 1.5 & 3.2 & 0.5 & 2.9 & 0.8 \\
\hline $3 \mathrm{~N} 2-\mathrm{a}$ & & 1.5 & 2.4 & 1.9 & 3.0 & 2.5 \\
\hline 3N8-b & & 1.7 & 3.5 & 0.5 & 3.2 & 0.7 \\
\hline $3 N 6-f$ & & 1.8 & 2.7 & 2.1 & 3.4 & 2.9 \\
\hline $3 \mathrm{~N} 1-\mathrm{c}$ & & 1.9 & 2.7 & 2.4 & 0.5 & 0.3 \\
\hline $3 N 8-c$ & & 2.0 & 3.7 & 0.7 & 3.2 & 0.8 \\
\hline $3 \mathrm{~N} 1-\mathrm{d}$ & & 2.3 & 3.0 & 2.3 & 2.6 & 1.7 \\
\hline $3 N 6-g$ & & 2.4 & 1.4 & 1.0 & 1.5 & 1.2 \\
\hline 3 N1-e & & 2.4 & 3.1 & 3.0 & 0.7 & 0.8 \\
\hline $3 N 8-d$ & & 2.4 & 2.4 & 2.0 & 2.4 & 2.1 \\
\hline $3 N 1-f$ & & 2.4 & 3.0 & 3.3 & 0.9 & 1.4 \\
\hline $3 N 1-g$ & & 2.5 & 3.2 & 2.8 & 2.9 & 2.6 \\
\hline $3 N 8-e$ & & 2.6 & 3.5 & 2.8 & 4.2 & 3.6 \\
\hline $3 \mathrm{~N} 2-\mathrm{b}$ & c & 2.8 & 1.2 & 1.0 & 1.1 & 1.0 \\
\hline 3N1-h & & 2.8 & 3.3 & 3.7 & 1.0 & 1.5 \\
\hline 3N6-h & & 2.8 & 4.3 & 3.3 & 4.9 & 3.9 \\
\hline $3 \mathrm{~N} 1-\mathrm{i}$ & & 2.9 & 3.3 & 3.6 & 1.0 & 1.5 \\
\hline $3 N 6-i$ & & 3.2 & 3.6 & 3.2 & 4.2 & 3.9 \\
\hline $3 \mathrm{~N} 1-\mathrm{j}$ & & 3.3 & 3.5 & 3.5 & 2.4 & 2.1 \\
\hline $3 \mathrm{~N} 1-\mathrm{k}$ & & 3.3 & 4.4 & 2.8 & 3.1 & 2.0 \\
\hline $3 N 8-f$ & & 3.3 & 4.8 & 2.3 & 5.0 & 2.9 \\
\hline $3 \mathrm{~N} 1 \mathrm{H}$ & & 3.3 & 4.1 & 3.3 & 1.7 & 1.4 \\
\hline $3 N 6-j$ & & 3.4 & 4.0 & 2.9 & 4.0 & 2.8 \\
\hline $3 \mathrm{~N} 2-\mathrm{c}$ & & 3.4 & 4.2 & 3.5 & 1.7 & 1.3 \\
\hline 3NI-m & & 3.4 & 4.1 & 4.5 & 2.1 & 2.4 \\
\hline 3N1-n & & 3.5 & 3.3 & 3.2 & 2.4 & 2.1 \\
\hline 3N6-k & & 3.5 & 3.8 & 3.0 & 1.8 & 1.0 \\
\hline $3 N I-0$ & & 3.5 & 4.1 & 3.5 & 1.5 & 1.5 \\
\hline $3 \mathrm{~N} 1-\mathrm{p}$ & & 3.6 & 4.2 & 3.5 & 4.0 & 3.1 \\
\hline $3 \mathrm{~N} 8-\mathrm{g}$ & & 3.6 & 5.1 & 4.1 & 5.9 & 4.9 \\
\hline 3N8-h & & 3.7 & 5.0 & 2.6 & 5.1 & 3.2 \\
\hline $3 N 1-q$ & & 3.7 & 4.2 & 4.6 & 1.4 & 1.8 \\
\hline $3 \mathrm{~N} 1-\mathrm{r}$ & & 3.7 & 5.3 & 5.5 & 2.9 & 3.2 \\
\hline $3 N 3-a$ & & 3.8 & 4.0 & 2.0 & 3.7 & 2.2 \\
\hline $3 N 3-b$ & & 3.8 & 4.1 & 2.2 & 3.7 & 2.3 \\
\hline $3 \mathrm{~N} 1-\mathrm{s}$ & & 3.9 & 4.8 & 3.4 & 3.4 & 2.5 \\
\hline
\end{tabular}

$\begin{array}{lll} & \text { a. Lowest energy structure in Ref. } 41 & \text { b. Ref. } 42 \text { c. Ref. } 25\end{array}$ 
TABLE 3: (continued)

EFP1/HF and Full RHF/ MP2//RHF/ PCM+RHF/RHF/ PCM+MP2//RHF/

Structure Refs. RHF/6-31++G(d,p) 6-31++G(d,p) 6-31++G(d,p) 6-31++G(d,p) $\quad 6-31++\mathrm{G}(\mathrm{d}, \mathrm{p})$

\begin{tabular}{|c|c|c|c|c|c|c|}
\hline $3 \mathrm{~N} 4-\mathrm{a}$ & & 3.9 & 4.7 & 2.0 & 1.8 & 0.0 \\
\hline $3 \mathrm{~N} 1-\mathrm{t}$ & & 4.0 & 4.2 & 4.3 & 4.0 & 4.3 \\
\hline 3N8-i & & 4.0 & 5.2 & 2.9 & 5.6 & 3.6 \\
\hline $3 N 2-d$ & & 4.1 & 4.8 & 4.1 & 4.1 & 3.7 \\
\hline $3 N 1-1$ & & 4.1 & 4.2 & 4.3 & 4.1 & 4.4 \\
\hline $3 N 6-1$ & & 4.1 & 4.9 & 4.1 & 4.6 & 4.1 \\
\hline $3 N 6-m$ & & 4.1 & 4.5 & 4.3 & 3.2 & 3.1 \\
\hline 3N6-n & & 4.1 & 4.9 & 3.2 & 4.3 & 3.0 \\
\hline $3 N 2-e$ & & 4.2 & 4.4 & 4.4 & 2.1 & 2.4 \\
\hline $3 N 7-a$ & & 4.2 & 5.6 & 1.8 & 3.3 & 0.4 \\
\hline 3N6-o & & 4.2 & 5.2 & 3.9 & 4.1 & 3.2 \\
\hline $3 N 3-c$ & & 4.2 & 4.5 & 2.5 & 3.9 & 2.5 \\
\hline $3 N 3-d$ & & 4.2 & 4.5 & 2.5 & 4.0 & 2.6 \\
\hline $3 N 3-e$ & & 4.3 & 3.9 & 2.1 & 3.6 & 2.2 \\
\hline $3 N 3-f$ & & 4.3 & 4.5 & 2.8 & 3.6 & 2.4 \\
\hline $3 \mathrm{~N} 8-\mathrm{j}$ & & 4.3 & 2.2 & 1.8 & 2.3 & 2.0 \\
\hline $3 \mathrm{Nl} l-\mathrm{v}$ & & 4.3 & 4.7 & 5.5 & 1.6 & 2.4 \\
\hline $3 N 6-p$ & & 4.3 & 5.9 & 4.8 & 5.1 & 4.2 \\
\hline $3 N 6-q$ & & 4.3 & 5.2 & 3.7 & 4.2 & 3.2 \\
\hline $3 \mathrm{~N} 2-\mathrm{f}$ & & 4.4 & 4.8 & 4.8 & 2.4 & 2.7 \\
\hline 3N6-r & & 4.4 & 6.0 & 4.8 & 5.3 & 4.3 \\
\hline $3 N 1-W$ & & 4.6 & 5.1 & 4.4 & 4.8 & 4.2 \\
\hline 3N6-s & & 4.6 & 5.0 & 4.9 & 2.7 & 2.9 \\
\hline $3 N 1-x$ & & 4.6 & 5.0 & 5.0 & 2.8 & 2.8 \\
\hline 3N8-k & & 4.6 & 6.0 & 3.5 & 6.8 & 4.8 \\
\hline 3N6-t & & 4.6 & 5.7 & 4.5 & 4.5 & 3.6 \\
\hline $3 \mathrm{~N} 1-\mathrm{y}$ & & 4.6 & 6.1 & 4.2 & 4.6 & 3.2 \\
\hline $3 \mathrm{~N} 2-\mathrm{g}$ & $\mathrm{c}$ & 4.6 & 5.5 & 4.7 & 5.1 & 4.1 \\
\hline 3N1-aa & & 4.7 & 5.4 & 5.5 & 4.6 & 4.5 \\
\hline $3 \mathrm{~N} 1-\mathrm{Z}$ & & 4.7 & 5.0 & 4.9 & 3.2 & 3.0 \\
\hline $3 \mathrm{~N} 2-\mathrm{h}$ & & 4.7 & 5.4 & 5.5 & 3.2 & 3.4 \\
\hline 3N6-u & & 4.7 & 5.5 & 5.5 & 3.5 & 3.7 \\
\hline $3 N 6-y$ & & 4.8 & 6.0 & 4.5 & 4.7 & 3.7 \\
\hline $3 N 6-w$ & & 4.8 & 5.0 & 4.7 & 3.9 & 3.4 \\
\hline $3 \mathrm{~N} 3-\mathrm{g}$ & & 4.9 & 5.6 & 2.9 & 5.4 & 3.2 \\
\hline $3 \mathrm{~N} 2-\mathrm{i}$ & & 4.9 & 5.5 & 5.0 & 4.4 & 3.9 \\
\hline 3N6-X & & 4.9 & 5.7 & 4.7 & 3.5 & 3.0 \\
\hline 3N6-y & & 4.9 & 6.1 & 4.7 & 4.4 & 3.5 \\
\hline $3 N 8-1$ & & 4.9 & 5.7 & 4.9 & 5.3 & 4.8 \\
\hline $3 \mathrm{~N} 2-\mathrm{j}$ & & 5.0 & 5.6 & 4.7 & 5.6 & 4.6 \\
\hline $3 \mathrm{~N} 6-\mathrm{Z}$ & & 5.1 & 1.6 & 1.3 & 1.5 & 1.3 \\
\hline $3 \mathrm{~N} 2-\mathrm{k}$ & & 5.1 & 6.2 & 4.4 & 4.3 & 3.2 \\
\hline 3N2-I & & 5.1 & 5.6 & 5.9 & 2.5 & 2.9 \\
\hline $3 \mathrm{~N} 2-\mathrm{m}$ & & 5.1 & 5.5 & 4.8 & 5.2 & 4.3 \\
\hline $3 \mathrm{~N} 2-\mathrm{n}$ & & 5.2 & 5.8 & 5.9 & 2.8 & 3.0 \\
\hline
\end{tabular}


TABLE 3: (continued)

EFP1/HF and Full RHF/ $\quad$ MP2/RHF/ PCM+RHF/RHF/ PCM+MP2//RHF/

Structure Refs $\mathrm{RHF} / 6-31++\mathrm{G}(\mathrm{d}, \mathrm{p}) \quad 6-31++\mathrm{G}(\mathrm{d}, \mathrm{p}) \quad 6-31++\mathrm{G}(\mathrm{d}, \mathrm{p}) \quad 6-31++\mathrm{G}(\mathrm{d}, \mathrm{p}) \quad 6-31++\mathrm{G}(\mathrm{d}, \mathrm{p})$

\begin{tabular}{|c|c|c|c|c|c|c|}
\hline 3N6-aa & & 5.2 & 5.6 & 5.9 & 2.9 & 3.2 \\
\hline $3 \mathrm{~N} 2-\mathrm{O}$ & & 5.2 & 5.2 & 4.5 & 5.3 & 4.3 \\
\hline 3N6-ab & & 5.2 & 6.8 & 5.3 & 4.1 & 3.3 \\
\hline 3N8-m & & 5.2 & 6.3 & 4.8 & 4.1 & 2.8 \\
\hline 3N6-ac & & 5.2 & 5.7 & 5.9 & 2.9 & 3.2 \\
\hline 3N6-ad & & 5.3 & 6.0 & 3.5 & 6.8 & 4.6 \\
\hline 3N2-p & & 5.3 & 5.5 & 4.8 & 4.4 & 3.7 \\
\hline $3 \mathrm{~N} 1-\mathrm{ab}$ & & 5.3 & 5.7 & 6.0 & 4.2 & 4.3 \\
\hline 3N1-ac & & 5.4 & 5.7 & 6.1 & 4.2 & 4.3 \\
\hline 3N6-ae & & 5.4 & 5.0 & 3.6 & 3.6 & 2.7 \\
\hline 3N8-n & & 5.4 & 5.5 & 5.5 & 3.3 & 3.5 \\
\hline 3N1-ad & & 5.4 & 5.8 & 5.2 & 5.2 & 4.5 \\
\hline $3 \mathrm{~N} 2-\mathrm{q}$ & & 5.5 & 6.3 & 4.8 & 4.4 & 3.5 \\
\hline 3N1-ae & & 5.5 & 5.6 & 6.2 & 4.4 & 4.9 \\
\hline 3N3-h & $b, c$ & 5.5 & 6.5 & 3.9 & 6.7 & 4.3 \\
\hline 3N6-af & & 5.5 & 6.3 & 5.0 & 5.3 & 4.0 \\
\hline 3N8-o & & 5.5 & 6.2 & 6.3 & 4.3 & 4.4 \\
\hline 3N3-i & & 5.5 & 6.8 & 3.9 & 6.9 & 4.5 \\
\hline $3 \mathrm{~N} 2-\mathrm{r}$ & & 5.5 & 6.3 & 5.1 & 3.3 & 2.8 \\
\hline 3N1-af & & 5.5 & 5.7 & 6.1 & 4.4 & 4.6 \\
\hline 3N2-s & & 5.6 & 6.3 & 4.8 & 4.4 & 3.5 \\
\hline 3N1-ag & & 5.6 & 5.9 & 6.3 & 4.6 & 4.8 \\
\hline 3N1-ah & & 5.6 & 5.7 & 5.9 & 4.6 & 4.7 \\
\hline 3N6-ag & & 5.6 & 5.7 & 5.5 & 5.8 & 5.8 \\
\hline 3N1-ai & & 5.6 & 5.9 & 5.4 & 5.1 & 4.5 \\
\hline 3N6-ah & & 5.7 & 5.8 & 5.6 & 5.7 & 5.8 \\
\hline 3N8-p & & 5.7 & 6.0 & 5.9 & 4.1 & 3.9 \\
\hline 3N1-aj & & 5.7 & 6.9 & 6.0 & 5.0 & 4.6 \\
\hline 3N6-ai & & 5.7 & 6.0 & 5.2 & 5.4 & 4.8 \\
\hline 3N6-aj & & 5.7 & 7.0 & 5.9 & 5.1 & 4.1 \\
\hline $3 N 7-b$ & & 5.7 & 6.9 & 3.2 & 7.3 & 4.0 \\
\hline 3N6-ak & & 5.8 & 6.4 & 5.7 & 5.8 & 5.3 \\
\hline 3N6-al & & 5.8 & 6.9 & 6.1 & 5.3 & 4.8 \\
\hline 3N6-am & & 5.8 & 6.8 & 6.2 & 5.3 & 4.9 \\
\hline 3N6-an & & 5.8 & 6.1 & 5.3 & 5.6 & 5.0 \\
\hline 3N8-q & & 5.8 & 6.2 & 5.5 & 5.2 & 4.5 \\
\hline $3 \mathrm{~N} 2-\mathrm{t}$ & & 5.8 & 5.7 & 5.4 & 5.3 & 5.4 \\
\hline $3 \mathrm{~N} 2-\mathrm{u}$ & & 5.8 & 6.2 & 6.1 & 5.1 & 4.9 \\
\hline 3N6-ao & & 5.8 & 6.6 & 6.8 & 5.5 & 5.9 \\
\hline 3N6-ap & & 5.9 & 6.2 & 6.1 & 4.2 & 4.1 \\
\hline $3 \mathrm{~N} 6-\mathrm{aq}$ & & 5.9 & 6.5 & 5.8 & 5.9 & 5.4 \\
\hline $3 \mathrm{~N} 2-\mathrm{v}$ & & 5.9 & 5.8 & 5.2 & 4.4 & 3.8 \\
\hline 3N8-r & & 5.9 & 6.4 & 6.6 & 3.6 & 3.9 \\
\hline 3N8-s & & 5.9 & 6.7 & 5.0 & 4.8 & 3.8 \\
\hline $3 N 2-w$ & & 5.9 & 6.3 & 5.4 & 5.8 & 4.9 \\
\hline
\end{tabular}


TABLE 3: (continued)

\begin{tabular}{|c|c|c|c|c|c|c|}
\hline Structure & Refs & $\begin{array}{c}\text { EFP1/HF and } \\
\text { RHF/6-31++G(d,p) }\end{array}$ & $\begin{array}{c}\text { Full RHF/ } \\
6-31++G(d, p)\end{array}$ & $\begin{array}{c}\mathrm{MP} 2 / / \mathrm{RHF} / \\
6-31++\mathrm{G}(\mathrm{d}, \mathrm{p})\end{array}$ & $\begin{array}{c}\mathrm{PCM}+\mathrm{RHF} / \mathrm{RHF} / \\
6-31++\mathrm{G}(\mathrm{d}, \mathrm{p})\end{array}$ & $\begin{array}{c}\mathrm{PCM}+\mathrm{MP} 2 / / \mathrm{RHF} / \\
6-31++\mathrm{G}(\mathrm{d}, \mathrm{p})\end{array}$ \\
\hline $3 \mathrm{~N} 6$-ar & & 5.9 & 6.1 & 5.1 & 5.7 & 5.0 \\
\hline 3N1-ak & & 5.9 & 6.9 & 6.4 & 6.5 & 6.0 \\
\hline 3N6-as & & 5.9 & 6.9 & 6.3 & 5.3 & 4.9 \\
\hline $3 N 8-t$ & & 6.0 & 6.5 & 6.7 & 3.6 & 3.9 \\
\hline 3N6-at & & 6.0 & 6.2 & 5.4 & 5.8 & 5.3 \\
\hline 3N6-au & & 6.0 & 6.3 & 6.2 & 4.4 & 4.3 \\
\hline 3N8-u & & 6.1 & 8.2 & 5.5 & 6.9 & 4.9 \\
\hline $3 N 3-j$ & & 6.1 & 7.3 & 4.4 & 7.0 & 4.8 \\
\hline $3 N 6-a v$ & & 6.1 & 7.2 & 6.4 & 5.2 & 4.5 \\
\hline 3N6-aw & & 6.1 & 5.8 & 5.6 & 5.8 & 5.8 \\
\hline 3N8-y & & 6.2 & 5.2 & 3.9 & 4.1 & 3.3 \\
\hline $3 N 5-a$ & & 6.2 & 7.2 & 3.6 & 4.1 & 1.6 \\
\hline $3 \mathrm{~N} 2-\mathrm{x}$ & & 6.2 & 6.5 & 6.2 & 6.1 & 5.4 \\
\hline $3 N 2-y$ & & 6.2 & 6.6 & 5.6 & 6.0 & 5.3 \\
\hline $3 \mathrm{~N} 1-\mathrm{al}$ & & 6.2 & 6.8 & 6.7 & 6.0 & 6.2 \\
\hline 3N8-w & & 6.2 & 7.4 & 5.0 & 7.0 & 4.9 \\
\hline 3N1-am & & 6.2 & 7.7 & 6.5 & 5.9 & 5.3 \\
\hline 3N1-an & & 6.2 & 7.8 & 6.9 & 5.0 & 4.6 \\
\hline $3 N 4-b$ & & 6.3 & 6.6 & 4.9 & 5.4 & 4.0 \\
\hline 3N1-ao & & 6.3 & 6.6 & 6.9 & 5.5 & 5.9 \\
\hline $3 \mathrm{~N} 4 \mathrm{c}$ & & 6.3 & 6.3 & 4.9 & 3.5 & 2.8 \\
\hline $3 \mathrm{~N} 2-\mathrm{z}$ & & 6.4 & 6.8 & 7.3 & 5.4 & 5.9 \\
\hline $3 N 8-x$ & & 6.5 & 6.7 & 5.1 & 5.1 & 4.1 \\
\hline 3N1-ap & & 6.5 & 7.1 & 7.5 & 5.8 & 6.4 \\
\hline $3 \mathrm{~N} 8-\mathrm{y}$ & & 6.5 & 6.6 & 6.3 & 6.4 & 6.4 \\
\hline $3 N 8-z$ & & 6.5 & 6.1 & 5.4 & 5.2 & 4.5 \\
\hline 3N8-aa & & 6.5 & 6.7 & 6.4 & 6.4 & 6.4 \\
\hline 3N2-aa & & 6.5 & 6.9 & 7.0 & 5.5 & 5.5 \\
\hline 3N6-ax & & 6.6 & 7.7 & 7.1 & 6.3 & 6.2 \\
\hline $3 N 1-a q$ & & 6.6 & 7.2 & 7.5 & 4.1 & 4.3 \\
\hline $3 N 8-a b$ & & 6.6 & 7.9 & 5.0 & 7.6 & 5.4 \\
\hline $3 N 2-a b$ & & 6.6 & 7.2 & 6.5 & 7.2 & 6.2 \\
\hline 3N1-ar & a & 6.6 & 7.1 & 7.3 & 4.1 & 4.2 \\
\hline $3 \mathrm{~N} 2-\mathrm{ac}$ & & 6.7 & 7.8 & 6.7 & 6.7 & 5.7 \\
\hline $3 \mathrm{~N} 1$-as & & 6.7 & 6.9 & 8.0 & 3.8 & 4.9 \\
\hline $3 N 8-a c$ & & 6.7 & 7.9 & 6.3 & 5.6 & 4.3 \\
\hline 3N6-ay & & 6.8 & 8.2 & 7.0 & 6.9 & 6.1 \\
\hline $3 \mathrm{~N} 8 \mathrm{-ad}$ & & 6.8 & 8.3 & 6.8 & 7.3 & 6.1 \\
\hline 3N8-ae & & 6.9 & 7.3 & 6.4 & 6.7 & 6.1 \\
\hline 3N3-k & & 6.9 & 7.9 & 5.8 & 6.3 & 4.7 \\
\hline $3 \mathrm{~N} 1$-at & & 6.9 & 7.8 & 8.9 & 5.8 & 6.8 \\
\hline 3N8-af & & 6.9 & 7.3 & 6.3 & 6.5 & 5.9 \\
\hline 3N8-ag & & 6.9 & 7.3 & 6.3 & 6.7 & 6.1 \\
\hline 3N5-b & & 6.9 & 7.5 & 5.3 & 6.6 & 5.0 \\
\hline 3N8-ah & & 7.0 & 7.5 & 6.6 & 7.3 & 6.4 \\
\hline
\end{tabular}


TABLE 3: (continued)

\begin{tabular}{|c|c|c|c|c|c|}
\hline Structure Refs & $\begin{array}{c}\text { EFP1/HF and } \\
\text { RHF/6-31++G(d,p) }\end{array}$ & $\begin{array}{c}\text { Full RHF/ } \\
6-31++G(d, p)\end{array}$ & $\begin{array}{c}\text { MP2//RHF/ } \\
6-31++G(d, p) \\
\end{array}$ & $\begin{array}{c}\mathrm{PCM}+\mathrm{RHF} / / \mathrm{RHF} / \\
6-31++\mathrm{G}(\mathrm{d}, \mathrm{p})\end{array}$ & $\begin{array}{c}\mathrm{PCM}+\mathrm{MP} 2 / / \mathrm{RHF} / \\
6-31++\mathrm{G}(\mathrm{d}, \mathrm{p}) \\
\end{array}$ \\
\hline 3N1-au & 7.0 & 7.9 & 8.5 & 5.9 & 6.6 \\
\hline $3 N 7-c$ & 7.1 & 8.2 & 5.6 & 6.5 & 4.5 \\
\hline 3N8-ai & 7.1 & 8.1 & 6.7 & 6.0 & 4.8 \\
\hline 3N8-aj & 7.1 & 7.4 & 7.6 & 6.2 & 6.4 \\
\hline 3N8-ak & 7.1 & 8.1 & 5.2 & 7.1 & 4.8 \\
\hline 3N6-az & 7.1 & 9.0 & 7.3 & 6.0 & 4.9 \\
\hline $3 \mathrm{~N} 1-\mathrm{av}$ & 7.1 & 7.9 & 8.2 . & 5.2 & 5.5 \\
\hline 3N1-aw & 7.2 & 8.0 & 7.9 & 4.9 & 4.8 \\
\hline 3N8-al & 7.2 & 7.5 & 7.9 & 5.3 & 5.8 \\
\hline 3N6-ba & 7.2 & 7.7 & 7.8 & 6.2 & 6.5 \\
\hline 3N8-am & 7.2 & 7.3 & 6.4 & 6.7 & 6.1 \\
\hline 3N1-ax & 7.3 & 8.0 & 7.8 & 5.1 & 5.1 \\
\hline 3N8-an & 7.3 & 7.4 & 7.7 & 6.5 & 6.7 \\
\hline 3N1-ay & 7.3 & 7.5 & 7.7 & 4.1 & 4.3 \\
\hline $3 N 5-c$ & 7.3 & 8.1 & 6.2 & 6.4 & 5.1 \\
\hline 3N1-az & 7.3 & 7.9 & 7.7 & 5.3 & 5.3 \\
\hline $3 \mathrm{~N} 2-\mathrm{ad}$ & 7.4 & 8.3 & 7.4 & 7.9 & 7.1 \\
\hline $3 N 7-d$ & 7.4 & 8.3 & 4.9 & 6.8 & 4.1 \\
\hline 3N3-1 & 7.4 & 7.4 & 6.1 & 4.3 & 3.9 \\
\hline 3NI-ba & 7.4 & 8.6 & 8.9 & 6.6 & 7.0 \\
\hline 3N5-d & 7.5 & 8.1 & 6.0 & 5.7 & 4.3 \\
\hline 3N8-ao & 7.5 & 8.1 & 6.7 & 5.0 & 4.4 \\
\hline 3N1-bb & 7.5 & 7.5 & 8.3 & 5.6 & 6.6 \\
\hline 3N6-bb & 7.5 & 8.5 & 7.4 & 6.7 & 5.5 \\
\hline 3N8-ap & 7.5 & 8.4 & 7.5 & 6.6 & 6.2 \\
\hline 3N3-m & 7.5 & 7.9 & 6.5 & 6.5 & 5.3 \\
\hline $3 \mathrm{~N} 2-\mathrm{ae}$ & 7.5 & 7.8 & 8.2 & 5.7 & 5.9 \\
\hline 3N1-bc & 7.5 & 7.5 & 8.2 & 5.6 & 6.6 \\
\hline $3 \mathrm{~N} 2$-af & 7.6 & 8.4 & 7.9 & 6.1 & 5.7 \\
\hline $3 \mathrm{~N} 8$-aq & 7.6 & 9.1 & 7.7 & 5.5 & 4.7 \\
\hline 3N7-e & 7.6 & 8.1 & 5.9 & 6.9 & 5.2 \\
\hline 3N6-bc & 7.6 & 8.4 & 8.3 & 5.0 & 5.0 \\
\hline 3N2-ag & 7.7 & 8.6 & 8.9 & 3.6 & 4.5 \\
\hline 3N7-f & 7.7 & 8.1 & 6.4 & 5.6 & 4.6 \\
\hline 3N5-e & 7.8 & 8.4 & 6.5 & 6.1 & 4.8 \\
\hline 3N6-bd & 7.8 & 8.3 & 9.0 & 5.0 & 5.9 \\
\hline 3N6-be & 7.8 & 8.2 & 8.1 & 6.5 & 6.4 \\
\hline $3 N 7-g$ & 7.9 & 4.1 & 2.3 & 3.6 & 2.3 \\
\hline 3N2-ah & 7.9 & 8.7 & 8.4 & 5.8 & 5.6 \\
\hline 3N2-ai & 7.9 & 9.0 & 8.6 & 5.9 & 5.6 \\
\hline 3N8-ar & 8.0 & 8.2 & 8.6 & 6.5 & 6.7 \\
\hline $3 N 6-b f$ & 8.0 & 8.7 & 9.3 & 6.7 & 7.4 \\
\hline 3N8-as & 8.0 & 8.3 & 7.6 & 6.8 & 6.6 \\
\hline 3N6-bg & 8.0 & 8.2 & 7.9 & 5.2 & 5.0 \\
\hline $3 N 3-n$ & 8.0 & 9.1 & 6.3 & 6.9 & 4.9 \\
\hline
\end{tabular}


TABLE 3: (continued)

\begin{tabular}{|c|c|c|c|c|c|}
\hline Structure Refs & $\begin{array}{c}\text { EFP1/HF and } \\
\text { RHF/6-31 }++G(d, p)\end{array}$ & $\begin{array}{c}\text { Full RHF/ } \\
6-31++\mathrm{G}(\mathrm{d}, \mathrm{p})\end{array}$ & $\begin{array}{c}\mathrm{MP} 2 / / \mathrm{RHF} / \\
6-31++G(\mathrm{~d}, \mathrm{p})\end{array}$ & $\begin{array}{c}\mathrm{PCM}+\mathrm{RHF} / / \mathrm{RHF} / \\
6-31++\mathrm{G}(\mathrm{d}, \mathrm{p})\end{array}$ & $\begin{array}{c}\mathrm{PCM}+\mathrm{MP} 2 / \mathrm{RHF} / \\
6-31++\mathrm{G}(\mathrm{d}, \mathrm{p}) \\
\end{array}$ \\
\hline 3 N7-h & 8.0 & 8.0 & 6.4 & 5.4 & 4.5 \\
\hline $3 N 7-i$ & 8.1 & 8.4 & 6.9 & 5.8 & 5.0 \\
\hline 3N8-at & 8.1 & 9.0 & 8.1 & 5.7 & 5.0 \\
\hline $3 N 7-j$ & 8.1 & 9.8 & 6.3 & 8.2 & 5.6 \\
\hline $3 N 7-k$ & 8.2 & 8.5 & 6.6 & 7.2 & 5.8 \\
\hline 3N8-au & 8.2 & 8.4 & 8.9 & 6.5 & 6.8 \\
\hline $3 N 8-a v$ & 8.2 & 8.4 & 9.0 & 6.7 & 7.0 \\
\hline 3N8-aw & 8.3 & 8.5 & 9.0 & 6.6 & 6.9 \\
\hline 3N8-ax & 8.3 & 8.5 & 9.0 & 6.8 & 7.2 \\
\hline 3N8-ay & 8.3 & 9.6 & 8.7 & 6.3 & 5.6 \\
\hline 3N8-az & 8.3 & 8.9 & 8.8 & 6.7 & 6.6 \\
\hline $3 N 1-b d$ & 8.4 & 8.9 & 10.0 & 4.6 & 5.8 \\
\hline 3N1-be & 8.4 & 9.0 & 8.4 & 6.0 & 5.9 \\
\hline 3N8-ba & 8.4 & 8.6 & 7.9 & 7.0 & 6.3 \\
\hline 3N6-bh & 8.4 & 8.8 & 8.5 & 5.3 & 5.7 \\
\hline $3 N 2-a j$ & 8.4 & 9.2 & 9.3 & 5.0 & 5.2 \\
\hline $3 N 8-b b$ & 8.4 & 9.7 & 9.0 & 6.3 & 5.9 \\
\hline $3 \mathrm{~N} 1-\mathrm{bf}$ & 8.5 & 8.5 & 9.7 & 5.2 & 6.3 \\
\hline 3N2-ak & 8.5 & 8.9 & 10.1 & 4.4 & 5.7 \\
\hline 3N8-bc & 8.5 & 8.9 & 8.7 & 7.3 & 7.0 \\
\hline 3N1-bg & 8.6 & 9.5 & 8.7 & 7.4 & 7.1 \\
\hline $3 \mathrm{~N} 2-\mathrm{al}$ & 8.6 & 9.2 & 8.5 & 7.2 & 6.4 \\
\hline 3N8-bd & 8.7 & 8.9 & 9.6 & 6.8 & 7.4 \\
\hline 3N8-be & 8.7 & 8.9 & 9.4 & 6.8 & 7.1 \\
\hline 3N6-bi & 8.7 & 9.5 & 9.3 & 5.9 & 6.3 \\
\hline 3N2-am & 8.7 & 9.3 & 9.5 & 7.3 & 7.7 \\
\hline 3N8-bf & 8.7 & 8.5 & 9.0 & 6.8 & 7.1 \\
\hline $3 \mathrm{~N} 2$-an & 8.8 & 9.3 & 8.8 & 7.1 & 6.7 \\
\hline 3N8-bg & 8.8 & 8.8 & 7.5 & 5.1 & 4.1 \\
\hline $3 N 7-1$ & 8.9 & 10.4 & 6.6 & 7,4 & 4.7 \\
\hline 3N1-bh & 8.9 & 10.0 & 9.5 & 5.1 & 5.0 \\
\hline 3N2-ao & 9.0 & 9.3 & 8.8 & 7.1 & 6.7 \\
\hline 3N8-bh & 9.0 & 9.6 & 10.5 & 5.7 & 6.7 \\
\hline 3N2-ap & 9.1 & 9.4 & 9.1 & 7.0 & 6.8 \\
\hline $3 \mathrm{~N} 6-\mathrm{bj}$ & 9.1 & 8.9 & 9.2 & 6.9 & 7.7 \\
\hline 3N8-bi & 9.1 & 9.2 & 10.2 & 6.9 & 7.8 \\
\hline 3N8-bj & 9.2 & 9.6 & 9.5 & 8.7 & 8.3 \\
\hline $3 N 3-0$ & 9.2 & 9.7 & 8.6 & 7.0 & 6.5 \\
\hline 3N1-bi & 9.2 & 9.3 & 10.6 & 5.4 & 6.6 \\
\hline 3N8-bk & 9.2 & 9.9 & 9.9 & 8.4 & 8.6 \\
\hline 3N8-bl & 9.2 & 9.8 & 10.0 & 8.1 & 8.6 \\
\hline 3N3-p & 9.2 & 9.6 & 8.6 & 6.9 & 6.4 \\
\hline 3N1-bj & 9.3 & 9.5 & 9.9 & 4.8 & 5.6 \\
\hline 3N8-bm & 9.3 & 9.7 & 10.7 & 5.8 & 6.9 \\
\hline 3N6-bk & 9.3 & 10.2 & 8.5 & 7.6 & 6.5 \\
\hline
\end{tabular}


TABLE 3: (continued)

\begin{tabular}{|c|c|c|c|c|c|}
\hline Structure Refs & $\begin{array}{c}\text { EFP1/HF and } \\
\text { RHF/6-31++G(d,p) }\end{array}$ & $\begin{array}{c}\text { Full RHF/ } \\
6-31++\mathrm{G}(\mathrm{d}, \mathrm{p})\end{array}$ & $\begin{array}{c}\mathrm{MP} 2 / / \mathrm{RHF} / \\
6-31++\mathrm{G}(\mathrm{d}, \mathrm{p})\end{array}$ & $\begin{array}{c}\mathrm{PCM}+\mathrm{RHF} / / \mathrm{RHF} / \\
6-31++\mathrm{G}(\mathrm{d}, \mathrm{p})\end{array}$ & $\begin{array}{c}\mathrm{PCM}+\mathrm{MP} 2 / / \mathrm{RHF} / \\
6-31++\mathrm{G}(\mathrm{d}, \mathrm{p})\end{array}$ \\
\hline $3 \mathrm{~N} 7-\mathrm{m}$ & 9.3 & 10.3 & 7.7 & 6.9 & 5.1 \\
\hline 3N8-bn & 9.4 & 9.5 & 10.5 & 7.1 & 8.0 \\
\hline 3N6-bl & 9.6 & 9.8 & 9.8 & 7.1 & 7.3 \\
\hline 3N3-q & 9.6 & 10.1 & 9.4 & 7.4 & 6.9 \\
\hline 3N8-bo & 9.6 & 10.4 & 9.7 & 8.3 & 8.4 \\
\hline 3N3-r & 9.6 & 9.9 & $8.9^{\circ}$ & 7.2 & 6.6 \\
\hline 3N6-bm & 9.6 & 10.4 & 11.4 & 5.9 & 7.2 \\
\hline 3N2-aq & 9.6 & 10.0 & 10.1 & 6.2 & 6.7 \\
\hline 3N8-bp & 9.7 & 10.5 & 11.4 & 8.3 & 9.3 \\
\hline 3N4-d & 9.7 & 10.7 & 8.3 & 6.4 & 5.1 \\
\hline 3N8-bq & 9.8 & 10.4 & 9.2 & 9.6 & 8.5 \\
\hline $3 N 3-s$ & 9.8 & 9.6 & 8.8 & 5.2 & 5.4 \\
\hline 3N6-bn & 9.9 & 10.1 & 10.5 & 7.2 & 7.7 \\
\hline 3N6-bo & 9.9 & 11.7 & 9.8 & 9.0 & 7.9 \\
\hline $3 N 6-b p$ & 10.0 & 10.6 & 10.5 & 6.8 & 7.1 \\
\hline $3 N 2-a r$ & 10.2 & 11.2 & 11.9 & 8.1 & 8.5 \\
\hline $3 \mathrm{~N} 8$-br & 10.2 & 10.5 & 10.1 & 8.4 & 8.1 \\
\hline 3N1-bk & 10.3 & 10.2 & 10.9 & 6.7 & 7.9 \\
\hline 3N2-as & 10.3 & 10.6 & 11.3 & 6.7 & 7.5 \\
\hline 3N6-bq & 10.3 & 10.5 & 11.5 & 6.3 & 7.3 \\
\hline 3N6-br & 10.3 & 10.5 & 11.4 & 6.6 & 7.5 \\
\hline $3 \mathrm{~N} 2$-at & 10.4 & 8.9 & 8.7 & 5.9 & 5.7 \\
\hline 3N8-bs & 10.4 & 11.4 & 11.1 & 4.8 & 4.9 \\
\hline 3N6-bs & 10.5 & 11.1 & 10.9 & 8.3 & 8.7 \\
\hline 3N4-e & 10.5 & 11.1 & 11.1 & 5.4 & 5.8 \\
\hline $3 N 8-b t$ & 10.5 & 11.2 & 11.2 & 7.0 & 7.2 \\
\hline $3 N 4-f$ & 10.7 & 11.4 & 10.7 & 5.9 & 6.0 \\
\hline $3 \mathrm{~N} 4 \mathrm{~g}$ & 10.8 & 10.7 & 9.6 & 8.5 & 7.9 \\
\hline 3N8-bu & 10.8 & 11.4 & 11.3 & 8.0 & 8.3 \\
\hline 3N3-t & 10.9 & 10.8 & 10.5 & 6.7 & 7.1 \\
\hline 3N4-h & 10.9 & 11.0 & 10.9 & 7.4 & 7.7 \\
\hline $3 \mathrm{~N} 4-\mathrm{i}$ & 11.0 & 10.9 & 10.8 & 7.3 & 7.6 \\
\hline 3N6-bt & 11.0 & 11.5 & 11.8 & 8.4 & 9.3 \\
\hline 3N7-n & 11.2 & 12.2 & 10.1 & 6.9 & 6.0 \\
\hline 3N8-bv & 11.2 & 11.5 & 12.0 & 7.8 & 8.5 \\
\hline $3 N 2-a u$ & 11.3 & 11.5 & 11.6 & 6.5 & 7.0 \\
\hline $3 \mathrm{~N} 4 \mathrm{j}$ & 11.3 & 12.0 & 11.3 & 6.9 & 7.2 \\
\hline 3N6-bu & 11.4 & 12.1 & 12.3 & 8.7 & 9.0 \\
\hline 3N8-bw & 11.4 & 11.5 & 12.0 & 8.4 & 8.8 \\
\hline 3N8-bx & 11.4 & 11.5 & 11.9 & 8.5 & 8.7 \\
\hline 3N8-by & 11.4 & 11.5 & 11.9 & 5.2 & 8.7 \\
\hline $3 \mathrm{~N} 2-\mathrm{av}$ & 11.5 & 11.6 & 12.2 & 7.4 & 8.0 \\
\hline $3 \mathrm{~N} 8-\mathrm{bz}$ & 11.6 & 12.8 & 11.2 & 8.5 & 7.4 \\
\hline 3N7-o & 11.6 & 12.7 & 10.2 & 8.4 & 6.8 \\
\hline $3 N 7-p$ & 11.7 & 12.7 & 10.6 & 7.2 & 6.2 \\
\hline
\end{tabular}


TABLE 3: (continued)

\begin{tabular}{|c|c|c|c|c|c|c|}
\hline Structure & Refs & $\begin{array}{c}\mathrm{EFP} 1 / \mathrm{HF} \text { and } \\
\mathrm{RHF} / 6-31++\mathrm{G}(\mathrm{d}, \mathrm{p})\end{array}$ & $\begin{array}{c}\text { Full RHF/ } \\
6-31++G(d, p)\end{array}$ & $\begin{array}{c}\mathrm{MP} 2 / / \mathrm{RHF} / \\
6-31++\mathrm{G}(\mathrm{d}, \mathrm{p})\end{array}$ & $\begin{array}{c}\mathrm{PCM}+\mathrm{RHF} / / \mathrm{RHF} / \\
6-31++\mathrm{G}(\mathrm{d}, \mathrm{p})\end{array}$ & $\begin{array}{c}\mathrm{PCM}+\mathrm{MP} 2 / \mathrm{RHF} / \\
6-31++\mathrm{G}(\mathrm{d}, \mathrm{p}) \\
\end{array}$ \\
\hline $3 \mathrm{~N} 7-\mathrm{q}$ & & 11.7 & 12.8 & 9.9 & 9.9 & 7.9 \\
\hline $3 N 5-f$ & & 11.7 & 11.9 & 10.2 & 8.0 & 7.0 \\
\hline $3 \mathrm{~N} 6-\mathrm{bv}$ & & 11.8 & 12.2 & 11.8 & 7.8 & 8.0 \\
\hline 3N8-ca & & 11.8 & 12.1 & 12.4 & 8.3 & 9.0 \\
\hline $3 N 5-g$ & & 11.9 & 12.8 & 12.1 & 7.7 & 8.0 \\
\hline $3 N 8-c b$ & & 11.9 & 11.4 & 11.0 & 8.6 & 8.5 \\
\hline 3N6-bw & & 11.9 & 11.7 & 12.4 & 7.9 & 9.3 \\
\hline 3N5-h & & 12.0 & 13.3 & 12.2 & 8.1 & 8.0 \\
\hline 3N2-aw & & 12.1 & 13.0 & 12.3 & 7.1 & 7.1 \\
\hline $3 N 7-r$ & & 12.1 & 13.3 & 11.2 & 7.2 & 6.2 \\
\hline $3 N 4-k$ & & 12.1 & 12.4 & 12.1 & 7.7 & 8.1 \\
\hline $3 \mathrm{~N} 4-\mathrm{l}$ & & 12.2 & 13.2 & 11.9 & 10.1 & 9.0 \\
\hline $3 N 7-s$ & & 12.4 & 14.0 & 13.2 & 7.3 & 7.3 \\
\hline $3 N 7-\mathrm{t}$ & & 12.4 & 12.7 & 12.1 & 8.7 & 8.7 \\
\hline $3 N 5-i$ & & 12.5 & 13.7 & 11.3 & 11.1 & 9.5 \\
\hline $3 N 8-c c$ & & 12.5 & 13.5 & 13.6 & 8.7 & 8.8 \\
\hline $3 \mathrm{~N} 7-\mathrm{u}$ & & 12.5 & 13.1 & 12.9 & 7.9 & 8.5 \\
\hline $3 N 7-v$ & & 12.6 & 13.3 & 11.9 & 6.9 & 6.6 \\
\hline $3 N 7-w$ & & 12.7 & 13.8 & 13.1 & 7.4 & 7.6 \\
\hline $3 N 5-j$ & & 12.7 & 13.0 & 12.7 & 8.7 & 8.9 \\
\hline $3 N 7-x$ & & 12.7 & 13.7 & 12.7 & 9.8 & 9.7 \\
\hline $3 \mathrm{~N} 3-\mathrm{u}$ & & 12.8 & 13.5 & 11.7 & 9.0 & 8.3 \\
\hline 3N5-k & & 12.9 & 13.9 & 12.4 & 7.7 & 7.3 \\
\hline 3N5-I & & 13.0 & 14.1 & 13.0 & 9.8 & 9.2 \\
\hline $3 N 7-y$ & & 13.0 & 13.5 & 13.4 & 6.5 & 7.2 \\
\hline $3 \mathrm{~N} 4-\mathrm{m}$ & & 13.0 & 14.0 & 13.3 & 8.1 & 8.3 \\
\hline $3 \mathrm{~N} 7-\mathrm{z}$ & & 13.0 & 13.6 & 13.7 & 6.6 & 7.4 \\
\hline 3N7-aa & & 13.1 & 14.7 & 13.5 & 6.9 & 6.9 \\
\hline $3 N 4-n$ & & 13.2 & 14.1 & 12.7 & 8.7 & 8.2 \\
\hline 3N6-bx & & 13.2 & 13.7 & 14.8 & 7.5 & 9.1 \\
\hline 3N5-m & & 13.2 & 13.9 & 12.6 & 10.5 & 9.9 \\
\hline $3 \mathrm{~N} 4-0$ & & 13.4 & 13.0 & 12.6 & 10.7 & 10.4 \\
\hline $3 N 7-a b$ & & 13.5 & 13.7 & 12.7 & 8.3 & 8.2 \\
\hline $3 N 7-a c$ & & 13.8 & 14.1 & 13.9 & 7.9 & 8.2 \\
\hline $3 N 7-a d$ & & 15.7 & 16.0 & 16.5 & 7.9 & 8.9 \\
\hline $3 N 7-a e$ & & 17.9 & 18.0 & 18.1 & 13.5 & 14.1 \\
\hline $3 \mathrm{~N} 7$-af & & 18.5 & 18.9 & 20.1 & 9.2 & 11.2 \\
\hline $3 Z$-a & $b, c$ & 14.7 & 15.6 & 5.2 & 1.9 & -6.9 \\
\hline $3 Z-b$ & & 15.7 & 17.2 & 6.8 & 3.4 & -5.3 \\
\hline $3 Z-c$ & & 15.8 & 15.9 & 6.1 & 1.7 & -6.4 \\
\hline $3 Z-d$ & & 16.3 & 15.5 & 6.0 & 1.2 & -6.6 \\
\hline 3Z-e & & 16.3 & 16.6 & 7.1 & 3.7 & -4.5 \\
\hline $3 Z-f$ & & 16.4 & 15.5 & 6.0 & 1.5 & -6.4 \\
\hline $3 Z-g$ & & 16.5 & 16.3 & 6.0 & 2.4 & -6.2 \\
\hline $3 Z$-h & & 16.6 & 16.7 & 7.4 & 3.7 & -4.2 \\
\hline
\end{tabular}


TABLE 3: (continued)

\begin{tabular}{|c|c|c|c|c|c|}
\hline Structure Refs & $\begin{array}{c}\mathrm{EFP} 1 / \mathrm{HF} \text { and } \\
\mathrm{RHE} / 6-31++\mathrm{G}(\mathrm{d}, \mathrm{p})\end{array}$ & $\begin{array}{c}\text { Full RHF } / \\
6-31++G(d, p)\end{array}$ & $\begin{array}{c}\mathrm{MP} 2 / / \mathrm{RHF} / \\
6-31++\mathrm{G}(\mathrm{d}, \mathrm{p})\end{array}$ & $\begin{array}{c}\mathrm{PCM}+\mathrm{RHF} / \mathrm{RHF} / \\
6-31++\mathrm{G}(\mathrm{d}, \mathrm{p})\end{array}$ & $\begin{array}{c}\mathrm{PCM}+\mathrm{MP} 2 / / \mathrm{RHF} / \\
6-31++\mathrm{G}(\mathrm{d}, \mathrm{p})\end{array}$ \\
\hline $3 Z-i$ & 17.0 & 17.4 & 7.4 & 3.3 & -4.8 \\
\hline $3 Z-j$ & 17.2 & 16.3 & 7.1 & 1.2 & -6.2 \\
\hline $3 Z-k$ & 17.4 & 17.7 & 8.1 & 1.8 & -5.9 \\
\hline $3 Z-1$ & 19.1 & 18.6 & 10.0 & 2.3 & -4.8 \\
\hline 3Z-m & 19.5 & 19.5 & 11.2 & 2.2 & -4.2 \\
\hline $3 Z$-n & 19.5 & 19.6 & 10.2 & 4.1 & -3.5 \\
\hline $3 Z-0$ & 19.6 & 19.2 & 10.6 & 3.4 & -3.2 \\
\hline 3Z-p & 19.6 & 19.6 & 11.3 & 2.2 & -4.1 \\
\hline $3 Z-q$ & 19.7 & 17.0 & 7.1 & 1.9 & -5.9 \\
\hline $3 Z-r$ & 20.0 & 20.3 & 11.6 & 2.7 & -4.1 \\
\hline $3 Z-s$ & 20.0 & 19.1 & 9.8 & 7.0 & -0.9 \\
\hline $3 Z-t$ & 22.2 & 21.6 & 12.3 & 6.1 & -1.6 \\
\hline $3 Z-u$ & 22.7 & 21.5 & 12.4 & 6.0 & -1.6 \\
\hline $3 Z-v$ & 23.0 & 22.0 & 14.6 & 4.5 & -1.4 \\
\hline $3 Z-w$ & 23.6 & 22.5 & 15.8 & 3.7 & -1.3 \\
\hline $3 Z-x$ & 25.0 & 24.2 & 17.3 & 5.7 & 0.3 \\
\hline
\end{tabular}


TABLE 4: Structures and relative energies for glycine $\left(\mathrm{H}_{2} \mathrm{O}\right)_{4}$

\begin{tabular}{|c|c|c|c|c|c|}
\hline Structure & $\begin{array}{c}\text { EFP1/HF and } \\
\text { RHF/6-31++G(d,p) }\end{array}$ & 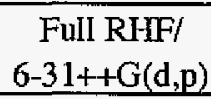 & $\begin{array}{c}\text { MP2//RHF/ } \\
6-31++\mathrm{G}(\mathrm{d}, \mathrm{p})\end{array}$ & $\begin{array}{c}\mathrm{PCM}+\mathrm{RHF} / / \mathrm{RHF} / \\
6-31++\mathrm{G}(\mathrm{d}, \mathrm{p})\end{array}$ & $\begin{array}{c}\mathrm{PCM}+\mathrm{MP} 2 / / \mathrm{RHF} / \\
6-31++\mathrm{G}(\mathrm{d}, \mathrm{p})\end{array}$ \\
\hline $4 \mathrm{~N} 1-\mathrm{a}$ & 0.0 & 0.0 & 0.0 & 0.0 & 0.0 \\
\hline $4 \mathrm{~N} 1-\mathrm{b}$ & 0.3 & 0.4 & 0.5 & 0.0 & 0.1 \\
\hline $4 \mathrm{~N} 1-\mathrm{c}$ & 0.7 & 1.0 & 0.8 & 0.4 & 0.3 \\
\hline $4 N 1-d$ & 0.9 & 0.3 & 0.4 & 0.3 & 0.5 \\
\hline $4 N 1-e$ & 1.2 & 1.4 & 1.3 & 0.5 & 0.5 \\
\hline $4 \mathrm{~N} 1-\mathrm{f}$ & 1.5 & 1.0 & 1.2 & 0.4 & 0.7 \\
\hline $4 N 1-g$ & 1.6 & 1.8 & 1.8 & 2.6 & 2.7 \\
\hline $4 \mathrm{~N} 1-\mathrm{h}$ & 1.7 & 1.6 & 1.2 & 2.1 & 1.7 \\
\hline $4 N 1-i$ & 1.7 & 1.4 & 1.1 & 0.7 & 0.5 \\
\hline $4 N 1-j$ & 1.8 & 2.4 & 2.3 & 2.1 & 1.8 \\
\hline $4 \mathrm{~N} 1-\mathrm{k}$ & 1.8 & 1.4 & 2.1 & 1.4 & 2.1 \\
\hline 4 N1-l & 1.9 & 1.4 & 2.3 & 1.4 & 2.3 \\
\hline $4 \mathrm{~N} 1-\mathrm{m}$ & 2.0 & 1.8 & 1.6 & 0.7 & 0.7 \\
\hline $4 N I-n$ & 2.1 & 2.1 & 2.0 & 0.9 & 1.1 \\
\hline $4 \mathrm{Nl}-\mathrm{O}$ & 2.2 & 2.3 & 2.3 & 2.1 & 2.0 \\
\hline $4 \mathrm{~N} 1-\mathrm{p}$ & 2.2 & 2.8 & 2.7 & 2.5 & 2.3 \\
\hline $4 N 1-q$ & 2.2 & 1.9 & 2.1 & 1.0 & 1.3 \\
\hline $4 \mathrm{~N} 1-\mathrm{r}$ & 2.2 & 2.1 & 2.2 & 0.9 & 1.2 \\
\hline $4 \mathrm{~N} 1-\mathrm{s}$ & 2.3 & 0.9 & 2.3 & 0.3 & 1.8 \\
\hline $4 \mathrm{~N} 1-\mathrm{t}$ & 2.3 & 1.7 & 2.7 & 1.6 & 2.6 \\
\hline $4 \mathrm{NI}-\mathrm{u}$ & 2.4 & 2.2 & 2.4 & 1.0 & 1.3 \\
\hline $4 \mathrm{~N} 1-\mathrm{V}$ & 2.4 & 2.1 & 2.4 & 1.2 & 1.5 \\
\hline $4 N 1-w$ & 2.4 & 2.2 & 2.3 & 1.1 & 1.4 \\
\hline $4 \mathrm{~N} 1-\mathrm{x}$ & 2.7 & 2.5 & 2.8 & 1.5 & 1.7 \\
\hline $4 \mathrm{~N} 1-\mathrm{y}$ & 2.9 & 3.5 & 2.8 & 4.2 & 3.3 \\
\hline $4 N 1-Z$ & 2.9 & 2.8 & 2.4 & 1.2 & 1.1 \\
\hline 4N6-a & 0.3 & 0.8 & -1.0 & 0.4 & -1.0 \\
\hline $4 \mathrm{Z}-\mathrm{a}$ & 12.1 & 11.7 & 1.6 & 1.2 & -7.7 \\
\hline $4 Z-b$ & 12.2 & 13.4 & 2.7 & 1.9 & -7.4 \\
\hline $4 \mathrm{Z}-\mathrm{c}$ & 12.3 & 13.3 & 3.0 & 0.9 & -7.8 \\
\hline $4 Z-d$ & 12.3 & 13.1 & 2.6 & 0.9 & -8.0 \\
\hline 4Z-e & 12.5 & 13.6 & 3.2 & 1.2 & -7.5 \\
\hline $4 Z$-f & 12.8 & 14.9 & 3.2 & 4.9 & -5.3 \\
\hline $4 Z-g$ & 13.1 & 13.2 & 3.9 & 0.2 & -7.6 \\
\hline 4Z-h & 13.3 & 13.1 & 3.1 & 1.0 & -7.4 \\
\hline $4 Z-i$ & 13.5 & 12.0 & 2.9 & 0.6 & -7.1 \\
\hline $4 Z-j$ & 13.5 & 14.0 & 3.6 & 1.8 & -7.0 \\
\hline $4 Z-k$ & 13.6 & 13.3 & 3.3 & 2.8 & -5.8 \\
\hline 4Z-1 & 13.6 & 14.8 & 4.8 & 3.2 & -5.3 \\
\hline $4 Z-m$ & 13.7 & 14.6 & 4.8 & 1.8 & -6.2 \\
\hline $4 Z-n$ & 13.7 & 12.5 & 3.4 & -0.5 & -8.0 \\
\hline $4 Z-o$ & 13.7 & 13.0 & 3.3 & 1.6 & -6.7 \\
\hline 4Z-p & 13.8 & 14.5 & 4.2 & 2.1 & -6.4 \\
\hline $4 Z-q$ & 13.9 & 12.8 & 3.2 & 1.5 & -6.6 \\
\hline 4Z-r & 14.0 & 13.0 & 3.4 & 0.1 & -7.9 \\
\hline
\end{tabular}


TABLE 4: (continued)

\begin{tabular}{|c|c|c|c|c|c|}
\hline Structure & $\begin{array}{c}\text { EFP1/HF and } \\
\text { RHF/6-31++G(d,p) }\end{array}$ & $\begin{array}{c}\text { Full RHF/ } \\
6-31++G(d, p)\end{array}$ & $\begin{array}{c}\mathrm{MP2} / / \mathrm{RHF} / \\
6-31++\mathrm{G}(\mathrm{d}, \mathrm{p})\end{array}$ & $\begin{array}{c}\mathrm{PCM}+\mathrm{RHF} / \mathrm{RHF} / \\
6-31++\mathrm{G}(\mathrm{d}, \mathrm{p})\end{array}$ & $\begin{array}{c}\mathrm{PCM}+\mathrm{MP} 2 / / \mathrm{RHF} / \\
6-31++\mathrm{G}(\mathrm{d}, \mathrm{p})\end{array}$ \\
\hline $4 \mathrm{Z}-\mathrm{s}$ & 14.1 & 14.1 & 4.9 & 0.9 & -6.6 \\
\hline $4 Z-t$ & 14.1 & 13.7 & 4.8 & 2.3 & -5.3 \\
\hline $4 Z-u$ & 14.1 & 14.5 & 4.8 & 1.6 & -6.5 \\
\hline $4 \mathrm{Z}-\mathrm{v}$ & 14.2 & 12.9 & 3.9 & -0.5 & -7.8 \\
\hline 4Z-w & 14.3 & 13.4 & 3.7 & 1.4 & -6.7 \\
\hline $4 Z-x$ & 14.5 & 12.9 & 4.0 & 2.7 & -4.7 \\
\hline $4 Z-y$ & 14.6 & 14.9 & 4.9 & 1.9 & -6.4 \\
\hline $4 \mathrm{Z}-\mathrm{z}$ & 14.6 & 13.7 & 5.0 & 1.6 & -5.8 \\
\hline 4Z-aa & 14.6 & 13.7 & 4.5 & -0.2 & -7.5 \\
\hline $4 Z-a b$ & 14.6 & 14.0 & 5.2 & 2.4 & -5.1 \\
\hline $4 Z-a c$ & 14.6 & 13.9 & 4.6 & 0.2 & -7.4 \\
\hline $4 Z$-ad & 14.6 & 14.2 & 4.8 & 3.3 & -4.7 \\
\hline $4 Z$-ae & 14.7 & 13.9 & 4.2 & 1.6 & -6.4 \\
\hline 4Z-af & 14.7 & 14.7 & 4.3 & 3.8 & -5.0 \\
\hline $4 Z$-ag & 14.7 & 13.1 & 4.6 & 3.0 & -4.2 \\
\hline $4 Z$-ah & 14.8 & 15.0 & 5.5 & 0.9 & -6.8 \\
\hline 4Z-ai & 14.8 & 14.2 & 4.8 & 0.6 & -7.2 \\
\hline $4 Z$-aj & 14.9 & 15.5 & 6.1 & 3.2 & -4.8 \\
\hline 4Z-ak & 15.0 & 14.8 & 4.9 & 2.5 & -5.8 \\
\hline 4Z-al & 15.0 & 14.1 & 5.5 & 1.6 & -5.7 \\
\hline $4 Z$-am & 15.1 & 14.1 & 4.9 & 0.0 & -7.3 \\
\hline $4 Z$-an & 15.1 & 13.6 & 4.5 & 1.2 & -6.3 \\
\hline 4Z-ao & 15.1 & 14.9 & 5.4 & 0.8 & -6.8 \\
\hline 4Z-ap & 15.1 & 13.8 & 4.9 & 1.8 & -5.6 \\
\hline 4Z-aq & 15.1 & 16.2 & 5.8 & 1.5 & -7.1 \\
\hline
\end{tabular}


TABLE 5: Structures and relative energies for glycine $\left(\mathrm{H}_{2} \mathrm{O}\right)_{5}$

\begin{tabular}{lccccc}
\hline Structure & $\begin{array}{c}\text { EFP1/HF and } \\
\text { RHF/6-31++G(d,p) }\end{array}$ & $\begin{array}{c}\text { Full RHF/ } \\
6-31++\mathrm{G}(\mathrm{d}, \mathrm{p})\end{array}$ & $\begin{array}{c}\mathrm{MP2} / / \mathrm{RHF} / \\
6-31++\mathrm{G}(\mathrm{d}, \mathrm{p})\end{array}$ & $\begin{array}{c}\mathrm{PCM}+\mathrm{RHF} / \mathrm{RHF} / \\
6-31++\mathrm{G}(\mathrm{d}, \mathrm{p})\end{array}$ & $\begin{array}{c}\text { PCM+MP2/RHF/ } \\
6-31++\mathrm{G}(\mathrm{d}, \mathrm{p})\end{array}$ \\
\hline 5N6-a & 0.0 & 0.0 & 0.0 & 0.0 & 0.0 \\
5N6-b & 0.1 & 0.2 & 0.3 & 0.2 & 0.3 \\
5N6-c & 0.3 & 0.3 & 0.5 & 0.1 & 0.4 \\
5N8-a & 0.3 & 1.0 & 0.3 & 1.5 & 0.8 \\
5N6-d & 0.4 & 0.8 & 0.8 & 0.3 & 0.4 \\
5N1-a & 0.4 & 0.2 & 2.2 & -0.1 & 1.7 \\
5Z-a & 8.6 & 9.5 & 0.4 & 0.8 & -7.3 \\
5Z-b & 8.7 & 9.9 & 1.0 & 0.6 & -7.1
\end{tabular}


TABLE 6: Structures and relative energies for glycine $\left(\mathrm{H}_{2} \mathrm{O}\right)_{6}$

\begin{tabular}{lccccc}
\hline Structure & $\begin{array}{c}\text { EFP1/HF and } \\
\text { RHF/6-31++G(d,p) }\end{array}$ & $\begin{array}{c}\text { Full RHF/ } \\
6-31++\mathrm{G}(\mathrm{d}, \mathrm{p})\end{array}$ & $\begin{array}{c}\text { MP2//RHF/ } \\
6-31++\mathrm{G}(\mathrm{d}, \mathrm{p})\end{array}$ & $\begin{array}{c}\mathrm{PCM}+\mathrm{RHF} / / \mathrm{RHF} / \\
6-31++\mathrm{G}(\mathrm{d}, \mathrm{p})\end{array}$ & $\begin{array}{c}\mathrm{PCM}+\mathrm{MP} 2 / \mathrm{RHF} / \\
6-31++\mathrm{G}(\mathrm{d}, \mathrm{p})\end{array}$ \\
\hline 6N6-a & 0.0 & 0.0 & 0.0 & 0.0 & 0.0 \\
6N8-a & 0.1 & 0.3 & 0.7 & -0.7 & -0.2 \\
6N8-b & 0.2 & 1.5 & 1.4 & 0.4 & 0.3 \\
6N8-c & 0.3 & 1.3 & 1.3 & 0.3 & 0.3 \\
6N6-b & 0.6 & 1.7 & 1.3 & 1.1 & 0.2 \\
6N1-a & 0.6 & 0.3 & 1.5 & 0.1 & 1.0 \\
6N6-c & 0.7 & 0.6 & 1.2 & -0.7 & -0.1 \\
6N8-d & 0.8 & 0.7 & 1.1 & -0.5 & 0.1 \\
6N1-b & 1.0 & 0.7 & 2.1 & 0.5 & 1.5 \\
6N1-c & 1.1 & 0.6 & 0.7 & -0.1 & 0.1 \\
6N1-d & 1.1 & 0.8 & 2.3 & 0.2 & 1.4 \\
6N1-e & 1.2 & 0.3 & 3.4 & -1.2 & 1.9 \\
6N8-e & 1.4 & 1.7 & 1.7 & 0.7 & 0.6 \\
6N1-f & 1.5 & 0.5 & 3.2 & -1.0 & 1.4 \\
6N1-g & 1.6 & 0.8 & 2.1 & 0.5 & 1.5 \\
6Z-a & 7.4 & 8.4 & 0.8 & -0.2 & -6.9
\end{tabular}


TABLE 7: Structures and relative energies for glycine $\left(\mathrm{H}_{2} \mathrm{O}\right)_{7}$

\begin{tabular}{|c|c|c|c|c|c|}
\hline Structure & $\begin{array}{c}\text { EFP1/HF and } \\
\text { RHF/6-31++G(d,p) }\end{array}$ & $\begin{array}{c}\text { Full RHF/ } \\
6-31++G(d, p)\end{array}$ & $\begin{array}{c}\text { MP2 } / / \text { RHF/ } \\
6-31++G(d, p)\end{array}$ & $\begin{array}{c}\mathrm{PCM}+\mathrm{RHF} / \mathrm{RHF} / \\
6-31++\mathrm{G}(\mathrm{d}, \mathrm{p})\end{array}$ & $\begin{array}{c}\mathrm{PCM}+\mathrm{MP} 2 / / \mathrm{RHF} / \\
6-31++\mathrm{G}(\mathrm{d}, \mathrm{p}) \\
\end{array}$ \\
\hline $7 \mathrm{~N} 1-\mathrm{a}$ & 0.0 & 0.0 & 0.0 & 0.0 & 0.0 \\
\hline $7 \mathrm{~N} 1-\mathrm{b}$ & 0.2 & 0.1 & 0.2 & 0.1 & 0.2 \\
\hline $7 \mathrm{~N} 8-\mathrm{a}$ & 0.5 & 1.2 & -1.0 & 1.6 & 0.0 \\
\hline 7N8-b & 0.6 & 1.3 & -0.7 & 1.7 & 0.3 \\
\hline $7 \times 6-a$ & 0.7 & 1.3 & -0.7 & 2.1 & 0.6 \\
\hline 7N6-b & 0.7 & 1.3 & -0.6 & 2.0 & 0.4 \\
\hline $7 \mathrm{~N} 8-\mathrm{c}$ & 0.9 & 1.5 & -0.6 & 1.7 & 0.3 \\
\hline $7 Z-a$ & 7.3 & 9.0 & -0.7 & 0.7 & -7.8 \\
\hline 7Z-b & 7.4 & 8.5 & -1.3 & -0.5 & -8.8 \\
\hline 7Z-c & 8.0 & 9.5 & 0.1 & 1.4 & -6.7 \\
\hline 7Z-d & 8.6 & 9.9 & 0.9 & 1.5 & -6.4 \\
\hline 7Z-e & 8.7 & 9.5 & 0.3 & 1.0 & -7.0 \\
\hline 7Z-f & 8.9 & 8.4 & -0.5 & 2.5 & -5.4 \\
\hline $7 Z$-g & 8.9 & 9.0 & 0.1 & 0.4 & -7.4 \\
\hline
\end{tabular}


TABLE 8: Nonionized-Zwitterion Energy Difference (kcal/mol)

\begin{tabular}{|c|c|c|c|c|c|c|c|}
\hline $\begin{array}{l}\text { Number } \\
\text { of waters }\end{array}$ & N Structure & Z Struclure & $\begin{array}{c}\text { EFP1/HF and } \\
\text { RHF/6-31+ } \mathrm{G}(\mathrm{d}, \mathrm{p})\end{array}$ & $\begin{array}{c}\text { Full RHE/ } \\
6-31++G(d, p)\end{array}$ & $\begin{array}{c}\mathrm{MP} 2 / \mathrm{RHF} / \\
6-31++\mathrm{G}(\mathrm{d}, \mathrm{p})\end{array}$ & $\begin{array}{c}\mathrm{PCM}+\mathrm{RHF} / \mathrm{RHF} / \\
6-31++\mathrm{G}(\mathrm{d}, \mathrm{p}) \\
\end{array}$ & $\begin{array}{c}\mathrm{PCM}+\mathrm{MP} 2 / \mathrm{RHF} / \\
6-3 \mathrm{I}+\div \mathrm{G}(\mathrm{d}, \mathrm{p}) \\
\end{array}$ \\
\hline 1 & IN1-a & $1 \mathrm{Z}-\mathrm{a}$ & 24.2 & 23.5 & 15.3 & 2.4 & -3.6 \\
\hline 2 & $2 \mathrm{Nl}-\mathrm{a}$ & $2 Z-a$ & 20.2 & 19.8 & 10.8 & 2.4 & -4.7 \\
\hline 3 & $3 \mathrm{~N} 1-\mathrm{a}$ & $3 Z-a$ & 14.7 & 15.6 & 5.2 & 1.9 & -6.9 \\
\hline \multirow[t]{2}{*}{4} & $4 N 1-a$ & $4 Z$-it & 12.1 & 11.7 & 1.6 & 1.2 & -7.7 \\
\hline & $4 N 6-a$ & $42-a$ & 11.8 & 10.5 & 2.6 & 0.8 & -6.7 \\
\hline 5 & 5N6-a & $5 Z-a$ & 8.6 & 9.5 & 0.4 & 0.8 & -7.3 \\
\hline 6 & 6N6-a & $6 \mathrm{Z}-\mathrm{a}$ & 7.4 & 8.4 & 0.8 & -0.2 & -6.9 \\
\hline \multirow[t]{2}{*}{7} & $7 \mathrm{~N} 1-\mathrm{a}$ & $7 \mathrm{Z}-\mathrm{a}$ & 7.3 & 9.0 & -0.7 & 0.7 & -7.8 \\
\hline & 7N8-a & 7Z-b & 6.9 & 7.4 & -0.3 & -2.1 & -8.8 \\
\hline
\end{tabular}


Figure 1. Neutral glycine conformer structures and relative energies $(\mathrm{kcal} / \mathrm{mol})$ at the RHF/6-31G(d,p) and MP2/6-31++G(d,p)//RHF/6-31G(d,p) levels of theory.

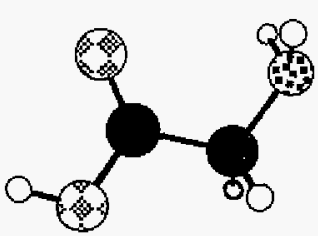

$\mathrm{N1}(0.0)$

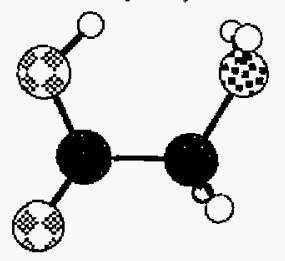

N5 (9.0)

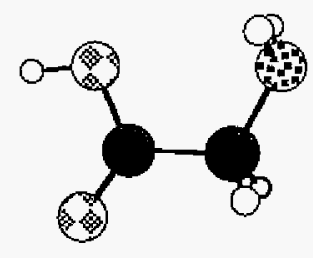

N2 (1.9)

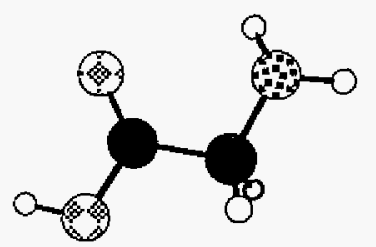

N6 (2.0)

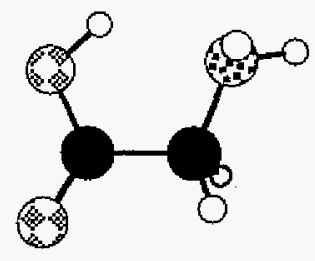

N3 (3.0)

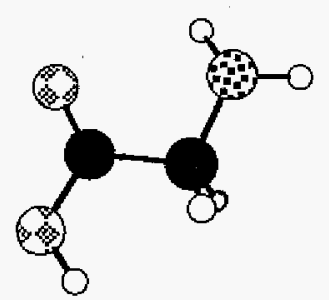

N7 (9.2)

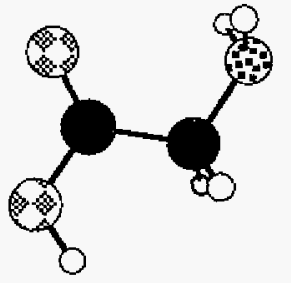

N4 (6.9)

(RHF/6-31G(d,p))

[MP2/6-31++G(d,p)//RHF/6-31G(d,p)]

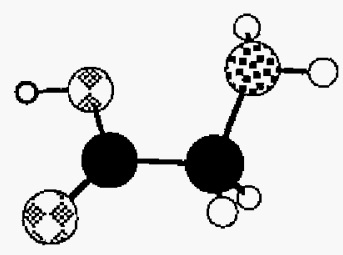

N8 (3.1)

$\Leftrightarrow 0$ (C)

Figure 2. Six lowest energy conformers and relative energies $(\mathrm{kcal} / \mathrm{mol})$ of nonionized glycine $\left(\mathrm{H}_{2} \mathrm{O}\right)$.

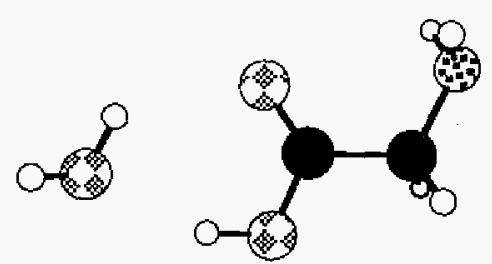

1N1-a $0.0(0.0)[0.0] 0.0[0.0]$

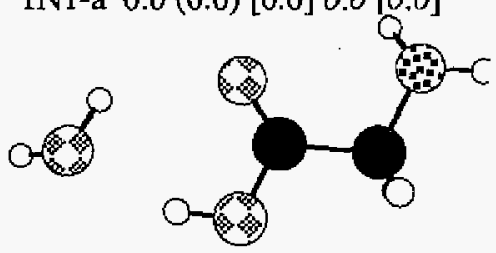

1N6-b $1.7(1.7)[1.4] 1.7[1.5]$

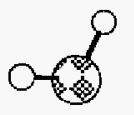

1N6-a $1.5(1.5)[1.2] 1.7[1.4]$

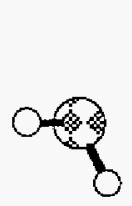

1N8-a $2.3(2.4)$ [2.0] 2.3 [2.0]
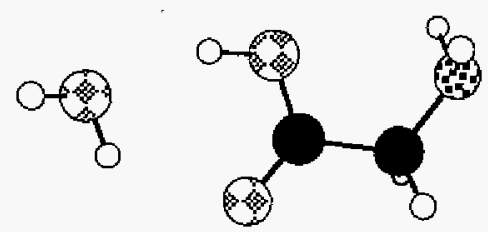

$1 \mathrm{~N} 2-\mathrm{a} 1.5(1.5)[1.2] 1.3[1.1]$

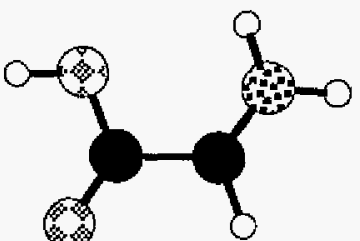

0

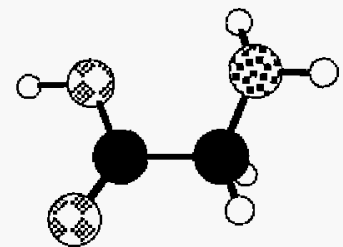

IN8-b $2.5(2.6)[2.2] 2.4[2.1]$

EFP1/HF waters and RHF/6-31++G(d,p) glycine (kcal/mol)

(RHF/6-31++G(d,p))

[MP2//RHF/6-31++G(d,p)]

$P C M+R H F / / R H F / 6-31++G(d, p)$

$[P C M+M P 2 / / R H F / 6-31++G(d, p)]$ 
Figure 3. Five lowest energy conformers and relative energies (kcal/mol) of zwitterionic glycine $\left(\mathrm{H}_{2} \mathrm{O}\right)$.

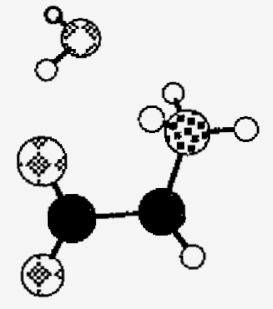

1Z-a $24.2(23.5)[15.3] 2.4[-3.6]$

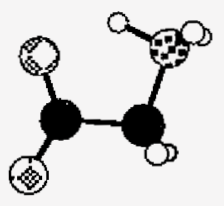<smiles></smiles>
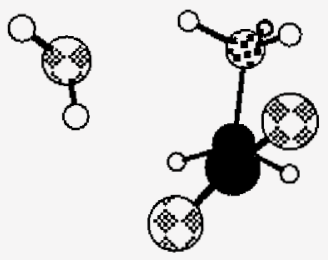

1Z-b $25.9(25.9)[16.9] 4.9[-2.0]$
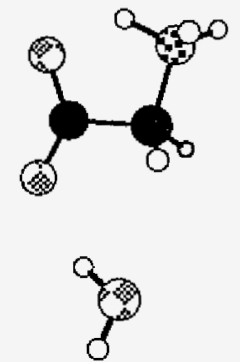

EFP1/HF waters and RHF/

$6-31++\mathrm{G}(\mathrm{d}, \mathrm{p})$ glycine $(\mathrm{kcal} / \mathrm{mol})$ (RHF/6-31++G(d,p)) [MP2//RHF/6-31++G(d,p)] $P C M+R H F / / R H F / 6-31++G(d, p)$ $[P C M+M P 2 / / R H F / 6-31++G(d, p)]$

1Z-c $27.2(26.7)[17.5] 4.8[-2.2] \quad$ 1Z-d $27.2(26.7)[17.5] 4.9[-2.2]$
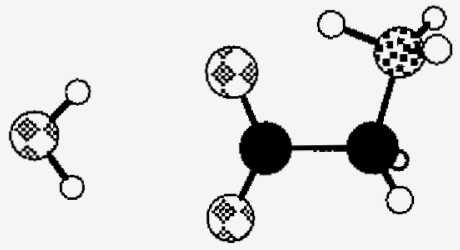

1Z-e $28.2(28.0)[19.4] 4.5[-1.7]$

Figure 4. Six lowest energy conformers and relative energies $(\mathrm{kcal} / \mathrm{mol})$ of nonionized glycine $\left(\mathrm{H}_{2} \mathrm{O}\right)_{2}$.

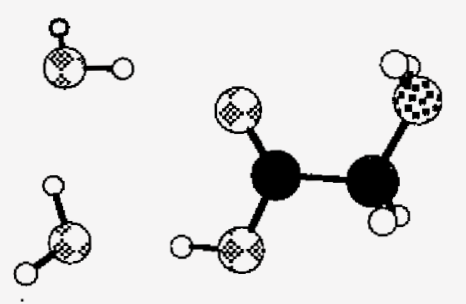

$2 \mathrm{~N} 1-\mathrm{a} \quad 0.0(0.0)[0.0] 0.0[0.0]$

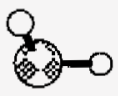

8

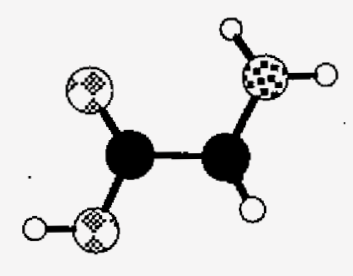

2N6-a $1.5(1.5)[1.2] 1.6[1.3]$
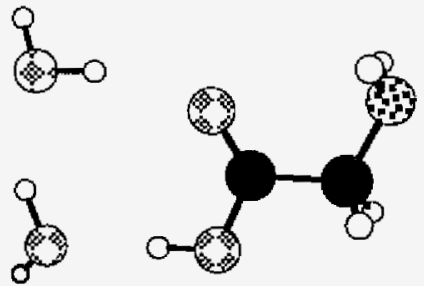

2N1-b $0.5(0.4)[0.6] 0.3[0.6]$
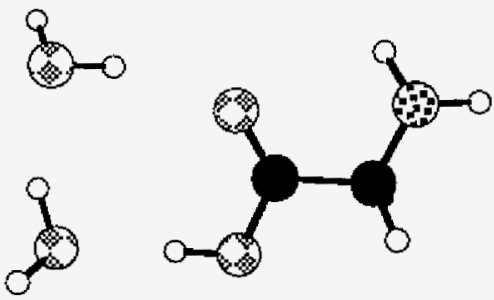

2N6-b $1.6(1.6)[1.3] 1.7[1.4]$
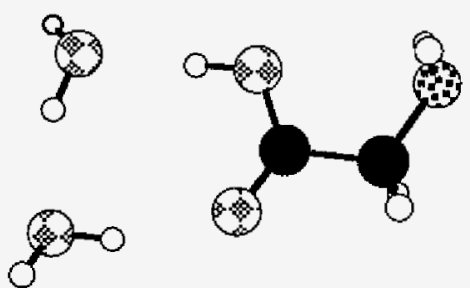

2N2-a $1.4(1.3)[1.1] 1.3[1.1]$
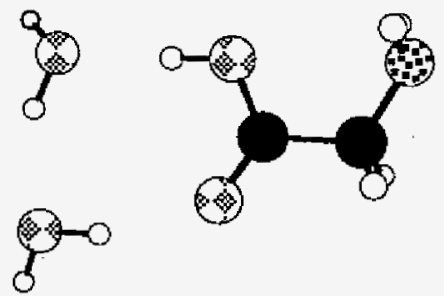

2N2-b $1.9(1.7)[1.7] 1.5[1.6]$

EFP1/HF waters and RHF/6-31+tG(d,p) glycine (kcal/mol)

(RHF/6-31+tG(d,p))

[MP2//RHF/6-31++G(d,p)]

$P C M+R H F / / R H F / 6-31++G(d, p)$

$[P C M+M P 2 / / R H F / 6-31++G(d, p)]$ 
Figure 5. Five lowest energy conformers and relative energies $(\mathrm{kcal} / \mathrm{mol})$ of zwitterionic glycine $\left(\mathrm{H}_{2} \mathrm{O}\right)_{2}$.

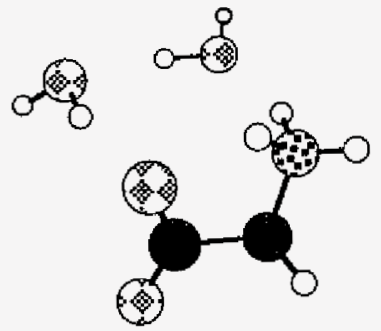

2Z-a $20.2(19.8)[10.8] 2.4[-4.7]$

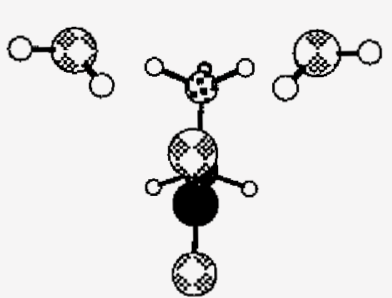

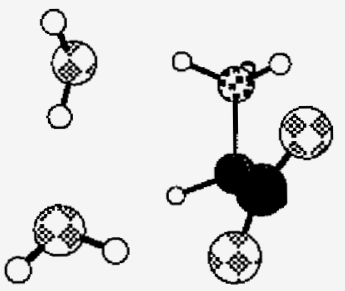

2Z-b $20.6(20.6)[11.3] 3.0[-4.7]$<smiles>C1CCC1</smiles>

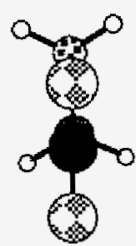

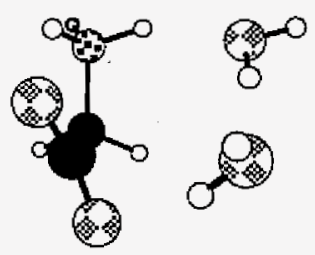

2Z-c $20.9(20.6)[11.4] 3.4[-4.7]$

EFP1/HF waters and RHF/

$6-31++\mathrm{G}(\mathrm{d}, \mathrm{p})$ glycine $(\mathrm{kcal} / \mathrm{mol})$ (RHF/6-31++G(d,p)) [MP2//RHF/6-31++G(d,p)] $P C M+R H F / / R H F / 6-3 l++G(d, p)$ $[P C M+M P 2 / / R H F / 6-31++G(d, p)]$

$2 Z-d 21.3(19.7)[11.4] 2.7[-4.7]$

2Z-e $21.3(19.7)[11.4] 2.8[-4.7]$

Figure 6. Conformers and relative energies $(\mathrm{kcal} / \mathrm{mol})$ of nonionized glycine $\left(\mathrm{H}_{2} \mathrm{O}\right)_{3}$.

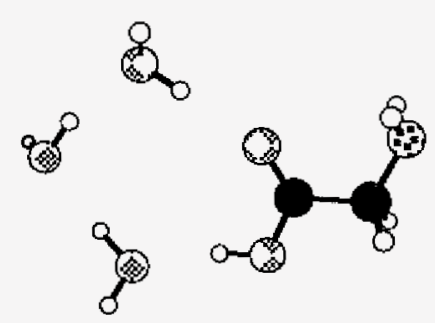

3N1-a $0.0(0.0)[0.0] 0.0[0.0]$

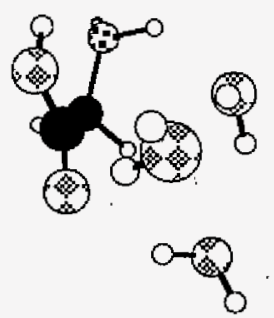

3N3-h $5.5(6.5)[3.9] 6.7[4.3]$
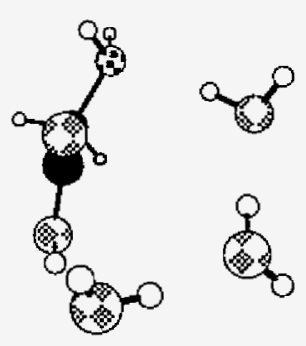

3N6-a $1.1(2.9)[0.2] 2.3[0 . I]$
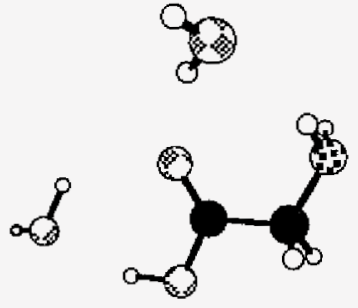

3N1-ar $6.6(7.1)[7.3] 4.1$ [4.2]

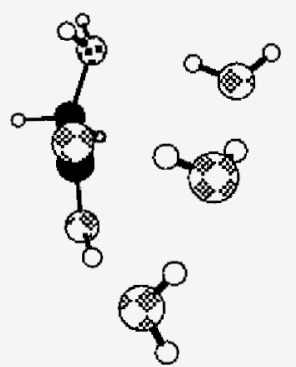

$3 N 6-c \quad 1.3(2.7)[0.1] 3.2[1.0]$

EFP1/HF waters and RHF/6-31++G(d,p) glycine $(\mathrm{kcal} / \mathrm{mol})$

(RHF/6-31++G(d,p))

[MP2//RHF/6-31++G(d,p)]

$P C M+R H F / / R H F / 6-31++G(d, p)$

$[P C M+M P 2 / / R H F / 6-31++G(d, p)]$ 
Figure 7. Conformers and relative energies $(\mathrm{kcal} / \mathrm{mol})$ of zwitterionic glycine $\left(\mathrm{H}_{2} \mathrm{O}\right)_{3}$.

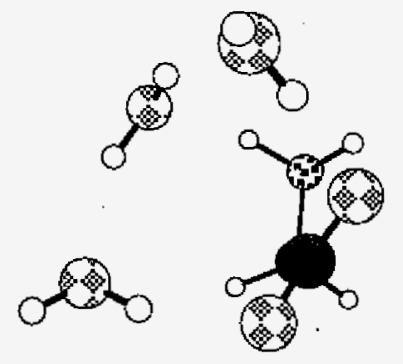

$3 Z$-a 14.7 (15.6) [5.2] $1.9[-6.9]$

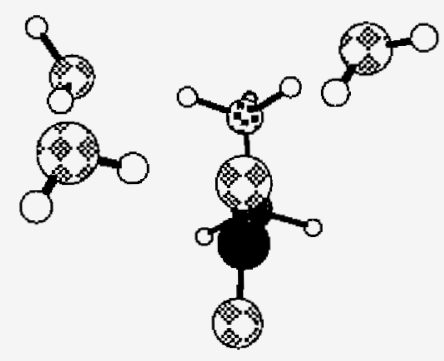

$3 Z-d \quad 16.3(15.5)[6.0] 1.2[-6.6]$
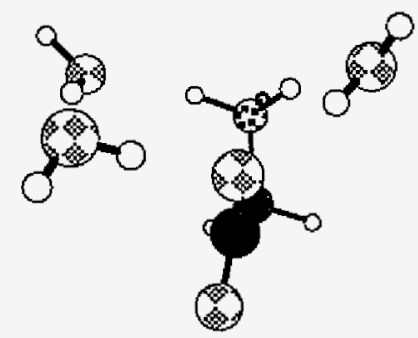

3Z-f $16.4(15.5)[6.0] 1.5[-6.4]$

EFPl/HF waters and RHF/6-31++G(d,p) glycine $(\mathrm{kcal} / \mathrm{mol})$

(RHF/6-31++G(d,p))

[MP2//RHF/6-31++G(d,p)]

$P C M+R H F / R H F / 6-31++G(d, p)$

$[P C M+M P 2 / / R H F / 6-31++G(d, p)]$

Figure 8. Conformers and relative energies $(\mathrm{kcal} / \mathrm{mol})$ of glycine $\left(\mathrm{H}_{2} \mathrm{O}\right)_{4}$.<smiles>Oc1ccc(OOc2cc(O)ccc2O)cc1</smiles>

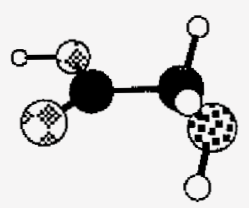

$4 \mathrm{~N} 1-\mathrm{a} \quad 0.0(0.0)[0.0] 0.0[0.0]$

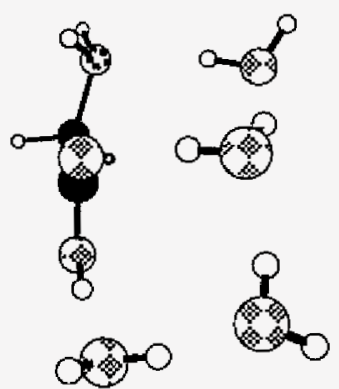

4N6-a $0.3(0.8)[-1.0] 0.4[-1.0]$

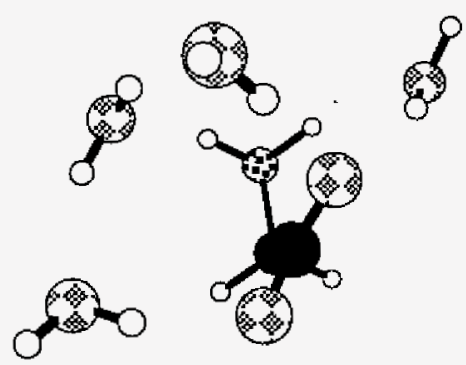

4Z-a $12.1(11.7)[1.6] 1.2[-7.7]$

EFP1/HF waters and RHF/6-31++G(d,p) glycine (kcal/mol)

(RHF/6-31++G(d,p))

[MP2/RHF/6-31++G(d,p)]

$P C M+R H F / / R H F / 6-3 I++G(d, p)$

$[P C M+M P 2 / / R H F / 6-3 I++G(d, p)]$ 
Figure 9. Conformers and relative energies $(\mathrm{kcal} / \mathrm{mol})$ of glycine $\left(\mathrm{H}_{2} \mathrm{O}\right)_{5}$.

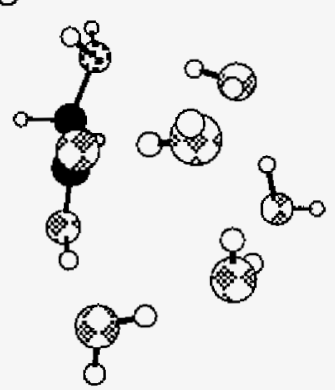

$5 \mathrm{NG}-\mathrm{a} 0.0(0.0)[0.0] 0.0[0.0]$

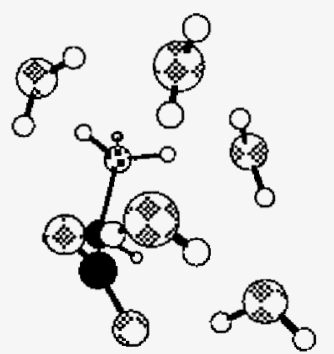

5Z-a $8.6(9.5)[0.4] 0.8[-7.3]$

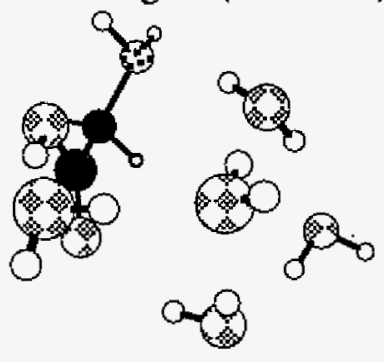

5N8-a $0.3(1.0)[0.3] 1.5[0.8]$
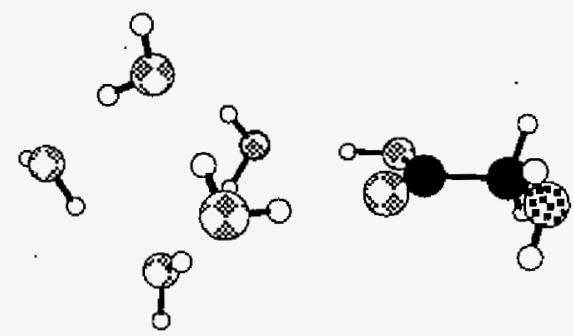

$5 \mathrm{~N} 1-\mathrm{a} 0.4(0.2)[2.2]-0.1[1.7]$

EFP1/HF waters and RHF/6-31++G(d,p) glycine $(\mathrm{kcal} / \mathrm{mol})$

(RHF/6-31++G(d,p))

[MP2//RHF/6-31++G(d,p)]

$P C M+R H F / / R H F / 6-31++G(d, p)$

$[P C M+M P 2 / / R H F / 6-31++G(d, p)]$

Figure 10. Conformers and relative energies (kcal/mol) of glycine $\left(\mathrm{H}_{2} \mathrm{O}\right)_{6}$.
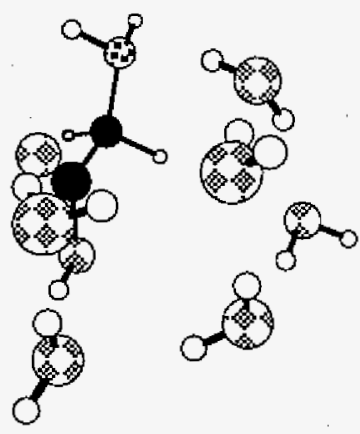

$6 \mathrm{~N} 6-\mathrm{a} 0.0(0.0)[0.0] 0.0[0.0]$

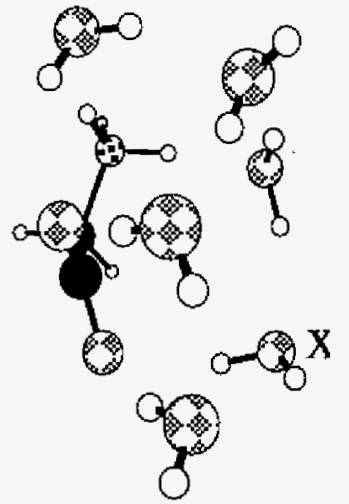

6Z-a $7.4(8.4)[0.8]-0.2[-6.9]$
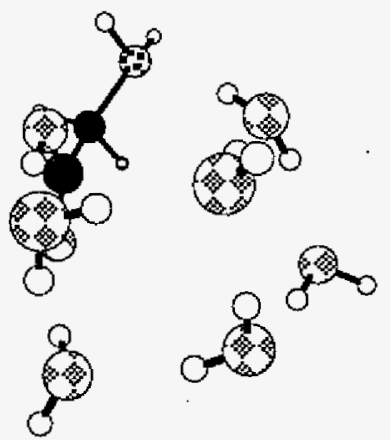

6N8-a $0.1(0.3)[0.7]-0.7[-0.2]$

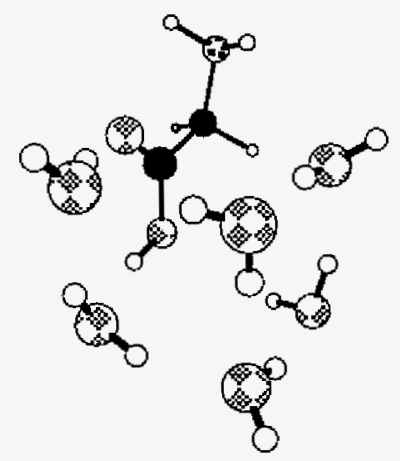

$6 \mathrm{~N} 1-\mathrm{a} 0.6(0.3)[1.5] 0.1[1.0]$

EFP1/HF waters and RHF/6-31++G(d,p) glycine $(\mathrm{kcal} / \mathrm{mol})$ (RHF/6-31++G(d,p)) [MP2//RHF/6-31++G(d,p)] $P C M+R H F / / R H F / 6-31++G(d, p)$ $[P C M+M P 2 / / R H F / 6-31++G(d, p)]$ 
Figure 11. Conformers and relative energies $(\mathrm{kcal} / \mathrm{mol})$ of glycine $\left(\mathrm{H}_{2} \mathrm{O}\right)_{7}$.

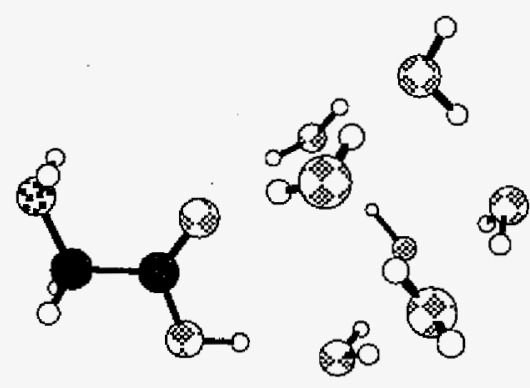

7N1-a (side view)

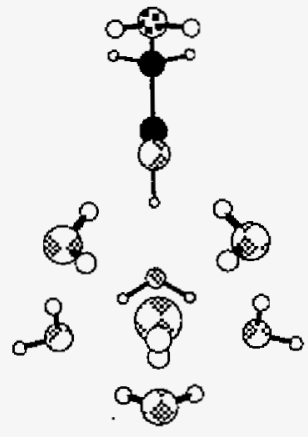

7N1-a (top view)

$7 \mathrm{~N} 1-\mathrm{a} \quad 0.0(0.0)[0.0] 0.0[0.0]$
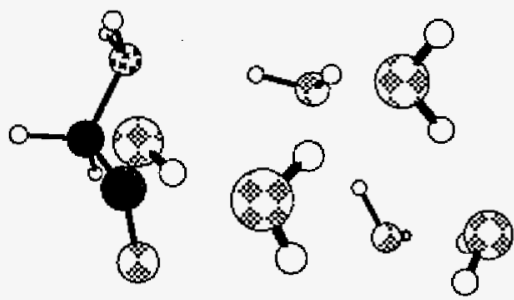<smiles>Oc1ccc(-c2ccco2)o1</smiles>

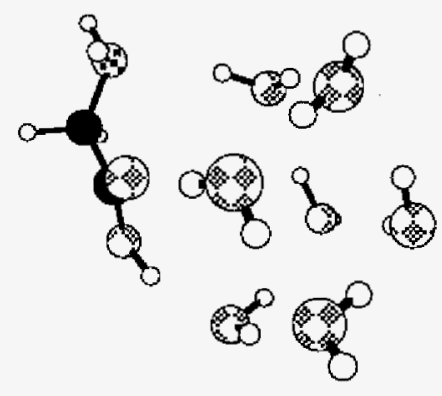

$7 \mathrm{~N} 8-\mathrm{a} \cdot 0.5(1.2)[-1.0] 1.6[0.0]$

7N6-a $0.7(1.3)[-0.7] 2.1[0.6]$
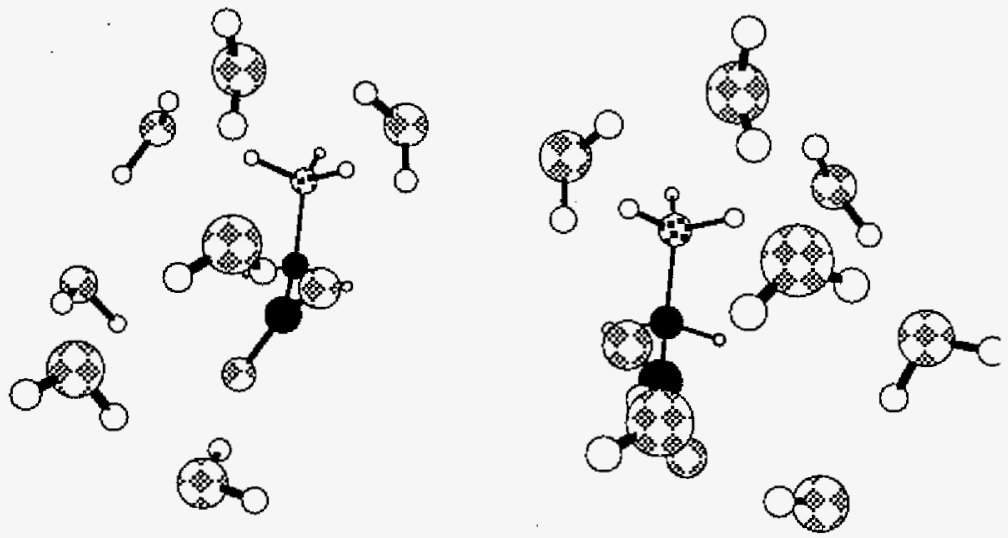

7Z-a $7.3(9.0)[-0.7] 0.7[-7.8]$

7Z-b $7.4(8.5)$ [-1.3]-0.5 f-8.8]

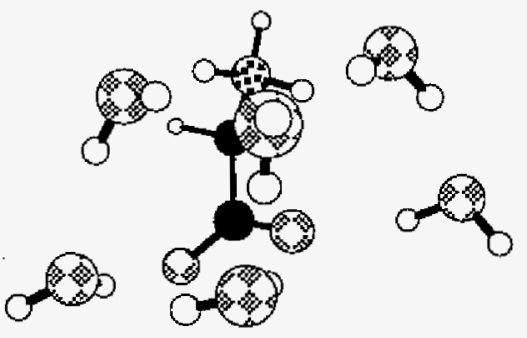

$7 Z$-f $8.9(8.4)[-0.5] 2.5[-5.4]$

EFP1/HF waters and RHF/6-31++G(d,p) glycine ( $\mathrm{kcal} / \mathrm{mol})$

(RHF/6-31++G(d,p))

[MP2//RHF/6-31++G(d,p)]

$P C M+R H F / / R H F / 6-3 I++G(d, p)$

$[P C M+M P 2 / / R H F / 6-31++G(d, p)]$ 


\title{
CHAPTER 5. PARALLEL UNRESTRICTED MP2 ANALYTIC GRADIENTS USING THE DISTRIBUTED DATA INTERFACE
}

\author{
A paper published in The Journal of Physical Chemistry A \\ Christine M. Aikens and Mark S. Gordon
}

A scalable distributed data parallel analytic gradient algorithm for unrestricted second-order Møller-Plesset perturbation theory is presented. Features of the implementation using the Distributed Data Interface are discussed in detail. Benchmark timing calculations on a parallel cluster system are presented for a variety of gold cluster molecules. The speedups, parallel efficiencies, and percentage parallelism for these calculations are reported.

\section{Introduction}

Professor Schaefer has made many contributions in the field of electronic structure theory, including early efforts at parallelization. ${ }^{1}$ We are pleased to be able to present this contribution in honor of his $60^{\text {th }}$ birthday.

Second-order Mǿller-Plesset (MP2) perturbation theory ${ }^{2}$ is a correlated electronic structure method that is widely used to calculate molecular energies and geometries, since it provides a balance between the amount of electron correlation recovered and the computational cost of the calculation. The first derivation of the MP2 gradient was presented in 1979 by Pople et al. ${ }^{3}$ Subsequent formulations by Handy et al. ${ }^{4}$ and Pulay and Saeb $\emptyset^{5}$ eliminated the storage of derivative integrals and three-virtual molecular orbital integrals, used the Z-vector method of Handy and Schaefer ${ }^{6}$ to reduce the number of unknown response vectors in the coupled-perturbed Hartree-Fock (CPHF) equations from $3 \mathrm{~N}$ (where $\mathrm{N}$ is the number of nuclei) to 1 , and eliminated the need to solve the CPHF equations in the 
occupied-occupied and virtual-virtual blocks. Frozen orbitals were introduced to reduce the computational requirements of the calculations, and an explicit derivation of the MP2 gradient using frozen orbitals was presented by Lee et al. ${ }^{7}$ The implementation of the first direct MP2 gradient algorithm, ${ }^{8}$ in which the two-electron repulsion integrals are recomputed as needed instead of stored on disk or in memory, allowed much larger calculations than were previously possible, although this came at a greater computational cost. Semi-direct algorithms were also developed in order to minimize computation depending on available memory and disk space. ${ }^{9}$ Recently, Head-Gordon developed an improved semi-direct MP2 gradient algorithm, which reduces the required memory and disk storage to that of a semidirect MP2 energy calculation, eliminates disk-based sorting and transposition steps, and accounts for frozen orbitals. ${ }^{10}$

For the MP2 methods, the time requirements for a calculation grow as $O\left(n^{5}\right)$ with the number of basis functions $n$, while the memory requirements can increase by as much as $\mathrm{O}\left(n^{3}\right)$, depending on the algorithm. As these methods are applied to increasingly larger molecules with reliable basis sets, the requirements of the calculation quickly outgrow the capabilities of a single-processor computer. Replicated-data parallel schemes are relatively easy to implement and reduce the time requirements of a calculation, but the size of systems that can be treated with them is limited by the memory on a single node. Distributed-data implementations are preferred, as these reduce both the single-node memory requirement and the wall clock time for a calculation.

The computer architecture must also be considered when designing an algorithm. Currently, clusters of workstations or PC's are an attractive alternative to large massively parallel processor (MPP) platforms due to a good performance/price ratio. Individual 
research groups and departments do not normally have enough resources to purchase large computer systems. Cluster computing also has the advantages that commodity parts can be used, installation is relatively easy, scalability can be attained in principle, and the computational resources are controlled locally. However, cluster computing also has some disadvantages that must be addressed. In particular, the slow speed interconnection between nodes in clusters can be a source of poor performance and scalability of algorithms designed for MPP systems. In addition, not all parallel programming tools are available or optimized for cluster computing.

Fletcher et al. developed the Distributed Data Interface (DDI) ${ }^{11,12}$ to provide a set of tools for distributed memory programming that is useful on both large parallel machines and clusters. It allows storage of large data arrays over the aggregate memory of distributed memory architectures. Like the Global Array (GA) tools, ${ }^{13} \mathrm{DDI}$ represents a global memory access model that is based on a data-passing model. It includes a set of basic network communication functions (Table 1) such as point-to-point operations like send and receive and collective operations like broadcast and global sum. It also includes features for using distributed and globally addressed arrays and one-sided communication. These functions are implemented using TCP/IP socket code or MPI-1 or SHMEM libraries, so DDI is available for a variety of architectures. The advantages of one-sided communication include reduced programming difficulty and increased efficiency due to asynchronous communication. The presence of remote memory adds a new level to the memory access time hierarchy: registers $<$ cache $(\mathrm{s})<$ main memory $<$ remote memory $<$ disk 
Most systems have significantly slower access time to remote memory than to local memory, so data locality must be considered in the design of an algorithm. Information on data Iocality is also available within DDI.

To date, DDI has been used to implement distributed storage versions of SCF energies, ${ }^{14}$ analytic SCF Hessians, ${ }^{15}$ multireference self-consistent field energies and gradients, ${ }^{16}$ closed shell MP2 energies and gradients, ${ }^{11}$ Z-averaged perturbation theory energies, ${ }^{17}$ multireference perturbation theory energies, ${ }^{18}$ singles CI energies and gradients, ${ }^{19}$ and Full CI energies. ${ }^{20}$ Other distributed data tools have been used to generate distributed memory versions of SCF energies, ${ }^{21-27}$ analytic SCF Hessians, ${ }^{28}$ CPHF equations, ${ }^{29}$ perturbation theory energies ${ }^{30-36}$ and gradients, ${ }^{37,38} \mathrm{CI}$ energies, ${ }^{39,40}$ and coupled cluster energies. $^{41,42}$

In this paper, the parallel implementation of unrestricted MP2 (UMP2) energies and gradients into the quantum chemistry package GAMESS ${ }^{17}$ through the use of DDI is discussed. An assessment of the speedup and parallel efficiency is reported for a series of gold clusters using a cluster architecture.

\section{Parallel UMP2 Gradient Algorithm}

A distributed-data UMP2 gradient algorithm is discussed in this section. The details of the gradient derivation and serial implementation may be found elsewhere. ${ }^{43}$ In general, the analytic derivative of the UMP2 electronic energy may be expressed as:

$$
E^{x}=\sum_{\mu v}^{A O} P_{\mu v}^{M P 2} H_{\mu v}^{x}+\sum_{\mu v}^{A O} W_{\mu v}^{M P 2} S_{\mu v}^{x}+\sum_{\mu v, \sigma \sigma}^{A O} \Gamma_{\mu v \lambda \sigma}^{M P 2}(\mu v \mid \lambda \sigma)^{x}
$$

where $H_{\mu \nu}^{x}$ are the core-Hamiltonian derivative integrals, $S_{\mu 1^{\prime}}^{x}$ are the overlap derivative integrals, $(\mu \nu \mid \lambda \sigma)^{x}$ are the derivatives of the electron repulsion integrals (ERI's), and $\mu, v, \lambda$, 
and $\sigma$ index atomic orbitals. The MP2 density matrix $P_{\mu \nu}^{M P 2}$, "energy-weighted" density matrix $W_{\mu v}^{M P 2}$, and two-particle density matrix $\Gamma_{\mu \nu 2}^{M P 2}$ in Eq. (1) are sums of their corresponding SCF and second-order correction terms:

$$
\begin{aligned}
& P_{\mu v}^{M P 2}=P_{\mu v}^{\alpha S C F}+P_{\mu v}^{\beta S C F}+P_{\mu v}^{(2)}(\alpha \alpha)+P_{\mu v}^{(2)}(\beta \beta) \\
& W_{\mu v}^{M P 2}=W_{\mu v}^{\alpha S C F}+W_{\mu v}^{\beta S C F}+W_{\mu v}^{(2)}(\alpha \alpha)+W_{\mu v}^{(2)}(\beta \beta) \\
& \Gamma_{\mu v 2 \sigma}^{M P 2}=\Gamma_{\mu v \lambda \sigma}^{S C F}+\Gamma_{\mu v \lambda \sigma}^{(2)}
\end{aligned}
$$

The second-order correction to the two-particle density matrix is normally divided into the sum of so-called separable $\left(\Gamma^{\mathrm{S}}\right)$ and non-separable $\left(\Gamma^{\mathrm{NS}}\right)$ terms:

$$
\Gamma_{\mu \nu \lambda \sigma}^{(2)}=\Gamma_{\mu v \lambda \sigma}^{N S}+\Gamma_{\mu \vee \lambda \sigma}^{S}
$$

In practice, Eq. (1) is usually evaluated by forming the density matrices $\mathbf{P}^{(2)}, \mathbf{W}^{(2)}$, and $\Gamma^{(2)}$ in the MO basis and back-transforming these matrices to the AO basis. The expressions for these matrix elements are shown in the appendix.

A. Implementation Considerations. In the MO basis, the expressions for the density matrix elements require 18 different types of integrals, which may be divided into five classes. Using " $v$ " to denote a virtual MO and " $\mathrm{o}$ " to denote an occupied MO, these integral types may be expressed as:

1. $\left(o^{\alpha} o^{\alpha} \mid o^{\alpha} o^{\alpha}\right)\left(o^{\alpha} o^{\alpha} \mid o^{\beta} o^{\beta}\right)\left(o^{\beta} o^{\beta} \mid o^{\beta} o^{\beta}\right)$

2. $\left(v^{\alpha} o^{\alpha} \mid o^{\alpha} o^{\alpha}\right)\left(v^{\alpha} o^{\alpha} \mid o^{\beta} o^{\beta}\right)\left(v^{\beta} o^{\beta} \mid o^{\alpha} o^{\alpha}\right)\left(v^{\beta} o^{\beta} \mid o^{\beta} o^{\beta}\right)$

3. $\left(v^{\alpha} v^{\alpha} \mid o^{\alpha} o^{\alpha}\right)\left(v^{\alpha} v^{\alpha} \mid o^{\beta} o^{\beta}\right)\left(v^{\beta} v^{\beta} l o^{\alpha} o^{\alpha}\right)\left(v^{\beta} v^{\beta} \mid o^{\beta} o^{\beta}\right)$

4. $\left(v^{\alpha} o^{\alpha} \mid v^{\alpha} o^{\alpha}\right)\left(v^{\alpha} o^{\alpha} \mid v^{\beta} o^{\beta}\right)\left(v^{\beta} o^{\beta} \mid v^{\beta} o^{\beta}\right)$

5. $\left(v^{\alpha} v^{\alpha} \mid v^{\alpha} o^{\alpha}\right)\left(v^{\alpha} v^{\alpha} \mid v^{\beta} o^{\beta}\right)\left(v^{\beta} v^{\beta} \mid v^{\alpha} o^{\alpha}\right)\left(v^{\beta} v^{\beta} \mid v^{\beta} o^{\beta}\right)$ 
Parallel processor systems with global memories in the terabyte range are now common, so it is feasible that the smaller integral classes may be stored in memory even for larger problems. Thus, global memory on the order of $n_{o}{ }^{2} n^{2}$ is assumed, where $n_{o}$ is the number of occupied orbitals and $n$ is the number of basis functions, and it is assumed that $n_{o}$ is much smaller than $n$. A different algorithm setup that trades additional computation for reduced memory requirements could also be envisioned, but will not be discussed here. The first four integral classes fall within the assumption of $\mathrm{O}\left(n_{0}{ }^{2} n^{2}\right)$ global memory, so these integrals may be stored in a distributed fashion across the nodes. The fifth class is closer in size to $\mathrm{O}\left(n_{0} n^{3}\right)$. However, this class is only used in the construction of the Lagrangian, so the terms involving these integrals will be calculated separately and in a direct fashion to avoid storage of this larger integral class. In addition, since $n^{4}$ memory is not assumed, the AO integrals will be calculated in a direct fashion. The density matrices, MO coefficients, orbital energies, and other data of order $n^{2}$ or less are replicated across the nodes.

The implementation of the following parallel UMP2 gradient scheme will be discussed in more detail in the subsequent sections:

1. Parallel direct transformation to yield MO integrals that contain at most two virtual orbital indices (stored in global memory)

2. Evaluation of UMP2 energy and construction of immediately obtainable terms of $\mathbf{P}^{(2)}, \mathbf{W}^{(2)}$, and the Lagrangian $\mathbf{L}$

3. Computation of the Lagrangian terms involving (vvlvo) class integrals directly from $\mathrm{AO}$ integrals

4. Solution of the Z-vector equations ${ }^{6}$ in the MO basis 
5. Completion of one-particle density matrices and the one-particle contribution to the gradient

6. Back transformation of integrals to generate $\Gamma^{\mathrm{NS}}$ and completion of the two-particle contribution to the gradient

B. Integral Transformation and Storage. First, the fourteen distributed arrays that hold the first four classes of transformed integrals must be created. These are depicted in Figure 1. Triangular pairings of two occupied or virtual indices are used wherever possible to reduce the number of integrals stored. Integral type $\left(v^{\alpha} o^{\alpha} \mid v^{\beta} o^{\beta}\right)$ has no available triangular pairings, so the full range of each index must be used for this array. Overall, the limiting storage requirement for the seven two-virtual integral types (and thus for the algorithm) is $\left(n_{0}{ }^{\alpha 2}+n_{0}^{\beta 2}+n_{0}^{\alpha} n_{0}^{\beta}\right) n^{2}$. The "supermatrix" symmetry of integral types $\left(\left.0^{\alpha} 0^{\alpha}\right|_{0} ^{\alpha} o^{\alpha}\right)$ and $\left(o^{\beta} o^{\beta} o^{\beta} o^{\beta}\right)$ is not used so that the arrays have a regular rectangular structure. The excess storage cost for this is not large, since this is the smallest integral class. For all integral types, all pairs of occupied indices are divided among the available nodes, with the full range of the other indices located on a given node. The integrals are distributed in this manner so that the long summations over virtual indices will be local.

Next, the fourteen integral types that correspond to the first four classes must be generated and stored in the distributed arrays. The general parallel transformation fourfold loop procedure has been described previously, ${ }^{11}$ so the details will not be presented here. The appropriate alpha and beta MO coefficients are used in the transformation of each index to generate the required integral types. The replicated data requirement for this procedure is $l^{2} n\left(n_{o}^{\alpha}+n_{o}^{\beta}\right)$, where $l$ is the length of a shell ( 1 for $s, 3$ for $p, 6$ for Cartesian $d$, etc.). After 
the integrals are generated, they are stored in the appropriate distributed arrays through the use of the DDI_PUT operation.

C. Density Matrix Creation. Most of the terms in the one-particle density matrices and the Lagrangian (Eqs. A1-A6, A13) may be evaluated from the integrals discussed in section B. The amplitudes for the virtual-virtual blocks of $\mathbf{P}^{(2)}$ (Eq. A3) and $\mathbf{W}^{(2)}$ (terms 1 and 2 of Eq. A5) are calculated from (volvo) integrals on the local node and multiplied by (volvo) integrals that are also locally held. Thus, these blocks do not require remote memory access. The occupied-occupied blocks of $\mathbf{P}^{(2)}$ (Eqs. A1 and A2) and $\mathbf{W}^{(2)}$ (terms 1 and 2 of Eq. A4) require remote DDI_GET operations to obtain a set of (volvo) integrals for a given vv pair. Then, the amplitude generation and integral multiplication steps may proceed locally. A global sum of $\mathbf{P}^{(2)}$ is performed so that each node holds the complete occupied-occupied and virtual-virtual blocks.

The fourth and fifth terms of Eq. A4 use the (ooloo) integrals when $p$ and $q$ are both occupied indices. Since this is the only matrix block that requires these integrals, the memory for these is released after the terms are computed. The (vvloo) class of integrals contributes to terms 4 and 5 of Eq. A4 when $p$ and $q$ are both virtual indices. This class is also used to compute the orbital Hessian in Eqs. A7 and A8, so it is retained in memory. The (voloo) class of integrals is used in the calculation of terms 1 and 2 of Eq. A6 and terms 1,2, 5, and 6 of Eq. A13. It will also contribute to the fourth and fifth terms of Eq. A4 after the virtual-occupied block of $\mathbf{P}^{(2)}$ is determined, so these integrals are retained in memory.

D. Three-Virtual Terms for Lagrangian. Terms 3,4,7, and 8 of Eq. A13 require the (vvlvo) integrals. These terms in the Lagrangian may be rearranged to form terms in a mixed $\mathrm{MO} / \mathrm{AO}$ basis as discussed previously. ${ }^{11,3738}$ For the UMP2 gradient, modified integrals 
instead of amplitudes will be transformed. For example, term 8 of Eq. A13 may be rearranged as:

$$
\begin{aligned}
& L_{a^{\alpha} i^{\alpha}}^{8}=\sum_{j^{\beta}}^{a c^{\beta}} \sum_{b^{\alpha}}^{\operatorname{virr}^{\alpha}{ }^{\alpha}} \sum_{c^{\beta}}^{\operatorname{vir} \beta^{\beta}} \frac{\left(i^{\alpha} b^{\alpha} \mid j^{\beta} c^{\beta}\right)}{D_{i^{\alpha} j^{\beta}}^{b^{\alpha} c^{\beta}}}\left(a^{\alpha} b^{\alpha} \mid j^{\beta} c^{\beta}\right)
\end{aligned}
$$

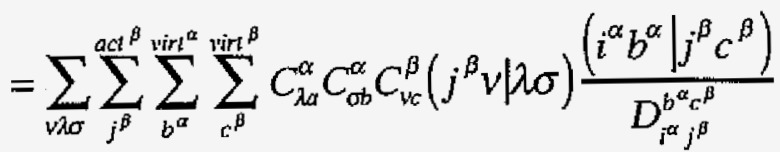

where $\mathrm{i}$ and $\mathrm{j}$ index occupied orbitals, $\mathrm{a}, \mathrm{b}$, and $\mathrm{c}$ index virtual orbitals, and $\lambda, v, \sigma$ index atomic orbitals. A mixed MO/AO Lagrangian is introduced on the left-hand side of Eq. 6 as $L_{a^{\alpha} i^{\alpha}}^{8}=\sum_{\lambda} C_{\lambda a}^{\alpha} L_{\lambda i^{\alpha}}^{8}$

and further rearrangement of Eq. 6 yields

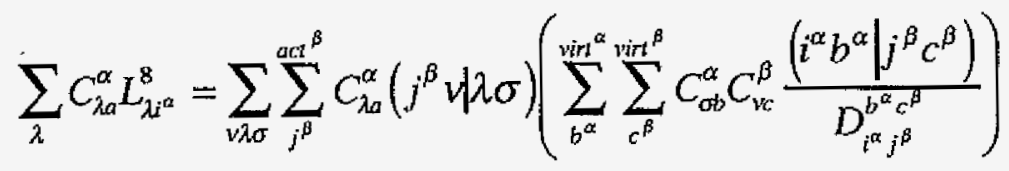

Thus,

$$
L_{i^{\alpha}}^{8}=\sum_{v \sigma}^{a \sum_{j}^{\beta}} \sum_{j^{\beta}}^{\beta}\left(j^{\beta} \psi \lambda \sigma\right) I_{i^{\alpha} j^{\beta}}^{\sigma v}
$$

where the half-transformed integral is:

$$
I_{i^{\alpha} j^{\beta}}^{\sigma \nu}=\sum_{b^{\alpha}}^{\operatorname{vin}^{\alpha}{ }^{\alpha}} \sum_{c^{\beta}}^{v^{\beta} n^{\beta}} C_{o b}^{\alpha} C_{v c}^{\beta} \frac{\left(i^{\alpha} b^{\alpha} \mid j^{\beta} c^{\beta}\right)}{D_{j^{\alpha} j^{\beta}}^{b^{\alpha}}}
$$

Term 7 of Eq. A13 can be represented as a difference of half-transformed integrals:

$$
L_{\lambda^{\alpha}}^{7}=\sum_{v \sigma}^{a c c^{\alpha}} \sum_{j^{\alpha}}^{\alpha}\left(j^{\alpha} v \mid \lambda \sigma\right)\left(I_{i^{\alpha} j^{\alpha}}^{\sigma v}-I_{j^{\alpha} j^{\alpha}}^{\sigma \sigma}\right)
$$

The half-transformed integrals may be generated from locally held (volvo) integrals without communication since all gets and puts are done locally (Figure 2). To save memory at the 
cost of extra computation later, the half-transformed integrals replace the (volvo) integrals in memory.

In a similar manner, terms 3 and 4 of Eq. A13 may be rearranged to the form

$$
\begin{aligned}
& L_{v^{\alpha}}^{3}=\sum_{\lambda \sigma}\left(i^{\alpha} \gamma \mid \lambda \sigma\right) P_{\lambda \sigma}^{(2)}(\alpha \alpha) \\
& L_{v^{\alpha}}^{4}=\sum_{\lambda \sigma}\left(i^{\alpha} v \mid \lambda \sigma\right) P_{\lambda \sigma}^{(2)}(\beta \beta)
\end{aligned}
$$

where the virtual-virtual density matrix has been back-transformed to the AO basis. Since the required storage for the $\mathrm{AO}$ density matrix is $\mathrm{O}\left(n^{2}\right)$ and the time required for the backtransformation is trivial, this back-transformation is not distributed.

Representation of these Lagrangian terms in the mixed MO/AO basis has the benefit that the quarter-transformed ERI's with one MO and three AO indices may be used as soon as they are generated. A second fourfold loop over shells is used to calculate and quartertransform the ERI's as described previously. ${ }^{11}$ After the inner two loops, a DDI_GET operation must be performed to read in half-transformed integrals such as $I_{i^{\alpha} j^{\beta}}^{\sigma v}$ for a given $\sigma, v$ pair. This requires communication among the processors. Once the quarter-transformed ERI's are contracted with the respective half-transformed integrals or AO density matrix elements and the mixed MO/AO Lagrangian terms are formed, these terms are transformed to the MO basis and combined with the other four terms of the Lagrangian. The Lagrangian is summed globally so each node holds the full matrix.

Once the Lagrangian has been calculated, the (volvo) integrals must be restored. The half-transformed integrals are transformed with the inverse MO coefficient matrix $\mathbf{C}^{-\mathbf{1}}$ (= $\mathbf{C}^{\mathrm{T}} \mathbf{S}$, where $\mathbf{S}$ is the overlap matrix over AOs), which restores the virtual MO indices, and are 
then multiplied by the appropriate orbital-energy factor (such as $D_{i^{\alpha} j^{\beta}}^{b^{\alpha} c^{\beta}}$ ) to recreate the original (volvo) integrals. Since the entire set of indices for a given occupied-occupied pair is on the local processor, this step requires no communication.

E. Solution of Z-vector Equations. A reduced Lagrangian and alpha and beta trial vectors containing only symmetry-allowed elements are used in the solution of the Z-vector equations. In each step of the iterations, blocks of the orbital Hessian are constructed from (volvo) and (vvloo) integrals. If the integrals for a given pair of occupied indices are held locally, the (volvo) and (vvloo) integrals for the alpha, beta, and mixed spin terms are used to form blocks of the orbital Hessian in Eqs. A7 and A8 (Figure 3). These blocks are multiplied by appropriate sections of the trial vectors, and the products are globally summed to generate the alpha and beta product vectors. In this way, storage of the full orbital Hessian is avoided. Alpha and beta error vectors are calculated. A Direct Inversion in the Iterative Subspace (DIIS) ${ }^{44,45}$ interpolation method is used to determine the trial vectors for the next iteration. Since previous trial and error vectors are needed for DIIS, these are stored in a distributed manner across the nodes. At convergence, the trial vectors are the virtual-occupied block of the alpha and beta one-particle density matrices. The (vvloo) integrals are not needed further, so the memory for these is released.

F. Completion of One-Particle Gradient. After solution of the Z-vector equations, the one-particle density matrix is complete. The third term in the virtual-occupied block of the one-particle energy-weighted density matrix (Eq. A6) may now be calculated. In addition, the final contribution to the fourth and fifth terms of Eq. A4 can be evaluated using the (voloo) integrals. This contribution may be computed in a distributed fashion and 
globally summed to complete the energy-weighted density matrix. This concludes the use of the (voloo) integrals, so memory for these is released. Finally, the completed alpha and beta one-particle density matrices and energy-weighted density matrices are back-transformed to the AO basis, added to their SCF counterparts (Eqs. 2 and 3), and contracted with the core Hamiltonian and overlap derivatives (Eq. 1) to yield the one-electron portion of the gradient

G. Two-Particle Gradient. The four-index back-transformation of the amplitudes in the non-separable two-particle density (Eq. A14) is similar in essence to the procedure described in section $\mathrm{D}$. The process begins with the half-back-transformation described earlier to generate half-transformed integrals (Figure 2). A third fourfold loop algorithm is required to generate the derivative ERI's. Inside the outer two loops, a DDI_GET operation necessitating communication between the processors is required to read in the halftransformed integrals with a given $\sigma, v$ pair (Figure 4). These half-transformed integrals are used to form the half-transformed amplitudes. Inside the third loop over shells, the halftransformed amplitudes are further back-transformed to all AO indices in one range and to AO indices over the third-loop shell in the other range. This step is done locally to avoid further communication. However, since the non-separable density is not symmetrized, the derivative ERI's must be calculated four times more than the minimal list. After the nonseparable density is calculated, it is combined with the separable density (Eq. A15), added to its SCF analog, and contracted with the derivative ERI's.

\section{Timings/Benchmarks}

The parallel UMP2 gradient code described above has been implemented in GAMESS and has been benchmarked on a cluster system. The cluster under consideration is comprised of IBM p640 nodes connected by dual Gigabit Ethernet. Each p640 node has 4 
Power3-II processors running at $375 \mathrm{MHz}$ and contains $16 \mathrm{~GB}$ of memory. On 8 nodes, global memory of $128 \mathrm{~GB}$ is available.

The smallest molecule under consideration in the benchmarks is $\mathrm{Au}_{3} \mathrm{H}_{4}$. Two basis sets have been used with this molecule. The smaller of the two consists of the $6-31++G * * 46-$ ${ }^{48}$ basis set on $\mathrm{H}$ and the Stevens-Basch-Krauss-Jasien-Cundari (SBKJC) ${ }^{49-51}$ effective core potential basis set with $\mathrm{f}$ polarization functions and one diffuse sp function on $\mathrm{Au}$, for a total of 170 spherical harmonic basis functions. The larger basis set consists of the aug-cc-pVTZ ${ }^{52}$ basis set on $\mathrm{H}$ and the uncontracted SBKJC basis set with $3 \mathrm{f} 2 \mathrm{~g}$ polarization functions and one sp diffuse function on $\mathrm{Au}$, for a total of 380 spherical harmonic basis functions. For both basis sets, there are 31 alpha occupied orbitals and 30 beta occupied orbitals for $\mathrm{Au}_{3} \mathrm{H}_{4}$. $\mathrm{A}$ UMP2 gradient calculation with the smaller basis set requires 4 Mwords of replicated memory and 116 Mwords of distributed memory, so it fits in the memory of a single processor on the IBM cluster. The calculation using the larger basis set requires 18 Mwords of replicated memory and 647 Mwords of distributed memory. This calculation requires the memory allotted to two processors on the IBM cluster.

A larger test case is $\mathrm{Au}_{3} \mathrm{O}_{4}$. The basis set used with this molecule consists of the augcc-pVTZ $Z^{52,53}$ basis set on $\mathrm{O}$ and the uncontracted SBKJC basis set with $3 \mathrm{f} 2 \mathrm{~g}$ polarization functions and one sp diffuse function on $\mathrm{Au}$, for a total of 472 spherical harmonic basis functions. For this molecule, there are 45 alpha occupied orbitals and 44 beta occupied orbitals. A UMP2 gradient calculation on this molecule requires 41 Mwords of replicated memory and 2166 Mwords of distributed memory. This calculation requires the memory allotted to six processors on the IBM cluster. 
Table 2 lists the average CPU time in seconds and the associated speedups and parallel efficiencies for a UMP2 gradient calculation on $1,2,4,8,16$, and 32 processors for the three gold clusters benchmarked in this study. Since the second and third test cases require more than one processor on the IBM cluster, the single-processor time required for these calculations is determined from runs on two and eight processors, respectively, assuming ideal speedup. The speedups may be visualized graphically in Figure 5. A superlinear speedup is exhibited for the smallest test case running on two processors. This may be due to the increased cache capacity available on two processors. As the number of processors increases, the observed speedup is less than the ideal speedup. This may be due to serial portions of the code, load balancing issues, or the communication and synchronization costs. On larger numbers of processors, the larger test cases exhibit greater parallel efficiencies than the smaller test cases. This is expected, since the amount of parallel computation relative to communication and other costs is higher for larger runs.

Table 3 lists an assessment of the "percentage parallelism" in each calculation. These values are determined by assuming Amdahl scaling and fitting an equation of the form T(P) $=\mathrm{Ts}+\mathrm{Tp} / \mathrm{P}$ to the series of wall clock times $\mathrm{T}(\mathrm{P})$ on $\mathrm{P}$ processors for a given calculation, as discussed in Ref 3. This yields Ts, the amount of time spent on serial portions of the calculation, and $\mathrm{Tp}$, the total amount of time spent on parallel sections. The parallel percentage represents the percentage of the calculation that is scalable. Unlike parallel efficiencies, which only compare two calculations, this model provides a way to assess the scalability over a range of processors. It does not consider effects due to load balancing or communication latencies, but these effects are usually small. Given the small number of data points in the analysis, it is not meaningful to quantitatively distinguish the three parallel\% 
values in the table. However, the $\mathrm{R}^{2}$ values suggest that the parallel percentage of the UMP2 gradient calculation is over $90 \%$.

\section{Conclusions}

A scalable parallel gradient algorithm for UMP2 using the Distributed Data Interface is presented. The purpose of this algorithm is to increase the speed for a given UMP2 gradient calculation as well as to permit the evaluation of larger jobs. The transformed molecular orbital integrals with two virtual indices or fewer are distributed across the nodes. Data of order $n^{2}$ or less is replicated across the nodes. The algorithm has been designed to use locally held data wherever possible, and sections where communication is required have been identified. Redundant computation of two-electron integrals and derivative integrals is used in order to reduce communication and required memory costs.

Benchmark calculations have been run on a series of three gold cluster molecules using an IBM cluster, and the calculations scale well. The percentage parallelism for the UMP2 gradient calculation is above $90 \%$.

Acknowledgement. The authors would like to thank Graham Fletcher, Mike Schmidt, and Ricky Kendall for helpful discussions. CMA is grateful to the National Science Foundation for providing a Graduate Research Fellowship. The authors also acknowledge the US-DOD Common High Performance Computing Software Support Initiative (CHSSI) administered by the Air Force Office of Scientific Research. The authors would also like to thank IBM for a Shared University Research (SUR) award, which provided a 128-processor cluster on which the benchmark calculations were run. 


\section{Appendix. Density Matrix Expressions}

In general, indices $\mathrm{p}, \mathrm{q}, \mathrm{r}$, and $\mathrm{s}$ represent any molecular orbital. Occupied orbitals are indexed by $\mathrm{i}, \mathrm{j}$, and $\mathrm{k}$; virtual orbitals are indexed by $\mathrm{a}, \mathrm{b}$, and $\mathrm{c}$; core orbitals are indexed by $\mathrm{K}$. The one-particle alpha-alpha density matrix expressions for the core-active, activeactive, and virtual-virtual blocks of $\mathbf{P}^{(2)}$ in the MO basis are

$$
\begin{aligned}
& P_{K^{\alpha} i^{\alpha}}^{(2)}=P_{i^{\alpha} K^{\alpha}}^{(2)}=\frac{1}{\left(\varepsilon_{i}^{\alpha}-\varepsilon_{K}^{\alpha}\right)}\left[\sum_{j^{\alpha}}^{a c c^{\alpha}{ }^{\alpha} \sum^{\alpha} b^{\alpha}} \frac{\left[\left(i^{\alpha} a^{\alpha} \mid j^{\alpha} b^{\alpha}\right)-\left(i^{\alpha} b^{\alpha} \mid j^{\alpha} a^{\alpha}\right)\right]}{D_{i^{\alpha} j^{\alpha}}^{\alpha^{\alpha} b^{\alpha}}}\left(K^{\alpha} a^{\alpha} \mid j^{\alpha} b^{\alpha}\right)\right. \\
& \left.+\sum_{j^{\beta}}^{a c t^{\beta}} \sum_{a^{\alpha}}^{\operatorname{virr}^{\alpha}{ }^{\alpha}} \sum_{b^{\beta}}^{\operatorname{vir}^{\beta}} \frac{\left(i^{\alpha} a^{\alpha} \mid j^{\beta} b^{\beta}\right)}{D_{i^{\alpha} j^{\beta}}^{a^{\alpha}}}\left(K^{\alpha} a^{\alpha} \mid j^{\beta} b^{\beta}\right)\right] \\
& P_{i^{\alpha} j^{\alpha}}^{(2)}=-\sum_{k^{\alpha}}^{a c c^{\alpha}} \sum_{a^{\alpha}}^{v_{i n}^{\alpha}} \sum_{b^{\alpha}}^{\alpha r r^{\alpha}} \frac{\left[\left(i^{\alpha} a^{\alpha} \mid k^{\alpha} b^{\alpha}\right)-\left(i^{\alpha} b^{\alpha} \mid k^{\alpha} a^{\alpha}\right)\right]}{D_{i^{\alpha} k^{\alpha}}^{\alpha^{\alpha}} b^{\alpha}} \frac{\left(j^{\alpha} a^{\alpha} \mid k^{\alpha} b^{\alpha}\right)}{D_{j^{\alpha} k^{\alpha}}^{a^{\alpha} b^{\alpha}}} \\
& -\sum_{k^{\beta}}^{a c c^{\beta}} \sum_{a^{\alpha}}^{v^{\alpha}} \sum_{b^{\beta}}^{\alpha^{\alpha}} \frac{\left[\left(i^{\alpha} a^{\alpha} \mid k^{\beta} b^{\beta}\right)\right]}{D_{i^{\alpha} k^{\beta}}^{a^{\alpha} b^{\beta}}} \frac{\left[\left(j^{\alpha} a^{\alpha} \mid k^{\beta} b^{\beta}\right)\right]}{D_{j^{\alpha} k^{\beta}}^{a^{\alpha} b^{\beta}}} \\
& P_{a^{\alpha} b^{\alpha}}^{(2)}=\sum_{i^{\alpha}}^{a c c^{\alpha}} \sum_{j^{\alpha}}^{a c c^{\alpha}} \sum_{c^{\alpha}}^{\operatorname{vin}^{\alpha}} \frac{\left[\left(i^{\alpha} a^{\alpha} \mid j^{\alpha} c^{\alpha}\right)-\left(i^{\alpha} c^{\alpha} \mid j^{\alpha} a^{\alpha}\right)\right]}{D_{i^{\alpha} j^{\alpha}}^{a^{\alpha} c^{\alpha}}} \frac{\left(i^{\alpha} b^{\alpha} \mid j^{\alpha} c^{\alpha}\right)}{D_{i^{\alpha}}^{b^{\alpha} c^{\alpha}}} \\
& +\sum_{i^{\alpha}}^{a c t^{\alpha}} \sum_{j^{\beta}}^{a c^{\beta}} \sum_{c^{\beta}}^{v_{i n}^{\beta} n^{\beta}} \frac{\left(i^{\alpha} a^{\alpha} \mid j^{\beta} c^{\beta}\right)}{D_{i^{\alpha} j^{\beta}}^{\alpha^{\alpha} c^{\beta}}} \frac{\left(i^{\alpha} b^{\alpha} \mid j^{\beta} c^{\beta}\right)}{D_{i^{\alpha} j^{\beta}}^{b^{\alpha} c^{\beta}}}
\end{aligned}
$$

The one-particle alpha-alpha energy-weighted density matrix expressions for the occupiedoccupied, virtual-virtual, and virtual-occupied blocks of $\mathbf{W}^{(2)}$ are 


$$
\begin{aligned}
& W_{i^{\alpha} j^{\alpha}}^{(2)}=-N_{i^{\alpha} j^{\alpha}} \sum_{k^{\alpha}}^{a c c^{\alpha}} \sum_{a^{\alpha} b^{\alpha}}^{v_{i r r^{\alpha}}^{\alpha}} \frac{\left[\left(i^{\alpha} a^{\alpha} \mid k^{\alpha} b^{\alpha}\right)-\left(i^{\alpha} b^{\alpha} \mid k^{\alpha} a^{\alpha}\right)\right]}{D_{i^{\alpha} k^{\alpha}}^{\alpha^{\alpha}} b^{\alpha}}\left(j^{\alpha} a^{\alpha} \mid k^{\alpha} b^{\alpha}\right) \\
& -N_{i^{\alpha} j^{\alpha}} \sum_{k^{\beta}}^{a c c^{\beta}} \sum_{a^{\alpha}}^{\operatorname{vin}^{\alpha}} \sum_{b^{\beta}}^{v^{\beta} r^{\beta}} \frac{\left(i^{\alpha} a^{\alpha} \mid k^{\beta} b^{\beta}\right)}{D_{i^{\alpha} k^{\beta}}^{a^{\alpha} b^{\beta}}}\left(j^{\alpha} a^{\alpha} \mid k^{\beta} b^{\beta}\right)-\frac{1}{2} P_{i^{\alpha} j^{\alpha}}^{(2)}\left(\varepsilon_{i}^{\alpha}+\varepsilon_{j}^{\alpha}\right) \\
& -\sum_{p^{\alpha} q^{\alpha}}^{a l^{\alpha}} P_{p^{\alpha} q^{\alpha}}^{(2)}\left[\left(p^{\alpha} q^{\alpha} \mid i^{\alpha} j^{\alpha}\right)-\left(p^{\alpha} i^{\alpha} \mid q^{\alpha} j^{\alpha}\right)\right]-\sum_{p^{\beta} q^{\beta}}^{a l \beta^{\beta}} P_{p^{\beta} q^{\beta}}^{(2)}\left(p^{\beta} q^{\beta} \mid i^{\alpha} j^{\alpha}\right)
\end{aligned}
$$

where $N_{i^{\alpha} j^{\alpha}} \equiv\left\{\begin{array}{l}0, \text { for both } i, j \in \text { core } \\ 1, \text { otherwise }\end{array}\right.$

$$
\begin{aligned}
& W_{a^{\alpha} b^{\alpha}}^{(2)}=-\sum_{i^{\alpha} j^{\alpha}}^{a c c^{\alpha}} \sum_{c^{\alpha}}^{v^{\alpha} r^{\alpha}} \frac{\left[\left(i^{\alpha} a^{\alpha} \mid j^{\alpha} c^{\alpha}\right)-\left(i^{\alpha} c^{\alpha} \mid j^{\alpha} a^{\alpha}\right)\right]}{D_{i^{\alpha} j^{\alpha}}^{\alpha^{\alpha} c^{\alpha}}}\left(i^{\alpha} b^{\alpha} \mid j^{\alpha} c^{\alpha}\right)
\end{aligned}
$$

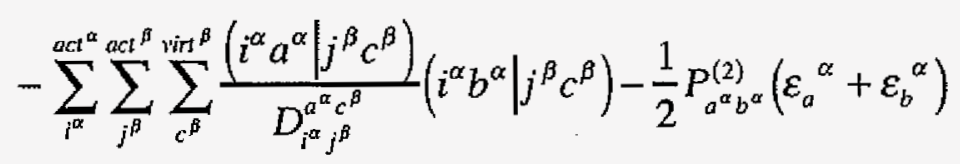

$$
\begin{aligned}
& W_{a^{\alpha} i^{\alpha}}^{(2)}=-2 \sum_{j^{\alpha} k^{\alpha}}^{a c^{\alpha}} \sum_{b^{\alpha}}^{v_{i n}^{\alpha}} \frac{\left[\left(j^{\alpha} a^{\alpha} \mid k^{\alpha} b^{\alpha}\right)-\left(j^{\alpha} b^{\alpha} \mid k^{\alpha} a^{\alpha}\right)\right]}{D_{j^{\alpha} k^{\alpha}}^{a^{\alpha} b^{\alpha}}}\left(\tilde{i}^{\alpha} j^{\alpha} b^{\alpha} k^{\alpha}\right) \\
& -2 \sum_{j^{\alpha}}^{a c c^{a}} \sum_{k^{\beta}}^{a c c^{\beta}} \sum_{b^{\beta}}^{v^{\beta} r^{\beta}} \frac{\left(j^{\alpha} a^{\alpha} \mid k^{\beta} b^{\beta}\right)}{D_{j^{\alpha} k^{\beta}}^{a^{\alpha} b^{\beta}}}\left(i^{\alpha} j^{\alpha} b^{\beta} k^{\beta}\right)-P_{a^{\alpha} i^{\alpha}}^{(2)} \varepsilon_{i}^{\alpha}
\end{aligned}
$$

The virtual-occupied block of $\mathbf{P}^{(2)}$ is obtained from the iterative solution of the Z-vector equations due to Handy and Schaefer ${ }^{6}$

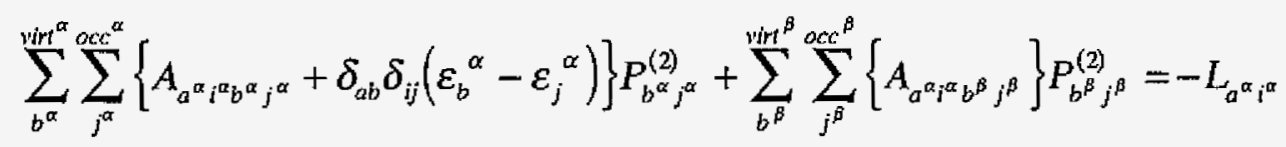

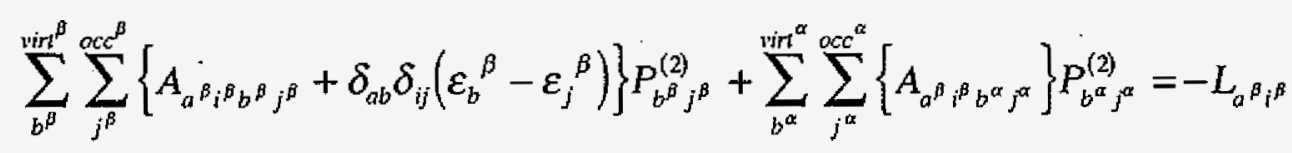

where the orbital Hessian is found by

$$
A_{p^{\alpha} q^{\alpha} r_{s}^{\alpha}}=2\left(p^{\alpha} q^{\alpha} \mid r^{\alpha} s^{\alpha}\right)-\left(p^{\alpha} r^{\alpha} \mid q^{\alpha} s^{\alpha}\right)-\left(p^{\alpha} s^{\alpha} \mid q^{\alpha} r^{\alpha}\right)
$$




$$
\begin{aligned}
& A_{p^{\alpha} q^{\alpha} r_{s}^{\beta}}=2\left(p^{\alpha} q^{\alpha} \mid r^{\beta} s^{\beta}\right), \\
& A_{p^{\beta} q^{\beta} r^{\alpha} s^{\alpha}}=2\left(p^{\beta} q^{\beta} \mid r^{\alpha} s^{\alpha}\right), \\
& A_{p^{\beta} q^{\beta} r_{s}^{\beta}}=2\left(p^{\beta} q^{\beta} \mid r^{\beta} s^{\beta}\right)-\left(p^{\beta} r^{\beta} \mid q^{\beta} s^{\beta}\right)-\left(p^{\beta} s^{\beta} \mid q^{\beta} r^{\beta}\right),
\end{aligned}
$$

and the alpha-alpha Lagrangian is given by

$$
\begin{aligned}
& L_{a^{\alpha_{i}^{\alpha}}}=\sum_{j^{\alpha} k^{\alpha}}^{o c^{\alpha}{ }^{\alpha}} P_{j^{\alpha} k^{\alpha}}^{(2)} A_{a^{\alpha^{\alpha}} j^{\alpha} j^{\alpha} k^{\alpha}}+\sum_{j^{\beta} k^{\beta}}^{o c c^{\beta}} P_{j^{\beta} k^{\beta}}^{(2)} A_{a^{\alpha} i^{\alpha} j^{\beta} k^{\beta}}
\end{aligned}
$$

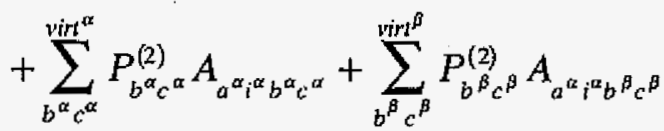

$$
\begin{aligned}
& -2 N_{a^{\alpha}} \sum_{j^{\alpha} k^{\alpha}}^{a c c^{\alpha}} \sum_{b^{\alpha}}^{v_{i n}^{\alpha}} \frac{\left[\left(j^{\alpha} a^{\alpha} \mid k^{\alpha} b^{\alpha}\right)-\left(j^{\alpha} b^{\alpha} \mid k^{\alpha} a^{\alpha}\right)\right]}{D_{j^{\alpha} k^{\alpha}}^{a^{\alpha} b^{\alpha}}}\left(i^{\alpha} j^{\alpha} \mid b^{\alpha} k^{\alpha}\right) \\
& -2 N_{a^{\alpha}} \sum_{j^{\alpha}}^{a c c^{\alpha}} \sum_{k^{\beta}}^{a c c^{\beta}} \sum_{b^{\beta}}^{\operatorname{vin}^{\beta} r^{\beta}} \frac{\left(j^{\alpha} a^{\alpha} \mid k^{\beta} b^{\beta}\right)}{D_{j^{\alpha} k^{\beta}}^{a^{\beta}}}\left(i^{\alpha} j^{\alpha} \mid b^{\beta} k^{\beta}\right) \\
& +2 N_{i^{\alpha}} \sum_{j^{\alpha}}^{a c c^{\alpha}} \sum_{b^{\alpha} c^{\alpha}}^{v_{i n}^{\alpha}} \frac{\left[\left(i^{\alpha} b^{\alpha} \mid j^{\alpha} c^{\alpha}\right)-\left(i^{\alpha} c^{\alpha} \mid j^{\alpha} b^{\alpha}\right)\right]}{D_{i^{\alpha} j^{\alpha}}^{b^{\alpha}} c^{\alpha}}\left(a^{\alpha} b^{\alpha} \mid j^{\alpha} c^{\alpha}\right)
\end{aligned}
$$

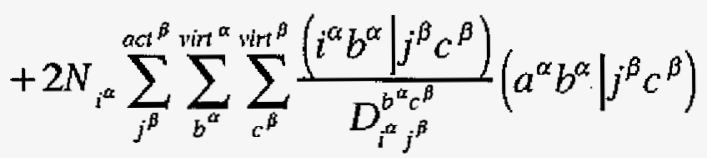

where $N_{i^{a}} \equiv \begin{cases}0, & \text { for } i=\text { core } \\ 1, & \text { for } i=\text { active }\end{cases}$

Expressions for the beta-beta matrices are direct analogs of the alpha-alpha expressions. The two-particle density matrices are given by 


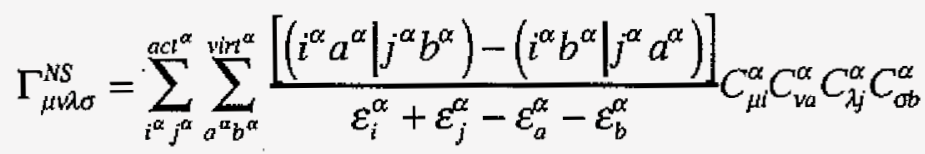

$$
\begin{aligned}
& +2 \sum_{i^{\alpha}}^{a c t^{\alpha}} \sum_{j^{\beta}}^{a c^{\beta}} \sum_{a^{\alpha}}^{\operatorname{pir}^{\alpha}{ }^{\alpha}} \sum_{b^{\beta}}^{\operatorname{vin}^{\beta}} \frac{\left(i^{\alpha} a^{\alpha} \mid j^{\beta} b^{\beta}\right)}{\varepsilon_{i}^{\alpha}+\varepsilon_{j}^{\beta}-\varepsilon_{a}^{\alpha}-\varepsilon_{b}^{\beta}} C_{\mu i}^{\alpha} C_{k j}^{\alpha} C_{\lambda j}^{\beta} C_{\sigma b}^{\beta} \\
& +\sum_{i^{\beta} j^{\beta}}^{a c t^{\beta}} \sum_{b_{b}^{\beta}}^{\operatorname{sirt} t^{\beta}} \frac{\left[\left(i^{\beta} a^{\beta} \mid j^{\beta} b^{\beta}\right)-\left(i^{\beta} b^{\beta} \mid j^{\beta} a^{\beta}\right)\right]}{\varepsilon_{i}^{\beta}+\varepsilon_{j}^{\beta}-\varepsilon_{a}^{\beta}-\varepsilon_{b}^{\beta}} C_{\mu i}^{\beta} C_{v a}^{\beta} C_{j j}^{\beta} C_{o b}^{\beta}
\end{aligned}
$$

and

$$
\begin{aligned}
\Gamma_{\mu \nu \lambda \sigma}^{S} & =P_{\mu \nu}^{(2)}(\alpha \alpha) P_{\lambda \sigma}^{\alpha S C F}-P_{\mu \lambda}^{(2)}(\alpha \alpha) P_{v \sigma}^{\alpha S C F}+P_{\mu \nu}^{(2)}(\alpha \alpha) P_{\lambda \sigma}^{\beta S C F} \\
& +P_{\mu \nu}^{(2)}(\beta \beta) P_{\lambda \sigma}^{\beta S C F}-P_{\mu \lambda}^{(2)}(\beta \beta) P_{\nu \sigma}^{\beta S C F}+P_{\mu \nu}^{(2)}(\beta \beta) P_{\lambda \sigma}^{\alpha S C F}
\end{aligned}
$$

\section{References}

(1) Whiteside, R. A.; Binkley, J. S.; Colvin, M. E.; Schaefer III, H. F. J. Chem. Phys. 1987, 86, 2185-2193.

(2) Møller, C, Plesset, M. S. Phys. Rev. 1934, 46, 618-622.

(3) Pople, J. A.; Krishnan, R.; Schlegel, H. B.; Binkley, J. S. Int. J. Quantum Chem. Symp. 1979, 13, 225.

(4) Handy, N. C.; Amos, R. D.; Gaw, J. F.; Rice, J. E.; Simandiras, E. D. Chem. Phys. Lett. 1985, 120, 151.

(5) Pulay, P.; Saebø, S. Theor. Chim. Acta 1986, 69, 357.

(6) Handy, N. C.; Schaefer, H. F. J. Chem. Phys. 1984, 81.

(7) Lee, T. J.; Racine, S. C.; Rice, J. E.; Rendell, A. P. Mol. Phys. 1995, 85, 561.

(8) Frisch, M. J.; Head-Gordon, M.; Pople, J. A. Chem. Phys. Lett. 1990, 166, 275.

(9) Frisch, M. J.; Head-Gordon, M.; Pople, J. A. Chem. Phys. Lett. 1990, 166, 281. 
(10) Head-Gordon, M. Mol. Phys. 1999, 96, 673.

(11) Fletcher, G. D.; Schmidt, M. W.; Gordon, M. S. In Advances in Chemical Physics; Prigogine, I., Rice, S. A., Eds.; John Wiley \& Sons, Inc., 1999; Vol. 110, pp 267294.

(12) Fletcher, G. D.; Schmidt, M. W.; Bode, B. M.; Gordon, M. S. Comput. Phys. Commun. 2000, 128, 190-200.

(13) Nieplocha, J.; Harrison, R. J.; Littlefield, R. J. In Proceedings of Supercomputing 1994; IEEE Computer Society Press: Washington DC, 1994, pp 340-349.

(14) Alexeev, Y.; Kendall, R. A.; Gordon, M. S. Comput. Phys. Commun. 2002, $143,69-82$.

(15) Alexeev, Y.; Schmidt, M. W.; Windus, T. L.; Gordon, M. S., manuscript in preparation.

(16) Fletcher, G. D.; Schmidt, M. W.; Gordon, M. S., manuscript in preparation.

(17) Schmidt, M. W.; Baldridge, K. K.; Boatz, J. A.; Elbert, S. T.; Gordon, M. S.; Jensen, J. H.; Koseki, S.; Matsunaga, N.; Nguyen, K. A.; Su, S.; Windus, T. L.; Dupuis, M.; Montgomery Jr., J. A. J. Comput. Chem 1993, 14, 1347-1363.

(18) Umeda, H.; Koseki, S.; Nagashima, U.; Schmidt, M. W. J. Comput. Chem $2001,22,1243-1251$.

(19) Webb, S. P.; Petrich, J. W.; Gordon, M. S., manuscript in preparation.

(20) Gan, Z.; Alexeev, Y.; Kendall, R. A.; Gordon, M. S. J. Chem. Phys. 2003, $119,47-59$

(21) Colvin, M. E.; Janssen, C. L.; Whiteside, R. A.; Tong, C. H. Theor. Chim. Acta 1993, 84, 301-314. 
(22) Furlani, T. R.; King, H. F. J. Comput. Chem 1995, 16, 91-104.

(23) Foster, I. T.; Tilson, J. L.; Wagner, A. F.; Shepard, R. L.; Harrison, R. J.;

Kendall, R. A.; Littlefield, R. J. J. Comput. Chem 1996, 17, 109-123.

(24) Harrison, R. J.; Guest, M. F.; Kendall, R. A.; Bernholdt, D. E.; Wong, A. T.;

Stave, M.; Anchell, J. L.; Hess, A. C.; Littlefield, R. J.; Fann, G. L.; Wagner, A. F.; Foster, I.

T.; Lusk, E.; Stevens, R. J. Comput. Chem 1996, 17, 124-132.

(25) Fruchtl, H.; Kendall, R. A.; Harrison, R. J.; Dyall, K. G. Int. J. Quantum Chem. 1997, 64, 63-69.

(26) Furlani, T. R.; King, H. F. In Quantum Mechanical Simulation Methods for Studying Biological Systems: Spencer, France, 1996.

(27) Furlani, T. R.; Kong, J.; Gill, P. M. W. Comput. Phys. Commun. 2000, 128, 170-177.

(28) Marquez, A. M.; Oviedo, J.; Sanz, J. F.; Dupuis, M. J. Comput. Chem 1997, $18,159-168$.

(29) Korambath, P. P.; Kong, J.; Furlani, T. R.; Head-Gordon, M. Mol. Phys. 2002, $100,1755-1761$.

(30) Limaye, A. C.; Gadre, S. R. J. Chem. Phys. 1994, 100, 1303.

(31) Marquez, A. M.; Dupuis, M. J. Comput. Chem 1995, 16, 395-404.

(32) Nielsen, I. M. B.; Seidl, E. T. J. Comput. Chem 1995, 16, 1301-1313.

(33) Wong, A. T.; Harrison, R. J.; Rendell, A. P. Theor. Chim. Acta 1996, 93, $317-$ 321.

(34) Bernholdt, D. E.; Harrison, R. J. J. Chem. Phys. 1995, 102, 9582-9589.

(35) Bernholdt, D. E. Chem. Phys. Lett. 1996, 250, 477-484. 
(36) Schütz, M.; Lindh, R. Theor. Chim. Acta 1997, 95, 13-34.

(37) Nielsen, I. M. B. Chem. Phys. Lett. 1996, 255, 210-216.

(38) Fletcher, G. D.; Rendell, A. P.; Sherwood, P. Mol. Phys. 1997, 91, 431-438.

(39) Daschel, H.; Lishka, H.; Shepard, R.; Nieplocha, J.; Harrison, R. J. J. Comput. Chem 1997, 18, 430-448.

(40) Dobbyn, A. J.; Knowles, P. J.; Harrison, R. J. J. Comput. Chem 1998, 19 , $1215-1228$.

(41) Rendell, A. P.; Guest, M. F.; Kendall, R. A. J. Comput. Chem 1993, 14, 1429 1439.

(42) Kobayashi, R.; Rendell, A. P. Chem. Phys. Lett. 1997, 265, 1-11.

(43) Aikens, C. M.; Webb, S. P.; Bell, R. L.; Fletcher, G. D.; Schmidt, M. W.;

Gordon, M. S. Theor. Chem. Acc. 2003, 110, 233.

(44) Pulay, P. Chem. Phys. Lett. 1980, 73, 393-398.

(45) Pulay, P. J. Comput. Chem 1982, 3, 556-560.

(46) Ditchfield, R.; Hehre, W. J.; Pople, J. A. J. Chem. Phys. 1971, 54, 724-728.

(47) Hariharan, P. C.; Pople, J. A. Theor. Chim. Acta 1973, 28, 213-222.

(48) Clark, T.; Chandrasekhar, J.; Spitznagel, G. W.; Schleyer, P. v. R. J. Comput. Chem 1983, 4, 294-301.

(49) Stevens, W. J.; Basch, H.; Krauss, M. J. Chem. Phys. 1984, 81, 6026.

(50) Stevens, W. J.; Basch, H.; Krauss, M.; Jaisen, P. Can. J. Chem. 1992, 70, 612.

(51) Cundari, T. R.; Stevens, W. J. J. Chem. Phys. 1993, 98, 5555.

(52) Dunning Jr., T. H. J. Chem. Phys. 1989, 90, 1007. 
(53) Kendall, R. A.; Dunning Jr., T. H.; Harrison, R. J. J. Chem. Phys. 1992, 96, 6769. 
TABLE 1: Distributed Memory Operations

\begin{tabular}{ll}
\hline DDI_SEND & Synchronous send \\
DDI_RECV & Synchronous receive \\
DDI_GET & Get block of distributed array \\
DDI_PUT & Put block of distributed array \\
DDI_ACC & Accumulate data into block \\
DDI_BCAST & Broadcast data to all nodes \\
DDI_GSUMF & Floating point global sum \\
DDI_GSUMI & Integer global sum \\
DDI_CREATE & Create distributed array \\
DDI_DESTROY & Destroy distributed array \\
DDI_DISTRIB & Obtain distributed matrix distribution
\end{tabular}




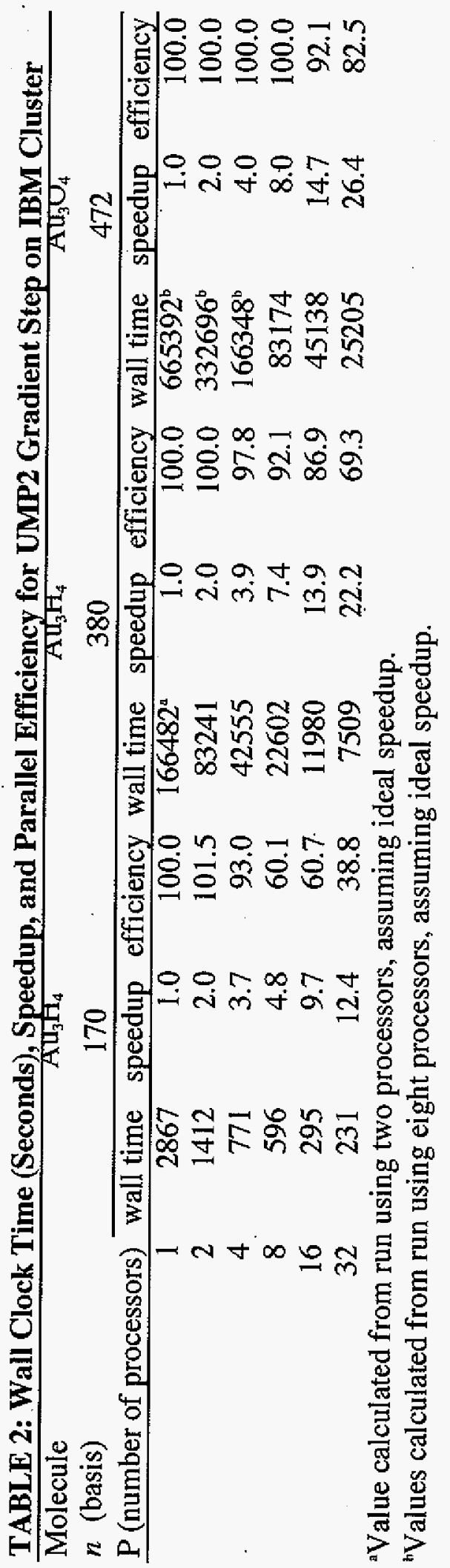


TABLE 3: Serial Time, Parallel Time, and Parallel Percentage for UMP2 Gradient Calculation

\begin{tabular}{lccc}
\hline & $\mathrm{Au}_{3} \mathrm{H}_{4}(170)$ & $\mathrm{Au}_{3} \mathrm{H}_{4}(380)$ & $\mathrm{Au}_{3} \mathrm{O}_{4}(472)$ \\
\hline Ts (seconds) & 150 & 3270 & 6187 \\
$\mathrm{Tp}$ (seconds) & 2679 & 159396 & 616942 \\
parallel \% & 93.5 & 95.7 & 92.7 \\
$\mathrm{R}^{2}$ & 0.99542 & 0.99994 & 0.99986
\end{tabular}




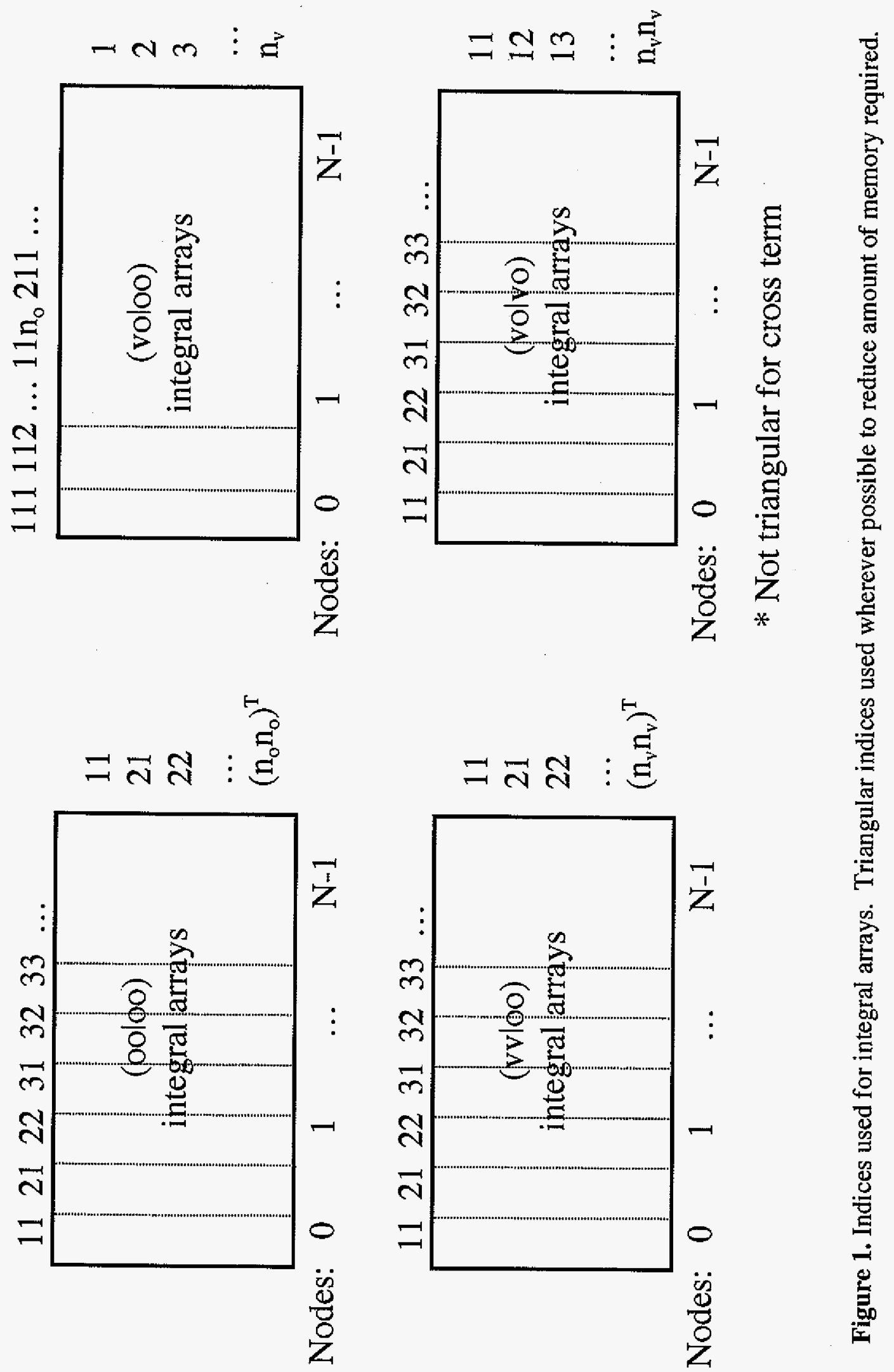




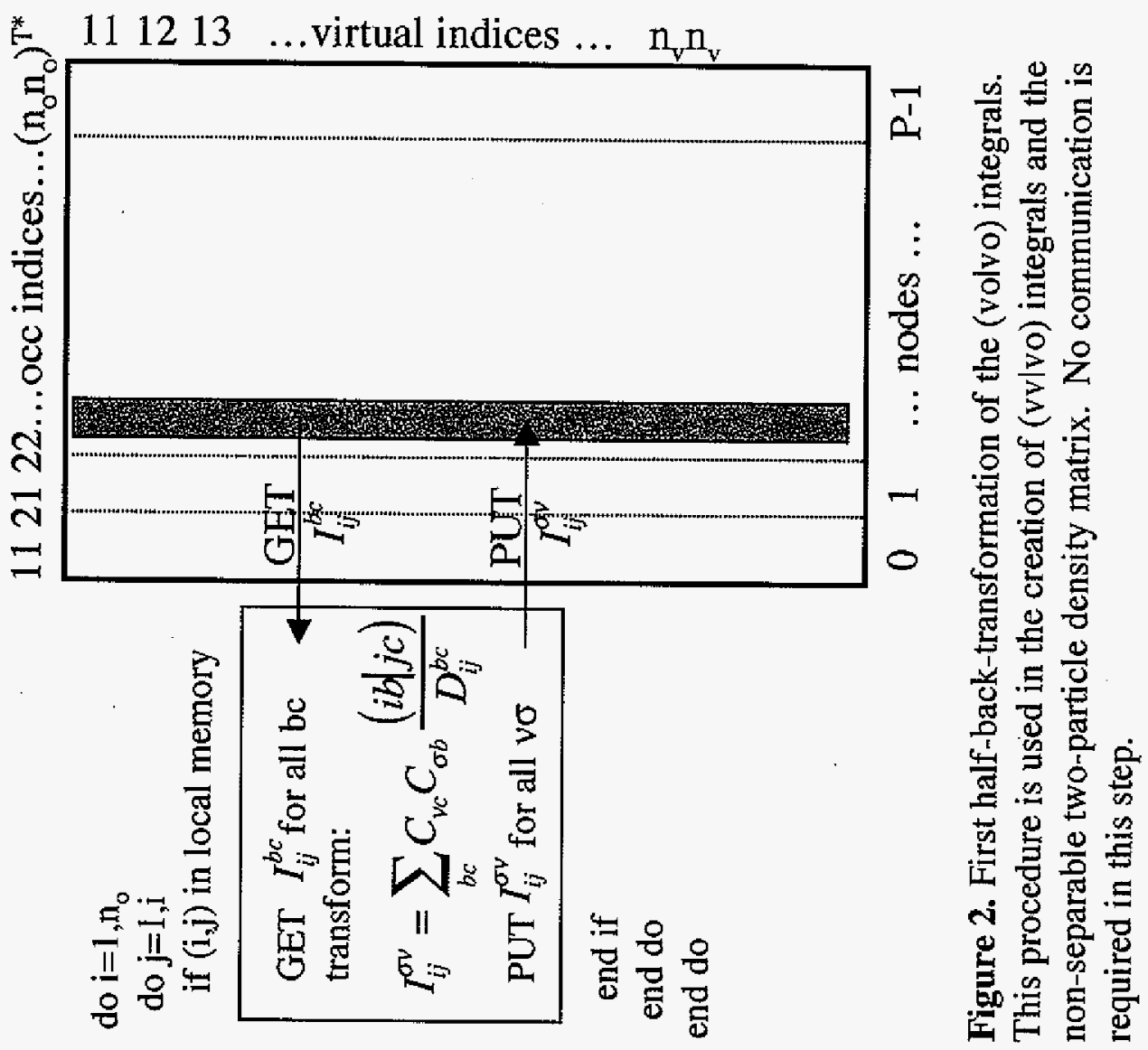




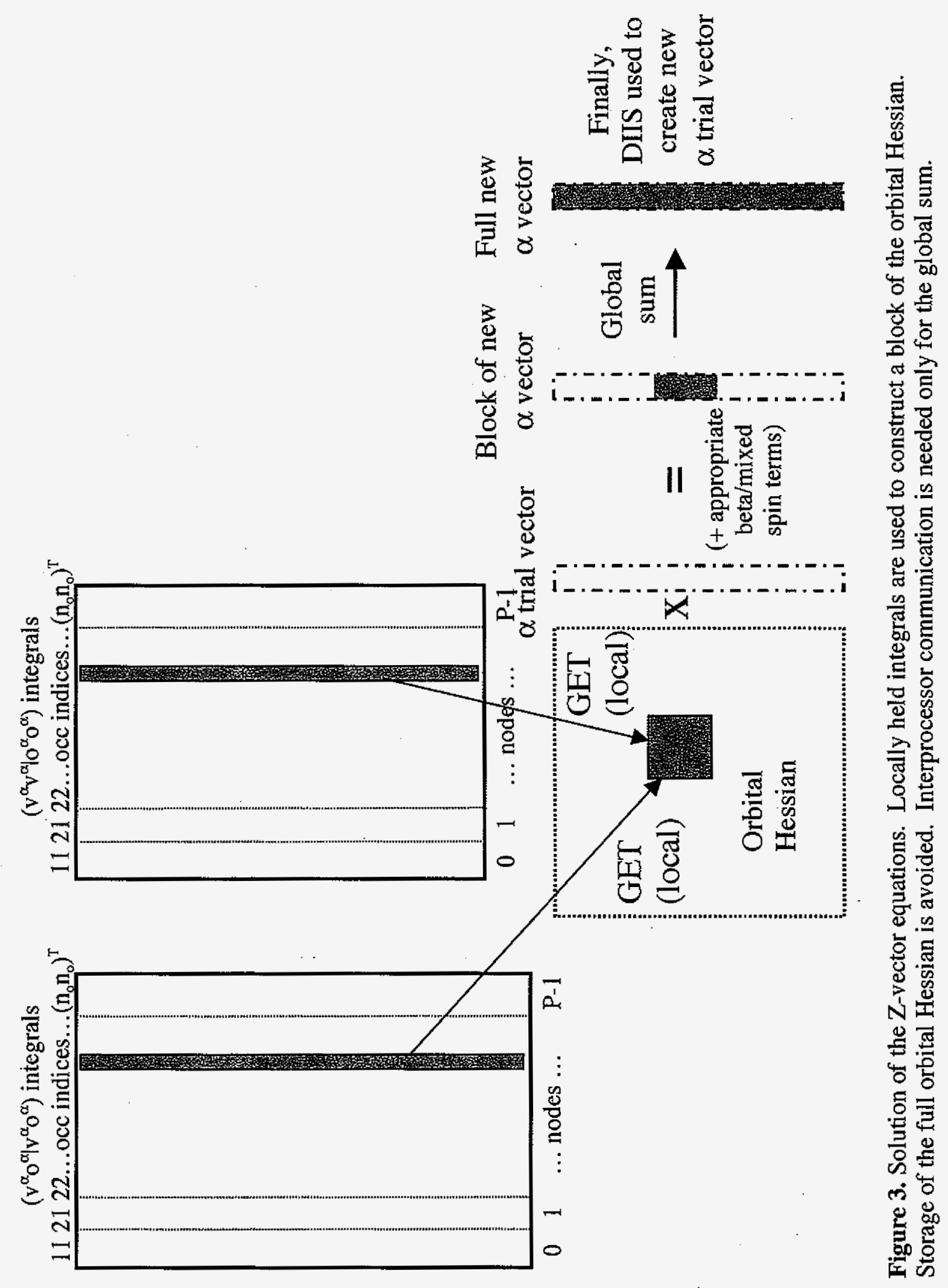




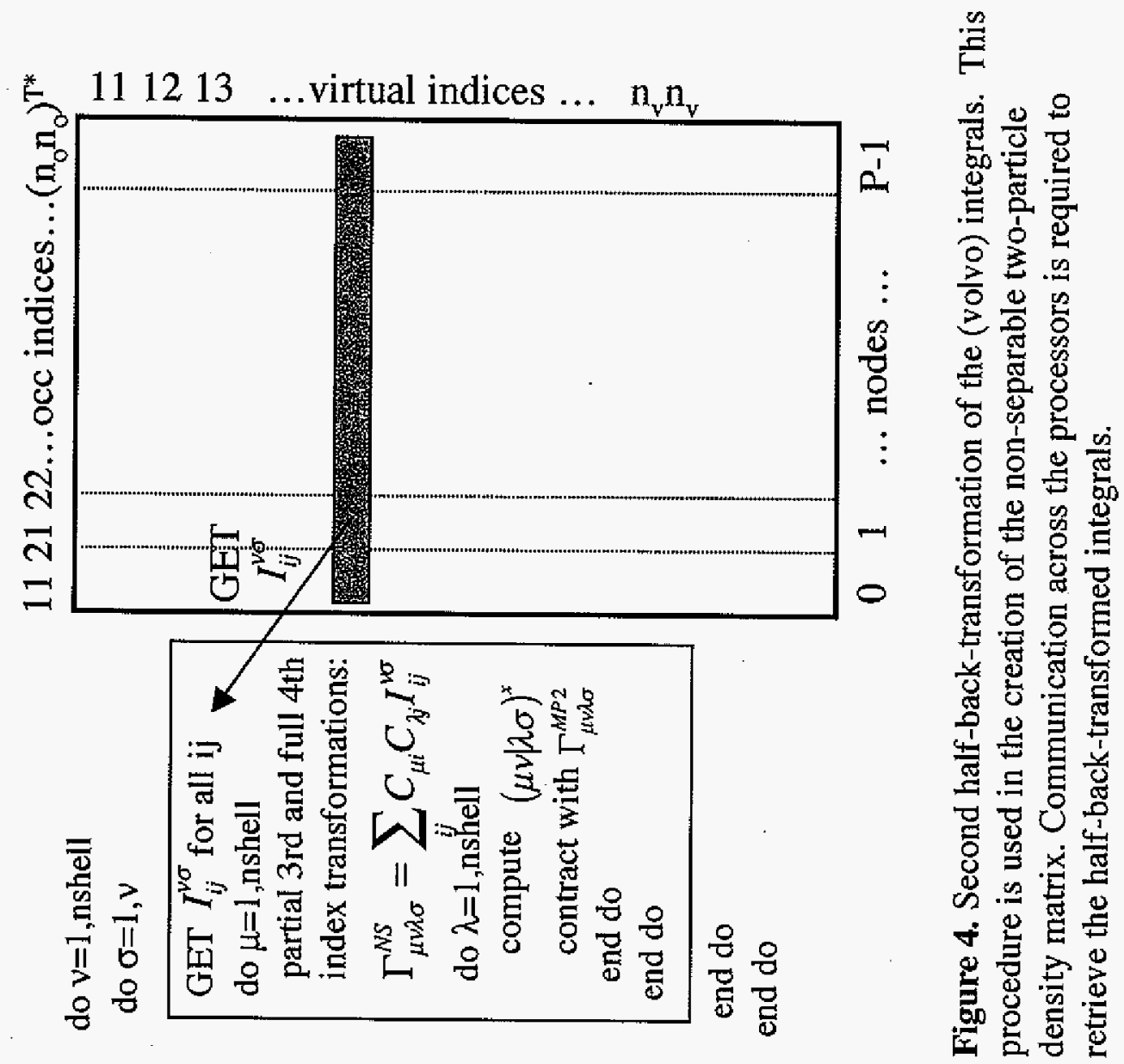




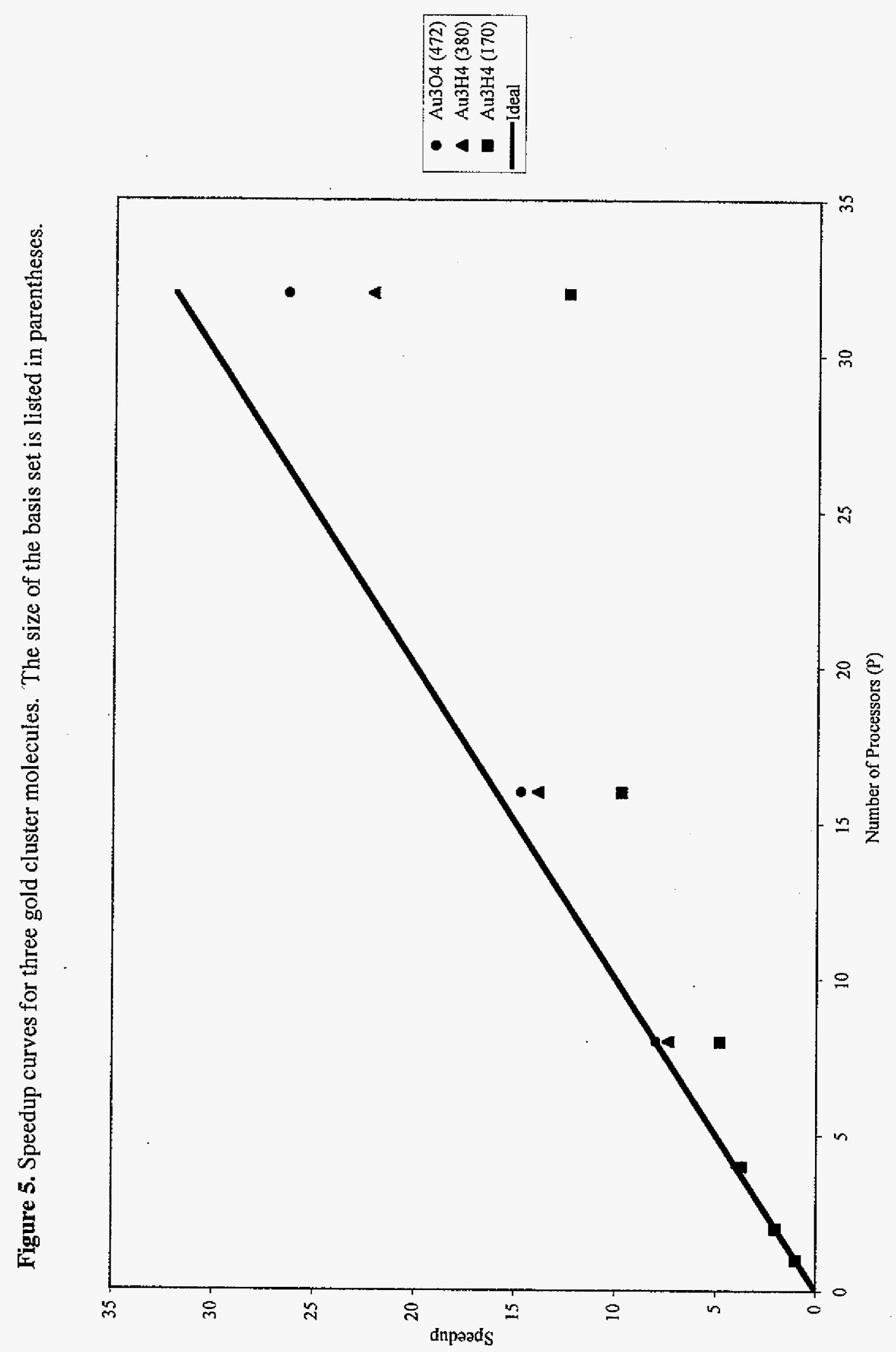




\title{
CHAPTER 6. SCALABLE IMPLEMENTATION OF ANALYTIC GRADIENTS FOR SECOND-ORDER Z-AVERAGED PERTURBATION THEORY USING THE DISTRIBUTED DATA INTERFACE
}

A paper to be submitted to the Journal of Chemical Physics

Christine M. Aikens, Graham D. Fletcher, Michael W. Schmidt, and Mark S. Gordon

\begin{abstract}
The analytic gradient expression for second-order Z-averaged perturbation theory is revised and its parallel implementation into GAMESS is described in detail. The Distributed Data Interface is used to access molecular orbital integral arrays stored in distributed memory. The algorithm is designed to maximize the use of local data and reduce communication costs. The iterative solution and the preconditioner used to induce convergence of the coupled perturbed Hartree-Fock equations are presented. Several illustrative timing examples are discussed.
\end{abstract}

\section{Introduction}

Second-order Møller-Plesset (MP2) perturbation theory ${ }^{1}$ is extensively employed to calculate molecular energies and geometries since it provides a balance between the amount of electron correlation recovered and the computational requirements of a calculation. For closed-shell systems, perturbation theory based on a restricted Hartree-Fock (RHF) wave function is well defined. However, open-shell systems are much more challenging. Although perturbation theory based on an unrestricted Hartree-Fock (UHF) wave function follows directly from the MP2 spin-orbital equations, the wave function is not an eigenfunction of the $\hat{S}^{2}$ operator, and this results in spin contamination problems. In 
addition, since different spatial orbitals are used for the $\alpha$ and $\beta$ electrons, the method requires 3-4 times as much memory, disk space, etc. as a comparable closed-shell calculation. Spin-projected methods may alleviate some of the spin-contamination, but this can introduce size-consistency problems. ${ }^{2}$

As a result, many open-shell perturbation theory methods based on RHF wave functions have been proposed ${ }^{3-9}$ These methods may be divided into two classes: those that have a configuration state function (CSF) basis (which are $\hat{S}^{2}$ eigenfunctions), and those that have a spin-orbital determinant basis. Methods with a CSF basis include the method of Hubac and Carsky (HCPT), ${ }^{3}$ the OPT1 and OPT2 methods, ${ }^{4}$ and the IOPT method. ${ }^{9}$ Methods using a spin-orbital basis include the $\mathrm{ROMP}^{5}{ }^{5} \mathrm{RMP}^{6} / \mathrm{ROHF}^{-M B P T},{ }^{7}$ and Z-averaged perturbation theory ${ }^{8}$ methods. The convergence of the perturbation series for HCPT and OPT1 is expected to be poor. ${ }^{5,10}$ OPT2 is not invariant with respect to rotations between degenerate singly-occupied orbitals. ${ }^{11}$ IOPT is not size-consistent, ${ }^{12}$ although the effects of this on its results have been debated. ${ }^{13}$ ROMP and RMP use different $\alpha$ and $\beta$ spatial orbitals, so the cost of these two methods will be similar to unrestricted perturbation theory.

Z-averaged perturbation theory (ZAPT) ${ }^{8}$ is based on a set of "symmetric spin orbitals"14, and the symmetry of these orbitals leads to significant computational savings over ROMP and RMP. The spatial parts of the spin orbitals come from an open-shell ROHF calculation. The standard $\alpha$ and $\beta$ spin functions are assigned to doubly occupied and unoccupied orbitals in the reference function. The spin parts of the singly occupied orbitals are assigned to be $\sigma^{+}$and $\sigma^{\circ}$, where

$$
\sigma^{+}=\frac{1}{\sqrt{2}}(\alpha+\beta)
$$




$$
\sigma^{-}=\frac{1}{\sqrt{2}}(\alpha-\beta)
$$

So, the reference function is symmetric with respect to the interchange of $\alpha$ and $\beta$ spin indices. The single determinant based on these orbitals is an eigenfunction of $\hat{S}^{2}$, although the $n$th order perturbed wavefunctions generally are not. There are no $\hat{S}^{2}$ contaminants in the second-order (ZAPT2) energies. The reference function is a linear combination of $\hat{S}_{z}$ eigenfunctions, but suitable use of the raising and lowering operators $\hat{S}_{+}$and $\hat{S}_{-}$can be used to recover eigenfunctions of $\hat{S}_{z} \cdot{ }^{14}$ The canonicalization chosen for the molecular orbitals (MO's) is equivalent to using $\frac{1}{2}\left(\hat{F}^{\alpha}+\hat{F}^{\beta}\right)$ to canonicalize the three shells (doubly occupied, singly occupied, and unoccupied (virtual)). ${ }^{15}$ The zeroth-order Hamiltonian is defined as the diagonal part of the spin orbital Fock matrix.

In order to effectively use this method, it is desirable to calculate analytic derivatives of the second-order energy. Equations for the ZAPT2 gradient have been previously derived by Fletcher et al. ${ }^{16}$ A few revisions to these equations are made in section 2 of this work, and the subsequent implementation is described in section 3.

The efficient implementation of gradients for post-Hartree-Fock methods has been of interest for many years. The first closed-shell MP2 gradient derivation was presented by Pople et al. in $1979 .{ }^{17}$ Later, the storage of derivative integrals and three-virtual MO integrals was eliminated, ${ }^{18}$ the number of unknown response vectors was reduced to one, ${ }^{19}$ and the need to solve the coupled perturbed Hartree-Fock equations in the occupied-occupied and virtual-virtual blocks was removed. ${ }^{20}$ Frozen orbitals further reduced the computational cost. $^{21}$ Direct and semi-direct algorithms reduced the required memory and disk storage 
requirements and permitted larger calculations, although this came at the cost of increased integral computation. ${ }^{22-24}$

Even with these improvements, the computational requirements for large molecules with reasonable basis sets quickly outgrow the capabilities of a single-processor computer. For second-order perturbation theory, the time requirements for a calculation increase as $\mathrm{O}\left(n^{5}\right)$ with the number of basis functions $n$, and the memory needs can grow as $\mathrm{O}\left(n^{3}\right)$, depending on the algorithm. Distributed data parallel schemes are desirable, as these alleviate both the single-node memory and time requirements of a calculation.

The Distributed Data Interface (DDI) was developed by Fletcher et al. to provide a set of tools for distributed memory programming. ${ }^{25,26}$ Like Global Arrays (GA), ${ }^{27}$ DDI provides a programming environment that mimics the ease of a shared-memory environment yet permits the scalability of a distributed memory architecture. Large data arrays can be stored over the collective memory of the system. These arrays can be easily accessed by any of the nodes, although the programmer must be aware of the increased time required for remote memory access and should design algorithms that maximize the use of local memory. In order to maximize scalability, the programmer must also limit the replicated memory requirements. To date, distributed storage algorithms for self-consistent field (SCF) energies, ${ }^{28}$ analytic SCF Hessians, closed-shell ${ }^{25}$ and unrestricted ${ }^{29}$ MP2 energies and gradients, ZAPT2 energies, multireference self-consistent field energies, ${ }^{30}$ gradients, ${ }^{30}$ and Hessians, ${ }^{31}$ multireference perturbation theory energies, ${ }^{32}$ single excitation configuration interaction (CI) energies, ${ }^{30}$ gradients, ${ }^{33}$ and full $\mathrm{CI}$ energies ${ }^{34}$ have been implemented using DDI into the electronic structure code GAMESS, ${ }^{35}$ which is freely available from Iowa State 
University at www.msg.ameslab.gov. Recently, DDI has been extended to take optimal advantage of shared memory processor (SMP) computers. ${ }^{36}$

\section{Theory}

\section{A. Notation and Energy Expression}

The notation used here is as similar as possible to a recent overview of MP2 gradient equations. ${ }^{37}$ The ZAPT2 energy is the sum of the SCF and second-order correction energies. The frozen-core ZAPT second-order energy correction may be expressed in the MO basis as

$$
\begin{aligned}
E_{Z A P T}^{(2)}= & \frac{1}{2} \sum_{i j} \sum_{p q}^{s, r_{i}}(i p \mid j q)\left[C_{p q}(i p \mid j q)-(i q \mid j p)\right] / D_{i j}^{p q} \\
& +\frac{1}{2} \sum_{a b} \sum_{p q}^{d . s .}(p a \mid q b)\left[C_{p q}(p a \mid q b)-(p b \mid q a)\right] / D_{p q}^{a b} . \\
& +\sum_{i x y a}(i x \mid y a)(i x \mid y a) / D_{i y}^{x a}+\frac{1}{2} \sum_{i \text { iya }}(i x \mid x a)(i y \mid y a) / D_{i}^{a}
\end{aligned}
$$

General MO's are indexed by $p, q, r, s$. Doubly occupied active MO's (referred to as DOCC) are indexed by $i, j, k$. Singly occupied MO's (SOCC) are indexed by $w, x, y, z$. Virtual (unoccupied) MO's (VIRT) are indexed by $a, b, c$. Doubly occupied frozen-core MO's (CORE) are indexed by $m, n$. The summation range denoted $s . v$. extends over the SOCC and VIRT spaces; likewise, d.s. extends over the DOCC and SOCC spaces and c.d. extends over the CORE and DOCC spaces. The four-index symbol $(p q \mid r s)$ is a two-electron repulsion integral (ERI) over MO's in Mulliken notation. These integrals are transformed into the MO basis from the atomic orbital (AO) basis by

$$
(p \dot{q} \mid r s)=\sum_{\mu \nu \lambda \sigma} C_{\mu p} C_{v q} C_{\lambda r} C_{\sigma s}(\mu v \mid \lambda \sigma)
$$


where $\mu, \nu, \lambda, \sigma$ index AO's, $C_{\mu p}$ is a MO coefficient, and $(\mu \nu \mid \lambda \sigma)$ is an ERI in the AO basis. The MO coefficient $C_{\mu p}$ must be distinguished from the coefficient in the ZAPT2 energy expression in Eqn. 1, where the coefficient $C_{p q}$ is

$$
\begin{aligned}
& C_{p q}=1 \text {, for both } p \in \text { SOCC and } q \in \mathrm{SOCC} \\
& C_{p q}=2 \text {, otherwise. }
\end{aligned}
$$

The four-index denominator is expressed as

$$
D_{p q}^{r s}=\varepsilon_{p}+\varepsilon_{q}-\varepsilon_{r}^{\prime}-\varepsilon_{s}^{\prime}
$$

and the two-index denominator is written as

$$
D_{p}^{q}=\varepsilon_{p}-\varepsilon_{q}^{\prime} .
$$

The orbital energies in Eqns. 4 and 5 are defined as

$$
\begin{aligned}
& \varepsilon_{p}=\varepsilon_{p}^{\prime}=\varepsilon_{p p}, \text { for } p \notin \mathrm{SOCC} \\
& \varepsilon_{p}=\varepsilon_{p p}-\frac{1}{2} \sum_{y}(p y \mid p y), \text { for } p \in \mathrm{SOCC} \\
& \varepsilon_{p}^{\prime}=\varepsilon_{p p}+\frac{1}{2} \sum_{y}(p y \mid p y), \text { for } p \in \mathrm{SOCC}
\end{aligned}
$$

with

$$
\varepsilon_{p p}=h_{p p}+\sum_{q}^{a l l} f_{q}[2(p p \mid q q)-(p q \mid p q)]
$$

where $h_{p q}$ is a core Hamiltonian element and $f_{p}$ is the occupation number of the $p$ th shell (1 for DOCC; $\frac{1}{2}$ for SOCC). The SOCC orbital energies in Eqn. 6 have an additional "integral component" that comes from the choice of canonicalization of the Fock matrix. The abbreviations IP and DP will be used to denote independent and dependent pairs of molecular orbitals, respectively. A rotation between two doubly occupied, between two singly 
occupied, or between two virtual orbitals does not change the SCF energy, so these pairs are called dependent pairs. The other orbital pairs are uniquely determined, so these are called independent pairs.

\section{B. General gradient expression}

The derivative of the ZAPT2 energy is the sum of the derivatives of the SCF and second-order correction contributions to the energy. The general form of this derivative with respect to a nuclear displacement $\gamma$ has the following form:

$$
E^{\gamma}=\sum_{\mu v,}^{A O} P_{\mu v} h_{\mu \nu}^{\gamma}+\sum_{\mu v}^{A O} W_{\mu \nu} S_{\mu \nu}^{\gamma}+\sum_{\mu \nu \lambda \sigma}^{A O} \Gamma_{\mu \nu \lambda \sigma}(\mu \nu \mid \lambda \sigma)^{\gamma}
$$

In Eqn. $7, h_{\mu v}^{\gamma}$ are the core Hamiltonian derivative integrals, $S_{\mu v}^{\gamma}$ are the overlap derivative integrals, and $(\mu v \mid \lambda \sigma)^{\gamma}$ are the derivatives of the ERI's in the AO basis. The one-particle density matrix $P_{\mu \nu}$, energy-weighted density matrix $W_{\mu v}$, and two-particle density matrix $\Gamma_{\mu \nu \lambda \sigma}$ are sums of their SCF analogues and a second-order correction:

$$
\begin{aligned}
& P_{\mu \nu}=P_{\mu v}^{S C F}+P_{\mu \nu}^{(2)} \\
& W_{\mu v}=W_{\mu v}^{S C F}+W_{\mu \nu}^{(2)} \\
& \Gamma_{\mu v \lambda \sigma}=\Gamma_{\mu \nu \lambda \sigma}^{S C F}+\Gamma_{\mu \nu \lambda \sigma}^{(2)} .
\end{aligned}
$$

The second-order two-particle density correction is expressed as the sum of separable (S) and non-separable (NS) terms:

$$
\Gamma_{\mu \nu \lambda \sigma}^{(2)}=\Gamma_{\mu \nu \lambda \sigma}^{S}+\Gamma_{\mu \nu \lambda \sigma}^{N S} .
$$

The equations for the SCF terms may be written as follows:

$$
P_{\mu \nu}^{S C F}=2 \sum_{p}^{C . d . S .} f_{p} C_{\mu p} C_{p p}
$$




$$
\begin{aligned}
& W_{\mu v}^{S C F}=2 \sum_{p q}^{a l l} C_{\mu p} C_{v q} \zeta_{p q} \\
& \Gamma_{\mu v \lambda \sigma}^{S C F}=\frac{1}{2} P_{\mu \nu}^{S C F} P_{\lambda \sigma}^{S C F}-\frac{1}{4} P_{\mu \lambda}^{S C F} P_{v \sigma}^{S C F}-\frac{1}{4} P_{\mu \lambda}^{S} P_{v \sigma}^{S}
\end{aligned}
$$

where

$$
P_{\mu \nu}^{S}=\sum_{x} C_{\mu r} C_{v x}
$$

and $\zeta_{p q}$ is defined in Eqn. 41 below.

\section{Gradient of the ZAPT2 energy}

The usual derivative techniques are employed; these are described in detail in Ref. 16. A few modifications to the previous procedure are presented in this section.

The derivative of the fourth term in the second-order energy expression (Eqn. 1) may be written

$$
\begin{aligned}
& \left(\frac{1}{2} \sum_{i x y a}(i x \mid x a)(i y \mid y a) / D_{i}^{a}\right)^{(\gamma)} \\
& \quad=\frac{1}{2} \sum_{\text {ixya }}\left\{2(i x \mid x a)^{(\gamma)}(i y \mid y a) / D_{i}^{a}-\left[D_{i}^{a}\right]^{\gamma}(i x \mid x a)(i y \mid y a) /\left(D_{i}^{a}\right)^{2}\right\}
\end{aligned} .
$$

where $(\gamma)$ indicates the derivative over MO's. The derivative of an ERI in the MO basis is well known ${ }^{38}$ to be

$$
\begin{aligned}
(p q \mid r s)^{(\gamma)}= & (p q \mid r s)^{\gamma}+\sum_{t} U_{t p}^{\gamma}(t q \mid r s)+\sum_{t} U_{t q}^{\gamma}(p t \mid r s) \\
& +\sum_{t} U_{t r}^{\gamma}(p q \mid t s)+\sum_{t} U_{t s}^{\gamma}(p q \mid r t)
\end{aligned}
$$

where the $\mathbf{U}^{\gamma}$ matrix describes the response of the MO coefficients to the perturbation $\gamma$. Upon substitution of Eqn. 18 into Eqn. 17, the first term in the resulting equation has the form 
$\sum_{i x y a}(i x \mid x a)^{\gamma}(i y \mid y a) / D_{i}^{a}$,

where

$(i x \mid x a)^{\gamma}=\sum_{\mu \vee \lambda \sigma} C_{\mu i} C_{v x} C_{\lambda r} C_{\sigma a}(\mu \nu \mid \lambda \sigma)^{\gamma}$.

Eqn. (19) can be rearranged as follows:

$$
\begin{aligned}
& \sum_{i x y a}(i x \mid x a)^{\gamma}(i y \mid y a) / D_{i}^{a}=\sum_{\mu \nu \lambda \sigma} \sum_{i y y a} C_{\mu i} C_{v x} C_{\lambda x} C_{\sigma a}(\mu \nu \mid \lambda \sigma)^{\gamma}(i y \mid y a) / D_{i}^{a} \\
& =\sum_{\mu \nu \lambda \sigma}(\mu \nu \mid \lambda \sigma)^{\gamma} \sum_{x} \frac{1}{2} C_{v x} C_{\lambda x} \sum_{i a} 2 C_{\mu i} C_{\sigma a} \sum_{y}(i y \mid y a) / D_{i}^{a} \\
& =\sum_{\mu \nu \lambda \sigma}(\mu \nu \mid \lambda \sigma)^{\gamma} P_{v \lambda}^{S} \sum_{i a} 2 C_{\mu i} C_{\sigma a} T_{i a}^{(4)} \\
& =\sum_{\mu v \lambda \sigma}(\mu \nu \mid \lambda \sigma)^{\gamma} P_{v \lambda}^{S} T_{\mu \sigma}^{(4)}
\end{aligned}
$$

where

$$
\begin{aligned}
& T_{i a}^{(4)}=\sum_{y}(i y \mid y a) / D_{i}^{a} \\
& T_{\mu \sigma}^{(4)}=2 \sum_{i a} C_{\mu i} C_{\sigma a} T_{i a}^{(4)} .
\end{aligned}
$$

This yields a separable density term $T_{\mu \sigma}^{(4)} P_{\nu \lambda}^{S}$.

During the derivation, terms such as

$2 \sum_{y>x} U_{y x}^{\gamma 1} P_{y x}^{(2)}\left(\varepsilon_{x}^{\prime}-\varepsilon_{y}^{\prime}\right)$

are formed, where ${ }^{1} P_{y x}^{(2)}$ indicates the first term of $P_{y x}^{(2)}$. Using Eqn. 6, Eqn. 24 can be rewritten as

$$
2 \sum_{y>x} U_{y x}^{\gamma 1} P_{y x}^{(2)}\left\{\varepsilon_{x x}-\varepsilon_{y y}+\frac{1}{2} \sum_{z}[(x z \mid x z)-(y z \mid y z)]\right\} .
$$

Eqn. 25 may be divided into an orbital energy part 
$2 \sum_{y>x} U_{y x}^{\gamma{ }^{1}} P_{y x}^{(2)}\left\{\varepsilon_{x x}-\varepsilon_{y y}\right\}$

and an integral component part

$2 \sum_{y>x} U_{y x}^{\gamma 1} P_{y x}^{(2)} F_{y x}$

where

$F_{y x}=\frac{1}{2} \sum_{z}[(x z \mid x z)-(y z \mid y z)]$

The orbital energy part in Eqn. 26 is treated with the usual procedure. ${ }^{16}$ Eqn. 27 is divided into two pieces, and the $x$ and $y$ indices are swapped in the first term as follows:

$\sum_{x>y} U_{x y}^{\gamma 1} P_{x y}^{(2)} F_{x y}+\sum_{y>x} U_{y x}^{\gamma 1} P_{y x}^{(2)} F_{y x}$

The derivative of the orthogonality condition,

$U_{p q}^{\gamma}+U_{q p}^{\gamma}+S_{p q}^{\gamma}=0$

may be used to rearrange the second half of Eqn. 29 to yield:

$\sum_{x>y} U_{x y}^{\gamma}{ }^{1} P_{x y}^{(2)} F_{x y}-\sum_{y>x} U_{x y}^{\gamma 1} P_{y x}^{(2)} F_{y x}-\sum_{y>x} S_{x y}^{\gamma{ }^{1}} P_{y, x}^{(2)} F_{y x}$.

Since ${ }^{1} P_{y x}^{(2)}={ }^{1} P_{x y}^{(2)}$ and $F_{x y}=-F_{y x}$, the first two terms can be combined and the third term can be modified slightly, giving:

$\sum_{x \neq y} U_{x y}^{\gamma}{ }^{i} P_{x y}^{(2)} F_{x y}+\sum_{y>x} S_{x y}^{\gamma 1} P_{x y}^{(2)} F_{x y}$.

The second term in Eqn. 32 produces a contribution to the one-particle energy-weighted density matrix. Given that

$U_{p q}^{\gamma}=\frac{Q_{p q}^{\gamma}}{\left(\varepsilon_{q q}-\varepsilon_{p p}\right)}$, 
the first term of Eqn. 32 becomes

$$
\sum_{x y} Q_{x y}^{\gamma}\left[\frac{1-\delta_{x y}{ }^{1}}{\left(\varepsilon_{y y}-\varepsilon_{x x}\right)} P_{x y}^{(2)} F_{x y}\right\rfloor
$$

which yields a contribution to the one-particle density matrix. Due to Eqn. 34, a potential singularity exists when singly occupied orbitals are degenerate and $\varepsilon_{y y}=\varepsilon_{x \tau}$. Assuming $F_{x y}$ goes to zero faster than the orbital energy difference, this term can be neglected for degenerate SOCC orbitals.

Also during the derivation, terms such as

$$
2 \sum_{i j} \sum_{p q}^{s . x_{i}} \sum_{m} U_{m i}^{\gamma}(m p \mid j q)\left[C_{p q}(i p \mid j q)-(i q \mid j p)\right] / D_{i j}^{p q}
$$

are produced. This term may be divided into two parts, and Eqn. 30 may be used to rearrange Eqn. 35 as:

$$
\begin{aligned}
& \sum_{i j} \sum_{p q}^{s . v} \sum_{m} U_{m i}^{\gamma}(m p \mid j q)\left[C_{p q}(i p \mid j q)-(i q \mid j p)\right] / D_{i j}^{p q} \\
& -\sum_{i j} \sum_{p q}^{s . y_{i}} \sum_{m} U_{i n}^{\gamma}(m p \mid j q)\left[C_{p q}(i p \mid j q)-(i q \mid j p)\right] / D_{i j}^{p q} \\
& -\sum_{i j} \sum_{p q}^{s . p_{j}} \sum_{m} S_{m i}^{\gamma}(m p \mid j q)\left[C_{p q}(i p \mid j q)-(i q \mid j p)\right] / D_{i j}^{p q}
\end{aligned}
$$

The third term in Eqn. 36 includes an overlap derivative integral, so the expression multiplying the integral is a contribution to the energy-weighted density matrix:

$$
\left.W_{i m}^{(2)}=-\sum_{j} \sum_{p q}^{s . v_{i}}(m p] j q\right)\left[C_{p q}(i p \mid j q)-(i q \mid j p)\right] / D_{i j}^{p q} .
$$

A similar procedure is used to determine the other three amplitude terms of $W_{i m}^{(2)}$. 
For implementation purposes, the energy-weighted density matrix is symmetrized.

Thus,

$W_{i m}^{(2)}=-P_{i m}^{(2)} \varepsilon_{m m}$

and

$W_{m i}^{(2)}=-P_{m i}^{(2)} \varepsilon_{i i}$

become

$W_{l m}^{(2)}=W_{m i}^{(2)}=\frac{1}{2}\left(W_{i m}^{(2)}+W_{m i}^{(2)}\right)=-\frac{1}{2} P_{m i}^{(2)}\left(\varepsilon_{m m}+\varepsilon_{i i}\right)$,

since the one-particle density is also symmetrized.

In the general restricted open-shell CPHF equations, the Lagrangian matrices $\zeta_{p q}$, the generalized Lagrangian matrices $\xi_{p q}^{r}$, and the $\tau$ matrices can be defined by

$$
\begin{aligned}
& \zeta_{p q}=f_{p} h_{p q}+\sum_{s}^{c . d . s .}\left[\alpha_{r s}(p q \mid s s)+\beta_{r s}(p s \mid q s)\right], \\
& \xi_{p q}^{r}=f_{r} h_{p q}+\sum_{s}^{c . d . s .}\left[\alpha_{r s}(p q \mid s s)+\beta_{r s}(p s \mid q s)\right],
\end{aligned}
$$

and

$\tau_{r s}^{p q}=2\left(\alpha_{r p}-\alpha_{s p}\right)(p q \mid r s)+\left(\beta_{r p}-\beta_{s p}\right)[(p r \mid q s)+(p s \mid q r)]$,

where $\alpha_{p q}$ and $\beta_{p q}$ are the Coulomb and exchange coupling constants, respectively. These

\begin{tabular}{|c|c|c|c|c|c|c|}
\hline & $D$ & $S$ & $V$ & $\beta_{p q}$ & $D$ & $S$ \\
\hline$D$ & 2 & 1 & 0 & $D$ & -1 & $-\frac{1}{2}$ \\
\hline$S$ & 1 & $\frac{1}{2}$ & 0 & $S$ & $-\frac{1}{2}$ & $-\frac{1}{2}$ \\
\hline$V$ & 0 & 0 & 0 & $V$ & 0 & 0 \\
\hline
\end{tabular}
constants have the values 
where $p$ and $q$ index DOCC (D), SOCC (S), or VIRT (V) MO's. From the variational conditions, $\zeta_{p q}=\zeta_{q p}$. In addition, $\xi_{p q}^{r}=\xi_{q p}^{r}$. If $r$ and $p$ belong to the same shell, $\xi_{p q}^{r}=\zeta_{p q}$. For virtual orbital $a, \zeta_{p a}=\zeta_{a p}=0, \xi_{p q}^{a}=\xi_{q p}^{a}=0$, and $\tau_{r s}^{a q}=0$. As a result, the $\zeta_{p q}$ and $\xi_{p q}^{r}$ terms do not contribute to the diagonal blocks of the $\mathbf{W}^{(2)}$ matrix. The expressions for the off-diagonal blocks are also simpler (see section IID).

Formally, $\tau_{r s}^{p q} \neq \tau_{r s}^{q p}$, but $\tau_{\mathrm{rs}}^{p q}=\tau_{r s}^{q p}$ if $p$ and $q$ belong to the same shell. Diagonal blocks of $\mathbf{W}^{(2)}$ contain terms with the form

$$
W_{r s}^{(2)}=-\frac{\delta_{r s}}{2} \sum_{p>q}^{i, p .} Z_{p q} \tau_{p q}^{r r}-\delta_{r s}^{\prime} \sum_{p>q}^{i . p .} Z_{p q} \tau_{p q}^{r s}
$$

where $Z_{p q}$ is the solution to the Z-vector equations (see section IIID) and a modified Kronecker delta is defined as

$$
\begin{gathered}
\delta_{p q}^{\prime}=1, p>q \\
\delta_{p q}^{\prime}=0, p \leq q
\end{gathered}
$$

By symmetrizing the terms, Eqn. 45 can subsequently be simplified to:

$$
\begin{aligned}
& \frac{W_{r s}^{(2)}+W_{s r}^{(2)}}{2}=-\frac{\delta_{r s}}{4} \sum_{p>q}^{i . p .} Z_{p q} \tau_{p q}^{r r}-\frac{\delta_{s r}}{4} \sum_{p>q}^{i . p .} Z_{p q} \tau_{p q}^{s s}-\frac{\delta_{r s}^{\prime}}{2} \sum_{p>q}^{i . p .} Z_{p q} \tau_{p q}^{r s}-\frac{\delta_{s r}^{\prime}}{2} \sum_{p>q}^{i . p .} Z_{p q} \tau_{p q}^{s r} \\
& =-\frac{\delta_{r s}}{2} \sum_{p>q}^{i . p .} Z_{p q} \tau_{p q}^{r r}-\frac{\delta_{r s}^{\prime}}{2} \sum_{p>q}^{i . p .} Z_{p q} \tau_{p q}^{r s}-\frac{\delta_{s r}^{\prime}}{2} \sum_{p>q}^{i . p .} Z_{p q} \tau_{p q}^{r s} \\
& =-\frac{\delta_{r s}}{2} \sum_{p>q}^{i . p .} Z_{p q} \tau_{p q}^{r r}-\frac{\left(1-\delta_{r s}\right)}{2} \sum_{p>q}^{i . p .} Z_{p q} \tau_{p q}^{r s} \\
& =-\frac{1}{2} \sum_{p>q}^{i . p .} Z_{p q} \tau_{p q}^{r s}
\end{aligned}
$$

\section{Density matrix expressions}


In this section, the density-like quantities, $\chi, P^{(2)}, W^{(2)}, \Gamma^{\mathrm{s}}$, and $\Gamma^{\mathrm{Ns}}$, and the Lagrangian, $L$, are summarized in terms of the matrix elements of their various shell-shell blocks. $G_{p q r s}$ is defined to be $G_{p q r s}=4(p q \mid r s)-(p r \mid q s)-(p s \mid q r)$.

- $\chi$ :

$$
\begin{aligned}
\chi_{x}= & \sum_{i j} \sum_{p}^{s . v i}(i x \mid j p)\left[C_{x p}(i x \mid j p)-(i p \mid j x)\right] / D_{i j}^{x p} D_{i j}^{x p} \\
& +\sum_{a b} \sum_{p}^{d \cdot s}(x a \mid p b)\left[C_{x p}(x a \mid p b)-(x b \mid p a)\right] / D_{x p}^{a b} D_{x p}^{a b} . \\
& +\sum_{i z a}^{a b}\left[(i x \mid z a)^{2} /\left(D_{i z}^{x a}\right)^{2}+(i z \mid x a)^{2} /\left(D_{i x}^{z a}\right)^{2}\right]
\end{aligned}
$$

- CORE-CORE response density: $P_{m n}^{(2)}=0$.

- DOCC-CORE response density:

$$
\begin{aligned}
P_{i m}^{(2)}=\frac{1}{\left(\varepsilon_{i}-\varepsilon_{m}\right)}[ & 2 \sum_{j} \sum_{p, q}^{s, k}(m p \mid j q)\left[C_{p q}(i p \mid j q)-(i q \mid j p)\right] / D_{i j}^{p q} \\
& +2 \sum_{a, b} \sum_{p}^{d . s_{s}}(m a \mid p b)[2(i a \mid p b)-(i b \mid p a)] / D_{i p}^{a b} \\
& \left.+2 \sum_{x, y} \sum_{a}(m x \mid y a)(i x \mid y a) / D_{i y}^{x a}+\sum_{x, y, a}(m x \mid x a)(i y \mid y a) / D_{i}^{a}\right]
\end{aligned}
$$

- DOCC-DOCC response density:

$$
\begin{aligned}
P_{i j}^{(2)}= & -\sum_{k} \sum_{p, q}^{s . p \cdot}(i p \mid k q)\left[C_{p q}(j p \mid k q)-(j q \mid k p)\right] / D_{i k}^{p q} D_{j k}^{p q} \\
& -\sum_{a, b} \sum_{p}^{d . s . j}(i a \mid p b)[2(j a \mid p b)-(j b \mid p a)] / D_{i p}^{a b} D_{j p}^{a b} \\
& -\sum_{x, y} \sum_{a}(i x \mid y a)(j x \mid y a) / D_{i y}^{x a} D_{j y}^{x a}-\frac{1}{2} \sum_{x, y, a}(i x \mid x a)(j y \mid y a) / D_{i}^{a} D_{j}^{a}
\end{aligned}
$$

- SOCC-SOCC response density: 


$$
\begin{aligned}
P_{x y}^{(2)}= & \sum_{i, j} \sum_{p}^{s . x}(i x \mid j p)\left[C_{y p}(i y \mid j p)-(i p \mid j y)\right] / D_{j j}^{x p} D_{i j}^{y p} \\
& -\sum_{a, b} \sum_{p}^{d . s .}(x a \mid p b)\left[C_{y p}(y a \mid p b)-(y b \mid p a)\right] / D_{x p}^{a b} D_{y p}^{a b} \\
& +\sum_{i, z} \sum_{a}\left[(i x \mid z a)(i y \mid z a) / D_{i z}^{x a} D_{i z}^{y a}-(i z \mid x a)(i z \mid y a) / D_{i x}^{z a} D_{i y}^{z a}\right] \\
& +\frac{\left(1-\delta_{x y}\right)}{2\left(\varepsilon_{y}-\varepsilon_{x}\right)} \sum_{w}[(y w \mid y w)-(x w \mid x w)] \times \\
& {\left[\sum_{i, j} \sum_{p}^{s . y_{i}}(i x \mid j p)\left[C_{y p}(i y \mid j p)-(i p \mid j y)\right] / D_{i j}^{x p} D_{i j}^{y p}\right.} \\
& +\sum_{a, b} \sum_{p}^{d . s}(x a \mid p b)\left[C_{y p}(y a \mid p b)-(y b \mid p a)\right] / D_{x p}^{a b} D_{y p}^{a b} \\
& \left.+\sum_{i, z} \sum_{a}\left[(i x \mid z a)(i y \mid z a) / D_{i z}^{x a} D_{i z}^{y a}+(i z \mid x a)(i z \mid y a) / D_{i x}^{z a} D_{i y}^{z a}\right]\right] \\
& +\frac{\left(1-\delta_{x y}\right)}{\left(\varepsilon_{y}-\varepsilon_{x}\right)} \sum_{z}(x z \mid y z)\left[\chi_{y}-\chi_{x}\right]
\end{aligned}
$$

- VIRT-VIRT response density:

$$
\begin{aligned}
P_{a b}^{(2)}= & \sum_{i, j} \sum_{p}^{s . v}(i a \mid j p)[2(i b \mid j p)-(i p \mid j b)] / D_{i j}^{a p} D_{i j}^{b p} \\
& +\sum_{c} \sum_{p, q}^{d . s .}(p a \mid q c)\left[C_{p q}(p b \mid q c)-(p c \mid q b)\right] / D_{p q}^{a c} D_{p q}^{b c} \\
& +\sum_{x, y} \sum_{i}^{p,}(i x \mid y a)(i x \mid y b) / D_{i y}^{x a} D_{i y}^{x b}+\frac{1}{2} \sum_{i, x, y}(i x \mid x a)(i y \mid y b) / D_{i}^{a} D_{i}^{b}
\end{aligned}
$$

- The off-diagonal IP response density for $p>q$ is given by:

$$
P_{p q}^{(2)}=\left(f_{p}-f_{q}\right) Z_{p q}
$$

- CORE-CORE energy-weighted response density:

$$
W_{m n}^{(2)}=-\frac{1}{2} \sum_{p, q}^{d . p .} P_{p q}^{(2)} G_{p q m n}-\frac{1}{2} \sum_{p>q}^{i . p .} Z_{p q} \tau_{p q}^{m n}
$$

- DOCC-CORE energy-weighted response density: 


$$
\begin{aligned}
W_{i m}^{(2)}= & -\sum_{j} \sum_{p, q}^{s . v .}(m p \mid j q)\left[C_{p q}(i p \mid j q)-(i q \mid j p)\right] / D_{i j}^{p q} \\
& -\sum_{a, b} \sum_{p}^{d . s .}(m a \mid p b)[2(i a \mid p b)-(i b \mid p a)] / D_{i p}^{a b} \\
& -\sum_{x, y} \sum_{a}(m x \mid y a)(i x \mid y a) / D_{i y}^{x a}-\frac{1}{2} \sum_{x, y, a}(m x \mid x a)(i y \mid y a) / D_{i}^{a} \\
& -\sum_{p, q}^{d . p .} P_{p q}^{(2)} G_{p q i m}-P_{i m}^{(2)} \frac{\varepsilon_{m}+\varepsilon_{i}}{2}-\sum_{p>q}^{i . p .} Z_{p q} \tau_{p q}^{i m}
\end{aligned}
$$

- DOCC-DOCC energy-weighted response density:

$$
\begin{aligned}
W_{i j}^{(2)}= & -\sum_{k} \sum_{p, q}^{s .4}(i p \mid k q)\left[C_{p q}(j p \mid k q)-(j q \mid k p)\right] / D_{j k}^{p q} \\
& -\sum_{a, b} \sum_{p}^{d . s .}(i a \mid p b)[2(j a \mid p b)-(j b \mid p a)] / D_{j p}^{a b} \\
& -\sum_{x, y} \sum_{a}(i x \mid y a)(j x \mid y a) / D_{j y}^{x a}-\frac{1}{2} \sum_{x, y, a}(i x \mid x a)(j y \mid y a) / D_{j}^{a} \\
& -\frac{1}{2} \sum_{p, q}^{d . p_{i}} P_{p q}^{(2)} G_{p q i j}-P_{i j}^{(2)} \varepsilon_{j}-\frac{1}{2} \sum_{p>q}^{i . p .} Z_{p q} \tau_{p q}^{i j}
\end{aligned}
$$

- SOCC-SOCC energy-weighted response density: 


$$
\begin{aligned}
& W_{x y}^{(2)}=-\sum_{i, j} \sum_{p}^{s . b}(i x \mid j p)\left[C_{y p}(i y \mid j p)-(i p \mid j y)\right] / D_{i j}^{y p} \\
& -\sum_{a, b} \sum_{p}^{d . s .}(x a \mid p b)\left[C_{y p}(y a \mid p b)-(y b \mid p a)\right] / D_{y p}^{a b} \\
& -\sum_{z, a} \sum_{i}\left[(i x \mid z a)(i y \mid z a) / D_{i z}^{y a}+(i z \mid x a)(i z \mid y a) / D_{i y}^{z a}\right] \\
& -\sum_{i, z, a}(i x \mid y a)(i z \mid z a) / D_{i}^{a}-\frac{1}{4} \sum_{p, q}^{d, p .} P_{p q}^{(2)} G_{p q, x y}-P_{x y}^{(2)} \varepsilon_{y} \\
& -\frac{1}{2} \sum_{p>q}^{i . p_{j}} Z_{p q} \tau_{p q}^{x y}-\frac{\delta_{x y}}{2} \sum_{z}(x z \mid x z)\left[\chi_{x}+\chi_{z}\right] \\
& +\frac{\delta_{y x}^{\prime}}{2} \sum_{w}[(y w \mid y w)-(x w \mid x w)] \times \\
& {\left[\sum_{i, j} \sum_{p}^{s . y}(i x \mid j p)\left[C_{y p}(i y \mid j p)-(i p \mid j y)\right] / D_{i j}^{x p} D_{i j}^{y p}\right.} \\
& +\sum_{a, b} \sum_{p}^{d .5}(x a \mid p b)\left[C_{y p}(y a \mid p b)-(y b \mid p a)\right] / D_{\cdot p}^{a b} D_{y p}^{a b} \\
& \left.+\sum_{z, a} \sum_{i}\left[(i x \mid z a)(i y \mid z a) / D_{i z}^{x a} D_{i z}^{y a}+(i z \mid x a)(i z \mid y a) / D_{i x}^{z a} D_{i y}^{z a}\right]\right]
\end{aligned}
$$

- VIRT-VIRT energy-weighted response density:

$$
\begin{aligned}
W_{a b}^{(2)}= & -\sum_{i, j} \sum_{p}^{s . p}(i a \mid j p)[2(i b \mid j p)-(i p \mid j b)] / D_{i j}^{p b} \\
& -\sum_{c} \sum_{p, q}^{d . s .}(p a \mid q c)\left[C_{p q}(p b \mid q c)-(p c \mid q b)\right] / D_{p q}^{b c} \\
& -\sum_{x, y} \sum_{i}(i x \mid y a)(i x \mid y b) / D_{i y}^{x b}-\frac{1}{2} \sum_{i, r, y}(i x \mid x a)(i y \mid y b) / D_{i}^{b}-P_{a b}^{(2)} \varepsilon_{b}
\end{aligned} .
$$

- SOCC-CORE and SOCC-DOCC energy-weighted response density: 


$$
\begin{aligned}
W_{x r}^{(2)}= & -2 \sum_{i, j} \sum_{p}^{s . l i}(i r \mid j p)\left[C_{x p}(i x \mid j p)-(i p \mid j x)\right] / D_{i j}^{x p} \\
& -2 \sum_{a, b} \sum_{p}^{d . s}(r a \mid p b)\left[C_{x p}(x a \mid p b)-(x b \mid p a)\right] / D_{x p}^{a b} \\
& -2 \sum_{y, a} \sum_{i}\left[(i r \mid y a)(i x \mid y a) / D_{i y}^{x a}+(i y \mid r a)(i y \mid x a) / D_{i x}^{y a}\right] \\
& -\sum_{i, y, a}[(i x \mid r a)+(i r \mid x a)](i y \mid y a) / D_{i}^{a} \\
& -\frac{1}{2} \sum_{p, q}^{d . p .} P_{p q}^{(2)} G_{p q, x}-2 \sum_{y} P_{x y}^{(2)} \varepsilon_{y r}-\sum_{p>q}^{i . p .} Z_{p q} \tau_{p q}^{x r} \\
& -\sum_{i}^{c . d .} Z_{x i}\left(\xi_{r i}^{x}-\zeta_{i r}\right)+\sum_{a} Z_{a r} \xi_{r a}^{x}-\sum_{z}(r z \mid x z)\left[\chi_{x}+\chi_{z}\right]
\end{aligned}
$$

where $r$ indexes a CORE or a DOCC MO.

- VIRT-CORE, VIRT-DOCC, and VIRT-SOCC energy-weighted response density:

$$
\begin{aligned}
W_{a r}^{(2)}= & -2 \sum_{i, j} \sum_{p}^{s, r .}(i r \mid j p)[2(i a \mid j p)-(i p \mid j a)] / D_{i j}^{a p} \\
& -2 \sum_{b} \sum_{p, s .}^{d . s .}(p r \mid q b)\left[C_{p q}(p a \mid q b)-(p b \mid q a)\right] / D_{p q}^{a b} \\
& -2 \sum_{x, y}^{b} \sum_{i}^{p}(i x \mid y r)(i x \mid y a) / D_{i y}^{x a} \\
& -\sum_{i, r, y}(i x \mid x r)(i y \mid y a) / D_{i}^{a}-2 \sum_{b} P_{a b}^{(2)} \varepsilon_{b r} \\
& +\sum_{i}^{c . d} Z_{a i} \zeta_{i r}+\sum_{x} Z_{a x} \zeta_{x r}
\end{aligned}
$$

where $r$ indexes a CORE, DOCC, or SOCC MO.

- SOCC-CORE Lagrangian elements: 


$$
\begin{aligned}
& L_{x m}=-2 \sum_{i, j} \sum_{p}^{s . y_{i}}(i m \mid j p)\left[C_{x p}(i x \mid j p)-(i p \mid j x)\right] / D_{i j}^{x p} \\
& -2 \sum \sum^{d . s .}(m a \mid p b)\left[C_{x p}(x a \mid p b)-(x b \mid p a)\right] / D_{x p}^{a b} \\
& -2 \sum_{y, a}^{a, b} \sum_{i}^{p}\left[(i m \mid y a)(i x \mid y a) / D_{i y}^{r a}+(i y \mid m a)(i y \mid x a) / D_{i r}^{y a}\right] \text {. } \\
& -\sum_{i, y, a}^{y, a}[(i x \mid m a)+(i m \mid x a)](i y \mid y a) / D_{i}^{a}-\sum_{y}(m y \mid x y)\left[\chi_{x}+\chi_{y}\right] \\
& +\frac{1}{2} \sum_{p q}^{d . p .} P_{p q}^{(2)} G_{p q x m}+2 \sum_{i}^{c . d} P_{i m}^{(2)} \varepsilon_{x i}-2 \sum_{y} P_{x y}^{(2)} \varepsilon_{y m}
\end{aligned}
$$

- VIRT-CORE Lagrangian elements:

$$
\begin{aligned}
L_{a m}= & -2 \sum_{i, j} \sum_{p_{p}}^{s . p .}(i m \mid j p)[2(i a \mid j p)-(i p \mid j a)] / D_{i j}^{a p} \\
& -2 \sum_{b} \sum_{p, q}^{d . s .}(p m \mid q b)\left[C_{p q}(p a \mid q b)-(p b \mid q a)\right] / D_{p q}^{a b} \\
& -2 \sum_{x, y}^{b} \sum_{i}^{a}(i x \mid y m)(i x \mid y a) / D_{i y}^{x a}-\sum_{i, x, y}(i x \mid x m)(i y \mid y a) / D_{i}^{a} \\
& +\sum_{p q}^{d . p} P_{p q}^{(2)} G_{p q a m}+2 \sum_{i}^{c d .} P_{i m}^{(2)} \varepsilon_{a t}-2 \sum_{b} P_{a b}^{(2)} \varepsilon_{b m}
\end{aligned}
$$

- SOCC-DOCC Lagrangian elements:

$$
\begin{aligned}
& L_{x i}=2 \sum_{j} \sum_{p, q}^{s . v}(x p \mid j q)\left[C_{p q}(i p \mid j q)-(i q \mid j p)\right] / D_{i j}^{p q} \\
& -2 \sum_{j, k} \sum_{p}^{s . p_{1}}(i k \mid j p)\left[C_{\cdot p}(k x \mid j p)-(k p \mid j x)\right] / D_{j k}^{m p} \\
& +2 \sum_{a, b} \sum_{p}^{d . s .}(x a \mid p b)[2(i a \mid p b)-(i b \mid p a)] / D_{i p}^{a b} \\
& -2 \sum_{a, b} \sum_{p}^{d . s .}(i a \mid p b)\left[C_{x p}(x a \mid p b)-(x b \mid p a)\right] / D_{x p}^{a b} \\
& +2 \sum^{a, b} \sum^{p}(x y \mid z a)(i y \mid z a) / D_{i z}^{y a} \\
& -2 \sum_{y, a}^{y, z} \sum_{j}^{a}\left[(i j \mid y a)(j x \mid y a) / D_{j y}^{x a}+(j y \mid i a)(j y \mid x a) / D_{j x}^{y a}\right] \\
& +\sum_{y, z, a}^{y, a}(x y \mid y a)(i z \mid z a) / D_{i}^{a}-\sum_{j, y, a}[(j x \mid i a)+(i j \mid x a)](j y \mid y a) / D_{j}^{a} \\
& -\sum_{z}(i z \mid x z)\left[\chi_{x}+\chi_{z}\right]+\frac{1}{2} \sum_{p q}^{d . p .} P_{p q}^{(2)} G_{p q x i}+2 \sum_{j}^{c . d .} P_{i j}^{(2)} \varepsilon_{x j}-2 \sum_{y} P_{x y}^{(2)} \varepsilon_{y i}
\end{aligned}
$$


- VIRT-DOCC Lagrangian elements:

$$
\begin{aligned}
& L_{a i}=2 \sum_{j} \sum_{p, q}^{s . v .}(p a \mid j q)\left[C_{p q}(i p \mid j q)-(i q \mid j p)\right] / D_{i j}^{p q} \\
& -2 \sum_{j, k} \sum_{p}^{s . j k}(i k \mid j p)[2(k a \mid j p)-(k p \mid j a)] / D_{j k}^{a p} \\
& +2 \sum_{b, c} \sum_{p}^{d . s .}(a b \mid p c)[2(i b \mid p c)-(i c \mid p b)] / D_{i p}^{b n} \\
& -2 \sum_{b} \sum_{p, q}^{d \cdot s}(i p \mid q b)\left[C_{p q}(p a \mid q b)-(p b \mid q a)\right] / D_{p q}^{a b} \\
& +2 \sum_{x, y}^{b} \sum_{b}^{p, q}(x a \mid y b)(i x \mid y b) / D_{i y}^{x b}-2 \sum_{x, y} \sum_{j}(i y \mid j x)(j x \mid y a) / D_{j y}^{x a} \\
& +\sum_{x, y, b}(x a \mid x b)(i y \mid y b) / D_{i}^{b}-\sum_{j, x, y}(i x \mid j x)(j y \mid y a) / D_{j}^{a} \\
& +\sum_{p q}^{d . p .} P_{p q}^{(2)} G_{p q a i}+2 \sum_{j}^{c . d .} P_{i j}^{(2)} \varepsilon_{a j}-2 \sum_{b} P_{a b}^{(2)} \varepsilon_{b i}
\end{aligned}
$$

- VIRT-SOCC Lagrangian elements:

$$
\begin{aligned}
& L_{a x}=2 \sum_{i, j} \sum_{p}^{s, v}(i a \mid j p)\left[C_{x p}(i x \mid j p)-(i p \mid j x)\right] / D_{i j}^{x p} \\
& -2 \sum_{i, j} \sum_{p}^{s . j}(i x \mid j p)[2(i a \mid j p)-(i p \mid j a)] / D_{i j}^{a p} \\
& +2 \sum_{b, c} \sum_{p}^{d . s .}(a b \mid p c)\left[C_{x p}(x b \mid p c)-(x c \mid p b)\right] / D_{x p}^{b c} \\
& -2 \sum \sum^{d \cdot s}(x p \mid q b)\left[C_{p q}(p a \mid q b)-(p b \mid q a)\right] / D_{p q}^{a b} \\
& +2 \sum^{b} \sum^{p, q}\left[(i a \mid y b)(i x \mid y b) / D_{i y}^{x b}+(i y \mid a b)(i y \mid x b) / D_{i \mathrm{r}}^{y b}\right] \\
& -2 \sum^{i, y} \sum_{i}^{b}(i z \mid x y)(i z \mid y a) / D_{i y}^{i a} \\
& +\sum_{i, y, b}^{y, z}[(i x \mid a b)+(i a \mid x b)](i y \mid y b) / D_{i}^{b}-\sum_{i, y, z}(i y \mid x y)(i z \mid z a) / D_{i}^{a} \\
& +\frac{1}{2} \sum_{p q}^{d . p .} P_{p q}^{(2)} G_{p q a x}+2 \sum_{y} P_{x y}^{(2)} \varepsilon_{a y}-2 \sum_{b} P_{a b}^{(2)} \varepsilon_{b x}+\sum_{y}(x y \mid y a)\left[\chi_{x}+\chi_{y}\right]
\end{aligned}
$$

- Separable two-particle density:

$$
\Gamma_{\mu \nu \lambda \sigma}^{S}=P_{\mu \nu}^{(2)} P_{\lambda \sigma}^{S C F}-\frac{1}{2} P_{\mu \lambda}^{(2)} P_{v \sigma}^{S C F}+\frac{1}{2} T_{\mu \sigma}^{(4)} P_{v \lambda}^{S}+\frac{1}{4} \chi_{v \sigma} P_{\mu \lambda}^{S}+\frac{1}{4} \chi_{\mu \lambda} P_{v \sigma}^{S}+\frac{1}{4}\left(Z_{\mu \lambda}^{v S}-Z_{\mu \lambda}^{S D}\right) P_{v \sigma}^{S}
$$


where,

$$
\begin{aligned}
T_{\mu v}^{(4)} & =2 \sum_{i a} C_{\mu i} C_{v a} T_{i a}^{(4)}, T_{i a}^{(4)}=\sum_{y}(i y \mid y a) / D_{i}^{a} \\
\chi_{\mu v} & =\sum_{x} C_{\mu v} C_{v x} \chi_{x} \\
Z_{\mu v}^{V S} & =\sum_{a x}^{x} C_{\mu a} C_{v x} Z_{a x}, \quad Z_{\mu v}^{S D}=\sum_{x i} C_{\mu x} C_{v i} Z_{x i}
\end{aligned}
$$

- Non-separable two-particle density:

$$
\Gamma_{\mu \nu \lambda \sigma}^{N S}=\sum_{p, q}^{d . s} \sum_{r, s}^{s . v \cdot} C_{\mu p} C_{v r} C_{\lambda q} C_{\sigma s} \mathrm{~T}_{p q}^{r s},
$$

where,

$$
\begin{aligned}
& \mathrm{T}_{i j}^{a b}=2[2(i a \mid j b)-(i b \mid j a)] / D_{i j}^{a b}, \\
& \mathrm{~T}_{i j}^{a x}=[2(i a \mid j x)-(i x \mid j a)] / D_{i j}^{a x}, \mathrm{~T}_{i j}^{x a}=[2(i x \mid j a)-(i a \mid j x)] / D_{i j}^{x a}, \\
& \mathrm{~T}_{i j}^{x y}=[(i x \mid j y)-(i y \mid j x)] / D_{i j}^{x y}, \\
& \mathrm{~T}_{i y}^{x a}=2(i x \mid y a) / D_{i y}^{x a}, \\
& \mathrm{~T}_{i x}^{a b}=[2(i a \mid x b)-(i b \mid x a)] / D_{i x}^{a b}, \mathrm{~T}_{x i}^{a b}=[2(x a \mid i b)-(x b \mid i a)] / D_{x i}^{a b}, \\
& \mathrm{~T}_{x y}^{a b}=[(x a \mid y b)-(x b \mid y a)] / D_{x y}^{a b}, \\
& \mathrm{~T}_{i x}^{y z}=\mathrm{T}_{x i}^{y z}=\mathrm{T}_{x y}^{z a}=\mathrm{T}_{x y}^{a z}=\mathrm{T}_{w x}^{y z}=0
\end{aligned}
$$

\section{Parallel ZAPT2 Gradient Algorithm}

The implementation of the following parallel ZAPT2 gradient algorithm is organized below into the following subsections:

1. Creation of distributed integral arrays

2. Construction of immediately obtainable terms of $\mathbf{P}^{(2)}, \mathbf{W}^{(2)}$, and $\mathbf{L}$

3. Three-virtual integrals and the completion of $\mathbf{L}$ 
4. Solution of the Z-vector equations

5. Completion of the one-particle density matrices and computation of the one-particle gradient

6. Back-transformation of amplitudes to generate the nonseparable density matrix and calculation of the two-particle gradient

\section{A. Distributed Integral Arrays}

The equations for the density matrices in section IID require five classes of integrals.

Using " $\mathrm{v}$ " to denote a virtual MO (VIRT) and " $\mathrm{o}$ " to denote an occupied MO (CORE, DOCC, or SOCC), these classes are:

1. (ooloo)

2. (voloo)

3. (vvloo)

4. (volvo)

5. (vvlvo)

The first four integral classes are created and stored in distributed memory as described previously. ${ }^{25}$ The fifth class is the largest and is only used in the construction of the Lagrangian, so the terms involving these integrals are calculated in a direct fashion as described in section IIIC.

In addition to the integral arrays, the trial vectors of the $\mathrm{Z}$-vector equation are distributed across the nodes. The density matrices $\left(\mathbf{P}^{(2)}\right.$ and $\left.\mathbf{W}^{(2)}\right)$ and other data of order $n^{2}$ or less are stored in a replicated fashion. 


\section{B. Density Matrix Creation}

The "integral component" $\frac{1}{2} \sum_{y}(p y \mid p y)$ in Eqn. 6 distinguishes ZAPT2 from other related methods. Since these values will be used often in the creation of the density matrices, an array of integral components is stored in replicated memory. These terms require $(x y \mid x y)$ integrals, which are also used in the multiplicative factor in term 4 of $P_{x y}$ and term 9 of $W_{x y y}$ This factor is stored in an intermediate matrix:

$$
F_{x y}=\frac{1}{2} \sum_{w}[(y w \mid y w)-(x w \mid x w)]
$$

Each processor reads local integrals and computes a contribution to both arrays. These contributions are then globally summed.

The algorithm for density matrix term creation is structured so as to reduce communication needs as much as possible. In general, a set of integrals is read from local or remote processors, amplitudes are formed by subtracting appropriate integrals and dividing by an orbital energy denominator, and suitable integrals and amplitudes are contracted (multiplied) in order to create each term of the density matrix blocks. More details about the structure of this algorithm are discussed in the Appendix. During the density matrix creation, the ZAPT2 energy can be calculated according to

$$
E_{Z A P T}^{(2)}=-\frac{1}{4} \sum_{p}^{d . S . P .} W_{p p}^{(2)}
$$

where $W_{p p}^{(2)}$ includes terms $1-4$ of $W_{i i}^{(2)}, W_{x x}^{(2)}$, and $W_{a a}^{(2)}$ (Eqns. 57, 58, and 59). 


\section{Three-Virtual Terms}

The (vvlvo) orbitals are required for terms $1-\mathrm{VV}$ (1-VV refers to $p \in$ VIRT and $q \in$ VIRT in term 1), 3, and 9 of $L_{a i}$ (Eqn. 65) and terms 3 and 9 of $L_{a x}$ (Eqn. 66). As discussed previously, ${ }^{25,29,39,40}$ these terms can be written in a mixed $\mathrm{MO} / \mathrm{AO}$ basis and consequently use quarter-transformed ERI's with one occupied MO index and three AO indices that are computed in a direct fashion. Terms $1-V V$ and 3 of $L_{a i}$ and term 3 of $L_{a x}$ may be rearranged as:

$$
\begin{aligned}
L_{a r} & =2 \sum_{b, c} \sum_{p}^{d . s .}(a b \mid p c)\left[C_{r p}(r b \mid p c)-(r c \mid p b)\right] / D_{r p}^{b c} \\
& =2 \sum_{b, c} \sum_{p}^{d . s} \sum_{v \lambda \sigma} C_{v c} C_{\lambda a} C_{o b}(p v \mid \lambda \sigma)\left[C_{r p}(r b \mid p c)-(r c \mid p b)\right] / D_{r p}^{b c} \\
& =2 \sum_{p}^{d . s .} \sum_{v \lambda \sigma} C_{\lambda a}(p v \mid \lambda \sigma)\left[C_{r p} I_{r p}^{\sigma v}-I_{r p}^{v \sigma}\right] / D_{r p}^{\sigma v}
\end{aligned}
$$

where the half-transformed integral is

$$
l_{r p}^{\sigma v}=\sum_{b, c} C_{v c} C_{o b}(r b \mid p c) / D_{r p}^{b c}
$$

Then, a mixed MO/AO Lagrangian may be formed as follows:

$$
\begin{aligned}
& L_{\Delta r}=\sum_{\lambda} C_{\lambda \sigma} L_{\lambda r}=2 \sum_{p}^{d . s} \sum_{\nu \lambda \sigma} C_{\lambda \sigma}(p v \mid \lambda \sigma)\left[C_{r p} I_{r p}^{\sigma v}-I_{r p}^{v \sigma}\right] / D_{r p}^{\sigma v} \\
& L_{\lambda r}=2 \sum_{p}^{d s} \sum_{v \sigma}(p v \mid \lambda \sigma)\left[C_{r p} I_{r p}^{\sigma v}-I_{r p}^{v \sigma}\right] / D_{r p}^{\sigma v} .
\end{aligned}
$$

Term 9 of $L_{a i}$ and $L_{a r}$ may be similarly rearranged to yield

$$
L_{v r}=\sum_{\lambda \sigma}(r v \mid \lambda \sigma) P_{\lambda \sigma}^{(2)}
$$

Half-transformed integrals are generated from (volvo) integrals. The transformation is done locally, so no communication is required (Figure 1). In order to save memory, the half- 
transformed integrals overwrite the (volvo) integrals. The quarter-transformed integrals are generated as described previously. ${ }^{25}$ After the inner two loops, half-transformed integrals for a given $v, \sigma$ pair are read, which requires communication among the processors (Figure 2). Once the mixed MO/AO Lagrangian terms are created, these terms are transformed to the MO basis. The complete Lagrangian is globally summed so that each processor holds the full matrix. Then, the (volvo) integrals are restored by transforming with the inverse MO coefficient matrix $\mathbf{C}^{-1}=\mathbf{C}^{\mathrm{T}} \mathbf{S}$, where $\mathrm{S}$ is the overlap matrix over AOs. Multiplication by the appropriate orbital-energy factor ( $D_{r p}^{b c}$ ) recreates the original (volvo) integrals. This step requires no communication.

\section{Solution of the CPHF Equations}

The General Restricted Open-Shell Coupled-Perturbed Hartree-Fock (CPHF) equations must be solved for the response vectors. The Z-vector substitution is used, ${ }^{19}$ where $\mathbf{Z}$ is the solution to the linear equation

$\sum_{P, q}^{I P} A_{p q r s}^{\prime} Z_{p q}=L_{r s}$.

A reduced Lagrangian $L_{r s}$ containing only symmetry-allowed elements is used in the solution of (80). The ZAPT2 orbital Hessian $A_{p q r s}^{\prime}$ has more terms than the closed-shell form; this may be visualized in Figure 3. The equations governing the six unique matrix blocks may be written as: 


$$
\begin{aligned}
& A_{x i y j}^{\prime}=(x i \mid y j)-\frac{1}{2}(x j \mid y i)-\frac{1}{2}(x y \mid i j)+\delta_{x y}\left(\xi_{i j}^{x}-\zeta_{j i}\right)+\delta_{i j}\left(\xi_{x y}^{i}-\zeta_{y x}\right) \\
& A_{a i y j}^{\prime}=2(a i \mid y j)-\frac{1}{2}(a j \mid y i)-\frac{1}{2}(a y \mid i j)+\delta_{i j} \xi_{a y}^{i} \\
& A_{a x y j}^{\prime}=(a x \mid y j)-\delta_{x y} \xi_{a j}^{x} \\
& A_{a i b j}^{\prime}=4(a i \mid b j)-(a j \mid b i)-(a b \mid i j)-\delta_{a b} \zeta_{j i}+\delta_{i j} \xi_{a b}^{i} \\
& A_{a x b j}^{\prime}=2(a x \mid b j)-\frac{1}{2}(a j \mid b x)-\frac{1}{2}(a b \mid x j)-\delta_{a b} \zeta_{j x} \\
& A_{a x b y}^{\prime}=(a x \mid b y)-\frac{1}{2}(a y \mid b x)-\frac{1}{2}(a b \mid x y)-\delta_{a b} \zeta_{y x}+\delta_{x y} \xi_{a b}^{x}
\end{aligned} .
$$

The notation $A_{p q r s}$ (without a prime) will be used to indicate the integral-only part of the orbital Hessian (no $\xi_{p q}^{r}$ or $\zeta_{p q}$ contributions). Portions of the $\xi_{p q}^{r}$ and $\zeta_{p q}$ values are formed from locally held integrals and then summed onto all processors. Explicit storage of the orbital Hessian is impractical for systems with a large number of orbitals, so the CPHF equations are solved iteratively. In each step of the iterations, blocks of the orbital Hessian are created from locally held integrals. For $A_{a i b j}$ (the closed-shell-like block), $A_{a x b j}$, and $A_{a x b y}$ the (volvo) and (vvloo) integrals reside on the same processor for a given oo pair. A local contribution to the orbital Hessian is constructed and subsequently multiplied by the appropriate section of the trial vector in order to yield a segment of the new vector. For $A_{x i y j}$, a similar procedure is followed for the (xylij) integrals and for the (xilyj) integrals.

Contributions to the orbital Hessian are formed from local (voloo) integrals for the $A_{\text {aiyj }}$ and $A_{a x y j}$ blocks.

For closed-shell systems, the linear equations are

$$
\sum_{b} \sum_{j}\left\{A_{a i b j}+\delta_{a b} \delta_{i j}\left(\varepsilon_{b}-\varepsilon_{j}\right)\right\} Z_{b j}=L_{a i}
$$

Normally, the orbital energy term is taken outside the summation to yield:

$$
\left(\varepsilon_{a}-\varepsilon_{i}\right) Z_{a i}+\sum_{b} \sum_{j} A_{a i b j} Z_{b j}=L_{a i}
$$


This equation is divided by the orbital energy terms to yield a "preconditioned" equation

$Z_{a i}+\sum_{b} \sum_{j} A_{a i b j} \frac{Z_{b j}}{\left(\varepsilon_{a}-\varepsilon_{i}\right)}=\frac{L_{a i}}{\left(\varepsilon_{a}-\varepsilon_{i}\right)}$

whose diagonal element $\left(A_{\text {aiai }} /\left(\varepsilon_{a}-\varepsilon_{i}\right)\right)$ are of the order of unity, and then this is solved iteratively for $Z_{a i}$ In order to restructure the ZAPT2 equations and generate a similar form, a quantity $m_{p q}$ is added and subtracted in diagonal elements of Eqn. 80:

$\sum_{p, q}^{I P}\left\{A_{p q r s}+\delta_{p r}\left(\xi_{q s}^{p}-\zeta_{s q}\right)+\delta_{q s}\left(\xi_{p r}^{q}-\zeta_{r p}\right)-m_{p q} * \delta_{p r} \delta_{q s}+m_{p q} * \delta_{p r} \delta_{q s}\right\} Z_{p q}=L_{r s}$

where

$$
\begin{aligned}
& m_{x i}=\xi_{i i}^{x x}+\xi_{x x}^{i}-\zeta_{i i}-\zeta_{x x} \\
& m_{a i}=\xi_{a a}^{i}-\zeta_{i i}=\varepsilon_{a}-\varepsilon_{i} . \\
& m_{a x}=\xi_{a a}^{x}-\zeta_{x x}
\end{aligned}
$$

The last term in Eqn. 85 is separated out:

$$
\sum_{p, q}^{I P} Z_{p q} m_{p q} \delta_{p r} \delta_{q s}+\sum_{p, q}^{I P}\left\{A_{p q r s}+\delta_{p r}\left(\xi_{q s}^{p}-\zeta_{s q}\right)+\delta_{q s}\left(\xi_{p r}^{q}-\zeta_{r p}\right)-m_{p q} * \delta_{p r} \delta_{q s}\right\} Z_{p q}=L_{r s}
$$

and all terms are divided by $m_{r s}$ to yield:

$Z_{r s}+\sum_{p, q}^{I P}\left\{A_{p q r s}+\delta_{p r}\left(\xi_{q s}^{p}-\zeta_{s q}\right)+\delta_{q s}\left(\xi_{p r}^{q}-\zeta_{r p}\right)-m_{p q} * \delta_{p r} \delta_{q s}\right\} \frac{Z_{p q}}{m_{r s}}=\frac{L_{r s}}{m_{r s}}$

This can be solved iteratively for $Z_{r s}$. The subtraction of and division by $m_{r s}$ is a necessary preconditioning in order to keep the diagonal elements close to one and induce convergence of the iterative equations.

\section{E. Completion of the One-Particle Density Matrices}

Once $Z_{r s}$ is known, the remaining terms in the one-particle density matrices may be finished. The off-diagonal blocks of $\mathbf{P}^{(2)}$ are determined by Eqn. 54. Terms 8 and 9 of $W_{x r}$ 
and terms 6 and 7 of $W_{a r}$ are computed from the $\xi$ and $\zeta$ values. Contributions to terms 1 and 2 of $W_{m m}$ and terms 5 and 7 of $W_{i m}, W_{i j}, W_{x r}$, and $W_{x y}$ are created from local integrals and then globally summed. The (vvloo) integrals are no longer required, so the memory for these is released. The remaining integrals are needed in the two-particle nonseparable density matrix, so these are retained in memory. The completed $\mathbf{P}^{(2)}$ and $\mathbf{W}^{(2)}$ matrices are back-transformed to the AO basis, combined with their SCF analogs, and contracted with the appropriate derivative integrals.

\section{F. Two-Particle Gradient}

The four-index back-transformation of the amplitude terms in $\Gamma^{\mathrm{NS}}$ is similar to the procedure described previously. ${ }^{25}$ For the closed-shell case, $\mathrm{T}_{i j}^{a b}$ amplitudes formed from (volvo) integrals that are locally held for a given oo pair are half-back-transformed to yield amplitudes with the form $\mathrm{T}_{i j}^{o v}$, which overwrite the (volvo) integrals in storage. For ZAPT2, an analogous procedure is employed for the closed-shell-like terms $\mathrm{T}_{i j}^{a b}, \mathrm{~T}_{i x}^{a b}, \mathrm{~T}_{x i}^{a b}$, and $\mathrm{T}_{x y}^{a b}$ to yield amplitudes with the form $\mathrm{T}_{p q}^{\sigma v}$, where $p$ and $q$ are occupied (DOCC and SOCC) indices. This part of the half-back-transformation requires no communication. The $\mathrm{T}_{i j}^{a x}, \mathrm{~T}_{i j}^{\mathrm{xa}}, \mathrm{T}_{i j}^{\mathrm{xy}}$, and $\mathrm{T}_{i y}^{\mathrm{xa}}$ amplitudes can also be transformed to yield $\mathrm{T}_{p q}^{\mathrm{v}}$ amplitudes, which can be added to the half-back-transformed closed-shell-like amplitudes in the (volvo) storage. Since the two occupied indices that have not been back-transformed do not constitute a local pair in either the (voloo) or (ooloo) integral storage, communication between processors must occur. The number of amplitudes that must be transmitted will likely be small compared to the number of closed-shell-like amplitudes since these amplitudes involve at least one singly occupied 
index. Once these amplitudes have been created, the memory for the (voloo) and (ooloo) integrals is released.

The separable two-particle density matrix for ZAPT2 includes terms that come from the back-transformation of $Z_{x i}, Z_{a r}, \chi_{x}$, and $\mathbf{P}^{\text {scr-s. }}$. These two-index transformations are not done in parallel since they are fairly trivial. A fourfold loop over shells is used to calculate the derivative ERI's. Inside the outer two loops, a set of $\mathrm{T}_{p q}^{o v}$ amplitudes is read in for a given $\sigma, v$ pair, which requires communication between the processors (Figure 4). Inside the third and fourth loops, the $p$ and $q$ indices are back-transformed to the AO basis. These steps are done locally. Inside the loops, the nonseparable and separable second-order two-particle density matrices are created, added to their SCF analog, and contracted with the appropriate derivative integrals. Since $\Gamma^{\mathrm{NS}}$ is not symmetrized, the derivative ERI's are computed four times more than the minimal list. This increased $n^{4}$ computation eliminates the need for $n^{4}$ storage and $n^{5}$ effort in the symmetrization.

\section{Timings}

In this section, the scalability of the ZAPT2 gradient algorithm described in Section III is examined. All calculations were performed on a cluster system comprised of IBM p640 nodes connected by dual Gigabit Ethernet. Each p640 node has four $375 \mathrm{MHz}$ Power3-II processors and $16 \mathrm{~GB}$ of memory.

Five molecular systems are considered in the benchmark calculations: three small gold clusters $\left(\mathrm{Au}_{3} \mathrm{H}_{4}, \mathrm{Au}_{3} \mathrm{O}_{4}\right.$, and $\left.\mathrm{Au}_{5} \mathrm{H}_{4}\right)$, a dimeric dicyclopentadienyltitanium(III) chloride system, and a Fe-porphyrin:imidazole system. The smallest molecule under consideration is $\mathrm{Au}_{3} \mathrm{H}_{4}$ (Figure 5). The basis set used on this molecule consists of the aug-cc-pVTZ ${ }^{41}$ basis 
set on $\mathrm{H}$ and the uncontracted Stevens-Basch-Krauss-Jasien-Cundari (SBKJC) ${ }^{42-44}$ effective core potential basis set, augmented with a set of $3 \mathrm{f} 2 \mathrm{~g}$ polarization functions and one set of $\mathrm{sp}$ diffuse functions on $\mathrm{Au}$, for a total of 380 spherical harmonic basis functions. This molecule has 31 doubly occupied orbitals and one singly occupied orbital. A ZAPT2 gradient calculation requires 9.5 MWords of replicated memory and $170 \mathrm{MWords}$ of distributed meriory, so it fits in the memory of a single processor on the IBM cluster. For $\mathrm{Au}_{3} \mathrm{O}_{4}$ (Figure 6), the aug-cc-pVTZ $Z^{41,45}$ basis set is used on $\mathrm{O}$ and the uncontracted SBKJC basis set with $3 f 2 \mathrm{~g}$ polarization functions and one sp diffuse function is used on Au, for a total of 472 spherical harmonic basis functions. Calculations on this molecule involve 44 doubly occupied orbitals and one singly occupied orbital. 20.7 MWords of replicated memory and 562 MWords of distributed memory are required for a ZAPT2 gradient calculation, so the memory allotted to two nodes of the IBM cluster is necessary. Calculations on $\mathrm{Au}_{5} \mathrm{H}_{4}$ (Figure 7) employ the same basis set as that used for $\mathrm{Au}_{3} \mathrm{H}_{4} .572$ spherical harmonic basis functions are used in the ZAPT2 gradient calculations. This molecule has 49 doubly occupied orbitals and one singly occupied orbital. Each calculation requires 30.1 MWords of replicated memory and $1011 \mathrm{MWords}$ of distributed memory. The memory allotted to three processors of the IBM cluster is sufficient to run a calculation on this system. For the $\mathrm{Ti}_{2} \mathrm{Cl}_{2} \mathrm{Cp}_{4}$ system (Figure 8 ), the TZV basis set as defined in $\mathrm{GAMESS}^{35}$ was employed, yielding 486 basis functions. A ZAPT2 gradient calculation on the lowest energy triplet state of this system involves 108 doubly occupied orbitals and two singly occupied orbitals, and requires 30.5 MWords of replicated memory and 2470 MWords of distributed memory. Six processors of the IBM cluster are required in order to run a calculation on this system. For the iron-porphyrin:imidazole system (Figure 9), two basis sets were used. The smaller basis 
set consists of the MIDI basis set ${ }^{46}$ with d polarization functions, and a calculation with this basis set has 493 basis functions. The larger basis set consists of the TZV basis set with $\mathrm{d}$ and $\mathrm{p}$ polarization functions, and a calculation with this basis set has 728 basis functions. For the triplet state, 110 orbitals are doubly occupied and two orbitals are singly occupied. A ZAPT2 gradient calculation with the smaller basis set requires 32.1 MWords of replicated memory and $2635 \mathrm{MWords}$ of distributed memory, which corresponds to the memory allotted to seven processors on the IBM system. A similar calculation with the larger basis set requires 52.1 MWords of replicated memory and 5536 MWords of distributed memory, which corresponds to memory allotted to 15 processors on the IBM system.

Table 1 lists the wall clock time in seconds for a ZAPT2 gradient calculation on 1,2, $4,8,16,32$, and 64 processors for the molecules benchmarked in this study. Tables 2 and 3 list the associated speedups and parallel efficiencies, respectively. The speedups may be visualized in Figure 10. Some superlinear speedup is noted for $\mathrm{Ti}_{2} \mathrm{Cl}_{2} \mathrm{Cp}_{4}$ with the TZV basis set and Fe-porphyrin:imidazole with the MIDI(d) basis set with 16 processors and for the Feporphyrin:imidazole with the TZV (d,p) basis set with 32 and 64 processors. Most likely, this is due to an unusually long time for the run with 16 processors. Calculations investigating this hypothesis are in progress. The parallel efficiency for the ZAPT2 gradients is at least $85 \%$ on 32 processors and at least $73 \%$ on 64 processors for the systems examined in this analysis. As the size of the system increases, the parallel efficiency tends to increase as the time required for computation grows faster than the time required for communication.

ZAPT2 gradients require much less memory and computational time than similar UMP2 gradient calculations. A UMP2 gradient calculation on the $\mathrm{Au}_{3} \mathrm{H}_{4}$ system requires 18 MWords of replicated memory and 647 MWords of distributed memory, so it requires two 
processors on the IBM cluster. This UMP2 calculation takes 79828 seconds, which is approximately a factor of three times the time required for a ZAPT2 gradient calculation (28292 seconds). For $\mathrm{Au}_{5} \mathrm{H}_{4}$, a UMP2 gradient calculation requires 59.2 MWords of replicated memory and 3911 MWords of distributed memory. This would require the use of 11 processors on the IBM system. For a calculation with 16 processors on this system, the UMP2 gradient step takes 98418 seconds in contrast to a ZAPT2 gradient step that takes 26690 seconds.

\section{Conclusion}

The ZAPT2 gradient equations have been revised and subsequently implemented in GAMESS. Features of the scalable implementation using DDI have been discussed in detail. Data of order $n^{2}$ or less is replicated across the nodes, while molecular orbital integrals with two virtual indices or fewer are distributed across the nodes. Gradient terms involving molecular orbital integrals with three virtual indices have been adapted to utilize quartertransformed integrals in a direct fashion. The algorithm has been designed to use locally held data as much as possible in order to reduce communication costs.

Benchmark calculations have been run on an IBM cluster for five molecular systems. The parallel efficiency for 32 processors is over $85 \%$, and the parallel efficiency for 64 processors is over $73 \%$. As the number of basis functions increases, the parallel efficiencies tend to increase. ZAPT2 gradient calculations require approximately one fourth of the memory and one third of the computational time necessary for a UMP2 gradient calculation.

\section{Acknowledgement}

This work was supported by a Department of Energy SciDAC grant to the Ames Laboratory. The authors would like to thank Prof. Daniel Crawford and Dr. Tim Dudley for 
discussions. In addition, they would like to thank Ryan Olson for writing the five-point numerical gradient code used in testing this work.

\section{Appendix. Density Matrix Term Creation}

In order to reduce communication needs, the algorithm for density matrix term creation is organized to take advantage of local integrals as much as possible. The following paragraphs outline the construction of each term, with emphasis on the integrals required.

For the $P_{a b}$ block (Eqn. 53), the four terms that must be computed are:

$\operatorname{Term} 1: \sum_{i, j} \sum_{p}^{s, k}(i a \mid j p)[2(i b \mid j p)-(i p \mid j b)] / D_{i j}^{a p} D_{i j}^{b p}$

Term 2: $\sum_{c} \sum_{p, q}^{d, s}(p a \mid q c)\left[C_{p q}(p b \mid q c)-(p c \mid q b)\right] / D_{p q}^{a c} D_{p q}^{b c}$

Term 3: $\sum_{x, y} \sum_{i}(i x \mid y a)(i x \mid y b) / D_{i y}^{x a} D_{i y}^{x b}$

Term 4: $\frac{1}{2} \sum_{i, x, y}(i x \mid x a)(i y \mid y b) / D_{i}^{a} D_{i}^{b}$

In order to further classify terms 1 and 2, the notation 1-P and 2-PQ will be used, where $\mathrm{P}$ and $\mathrm{Q}$ denote summations over V(IRT), S(OCC), or D(OCC) orbitals. For example, 1-V refers to $p \in$ VIRT in term 1 and 2-DS refers to $p \in$ DOCC and $q \in$ SOCC in term 2 . Similar notation is used for each density matrix block.

For terms $1-\mathrm{V}$ and 2 of $W_{a b}$ and $P_{a b}$, (volvo) integrals for a given oo pair are read from the local processor, amplitudes are formed, and the integrals and amplitudes are contracted without the need for communication between processors. However, most terms can not be completed in this manner. In order to create terms $1-\mathrm{VV}$ and 2 of $W_{i m}$ and $P_{i m}$, terms $1-\mathrm{VV}$ and 2 of $W_{i j}$ and $P_{i j}$, term 2 of $W_{x y}$ and $P_{x y}$, term 2 of $W_{x r}$, and terms $1-\mathrm{VV}$ and 3 of $L_{x i}$, a single 
DDI_GET command ${ }^{25,26}$ is used in order to read a set of (volvo) integrals for a given vv pair. No further communication is required, since the essential amplitudes for these terms are created and contracted with these integrals. As each $P_{x y}$ term is calculated, its contribution to $\chi_{x}$ and to term 4 of $P_{x y}$ and term 9 of $W_{x y}$ is determined. Term 9 of $W_{x y}$ is held in a separate matrix until after the energy is calculated. Locally held (volvo) integrals are used to form amplitudes for contraction with remote (voloo) integrals to form terms $1-\mathrm{VV}$ and 2 of $\mathrm{W}_{\mathrm{ar}}$.

Local (ooloo) integrals are used in the creation of term 1-SS of $W_{i m}$ and $P_{i m}$, term 1-SS of $W_{i j}$ and $P_{i j}$, term 1-S of $W_{x y}$ and $P_{x y}$, term 1-SS of $L_{x i}$ and term 1-S of $W_{x r}$. Some communication is required to read in (voloo) integrals for term 1-SS of $L_{a i}$ and 1-S of $L_{\alpha r}$ for use with the (ooloo) amplitudes. Local (voloo) integrals are used to form amplitudes, which are contracted with two sets of remote (voloo) integrals in order to form terms 1-S of $W_{a b}$ and $P_{a b}$ and terms 1-SV and 1-VS of $W_{i m}, P_{i m}, W_{i j}$, and $P_{i j}$. These amplitudes are also contracted with remote integrals to create term 1-S of $W_{a r}$ and terms 1-SV and 1-VS of $L_{x l}$ and $L_{a r}$. Next, local integrals are used to form term $1-\mathrm{V}$ of $W_{x y}$ and $P_{x y}$, and the amplitudes created are also used with remote integrals to form term $1-V$ of $W_{x r}$ and $L_{a r}$

For terms involving amplitudes of the form $(i x \mid y a) / D_{i y}^{x a}$, contributions to the amplitudes are produced from local integrals on each processor. These contributions are summed globally so that each processor has the full set of amplitudes in its local replicated memory. Then, they are contracted with locally held integrals to form term 3 of $W_{a b}, P_{a b}, W_{i j}$, $P_{i j}, W_{i m}, P_{i m}, W_{x y}, P_{x y}, W_{x r}$, and $W_{a r}$ and term 5 of $L_{x i}, L_{a i}$, and $L_{a r}$. At this point, $\chi_{x}$ is complete so it is globally summed onto all processors. The amplitudes described in this paragraph may then be adjusted to form amplitudes of the type $\frac{1}{2}(i x \mid x a) / D_{i}^{a}$. Finally, term 4 of $W_{i m}, P_{i m}$, 
$W_{i j}, P_{i j}, W_{x y}, W_{a b}, P_{a b}, W_{x r}$, and $W_{a r}$ and term 7 of $L_{a x}, L_{a i}$, and $L_{x i}$ are created from contraction with locally held integrals.

At this point, the ZAPT2 energy can be calculated according to Eqn. 74. Then, $\chi_{x}$ and local integrals are used to form term 5 of $P_{x y}$, term 8 of $W_{x y}$, term 10 of $W_{x x}$, and term 12 of $L_{a x}$ This completes $\mathbf{P}^{(2)}$, so it is globally summed onto all processors.

Orbital energies are multiplied by appropriate elements of $\mathbf{P}^{(2)}$ in order to form term 6 of $W_{i m}, W_{i j}$, and $W_{x y}$ and term 5 of $W_{a b}$. Likewise, locally held integrals are multiplied by elements of $\mathbf{P}^{(2)}$ in order to create term 9 of $L_{a i}$ and $L_{a \mathrm{r}}$ and term 10 of $L_{x i}$. The $\varepsilon$ matrix is calculated from the $\alpha$ and $\beta$ Fock matrices. Term 6 of $W_{x r}$, term 5 of $W_{a r}$, term 11 of $L_{x i}$, and term 10 of $L_{a x}$ are formed by multiplying appropriate $\varepsilon$ and $\mathbf{P}^{(2)}$ values.

\section{References}

(1) Møller, C.; Plesset, M. S. Phys. Rev. 1934, 46, 618.

(2) Schlegel, H. B. J. Chem. Phys. 1986, 84, 4530.

(3) Hubac, I.; Carsky, P. Phys. Rev. A 1980, 22, 2392.

(4) Murray, C.; Davidson, E. R. Chem. Phys. Lett. 1991, 187, 451.

(5) Amos, R. D.; Andrews, J. S.; Handy, N. C.; Knowles, P. J. Chem. Phys. Lett. 1991, $185,256$.

(6) Knowles, P. J.; Andrews, J. S.; Amos, R. D.; Handy, N. C.; Pople, J. A. Chem. Phys. Lett. 1991, 186, 130.

(7) Lauderdale, W. J.; Stanton, J. F.; Gauss, J.; Watts, J. D.; Bartlett, R. J. Chem. Phys. Lett. 1991, 187, 21.

(8) Lee, T. J.; Jayatilaka, D. Chem. Phys. Lett. 1993, 201, 1. 
(9) Kozlowski, P. M.; Davidson, E. R. Chem. Phys. Lett. 1994, 226, 440.

(10) Murray, C.; Handy, N. C. J. Chem. Phys. 1992, 97, 6509.

(11) Lee, T. J.; Rendell, A. P.; Dyall, K. G.; Jayatilaka, D. J. Chem. Phys. 1994, 100,7400 .

(12) Malmqvist, P.-Å. Chem. Phys. Lett. 1995, 241, 429.

(13) Davidson, E. R. Chem. Phys. Lett. 1995, 241, 432.

(14) Jayatilaka, D.; Lee, T. J. Chem. Phys. Lett. 1992, 199, 211.

(15) Guest, M. F.; Saunders, V. Mol. Phys. 1974, $28,819$.

(16) Fletcher, G. D.; Gordon, M. S.; Bell, R. L. Theor. Chem. Acc. 2002, 107, 57.

(17) Pople, J. A.; Krishnan, R.; Schlegel, H. B.; Binkley, J. S. Int. J. Quantum Chem. Symp. 1979, 13, 225.

(18) Pulay, P.; Saeb $\emptyset$, S. Theor. Chim. Acta 1986, 69, 357.

(19) Handy, N. C.; Schaefer, H. F. J. Chem. Phys. 1984, 81.

(20) Handy, N. C.; Amos, R. D.; Gaw, J. F.; Rice, J. E.; Simandiras, E. D. Chem. Phys. Lett. 1985, 120, 151.

(21) Lee, T. J.; Racine, S. C.; Rice, J. E.; Rendell, A. P. Mol. Phys. 1995, 85, 561.

(22) Frisch, M. J.; Head-Gordon, M.; Pople, J. A. Chem. Phys. Lett. 1990, 166, 275.

(23) Frisch, M. J.; Head-Gordon, M.; Pople, J. A. Chem. Phys. Lett. 1990, 166, 281.

(24) Head-Gordon, M. Mol. Phys. 1999, 96, 673. 
(25) Fletcher, G. D.; Schmidt, M. W.; Gordon, M. S. Developments in Parallel Electronic Structure Theory. In Advances in Chemical Physics; Prigogine, I., Rice, S. A., Eds.; John Wiley \& Sons, Inc., 1999; Vol. 110; pp 267.

(26) Fletcher, G. D.; Schmidt, M. W.; Bode, B. M.; Gordon, M. S. Comput. Phys. Commun. 2000, 128, 190.

(27) Nieplocha, J.; Harrison, R. J.; Littlefield, R. J. Global Arrays: A Portable "Shared-Memory" Programming Model for Distributed Memory Computers. In Proceedings of Supercomputing 1994; IEEE Computer Society Press: Washington DC, 1994; pp 340.

(28) Alexeev, Y.; Kendall, R. A.; Gordon, M. S. Comput. Phys. Commun. 2002, $143,69$.

(29) Aikens, C. M.; Gordon, M. S. J. Phys. Chem. A 2004, 108, 3103.

(30) Fletcher, G. D., manuscript in preparation.

(31) Dudley, T. J.; Olson, R. M.; Schmidt, M. W.; Gordon, M. S. J. Comput. Chem, submitted.

(32) Umeda, H.; Koseki, S.; Nagashima, U.; Schmidt, M. W. J. Comput. Chem 2001, 22, 1243.

(33) Krishnamoorthy, G.; Webb, S. P.; Nguyen, T.; Chowdhury, P. K.; Halder, M.; Wills, N. J.; Carpenter, S.; Kraus, G. A.; Gordon, M. S.; Petrich, J. W. Photochem. Photobio, in press.

(34) Gan, Z.; Alexeev, Y.; Kendall, R. A.; Gordon, M. S. J. Chem. Phys. 2003, $119,47$. 
(35) Schmidt, M. W.; Baldridge, K. K.; Boatz, J. A.; Elbert, S. T.; Gordon, M. S.; Jensen, J. H.; Koseki, S.; Matsunaga, N.; Nguyen, K. A.; Su, S.; Windus, T. L.; Dupuis, M.; Montgomery Jr., J. A. J. Comput. Chem 1993, 14, 1347.

(36) Olson, R. M.; Schmidt, M. W.; Gordon, M. S.; Rendell, A. P. Proc. Supercomputing 2003.

(37) Aikens, C. M.; Webb, S. P.; Bell, R. L.; Fletcher, G. D.; Schmidt, M. W.; Gordon, M. S. Theor. Chem. Acc. 2003, 110, 233.

(38) Yamaguchi, Y.; Osamura, Y.; Goddard, J. D.; Schaefer III, H. F. A New Dimension to Quantum Chemistry. Analytic Derivative Methods in Ab Initio Molecular Electronic Structure Theory.; Oxford University Press: New York, 1994.

(39) Nielsen, I. M. B. Chem. Phys. Lett. 1996, 255, 210.

(40) Fletcher, G. D.; Rendell, A. P.; Sherwood, P. Mol. Phys. 1997, 91, 431.

(41) Dunning Jr., T. H. J. Chem. Phys. 1989, 90, 1007.

(42) Stevens, W. J.; Basch, H.; Krauss, M. J. Chem. Phys. 1984, 81, 6026.

(43) Stevens, W. J.; Basch, H.; Krauss, M.; Jaisen, P. Can. J. Chem. 1992, 70, 612.

(44) Cundari, T. R.; Stevens, W. J. J. Chem. Phys. 1993, 98, 5555.

(45) Kendall, R. A.; Dunning Jr., T. H.; Harrison, R. J. J. Chem. Phys. 1992, 96, 6769.

(46) Huzinaga, S.; Andzelm, J.; Klobukowski, M.; Radzio-Andzelm, E.; Sakai, Y.; Tatewaki, H. Gaussian Basis Sets for Molecular Calculations; Elsevier: Amsterdam, 1984. 
TABLE 1: Wall Clock Time (Seconds) for ZAPT2 Gradient Step on IBM Cluster

\begin{tabular}{|c|c|c|c|c|c|c|}
\hline$n$ & $\begin{array}{c}\mathrm{Au}_{3} \mathrm{H}_{4} \\
380\end{array}$ & $\begin{array}{c}\mathrm{Al}_{3} \mathrm{O}_{4} \\
472\end{array}$ & $\begin{array}{c}\mathrm{Au}_{5} \mathrm{H}_{4} \\
570\end{array}$ & $\begin{array}{c}\mathrm{Ti}_{2} \mathrm{Cl}_{2} \mathrm{Cp}_{4} \\
486\end{array}$ & $\begin{array}{c}\text { Fe-porphyrin } \\
493\end{array}$ & $\begin{array}{c}\text { Fe-porphyrin } \\
728\end{array}$ \\
\hline \multicolumn{7}{|l|}{$\mathrm{P}$} \\
\hline 1 & 54943 & & & & & \\
\hline 2 & 28292 & 68645 & & & & \\
\hline 4 & 13904 & 35181 & 105567 & & & \\
\hline 8 & 6975 & 18324 & 53171 & 24852 & 65042 & \\
\hline 16 & 3596 & 9422 & 26690 & 12205 & 31866 & 232551 \\
\hline 32 & 1895 & 4965 & 13858 & 6859 & 16671 & 96404 \\
\hline 64 & 1087 & 2843 & 7453 & 4214 & 9437 & 55019 \\
\hline
\end{tabular}

TABLE 2: Speedup for ZAPT2 Gradient Step on IBM Cluster

\begin{tabular}{|c|c|c|c|c|c|c|}
\hline$n$ & $\begin{array}{c}\mathrm{Au}_{3} \mathrm{H}_{4} \\
380 \\
\end{array}$ & $\begin{array}{c}\mathrm{Au}_{3} \mathrm{O}_{4} \\
472 \\
\end{array}$ & $\begin{array}{c}\mathrm{Au}_{5} \mathrm{H}_{4} \\
570 \\
\end{array}$ & $\begin{array}{c}\mathrm{Ti}_{2} \mathrm{Cl}_{2} \mathrm{Cp}_{4} \\
486 \\
\end{array}$ & $\begin{array}{c}\text { Fe-porphyrin } \\
493\end{array}$ & $\begin{array}{c}\text { Fe-porphyrin } \\
728\end{array}$ \\
\hline$P$ & & & & & & \\
\hline 1 & 1.0 & & & & & \\
\hline 2 & 1.9 & 1.0 & & & & \\
\hline 4 & 4.0 & 2.0 & 1.0 & & & \\
\hline 8 & 7.9 & 3.7 & 2.0 & 1.0 & 1.0 & \\
\hline 16 & 15.3 & 7.3 & 4.0 & 2.0 & 2.0 & 1.0 \\
\hline 32 & 29.0 & 13.8 & 7.6 & 3.6 & 3.9 & 2.4 \\
\hline 64 & 50.5 & 24.1 & 14.2 & 5.9 & 6.9 & 4.2 \\
\hline
\end{tabular}

TABLE 3: Parallel Efficiencies for ZAPT2 Gradient Step on IBM Cluster

\begin{tabular}{|c|c|c|c|c|c|c|}
\hline$n$ & $\begin{array}{c}\mathrm{Au}_{3} \mathrm{H}_{4} \\
380 \\
\end{array}$ & $\begin{array}{c}\mathrm{Au}_{3} \mathrm{O}_{4} \\
472 \\
\end{array}$ & $\begin{array}{c}\mathrm{Au}_{5} \mathrm{H}_{4} \\
570 \\
\end{array}$ & $\begin{array}{c}\mathrm{Ti}_{2} \mathrm{Cl}_{2} \mathrm{Cp}_{4} \\
486\end{array}$ & $\begin{array}{c}\text { Fe-porphyrin } \\
493\end{array}$ & $\begin{array}{c}\text { Fe-porphyrin } \\
728\end{array}$ \\
\hline \multicolumn{7}{|c|}{ 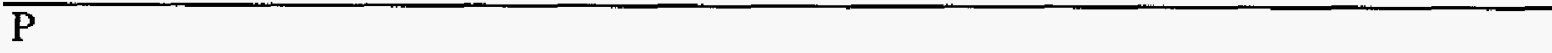 } \\
\hline 1 & 100.0 & & & & & \\
\hline 2 & 97.1 & 100.0 & & & & \\
\hline 4 & 98.8 & 97.6 & 100.0 & & & \\
\hline 8 & 98.5 & 93.7 & 99.3 & 100.0 & 100.0 & \\
\hline 16 & 95.5 & 91.1 & 98.9 & 101.8 & 102.1 & 100.0 \\
\hline 32 & 90.6 & 86.4 & 95.2 & 90.6 & 97.5 & 120.6 \\
\hline 64 & 79.0 & 75.5 & 88.5 & 73.7 & 86.2 & 105.7 \\
\hline
\end{tabular}




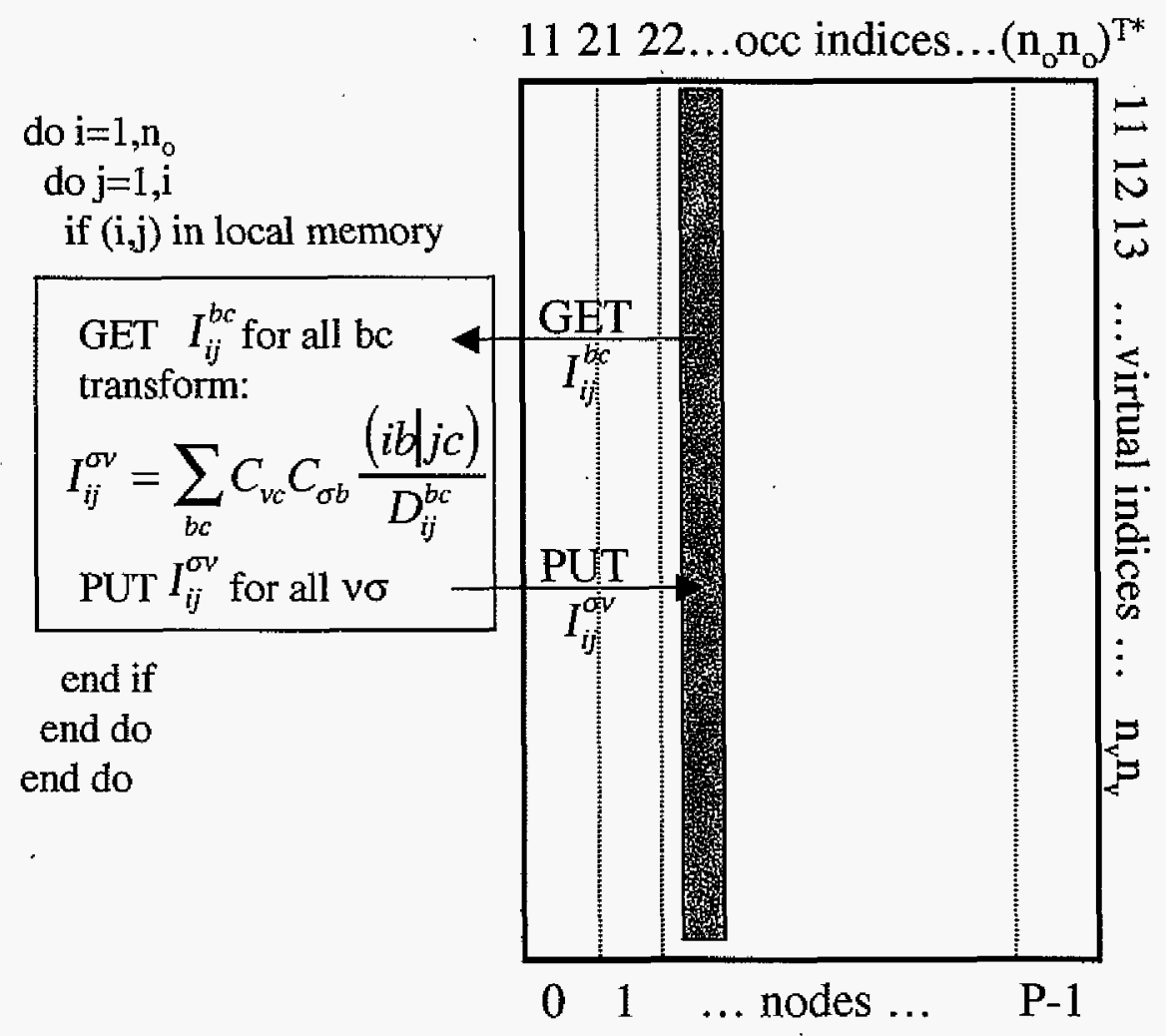

Figure 1. First half-back-transformation of the (volvo) integrals. This procedure is used to form half-back-transformed integrals in the creation of ( $\mathrm{v} / \mathrm{vo}$ ) integrals. An analogous procedure yields half-back-transformed amplitudes for the creation of the nonseparable two-particle density matrix. No communication is required in this step. 


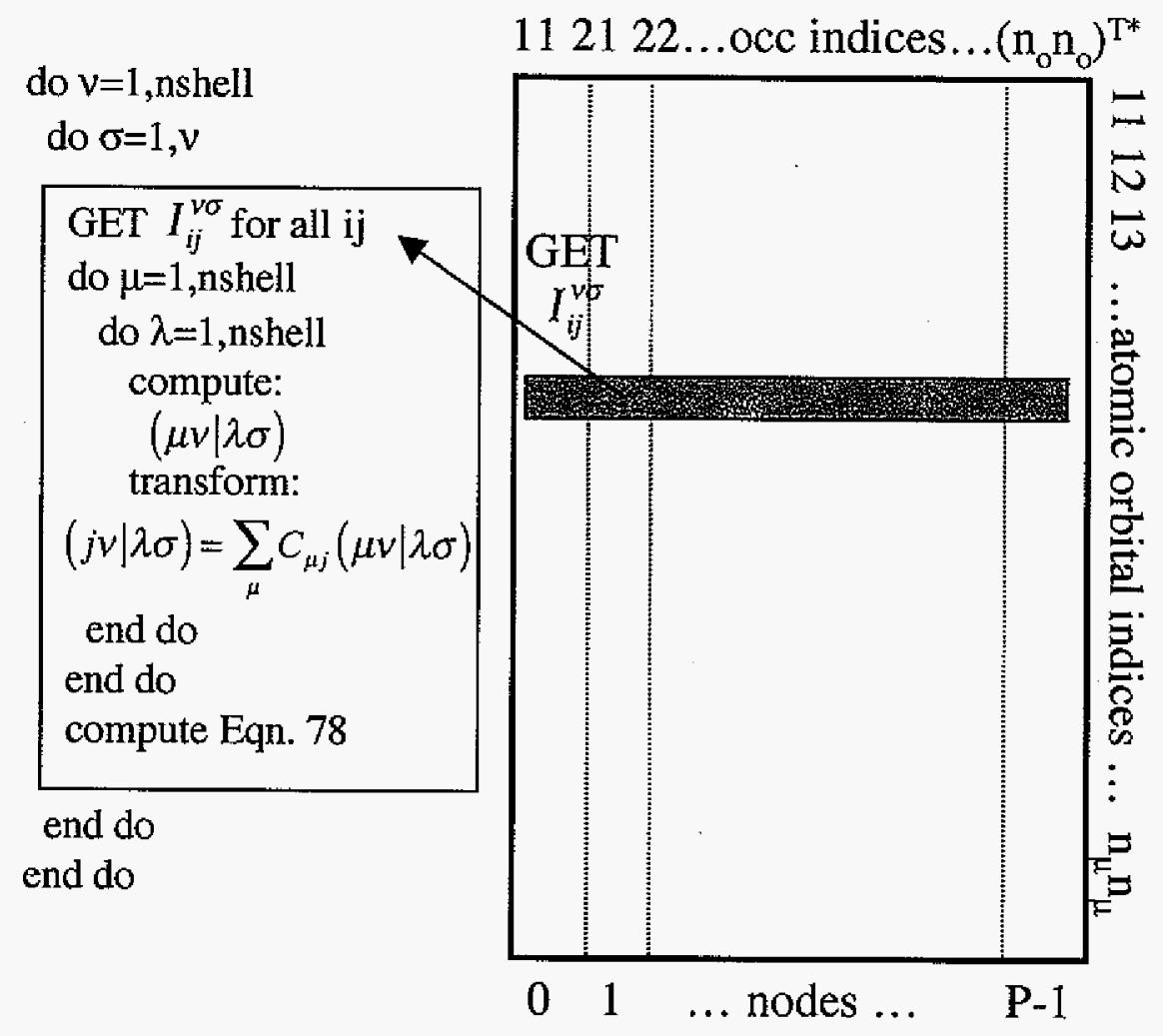

Figure 2. Algorithm for the creation of the Lagrangian (vvlvo) terms. This step requires communication across the processors in order to read in the half-back-transformed integrals. 


\begin{tabular}{|c|c|c|}
\hline$y j$ & $b j$ & by \\
\hline$i{\begin{array}{c}A_{x i y j} \\
\text { (ooloo) }\end{array}}$ & $\begin{array}{c}A_{x i b j} \\
\text { (voloo) }\end{array}$ & $\begin{array}{c}A_{\text {xiby }} \\
\text { (voloo) }\end{array}$ \\
\hline$a i\left[\begin{array}{c}A_{\text {aiyj }} \\
\text { (voloo) }\end{array}\right.$ & $\begin{array}{c}A_{\text {aibj }} \\
\text { (vvloo) } \\
\text { (volvo) }\end{array}$ & $\begin{array}{c}A_{\text {aiby }} \\
\text { (vvloo) } \\
\text { (volvo) }\end{array}$ \\
\hline $\begin{array}{c}A_{\text {axyj }} \\
\text { (voloo) }\end{array}$ & $\begin{array}{c}A_{\text {aiby }} \\
\text { (vvloo) } \\
\text { (volvo) }\end{array}$ & $\begin{array}{c}A_{\text {axby }} \\
\text { (vvloo) } \\
\text { (volvo) }\end{array}$ \\
\hline
\end{tabular}

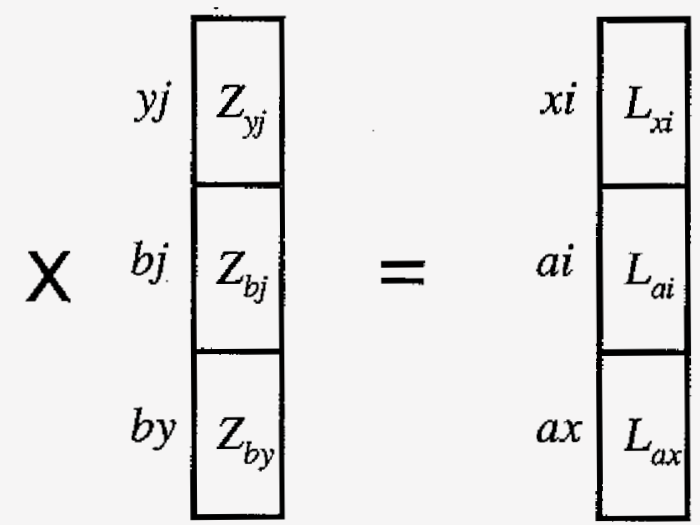

Figure 3. Pictorial representation of the Z-vector equations. 


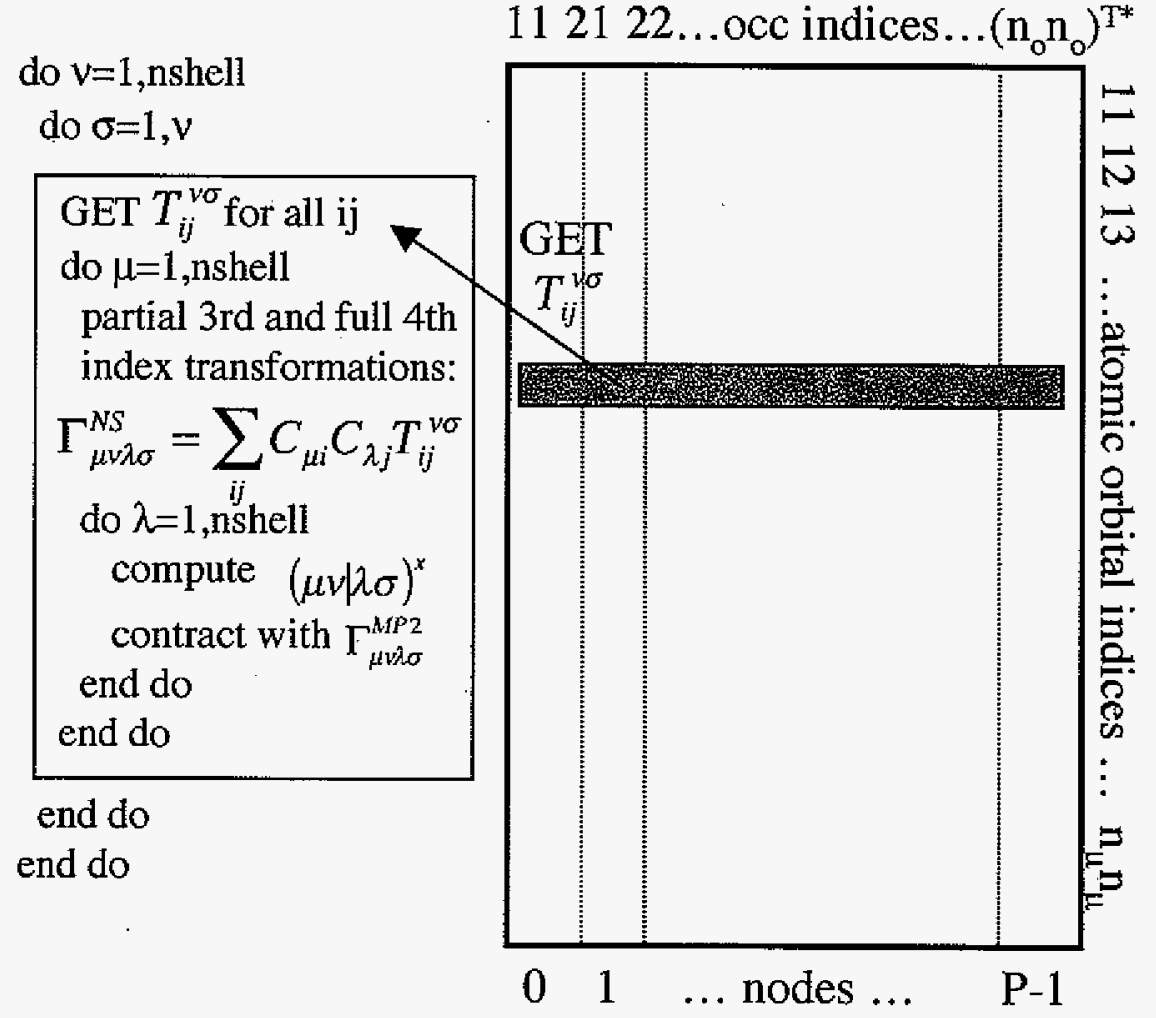

Figure 4. Second half-back-transformation of the amplitudes for the creation of the non-separable two-particle density matrix. This step requires communication across the processors in order to retrieve the half-back-transformed amplitudes. 
$\mathrm{Au}$ :

H:

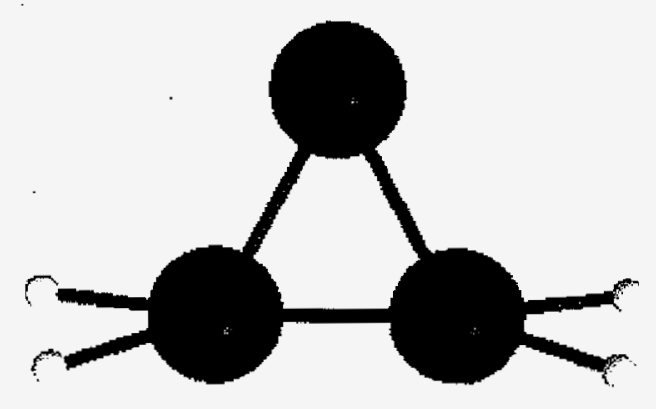

Figure 5. Structure of $\mathrm{Au}_{3} \mathrm{H}_{4}$.

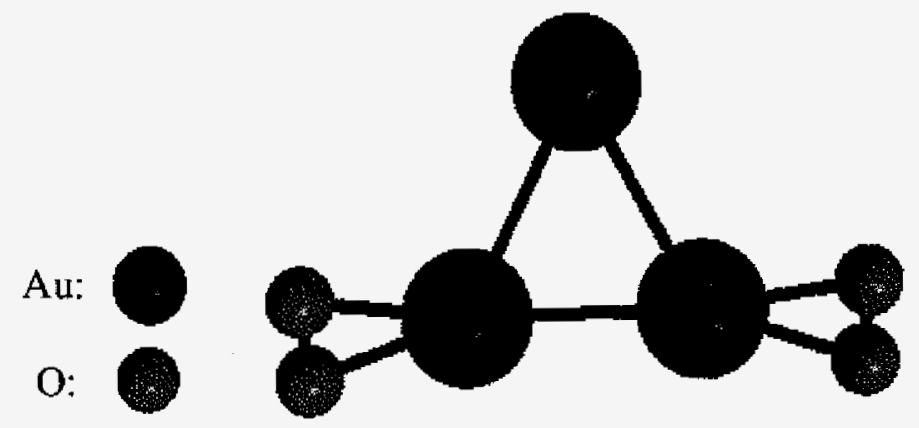

Figure 6. Structure of $\mathrm{Au}_{3} \mathrm{O}_{4}$.
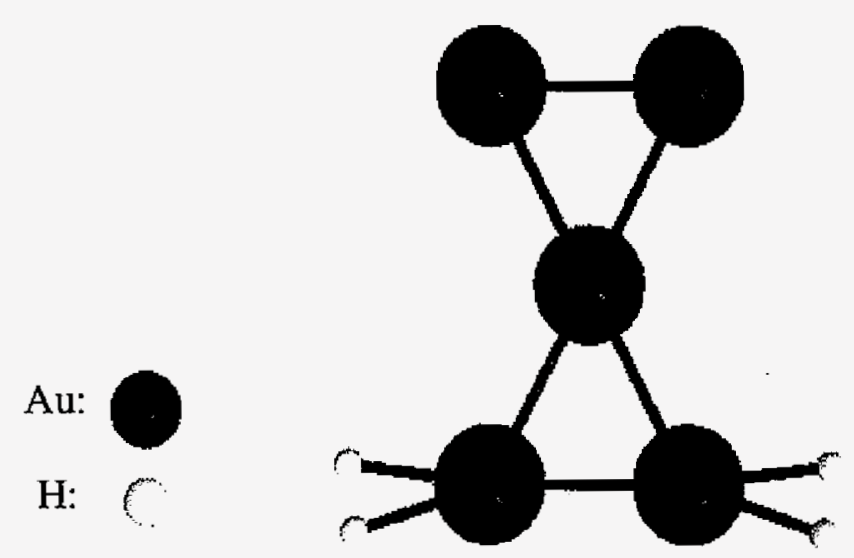

Figure 7. Structure of $\mathrm{Au}_{5} \mathrm{H}_{4}$. 

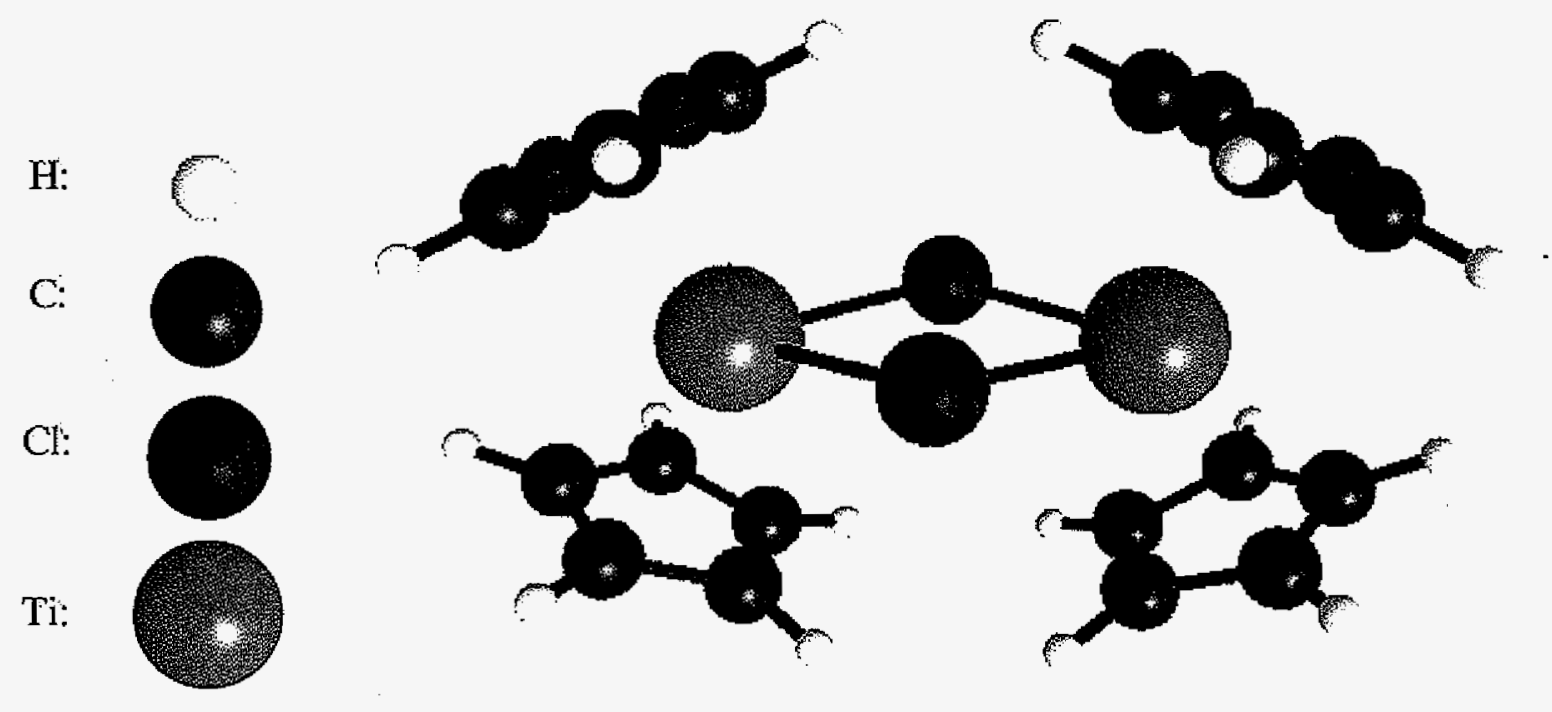

Figure 8. Structure of $\mathrm{Ti}_{2} \mathrm{Cl}_{2} \mathrm{Cp}_{4}$.

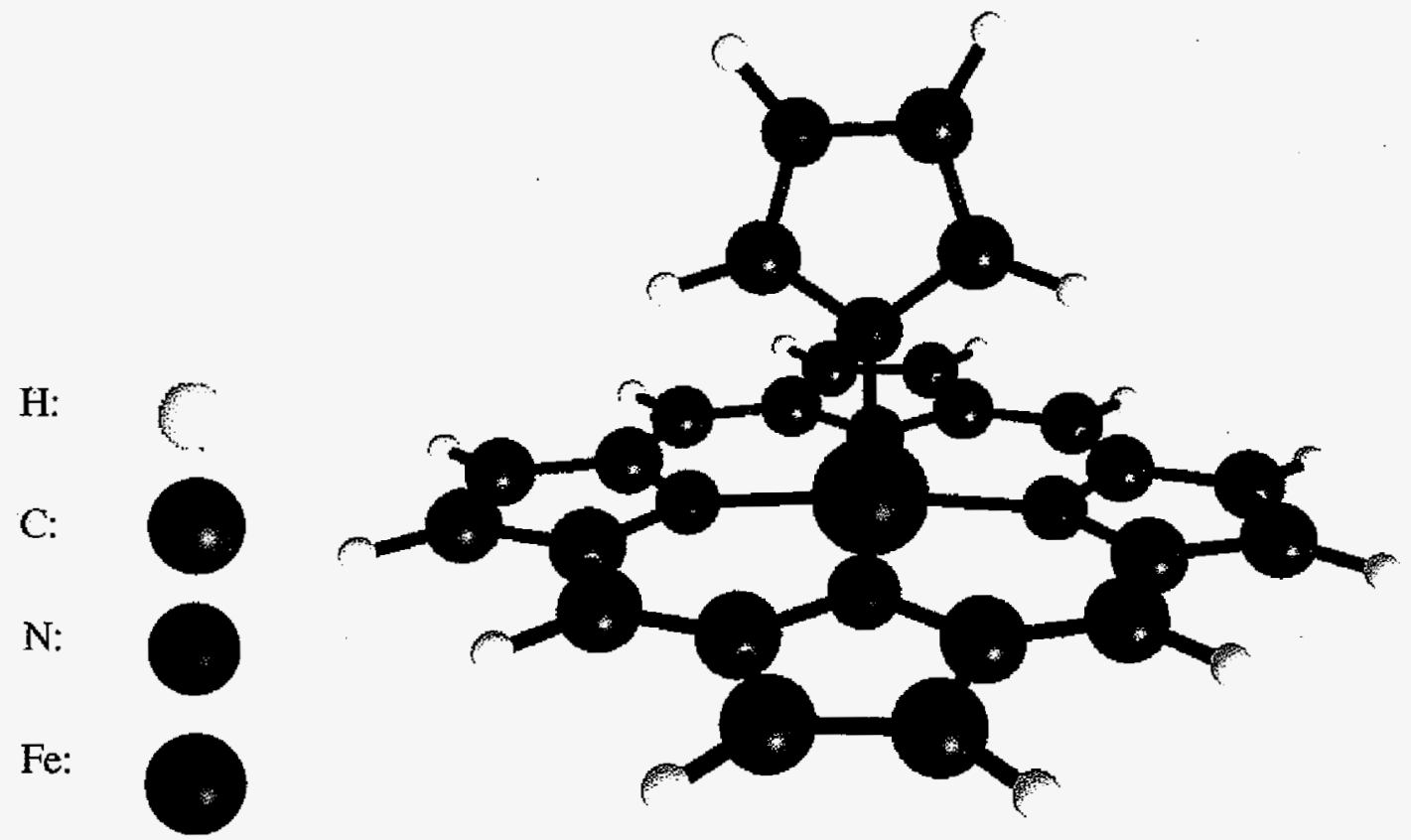

Figure 9. Structure of iron-porphyrin:imidazole. 


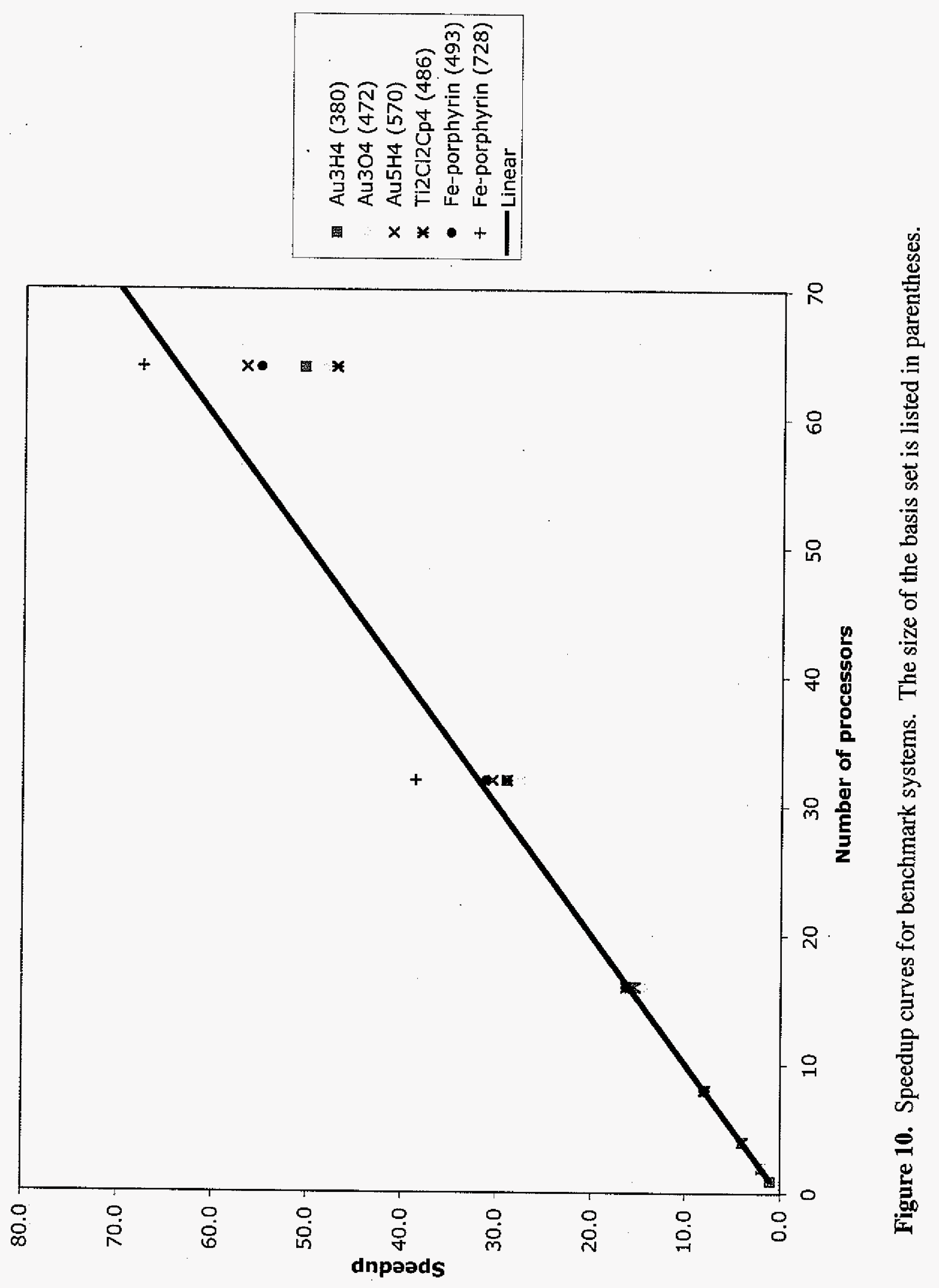

